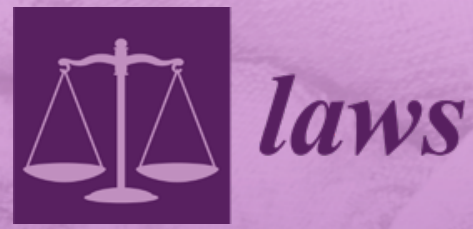

\title{
The New Frontiers of Fashion Law
}

Edited by

Rossella Esther Cerchia and Barbara Pozzo Printed Edition of the Special Issue Published in Laws 
The New Frontiers of Fashion Law 



\section{The New Frontiers of Fashion Law}

Editors

Rossella Esther Cerchia

Barbara Pozzo

MDPI $\bullet$ Basel $\bullet$ Beijing $\bullet$ Wuhan $\bullet$ Barcelona $\bullet$ Belgrade $\bullet$ Manchester $\bullet$ Tokyo $\bullet$ Cluj $\bullet$ Tianjin 


\section{Editors}

Rossella Esther Cerchia

University of Milan

Italy
Barbara Pozzo

Università degli Studi dell'Insubria

Italy

Editorial Office

MDPI

St. Alban-Anlage 66

4052 Basel, Switzerland

This is a reprint of articles from the Special Issue published online in the open access journal Laws (ISSN 2075-471X) (available at: https:/ / www.mdpi.com/journal/laws/special_issues/fashion_law).

For citation purposes, cite each article independently as indicated on the article page online and as indicated below:

LastName, A.A.; LastName, B.B.; LastName, C.C. Article Title. Journal Name Year, Article Number, Page Range.

ISBN 978-3-03943-707-8 (Hbk)

ISBN 978-3-03943-708-5 (PDF)

Cover image courtesy of Nicolò Lamberti.

(c) 2020 by the authors. Articles in this book are Open Access and distributed under the Creative Commons Attribution (CC BY) license, which allows users to download, copy and build upon published articles, as long as the author and publisher are properly credited, which ensures maximum dissemination and a wider impact of our publications.

The book as a whole is distributed by MDPI under the terms and conditions of the Creative Commons license CC BY-NC-ND. 


\section{Contents}

About the Editors $\ldots \ldots \ldots \ldots \ldots \ldots \ldots \ldots \ldots \ldots \ldots \ldots \ldots$

Preface to "The New Frontiers of Fashion Law" $\ldots \ldots \ldots \ldots \ldots \ldots \ldots$ ix

\section{Barbara Pozzo}

Fashion between Inspiration and Appropriation

Reprinted from: Laws 2020, 9, 5, doi:10.3390/laws9010005 . . . . . . . . . . . . . . . . . . . 1

\section{Rossella Esther Cerchia and Katherine Piccolo}

The Ethical Consumer and Codes of Ethics in the Fashion Industry

Reprinted from: Laws 2019, 8, 23, doi:10.3390/laws8040023 . . . . . . . . . . . . . . . . 27

Mark K. Brewer

Slow Fashion in a Fast Fashion World: Promoting Sustainability and Responsibility

Reprinted from: Laws 2019, 8, 24, doi:10.3390/laws8040024 . . . . . . . . . . . . . . . . . 47

\section{Valentina Jacometti}

Circular Economy and Waste in the Fashion Industry

Reprinted from: Laws 2019, 8, 27, doi:10.3390/laws8040027 . . . . . . . . . . . . . . . . 57

\section{Mariacristina Reale}

Digital Market, Bloggers, and Trendsetters: The New World of Advertising Law

Reprinted from: Laws 2019, 8, 21, doi:10.3390/laws8030021 . . . . . . . . . . . . . . . . . 71

\section{Elena Varese and Valentina Mazza}

The Protection of Fashion Shows: An Uncharted Stage

Reprinted from: Laws 2019, 8, 29, doi:10.3390/laws8040029 . . . . . . . . . . . . . . . . 85

\section{Susy Bello Knoll}

Photoshop \& The (Virtual) Body of Models

Reprinted from: Laws 2020, 9, 3, doi:10.3390/laws9010003 . . . . . . . . . . . . . . . . . . 95

\section{Lucrezia Palandri}

Fashion as Art: Rights and Remedies in the Age of Social Media

Reprinted from: Laws 2020, 9, 9, doi:10.3390/laws9010009 . . . . . . . . . . . . . . . . . 109

\section{Giovanni Ziccardi}

Wearable Technologies and Smart Clothes in the Fashion Business: Some Issues Concerning Cybersecurity and Data Protection 



\section{About the Editors}

Rossella Esther Cerchia is a Full Professor of Comparative Law at the University of Milan (Italy) and an Adjunct Professor of Law at Cornell Law School (USA). She also serves as Coordinator for the University of Milan of the post-graduate courses in "FASHION LAW, The legal problems of the fashion industry", as well as the Ph.D. Program in Comparative Law at the University of Milan. Rossella Esther Cerchia is a Member of various scientific committees, such as the Consultative Committee of the American Law Institute (ALI) and European Law Institute (ELI) for the Project "Principles for a Data Economy"; the Scientific Committee of the "Information Society Law Center" at the University of Milan; the Scientific Committee of the Interuniversity Centre for Research in Comparative Law (CCDC); the Scientific board of the Centre of Research on European and Transnational Dispute Settlement. She is both a Member and Delegate of the Commission for the Internationalization of the Law School at the University of Milan, as well as a Representative of the Law School of the University of Milan for the League of European Research Universities. She sits on the Board of Professors and Review Commission for the LLM Program in Sustainable Development-University of Milan. Furthermore, she is a Member of the "Società Italiana per la Ricerca nel Diritto Comparato" (SIRD), an Elected Associate Member of the International Academy of Comparative Law, a Fellow of the European Law Institute (ELI), and a Member of the Scientific Board of many Italian and International law journals. Finally, she has lectured in several national and international Universities and has authored many books and articles in her areas of research.

Barbara Pozzo is a Full Professor of Comparative Law at the University of Insubria (Como), and Director of the Department of Law, Economics and Cultures; Coordinator for the University of Insubria of the post-graduate course in "FASHION LAW, The legal problems of the fashion industry", in partnership with the University of Milan; Coordinator of the PhD Program in "Law and Social Sciences" of the University of Insubria; Member of the Board of the "Società Italiana per la Ricerca nel Diritto Comparato (SIRD); Elected Titular Member of International Academy of Comparative Law; Director of the Summer School Program in Comparative Environmental Law, in association with the University of Aix-en-Provence/Marseille (France), Utrecht University (The Netherlands) and Opole University (Poland). She has been invited to speak at the Fashion Law Institute at Fordham University in New York, as well as at symposia organized by the International Bar Association on Fashion Law organized in Milan (2018) and London (2019). She has been a visiting professor at the University of Hamburg (Germany), Montpellier (France), Louisiana State University, University of California at Davis, McGeorge School of Law at Pacific University, William S. Boyd School of Law at Nevada University (U.S.), Hitotsubashi University (Tokyo), Pontifícia Universidade Católica do Rio Grande do Sul—Porto Alegre (Brazil), Universidade Federal de Santa Catarina—Florianopolis (Brazil), and is also a Member of the Scientific and Editorial Boards of various Italian and International Law Reviews. In September 2018, she was awarded the UNESCO Chair on “Gender Equality and Women's Rights in the Multicultural Society". 



\section{Preface to "The New Frontiers of Fashion Law"}

Fashion law encompasses a wide variety of legal issues that accompany a fashion item throughout its lifecycle, from the need to protect the artist's creativity to problems related to the protection of end consumers. The fundamental aspects that define this new field of law (which are deeply embedded in different cultural backgrounds) depend on the business, market, and legal circumstances specific to various phases of production and distribution. More specifically, whether the subject is haute couture or ordinary clothing, fashion law incorporates the legal questions inherent to the design, manufacture, distribution, marketing, retailing, advertising, and promotion of all types of fashion products. Sector growth and the presence of various industrial players have encouraged market actors to specialize in a variety of areas. Moreover, production is increasingly dispersed along a complex global supply chain and various distribution channels are utilized to deliver products internationally. Contract law, intellectual property law, company law, tax law, international trade, and customs law are of fundamental importance in defining this new area of law that is gradually being studied in a growing number of universities around the world. At the same time, the fashion industry appears to be characterized by an internal tension that defines our time; on the one hand, fashion is increasingly becoming a globalized phenomenon, on the other, it is clear that certain products, traditions, and ways of thinking are particularly culture-bound compared to local realities. This tension implies the need to acquire a vision of the phenomenon that holds together the global perspective with the understanding and respect of local cultures that reflect ancient traditions and religious beliefs. Against this background, it is important to identify the new challenges this sector will face in the future. For instance, as securing the future of the planet and humanity is a pressing concern of our time, sustainability is a central challenge of the fashion industry. Indeed, the fashion industry has been recognized as one of the most polluting. It has been described as a foe to animals and its involvement in the labor market of fragile economies cannot be ignored. Thus, given the significant portion of the world's population involved in the fashion industry, sustainability is on the agenda of most national governments. To this end, great efforts are being made to promote the establishment of a circular economy, one in which unused or unwanted textiles and/or clothing items are upcycled, recycled, and re-used-such that what was once considered "waste" becomes a resource. The call for "green fashion" also appears to have had an impact on consumption patterns-especially amongst the so-called "Generation Z" - as an unprecedented number of consumers ask themselves "who made my clothes?" and base purchasing decisions on variables such as climate change. It is therefore not surprising that the fashion industry has responded with private initiatives to address the issues consumers care about, such as corporate social responsibility (CSR) programs and codes of ethics. A so-called "slow fashion" business model has been proposed as a sustainable alternative to its fast fashion counterpart, which encourages incessant production and consumption at unsustainable levels. At the same time, the role of the press, social media, and the internet must also be accounted for. In fact, both intellectual property and advertising law must contend with rapidly evolving technology. For instance, one cannot ignore discussions related to the manipulation of photographed images, made possible by programs such as Photoshop. In fact, excessive "touch-ups" may harm the personal image of photographed models, as well as the public. For this reason, fashion law deals with the regulations and mechanisms adopted to restrict image manipulation practices and/or inform consumers that graphics editing techniques have been used. Further, digital marketing, e-commerce (which proved especially effective during 
the height of the Covid period), and the role of bloggers and influencers that promote en vogue styles present an assortment of legal issues. For example, expression through digital technology raises questions regarding transparency, the veracity of commercial communications, and consumers' freedom of choice, especially as these new technologies could facilitate the sale of counterfeit goods. Likewise, legal compliance is increasingly difficult in a world where a growing number of users avail of smart electronic devices that can detect, analyze, and transmit users' personal data. Thus, fashion law addresses issues such as whether traditional advertising and other consumer protection laws are capable of effectively regulating digital marketing and forms of expression without compromising fundamental rights-such as freedom of speech, including commercial speech—or stifling competition. Today's increasingly widespread recognition of fashion's artistic value has revamped the debate on the appropriateness of rights and remedies provided by IP law to fashion designs. Even catwalks, which have traditionally represented private sales channels for select wealthy customers, appear to take on a new function, as their current value might lie more in their ability to entertain a crowd than sell chic clothing. All of this brings a variety of new legal issues. This Special Issue focuses on the new frontiers of fashion law, taking into account the various facets that have recently emerged, and which are of great interest for the entire fashion world. The scope of this research will range from sustainable fashion to wearable technologies, from new remedies to cultural appropriation it will also address regulation of models' weight and advertising law in the digital market before finally addressing the impact of new technologies on product distribution and much more. In an attempt to highlight the newest international developments and stimulate discussion on emerging problems capable of defining new boundaries of fashion law, the purpose of this Special Issue is to reflect recent trends in order to arouse ideas for new legal solutions from a comparative and global perspective. Therefore, this Special Issue, "The New Frontiers of Fashion Law", aims to outline the areas of law in which the fashion industry was engaging before the Covid-19 pandemic, identifying some new legal issues that are not comprehensively addressed by current literature. Indeed, composition was nearly complete when the global health crisis set into motion a "tsunami" that affected all sectors worldwide. As concerns the fashion industry, it was hit in such a way that it is difficult to imagine the industry will ever be the same after Covid-19, as the contagion appears to have caused the development of certain new processes to accelerate while slowing the progression of others, whose outcomes are to be evaluated. The prolonged crisis situation will inevitably cause the fashion industry to reinvent itself and the way it does business, leading to new frontiers that will have to be analyzed again.

Rossella Esther Cerchia, Barbara Pozzo 
Article

\title{
Fashion between Inspiration and Appropriation
}

\author{
Barbara Pozzo \\ The Faculty of Law, Department of Law, Economics and Cultures, University of Insubria, Via S. Abbondio 12, \\ 22100 Como, Italy; barbara.pozzo@uninsubria.it
}

Received: 20 October 2019; Accepted: 6 January 2020; Published: 12 February 2020

\begin{abstract}
Fashion is considered an element of "cultural identity". At the same time, it has always been a dynamic phenomenon in which different styles, designs and models converged, acting both as a source of attraction for designers as well as a source of inspiration to draw and depart from in an attempt at innovation. Influences were reciprocal, with the phenomenon of Orientalism going hand in hand with that of Occidentalism. Today's discussion focuses on the vindication by various ethnic groups of ways to protect their own folklore as expression of their own cultural identity. The questions that arise are manifold. This contribution aims at framing the problem in the nowadays fashion industry as well as investigating the various possibilities of protecting folklore while preserving cultural identity. The discussion will deal with recent studies that have analyzed the various aspects of cultural appropriation. Intellectual property will be taken into consideration as a way to protect folklore. Nevertheless, this article suggests that other options for achieving protection of cultural heritage and folklore emerge in the field of Private Governance and Corporate Social Responsibility that will offer new opportunities to tackle the problem of cultural appropriation in the fashion world.
\end{abstract}

Keywords: cultural appropriation; intellectual property; traditional knowledge; traditional designs; private governance; Corporate Social Responsibility; folklore

\section{Introduction}

The topic of cultural appropriation in fashion has received much attention in recent years by media as well as by the specialist literature. This paper aims at inquiring the phenomenon of cultural appropriation in the fashion field, taking into account a historical perspective, in which famous examples are analyzed in order to understand that this phenomenon is not new and how it has developed (Part 2), and a comparative law perspective, in which different solutions are taken into consideration.

It then discusses the main features of the phenomenon in nowadays' society, illustrating those cases that have attracted the attention of the vast public (Part 3), describing the tension between the idea of folklore as an expression of cultural identity and the idea of folklore as a source of inspiration. Particular attention is devoted to those cases where inspiration can be understood as the creative re-interpretation by designers (Section 3.1), distinguishing them from those other cases in which cultural appropriation may become offensive (Section 3.2) or might lead to an undesired commodification (Section 3.3).

Part 4 aims to describe the regulatory framework of folklore at national level (Section 4.1) as well as at international level (Section 4.2) and at analyzing if this framework might be considered to be offering efficient tools to prevent cultural appropriation.

The last part of this paper (Part 5) is devoted to the search of new solutions to protect folklore in the fashion field, taking into consideration the actual needs behind the protection of folklore. It concludes that an important role may be played in the future by private governance tools and, in particular, by Corporate Social Responsibility standards. 


\section{A Look into the Past}

Among the famous quotations by Coco Chanel, one stands out: "Fashion is made to become unfashionable» (Life Magazine, 19 August 1957).

Clothes, hats, shoes, and accessorizes as "fashion" expressions involve an element of volatility, of transience. At the same time, they may constitute the "identity" element of a certain culture.

Before examining the debate on "fashion" as "identity" expression, some caveats are necessary.

First, attitudes to "fashion" have changed radically in the twenty-first century in the light of globalization, technological innovation and the growth of the internet. Clothes have been increasingly approached as a means of self-expression, rather than as a signifier of status or profession (Geczy and Karaminas 2018). As a result, the identity issue in fashion is changing at different speeds in various parts of the world, depending on how much the region is connected with the global world, or instead is still anchored into its local traditions and heritage.

Secondly, the debate around the concept of "identity" itself tends to take on new perspectives. At the base of every identity aspect, such as religion, nationality, class, race, culture, gender, we believe that there is a common thread that keeps all its actors together. But in most cases, this is not true in today's society. As Kwame Anthony Appiah has highlighted in a recent book: "Much of our contemporary thinking about identity is shaped by pictures that are in various ways unhelpful or just plain wrong" (Appiah 2018, p. XIII). In this respect, Appiah points out that "we are living with the legacies of ways of thinking that took their modern shape in the nineteenth century, and that it is high time to subject them to the best thinking of the twenty first" (Appiah 2018, p. XIII).

Thirdly, the differentiation between East and West, between Occident and Orient, often referred to in this paper, requires some explanations. Nowadays, East and West are characterized by different approaches in many different areas: religion, society, and —of course—-fashion. This differentiation is nevertheless fluid and not static, as it relies on ideas that have changed throughout history and that have given rise to different traditions of thought according to the perspective taken as the privileged one. Although "East" and "West" are often understood as indicating two abstract categories, as symbolic representations of two different and often opposing concepts of life and thought, of two well distinct and sometimes antithetical Weltanschauungen, these two geographical entities support and reflect each other. The Orient is not only adjacent to Europe, as it has been the source of its civilizations and languages. Furthermore, the Orient has helped to define Europe as its contrasting image, idea, personality, experience (Said 1978, p. 9).

That said, it is also true that in a historical perspective, through changes of "fashions", it becomes possible to grasp the social transformations that have characterized Western society (Vigarello 2017). This was true for detecting the division of society into a hierarchy (Riello 2012; Muzzarelli 1999), the rise of new social classes (Muzzarelli and Campanini 2003), the emancipation of women (Marchetti 1995), or the impact of a social crisis (Summers 2016).

On the contrary, the immutability of customs and styles of clothing is said to express the stability and political and social immobility order of the Orient (Braudel 1979). In 1926, a retired French missionary doctor described his impressions on Chinese clothing in the following way: "With Chinese clothing, it is the same as with houses: there is no change over periods of thousands of years. In China, one ignores fashion; even the most progressive mandarins, the most elegant taitai (grandes dames), dress themselves now as did the contemporaries of Confucius; and their clothing does not differ from that of workers except in the richness of its material" (Legendre 1926, p. 86).

This view of the East often corresponds to a stereotypical view (Steele and Major 1999, p. 1). The belief in the immutability of China seems to be a cliché that has continued until recently to influence Western ideas, ignoring the complex interaction and the process of westernization of clothes that over time has occurred in various forms in China.

Despite the acclaimed immutability of the costumes, influences coming from the West into the East are equally demonstrable, even if the Eastern immobility mentioned by Braudel has probably meant that Western fashion did not have the same impact on Eastern society. 
The constant desire to innovate with original and effective solutions led Western designers to incorporate other cultures' distinctive looks, reinterpreted by the designer's creativity and sensitivity to other cultures. This cannot be considered a novelty, as influences from far away cultures were present in European fashion since the opening of the silk trade, dating back to the fourth century (Geczy 2013, p. 17). Fabrics, together with spices, are among the products of the first routes of commerce (Segre Reinach 2006).

This appears particularly evident, if we think that almost every word for pre-synthetic textiles derives from Middle East or Asiatic roots: "cotton" derives from the Arabic kutun; "taffeta" evolved from the Old French taffetas or medieval Latin taffeta, based on the Persian täftan (to shine); "chintz" indicates that the word derived from the Hindi "chitta" or "chint", which means variegated or spotted. Other textiles derive their names from particular areas of the Orient: "satin" goes back to the Arabic zaytūni, meaning "of Tsinhiang", a town in China; "damask" comes from Damascus, "angora" from Ankara, "cashmere" from Kashmir; "calico", a plain-woven textile made from unbleached cotton, derives its name from the town Calicut, situated in the State of Kerala in Southern India (Geczy 2013, p. 2; Nassu 2016).

It can be said that textiles began to travel between countries even before men, almost in their place and since ancient times. On the other side, beyond the exchanges and hybridizations, which constitute the essence of the textile product, there are specific traditions that closely reflect the culture in which they were born and for this very reason, textiles have always been a perfect vehicle to establish, express and maintain people's cultural identity (Segre Reinach 2006, p. 54).

Influences, sometimes reciprocal, spread out, involving not only the trade of goods and materials, but also of styles, shapes and beauty ideals. "Design appropriation" can be documented in the past, already many centuries ago (Lunde 2018).

A recent study made on the so-called 'roundel-and-pearl' motif attributes its origins to several cultures and locations in Central Asia and China between the 6th and 13th centuries (Lunde 2018). The long journey of this motif can ultimately be traced back to Egypt and the Eastern lands of the Mediterranean, in representations dated to the 1st and 2 nd century. The roundel design was initially linked with the status of power and nobility, and continued to be used indicating such a prerogative in its various transplants (Lunde 2018). For its specific history, it has been claimed that the iconic roundel motif may therefore be considered to be a design with no single or pure cultural heritage claiming its provenance: "The recurring uses of the same type of motif renders this design multicultural rather than a hybrid. The roundel motif could also be considered as belonging to an international design repertoire representing a geographical region stretching over many consumers or cultural spaces" (Lunde 2018, p. 4).

In all the discussions that will accompany us on our journey, we must therefore remember that textiles and designs are not easy to culture-classify with certainty when considering their movements and appropriations. As it has been underlined: "One of the most compounding issues of culture-classification is that textile designs rarely contain any concrete or definitive indication of their origin" (Lunde 2018, p. 4).

Even if the examples could be multiplied over the centuries (Chiara 2016), coming to more modern times, the West's fascination with and assimilation of the ideas and styles of the East lived a period of great vivacity at the beginning of the XXth century, with the expansion of Colonialism (Said 1978).

In this perspective, Orientalism was not reproducing any objective knowledge on usages and customs of the East. It was, on the contrary, a fabrication of the West: "The perilous voyages to Cathay and Edo, and even the narrower crossing to the mysterious harems and itinerant lifestyles of North Africa and the Middle East, gave Europe a secular heaven-on-earth, a paradise undefiled by Western civilization" (Martin and Koda 1994).

The fascination with the East reaped its victims also in the field of fashion. The French couturier Paul Poiret (Poiret 1930), for example, became a celebrity in the first half of the 20th century, not only for dispensing women from the obligatory corset, but also for re-interpreting Orientalism in fashion (Pham 2013). He launched harem pants and tunics as the new fashion, while designing several hundred costumes for a three act play by Jacques Richepin, Le Minaret, in 1913 (Troy 2002; Geczy 2013, p. 136). 
Of course, Poiret was offering a reinterpretation, his personal vision of the East, as it was pointed out: "The Orient" may have appeared in Oriental Studies to be a term with a concrete referent, a real region of the world with real attributes, in practice it took on meaning only in the context of another term, "the West"» (Carrier 1995, p. 3).

It was not only the West to have fallen in love with the exotic East. On the contrary, East and West maintained to some extent a dialectical relationship, so that also the opposite phenomenon to "Orientalism", what we might call "Occidentalism", took place.

Much has been said and written about Orientalism, but little is yet known of the inverse relationship: that complex and multifaceted phenomenon that led some Eastern arts to assimilate forms and contents of a purely western matrix (Sgubin and Landini 2018).

It happened in the field of arts, but it happened also in the field of fashion.

Japan, after having influenced European Art and Design since leaving its "Splendid Isolation", was experiencing, in the time span between the late nineteenth century and the forties of the twentieth century, a conflicting attitude, poised between the thrill of novelties coming from overseas and the reassuring attachment to tradition. Kimonos which, more than any other art form, were influenced by the change of the Japanese society, began to represent, aside from traditional motifs, colorful designs that recall European artistic currents (Sgubin and Landini 2018). The Meisen kimonos adopted fantasies suggested by the avant-garde movements: from the Viennese Secession to the Glasgow School, from Futurism to Cubism, from Divisionism to the abstract Expressionism of Jackson Pollock. The new production was inspired by facts of contemporary history or by technological achievements, in an exciting and very surprising kaleidoscope of colors, patterns, decoration and weaving techniques, also inspired by western textile production (Sgubin and Landini 2018).

Another interesting phenomenon to analyze concerns the influences that the British Raj had on Indian fashion (Tarlo 1996). This is due to different reasons. On the one side, the British were able to produce cheap machine-made versions of the finely textured fabrics previously worn only by the upper classes, attracting new and enthusiastic customers. On the other side, aniline dyes used in Europe introduced a whole new range of colors, which held an "exotic" appeal in India (Tarlo 1996, p. 46). Finally, for some Indians, it was the very "foreignness" of European clothes that rendered them appealing (Tarlo 1996, p. 46). Dress codes would also vary, according to men and women's preferences. Indian women would generally prefer to adopt European fabrics and accessorizes, while retaining Indian styles (Tarlo 1996, p. 46). Menswear fashion followed another path. The Sherwani, which is considered a traditional Indian and Pakistani menswear, was born during the British Rule and is an influence of British influence on élite Indian menswear (Gupta 2016). It was eventually Gandhi who inspired a return to the origin and the recreation of the Indian dress (Tarlo 1996, p. 62).

On another trajectory, anthropologists like Anne Grosfilley have recently told us how "African wax prints" are usually neither made in Africa nor designed by Africans. The most emblematic African fabric is actually an invented tradition (Hobsbawm and Ranger 1983), whose story is the result of a fabulous contamination between East and West (Grosfilley 2017). The story begins in Java that was part of the nationalised colonies of the Dutch East India Company, which came under direct administration of the Dutch government in 1800. In this part of the world, beautiful garments called Batik were produced, that were considered the traditional fabric of Indonesia. It is important to stress how many Indonesian Batik patterns are symbolic for Javanese people and that Batik garments play an important role in traditional ceremonies. That is why UNESCO (the United Nations Educational, Scientific and Cultural Organization) inscribed Indonesian Batik on the Representative List of the Intangible Cultural Heritage of Humanity in 2009.

In the XIXth century, the Dutch developed in this area an ambitious industrial and commercial strategy in order to launch a true industrial Batik. Known as Wax print, this textile did not manage to establish itself against the Java Batiks, for aesthetic and economic reasons. From an aesthetic point of view, the "veined" effect caused when the dye bled into the wax cracks was not considered attractive. 
Nor was the price, since the Javanese artisans were able to increase productivity by applying the wax with stamps made from copper bends rather than the traditional bamboo stylus (Grosfilley 2017).

The failure of their industrial textile products in Indonesia, induced the Dutch to look for new markets that were to be found along the way back to Europe on the western coasts of Africa, where the Dutch used to refuel. In the Gold Coast, today's Ghana, the success obtained by "Wax", the Dutch industrial version of "Batik", reproducing patterns of Indonesian origin, was enormous. The product was immediately in great demand, even outside Ghana, spreading throughout Western and Central Africa. One of the reasons for its success is to be found in the creativity of the traders, who adapted colors and designs to the African preferences to cater to the tastes of this new market (Grosfilley 2017).

In the end, Wax, the printed cotton fabric in colorful patterns, considered the African fabric par excellence, has become, more than anything else, a powerful symbol of the encounter between cultures. At the same time, it has become an element of pan-African unity, although its arrival in Africa can be considered purely random (Grosfilley 2017).

We might, in conclusion, wonder what can be considered as a "traditional textile". In some regions of the world, indigenous communities have been exposed to trade routes that have been active even before the arrival of Europeans: "Such exposure has led to a "global market» that has influenced the way in which these communities behave. Textiles (from fibres and dyes to yarns and finished cloths) have been a part of this very active exchange. What could be considered traditional now, was in fact very avant-garde at the beginning" (Meneses Lozano 2014).

On the other side, some "traditional" textiles have changed during history their role of social markers. Let us take the example of Adinkra and Kente cloth, fabrics produced by the Asante people of Ghana. They were initially markers of Asante royal power and then of Ghanaian cultural distinction. They were originally handmade and reserved for the exclusive use of the Asante ruler. Nowadays, there are cheap mass-produced reproductions that proliferate in all Ghanaian markets (Boateng 2014).

\section{The Discussion on Cultural Appropriation in Modern Fashion Business}

Fashion, as we have seen, is often the result of lucky encounters. Taking inspirations from other cultures has always been a prevailing trend in the world of fashion.

What characterizes, then, the current debate in the fashion world today as today?

Cultural appropriation, framed as the taking of intellectual property, traditional knowledge, cultural expressions, or artifacts from someone else's culture without permission (Young and Brunk 2012, p. 4; Scafidi 2005, p. 9; Brown 2003, p. 3), is a multifaceted phenomenon that characterizes various aspects of human life. Much research in this field has been devoted to Aboriginal or Ethnic art (Brown 2003, p. 44), music (Coleman et al. 2012; Hall 1997), esoteric (Nason 1997) as well as scientific knowledge (Pullman and Arbour 2012).

The same definition of cultural appropriation may have different facets (Sharoni 2016, p. 4) that point out the attribution of a different meaning or practice outside the source community, the imbalance of power between the two cultures, or even the aim to borrow not for the intrinsic value of the item, but to caricature it (Scafidi 2001, p. 824).

Cultural appropriation is connected not only with proprietary issues, but also and furthermore with identity issues: "What really lies behind the debate about cultural appropriation is not ownership but gatekeeping - the making of rules or an etiquette to determine how a particular cultural form may be used and by whom. What critics of cultural appropriation want to establish is that certain people have the right to determine who can use such knowledge or forms, because at the heart of criticism of cultural appropriation is the relationship between gatekeeping and identity" (Malik 2017).

Commentators agree on one common feature of cultural appropriation, that is to say that the cultural property of some peoples is in danger: "The very cultural heritage that gives indigenous peoples their identity, now far more than in the past, is under real or potential assault from those who would gather it up, strip away its honored meanings, convert it to a product, and sell it. Each time that happens the heritage itself dies a little, and with it its people" (Greaves 1994). 
The debate in the field of cultural appropriation in the fashion industry turns around very different topics that express worries of various kinds and nature. While the use of textiles, images, patterns from other cultures might be, in some cases, at the basis of some transcultural creativity and lead to appreciation of cultural diversity (Section 3.1), in some others, the use of cultural or religious symbols to create fashion has been considered inappropriate. This may lead to harm the community where the appropriated item finds its origin (Sharoni 2016, p. 8), as in cases in which the religious or cultural symbols of other ethnic groups are borrowed for commercial purposes, disregarding the values they express. Fashion may also become offensive when items reproduce stereotyped representations of a culture, of a race or of a gender (Section 3.2). Finally, in some other cases, the borrowing of patterns, motifs or design features leads to a violation of one's cultural heritage with negative economic consequences. We have, in fact, to remember that one of the main critiques addressed to cultural appropriation is that it often implies a lack of compensation to the source community for the use of their cultural product (Sharoni 2016, p. 2) (Section 3.3).

\subsection{Inspiration as the Creative Re-Interpretation by Designers}

If we look back to the catwalks of the last fifty years, we can often find the re-interpretation of some cultural elements by designers, attracted by this or that culture.

Just to name few emblematic examples, Yves Saint Laurent, who apparently did not like travelling and whose most beautiful journeys were imagined, dedicated his Spring-Summer 1967 collection to Africa: "He created a series of delicate gowns from a variety of materials, including wooden beads, raffia, straw, and golden thread. At a time when industrial production predominated, it was a way for the couturier to renew with artisanal techniques" (Musée Yves Saint Laurent 2019).

Gianfranco Ferré, the famous Italian designer who was appointed Artistic Director of Christian Dior in 1989, made the first of his many trips to India in 1973, where he had the chance to visit every part of the country and to study local craftsmanship. Ferré fell literally in love with India and many were the influences in his work coming from this country. For the Fall/Winter Season (1988/1989), for example, he took inspiration from the designs of the Indian shawls of Kashmir to reproduce them on light organza fabrics, worked by Indian artisans (Fondazione Gianfranco Ferré 2019).

In 2007, John Galliano, inspired by the Opera "Madama Butterfly" and the love affair between Mr. Pinkerton and Ciociosan, presented on the catwalk for Christian Dior Haute Couture collection models wearing the Geisha-inspired makeup. As Vogue pointed out, "Kimonos, obis, and geisha makeup were Dior-ified, transformed into delicate translations of New Look peplum" (Mower 2007). The Diorification of Japanese fashion items is the exact word that exemplifies the artistic contribution of the Western Designer, that do not limit their work to a mere reproduction of an original idea stemming from another culture.

In 2010, Jean Paul Gautier dedicated his Spring/Summer catwalk to Andean cultures, to the heritage of Incas and Mayas, reinventing sombreros, mariachis trousers and sandals cut from cowboy boots (Lorelle 2010).

Ideas flow and are reinvented, in fashion as in law as in other fields of human activity, as "nothing comes from nowhere" (Young and Haley 2012). All these examples, in fact, show that designers may be inspired by a foreign culture and are able to re-elaborate it in a "new fashion".

But in more recent times, we do have to acknowledge that the use and misuse of cultural and religious symbols, as well as the appropriation of particular expressions of local folklore by Western designers, ended up under the magnifying glass of numerous critics.

\subsection{When Cultural Appropriation in Fashion becomes Offensive}

A series of cases have attracted the attention of the general public, as well as of academics. BBC News (Soh 2018), as many other bloggers and commentators on internet (Khopar 2018; Varagur 2017) devoted much attention to the discussion. 
These cases share the common feature that the community is harmed by uses that degrade cultural or religious items because they are displayed outside their traditional setting and for purposes that are different from those for which they were originally created (Kuruk 1999, p. 773).

In 1994, Claude Eliette, Chief executive of Chanel, had to apologize for putting a verse of the Koran across the chest of Claudia Schiffer when she modelled a new evening dress in Paris. The affair, that was irreverently dubbed 'the Satanic Breasts' threatened Chanel's exports to the Muslim world after Hasan Basri, the head of Indonesia's ulema, the doctors of Muslim religion, described the use of those verses as 'an insult to our religion' (O'Shea 2013).

In 2011, a Lisa Blue swimsuit featuring a print of Hindu goddess Lakshmi caused vibrant protests among Hindus. According to the North India Times, the label was called out by statesman Rajan Zed, who "said that it was disturbing to see goddess Lakshmi, who was highly revered in Hinduism, on a swimwear displayed by a model at a fashion show. Lakshmi was meant to be worshipped in temples or home shrines and not for pushing swimwear in fashion shows for mercantile greed of an apparel company" (Robinson 2011; Stancati 2011). In the aftermath of the protest, Lisa Blue released a response on Facebook, in which the Label was "offering an apology to anyone we may have offended and advise that the image of Goddess Lakshmi will not appear on any piece of Lisa Blue swimwear for the new season, with a halt put on all production of the new range and pieces shown on the runway from last week removed" (Moss 2011).

The debate around the possibility of considering cultural appropriation as offensive went on when, in December 2012, Karlie Kloss swept down the Victoria Secrets catwalk, wearing a native-style headdress for the annual fashion show. For many Native American tribes, headdresses are a traditional symbol of respect, worn by chiefs and warriors. Each feather placed on a headdress corresponds to an act of compassion or bravery. Protests coming from different groups pointed out that for these reasons, headdresses should not be worn to advertise lingerie (Heller 2017; Nicolas 2017). Even in this case, the label, and the model herself, apologized publicly.

In the discussion that developed after these critical cases, cultural appropriation in the fashion field was accused of being racist and discriminatory: "cultural appropriation cannot be divorced from the prevalent issues of institutional racism and discrimination. In the context of fashion, it is still a white dominated industry benefiting from picking and choosing from different cultures to then make fashionable for white middle class buyers. Sub-cultures of class or race, nationality or religion should not just be something white people can try on as a novelty. You cannot play dress-up with the reality of other people's lives or what they consider sacred" (Mulvaney 2013).

All these cases show how the public pays more and more attention to and becomes aware of the multiple implications of the use and misuse of cultural and religious symbols. Designers, on their part, understand very well that an increasingly attentive public will direct their choices and purchases towards those labels which are able to maintain an ethically correct approach as far as these matters are concerned. It is not only a question of brand's reputation, but also a question of losing entire segments of the market, if not the entire market.

The recent case related to the Dolce \& Gabbana advertising campaign in China clearly demonstrates that Western designers should adopt a multicultural approach that respects cultural and religious diversity in all its expressions, because what can be considered of particular bad taste in one culture, can be constructed as very offensive in another context leading to disastrous results. In the specific case, the three videos realized for the campaign of Dolce \& Gabbana were showing a young Asian model, wearing a red sequin D\&G dress, having trouble eating Italian foods such as pizza, pasta, and cannoli with chopsticks. Playing on a bad double entendre characterized by sexual innuendo, in the video featuring cannoli, a male narrator asked the model "is it too huge for you?" (Pan 2018)

The final result was that the Italian luxury company was forced to cancel the fashion show already scheduled in Shanghai, while their products were removed from several Chinese online retailers.

The lack of a multicultural approach may also lead to a reputational harm due to perpetuation of negative stereotypes (Sharoni 2016, p. 2). 
Only few months ago, Gucci was accused of racism because of a $\$ 890$ black-knit women's balaclava that could be pulled up over the lower half of the wearer's face. The sweater included bright red lips with an opening for the mouth, a detail widely denounced on social media as evoking blackface imagery (Hsu and Paton 2019).

This led Gucci to apologize for the offense caused by the balaclava's design. Gucci further released a statement in which the Company declared that "We consider diversity to be a fundamental value to be fully upheld, respected, and at the forefront of every decision we make. We are fully committed to increasing diversity throughout our organization and turning this incident into a powerful learning moment for the Gucci team and beyond" (Palmer 2019).

Gucci removed the image of the sweater from its e-commerce site and withdrew the item from all of its physical stores.

\subsection{The Commodification of Culture in the Fashion Business}

For different reasons, other cases of cultural appropriation have come to clamor. In these cases, it was not the offensive behavior towards the symbols of another culture that attracted attention, but their commodification, which has different aspects some of which are positive, others negative. In a book that made history on the matter, Susan Scafidi pointed out, "Although outsiders' commodification of a cultural product without the authorization of the source community may dilute or destroy the product or its identification with the source community, limited communal commodification may instead enhance the value of the product by forestalling inferior copies and providing an authentic version" (Scafidi 2005, p. 60).

Some selected cases of the last few years will better explain the values at stake, more than any merely theoretical discussion. They show how the use of artistic designs may occur without the attribution to the group they derive from and, even if the group's will is not to hinder commercialization of those products, this practice harms the group's ability to profit from commercial sales (Paterson and Karjala 2003, p. 637). As Paul Kuruk was pointing out twenty years ago, what strikes is that "in many cases where traditional art or knowledge is exploited, the communities derive wither no economic benefits, or if they do gain something, such benefits often pale in comparison to the huge profits made by the exploiters" (Kuruk 1999, p. 772).

In 2007, Matthew Williamson was targeted by the Ethiopian government for appropriating pattern similar to its national dress. In particular, two of the designer's outfits shown during London Fashion Week were accused to be copies of traditional Ethiopian dresses. The Intellectual Property Office in Addis Ababa released a declaration to newspapers, underlying that the patterns used by the Western stylist "symbolise our identity, faith and national pride. Nobody has the right to claim these designs as their own". In an article published on The Independent in those days, the Author doubted the morality of borrowing a country's national costume, especially when that country is one of the poorest in the world (Hailesalassie 2007). Williamson's spokesperson told The Independent: "Historically, Matthew Williamson bases his collections on the idea of a modern girl who is a global traveler. Her style is in part defined by incorporating many different cultures, traditions and customs. The spring-summer 2008 season was particularly inspired by the idea of modernizing and celebrating certain traditional African fabrics and costumes".

The comments did not take long to arrive: Ethiopians would be delighted if their traditional garments and costumes could be positively influential globally like those of India and the Far East. In this case, however, Williamson did not only take inspiration from Ethiopian traditional clothes to come up with his own unique style: "Designers can always be inspired from different traditional and cultural reflections. But copying them directly is a crime against the rightful owners" (Demilew 2008).

In 2011, a new case of cultural appropriation was the basis for a lawsuit in the United States. Urban Outfitters launched a series of Navajo-themed items, including underwear jewelry and flasks with traditional patterns, much to the discontent of the Navajo Nation, that issued a cease and desist letter to Urban Outfitters followed by a lawsuit in 2012 (United States District Court, D. New Mexico. The Navajo Nation, et al., Plaintiffs, v. Urban Outfitters, Inc., et al., Defendants. Civ. No. 12-195 BB/LAM, Signed 19 September 2016). 
The Navajo Nation has taken advantage of trademark law, registering the name "Navajo" as a trademark in 1943 (Fowler 2013). Navajos could, therefore, assert that Urban Outfitters used false advertising that implied trademark infringement as well as a violation of the federal Indian Arts and Craft Act. The Indian Arts and Crafts Act of 1990 (P.L. 101-644) is a truth-in-advertising law that prohibits misrepresentation in the marketing of Indian arts and crafts products within the United States and makes it illegal "to offer or display for sale, or sell any art or craft product in a manner that falsely suggests it is Indian produced, an Indian product, or the product of a particular Indian or Indian Tribe or Indian arts and crafts organization".

Eventually, the Navajo Tribe and the fashion company reached an undisclosed settlement in 2016 (Vézina 2019). The problem remains open for all those tribes that do not want to trademark their cultural property, because for various reasons "the requirement that U.S. trademark be used in commerce may itself be offensive if the name or symbol in question is something that is sacred, secret, or otherwise not an appropriate subject for commercialization".

In 2015, the French scene offered a new case of cultural appropriation to think about (D'Hoop 2017). The community of Santa Maria Tlahuitoltepec accused the French designer Isabel Marant of "plagiarism", after the launch of Marant's Spring/Summer 2015 collection, which featured a blouse very much resembling the traditional "Huipil" design of the Mexican Community. A group of Mixe women organized a press conference in which they denounced, "Isabel Marant is committing a plagiarism because the Etoile spring-summer 2015 collection contains the graphical elements specific to the Tlahuitoltepec blouse, a design which has transcended borders, and is not a novel creation as is affirmed by the designer" (Larson 2015).

The interesting aspect of the story lies in the fact that Marant admitted that the design was inspired by the work of the Mexican community and withdrew the blouse from sale as requested, but also announced to be currently sued by Antik Batik for copyright infringement.

Antik Batik, a French fashion brand founded in 1992, presents itself on its own website as a label that aims "to embody the dandy elegance of a globetrotting woman", and whose designer invents "a wardrobe that helps you remember the best moments of a traveler who has visited the whole world" (https://it.antikbatik.com/about-us.html).

In that particular situation, Antik Batik was claiming to own the copyright to the same indigenous garment that the Community of Santa Maria Tlahuitoltepec was vindicating as part of its own traditional heritage.

The question was decided by the District Court of Paris (Tribunal de Grande Instance de Paris, 3e Chambre, 4e Section, 3 décembre 2015, No. 15/03456) that ruled on the side of Isabelle Marant, holding not only that the design came from the said village, but that Antik Batik could not claim any property rights on it either.

\subsection{Making the Point about Cultural Appropriation in Fashion}

All these cases show how consumers are becoming increasingly attentive to the ethical aspects of fashion. As it has been underlined, there is a resurgence for the respect for the handmade especially in the West. Some authors have suggested that this is a search for authenticity in a mass-produced world, supported by a shift to ethical purchasing balanced with a desire for knowledge about the maker of the craft artefact (Littrell 2015, p. 458).

In a market like the fashion one, where the designer's reputation assumes a value equal to that of his creativity, attention to these issues will only increase in the coming years.

This leads us to analyze the problem of how to protect folklore as a form of traditional cultural expression. We will first take into consideration the regulatory framework of reference, in order to identify which solutions are available, whether intellectual property rights can offer a valid protection, or we should look for new solutions. 


\section{The Regulatory Framework}

The discussion that took place in the Academy and that reflects the debate launched by magazines, newspapers and bloggers, needs to be contextualized in a broader scenario, in which native cultures have gained more and more recognition at national and international level.

Fashion is strongly related to this scenario, as it is often fed by the creativity of native cultures that is expressed in works of folklore. Folklore has entered the agenda of International Institutions in order to provide a better protection, in the light of the recognition that it embodies creativity and is part of the cultural identity of indigenous and local communities (Brown 2003; Young and Brunk 2012; Ziff and Rao 1997).

We are going to use the term "folklore", although its definition has uncertain boundaries and does not have universal acceptance (Asmah 2008, p. 272). The Merriam-Webster Dictionary defines it as "traditional customs, tales, sayings, dances, or art forms preserved among a people" (https://www.merriam-webster.com/dictionary/folklore).

Kuruk (Kuruk 1999, p. 777) summarizes the debate around the definition of folklore. According to William Bascom, for example, "the tern folklore has come to mean myths, legends, folk tales, proverbs, riddles, verse, and a variety of other forms of artistic expression whose medium is the spoken word" (Bascom 1959). Theodor Gastor adds that folklore "is that part of a people's culture which is preserved, consciously or unconsciously, in beliefs and practices, customs and observances of general currency; in myths, legends, and tales of common acceptance; and in arts and crafts which express the temper and genius of a group rather than of an individual. Because it is a repository of popular traditions and an integral element of the popular "climate", folklore serves as a constant source and frame of reference for more formal literature and art; but it is distinct therefrom in that it is essentially of the people, by the people, and for the people" (Gastor 1959). According to other Authors, folklore of physical objects includes the shapes and uses of tools, costumes and the forms of villages and houses (Taylor 1959).

All definitions acknowledge some common features of folklore: the mode of transmission through generations, either orally or by imitation, the fact that it is generally not attributable to one individual subject and that it is continually developed within the indigenous community (Kuruk 1999, p. 777; Asmah 2008, p. 272).

According to the World Intellectual Property Organization (WIPO), "expressions of folklore" are included in the definition of Traditional Cultural Expression (TCE) that may refer to music, dance, art, designs, names, signs and symbols, performances, ceremonies, architectural forms, handicrafts and narratives, or many other artistic or cultural expressions (https:/www.wipo.int/tk/en/folklore/).

The aims of this accentuated attention to these themes stemmed from an awareness raising process of a set of factors.

First of all, native cultures find in folklore an essential mean of social identity. Originally, folklore was protected by customary law. As Kuruk recalls, rights in folklore are generally recognized "under social criteria depending upon the degree of the kinship, age, sex, title or role of individuals in the society, and are enforced either by sanctions based on common interests or a system of magical or religious beliefs" (Kuruk 1999, p. 781.) Observance to the norms that protect folklore is secured through a system of sanctions that may vary according to the degree of kinship, but which is not effective outside the group (Kuruk 1999, p. 786).

Second, there has been an increase in the commercial exploitation or appropriation of folklore or other forms of traditional cultural expressions, especially since new technologies were making folklore increasingly vulnerable to exploitation and misuse (Kuruk 1999, p. 770; WIPO 1982). This is a consequence of the different relationship between art and its mechanical reproduction, that has completely changed in our days (Benjamin 1936). As Paul Valéry was already pointing out at the beginning of the last century: "Our fine arts were developed, their types and uses were established, in times very different from the present, by men whose power of action upon things was insignificant in comparison with ours. But the amazing growth of our techniques, the adaptability and precision they have attained, the ideas and habits they are creating, make it a certainty that profound changes are impending in the ancient craft of the 
Beautiful. In all the arts there is a physical component which can no longer be considered or treated as it used to be, which cannot remain unaffected by our modern knowledge and power. For the last twenty years neither matter nor space nor time has been what it was from time immemorial. We must expect great innovations to transform the entire technique of the arts, thereby affecting artistic invention itself and perhaps even bringing about an amazing change in our very notion of art". (Valéry 1934).

Third, business that are able to exploit these traditions have generally no connection with the communities that have developed the traditions in question. Furthermore, the result of this commercial exploitation does not generally improve the life of the communities who were the custodians of these traditions, but ends up in an economic benefit for persons not belonging to the communities (Kuek 2005).

Fourth, the commercialization process of these forms of traditional expressions has sometimes led to situations considered degrading and culturally or spiritually offensive for the communities involved (Kuek 2005).

Last but not least, the acknowledgement that the Western Intellectual Property law system, which finds its origins in the context of the European Enlightenment, focuses on the individual genius, but neglects the property rights of a group, rendering folklore difficult to protect according to its basic schemes (Scafidi 2005, p. 11).

\subsection{The National Initiatives}

Notwithstanding the skepticism towards IP tools, it is exactly on this ground that the first attempts were made to protect folklore in an effective way (Von Lewinski 2008).

From a historical point of view it is noteworthy to underline that the first attempts to regulate the use of creations of folklore originate in the period of decolonization and find place in the framework of national copyright laws of those States that were afraid that their folklore would be depleted (WIPO 1997).

Tunisia, after having reached independence from France in 1956, was the first country to provide protection for folklore within its copyright law in 1966, whose art. 6 stated: "1. Folklore is part of the national heritage. 2. Except for national public legal persons, the direct or indirect fixation of this folklore with a view to its lucrative exploitation, requires an authorization from the Department in charge of Cultural Affairs, which may require for this fixing, a royalty fee under conditions to be determined by decree. 3 . The total or partial transfer of the copyright in a work inspired by folklore, or the exclusive license for such work, is valid only if it has been approved by the Department of Cultural Affairs. For the purposes of this law, "work inspired by folklore" means any work composed using elements borrowed from the traditional cultural heritage of the Republic of Tunisia" (Loi Nº66-12 du 14 février 1966 relative à la propriété littéraire et artistique, Journal Officielle de la République Tunisienne, 15 février 1966, p. 226).

Following the example of Tunisia, many developing countries in Africa expressed the need for a legal mechanism for the protection of folklore enacting provisions in their copyright laws (Matip and Koutouki 2008, Kutty 2007).

Morocco promulgated such a law in 1970 (Dahir n 1-69-135 du 25 joumada I 1390, 29 juillet 1970 relatif à la protection des cuvres littéraires et artistiques, Bulletin Officiel n ${ }^{\circ} 3023$ p. 1378), where folklore is considered part of the national heritage (art. 10.1.), that includes unpublished works whose identity is unknown but for which it is reasonable to assume that the author is or was a Moroccan resident (10.4.). The direct or indirect fixation of folklore with a view to its lucrative exploitation is subject to the prior authorization of a Committee provided for by the same law, against payment of a tax the proceeds of which will be spent for purposes of general or professional interest, under the conditions that will be specified by decree (art. 10.2.). The total or partial surrender of the right to use a work inspired by folklore, or the exclusive license for such work, is valid only if it has been approved by the Committee established by the law.

The Law of 1970 was finally replaced by a new Law in 2000 (Dahir n ${ }^{\circ} 1-00-20$ du 9 kaada 1420, 15 février 2000, portant promulgation de la loi $\mathrm{n}^{\circ}$ 2-00 relative aux droits d'auteur et droits voisins, 
Bulletin Officiel $n^{\circ} 4810$, p. 604), where art. 7 further amplifies the protection of folklore, stating, for example, that in all printed publications, and in connection with any communication to the public of an expression of identifiable folklore, the source of that expression of folklore shall be appropriately indicated by the mention of the community or geographic place whose expression of the folklore is used (art. 7.3).

In Ghana, the Law on Copyright of 1985 defines folklore as "all literary, artistic and scientific work belonging to the cultural heritage of Ghana which were created, preserved and developed by ethnic communities of Ghana or by unidentified Ghanaian authors, and any such works designated under this Law to be works of Ghanaian folklore" (Kuruk 1999, p. 778).

Soon after, other laws were promulgated that introduced elements of protection of folklore, not only in Africa (Zografos 2010).

All these new legislative texts consider works of folklore as part of the cultural heritage of the nation. They further have another common element: folklore must have been created by authors of unknown identity, but presumably being or having been nationals of the country.

The Document that was issued in occasion of the UNESCO-WIPO World Forum on the protection of folklore that took place in 1997 (WIPO 1997) provides a useful guide to the common features that the laws protecting folklore present.

Meanwhile, the idea that folklore needed a better protection was entering the international agenda of the 1967 Stockholm Diplomatic Conference for the Revision of the Berne Convention for the Protection of Literary and Artistic Works (The Berne Convention) (Zografos 2010). Although only in a limited way, the Stockholm Diplomatic Conference of 1967 reflected, for the first time, the aspirations of the developing world on protection of folklore when it adopted the following provisions in Article 15 (4) of the Berne Convention:

(a) In the case of unpublished works where the identity of the author is unknown, but where there is every ground to presume that he is a national of a country of the Union, it shall be a matter for legislation in that country to designate the competent authority which shall represent the author and shall be entitled to protect and enforce his rights in the countries of the Union.

(b) Countries of the Union which make such designation under the terms of this provision shall notify the Director General of WIPO by means of a written declaration giving full information concerning the authority thus designated. The Director General shall at once communicate this declaration to all other countries of the Union.

Anyway, the attempt to preserve folklore as community-owned cultural heritage through copyright laws failed because of a series of reasons. It is, in fact, quite difficult to protect knowledge and tradition handed down from generation to generation over a period of time and collectively owned by the community through a legislation that is based on the principle of originality, on a term of protection restricted to the life time of the author plus a limited period after his death and the concepts of "author" and "work", that are indistinguishably linked with a different legal tradition (Kutty 2007, p. 5).

Another noteworthy initiative was the Tunis Model Law on Copyright for Developing Countries, adopted in 1976 to provide developing countries with a text of a model law to assist them when framing or revising their national copyright legislation. The Tunis Model Law goes a few steps further than the Berne Convention by explicitly including folklore in the list of protected work (Zografos 2010). The Tunis Model Law defines folklore as "all literary, artistic and scientific works created on national territory by authors presumed to be nationals of such countries or by ethnic communities, passed from generation to generation and constituting one of the basic elements of the traditional cultural heritage" (\$18 Tunis Model Law on Copyright for Developing Countries).

In order to overcome the difficulties encountered to protect folklore under the Berne Convention, the Tunis Model Law has introduced some exceptions, as in the case of "fixation". Fixation is a frequent requirement in common law countries, but it could not possibly be applied to folklore. Works of folklore form part of the cultural heritage of peoples and their very nature lies in their being handed on from 
generation to generation orally and have never been recorded; the fixation requirement might, therefore, destroy the protection of folklore. For this reason, the Tunis Model Law, after having established in Subsection (5) the general principle that " ... a literary, artistic or scientific work shall not be protected unless the work has been fixed in some material form", provides an explicit exception for folklore.

In the African context, the process of providing specific protection to folklore led to the establishment of a regional arrangement on folklore (Asmah 2008). The idea of drafting a regional arrangement on folklore originated in the fact that several African countries protect folklore under intellectual property and a general agreement would strengthen these efforts.

The situation was somewhat fragmented, because of the post-colonial period. There were, in fact, several regional organizations in Africa under whose umbrella the issue of folklore could be tackled. These included: the Economic Community of West African States (ECOWAS) and in the intellectual property areas the African Regional Intellectual Property Organization (ARIPO), formed among English-speaking Africa, and the African Intellectual Property Organization (OAPI), formed among French-speaking Africa by the adoption of a convention signed in Bangui in 1977 (Asmah 2008, p. 8; Kuruk 1999, p. 806).

It should not be surprising that these intellectual property groupings were not able to establish a common and uniform folklore protection, if we think that common law and civil law do not share the same attitude towards copyright law and the traces of the two Colonial Powers, France and England, had left different heritages in different parts of Africa.

If we look more in detail, ARIPO, that had been established by the Lusaka Agreement in Zambia on December 9, 1976, concerns only patent law. The two protocols that were adopted to this convention: the Protocol on Patent and Industrial Designs within the Framework of the African Regional Industrial Property did not address the protection of folklore.

The OAPI was created in Libreville (Gabon) in 1962. In 1977, the Libreville Agreement was replaced by a new convention signed in Bangui (Central African Republic), that deals not only with patents but also with trademarks and copyrights (Kuruk 1999, p. 807).

OAPI includes extensive provisions on folklore protection in its Annex VII. In this agreement, folklore is defined as works that are "created by the national ethnic communities in member states which are passed from generation to generation" (Kuruk 1999, p. 811). According to OAPI, works of folklore are considered part of the national heritage: As a consequence, their exploitation is conditioned on notice to the appropriate state agency. Fees collected for such exploitation are aimed at financing social and cultural activities.

In conclusion, we might try to identify the reasons for the struggle to protect folklore within IP and - at the same time - to focus on the concrete difficulties to reach effective results.

The reasons that have pushed towards an IP solution are easy to grasp. First, there is an evident similarity between intellectual property law works and folklore, which has naturally led to the attempt to include folklore in the framework of IP protection. Second, in a globalized world where IP has a well-established law system, it would have been easier to connect folklore protection to such a pre-existing and well known system.

The concrete difficulties that arose derive from the main characteristics of folklore itself that have already been underlined: the non-individual nature, the oral transmission, the difficulty in putting a time limitation to its protection that collide with the typical features of IP.

A further obstacle, which rendered difficult the applicability of national IP laws in this framework derives from the inadequacy of national regimes to cope with a globalized market that pushed towards the creation of international regimes.

\subsection{International Initiatives}

A series of initiatives at international level have reinforced the awareness of the many problems connected to the protection of folklore from different perspectives. 
In particular, the World International Property Organization worked hand in hand with UNESCO to elaborate the Model Provisions for National Laws on the Protection of Expressions of Folklore Against Illicit Exploitation and Other Prejudicial Actions, that were released in 1982 and which signaled the beginning of a sui generis regulation around expressions of folklore (Model Provisions for National Laws on the Protection of Expressions of Folklore Against Illicit Exploitation and Other Prejudicial Actions, retrieved from https://www.wipo.int/edocs/lexdocs/laws/en/unesco/unesco001en.pdf).

The Model Provisions elaborated by UNESCO and WIPO acknowledge that folklore is an important cultural heritage of every nation, not only of developing countries. Nonetheless, folklore is of particular importance to developing countries, as a basis of their cultural identity and as means of self-expression of their peoples, both within their own communities and in their relationship to the world around them. The document further recognizes that the accelerating development of technology may lead to improper exploitation of the cultural heritage of poorer nations. WIPO and UNESCO express their worries concerning folklore, as it is commercialized by such means on a world-wide scale without due respect for the cultural or economic interests of the communities in which they originate and without conceding any share in the returns from such exploitations of folklore to the peoples who are the authors of their folklore (Kuruk 1999, p. 815).

According to the Model Provisions, "expressions of folklore" are defined as: "productions consisting of characteristic elements of the traditional artistic heritage developed and maintained by a community or by individuals reflecting the traditional artistic expectations of such a community, in particular:

(i) verbal expressions, such as folk tales, folk poetry and riddles;

(ii) musical expressions, such as folk songs and instrumental music;

(iii) expressions by action, such as folk dances, plays and artistic forms or rituals; whether or not reduced to a material form; and

(iv) tangible expressions, such as: (a) productions of folk art, in particular, drawings, paintings, carvings, sculptures, pottery, terracotta, mosaic, woodwork, metalwork, jewellery, basket weaving, needlework, textiles, carpets, costumes; (b) musical instruments; (c) architectural forms".

It is therefore important to underline that in particular textiles and needlework, often taken into consideration by fashion industries, are included in this definition.

The Model Provision foresee at Section 1 that the Expression of Folklore shall be protected against 'illicit exploitation' and 'other prejudicial actions'.

According to Section 3, the following utilizations of the expressions of folklore are subject to authorization when they are made both with gainful intent and outside their traditional or customary context:

(i) any publication, reproduction and any distribution of copies of expressions of folklore;

(ii) any public recitation or performance, any transmission by wireless means or by wire, and any other form of communication to the public, of expressions of folklore.

Section 4 provides an exception to this general principle in case of "fair use", which takes place if the utilization is made for the purposes of education; by way of illustration in the original work of an author, provided that the extent of such utilization is compatible with fair practice; by borrowing expressions of folklore for creating an original work.

It is further to underline that the Model provision foresees the establishment of 'competent authorities' in each country, while they do not deal with the question of the ownership of expressions of folklore, since this may be regulated in different ways from one country to another

In 1989, the UNESCO General Conference adopted a Recommendation on the Safeguarding of Traditional Culture and Folklore to Governments (UNESCO 1989), which provided a very broad definition of folklore: "Folklore (or traditional and popular culture) is the totality of tradition-based creations of a cultural community, expressed by a group or individuals and recognized as reflecting the expectations of a community in so far as they reflect its cultural and social identity; its standards and values are transmitted orally, by imitation 
or by other means. Its forms are, among others, language, literature, music, dance, games, mythology, rituals, customs, handicrafts, architecture and other arts".

The Recommendation provided guidelines for identification, conservation, preservation, dissemination, and protection of expressions of folklore through international cooperation. States were, therefore, requested to engage in the establishment of national inventories in order to create identification and recording systems. In particular, they were requested to stimulate the creation of a standard typology of folklore by way of:

i. a general outline of folklore for global use;

ii. a comprehensive register of folklore; and

iii. a regional classification of folklore, especially field-work pilot projects.

After the World Forum on the Protection of Folklore in Phuket, in 1997, WIPO launched nine global fact-finding missions between 1998 to 1999. The quest was to find an appropriate legal framework for regulation of folkloric expressions, which would ensure that its users achieve the objectives of a balanced IP system. In the Conclusions that accompany the Report on Fact-Finding Missions on Intellectual Property and Traditional Knowledge (1998-1999) we can read that "neither existing IP standards, nor the 1982 Model Provisions, alone are sufficient in meeting the needs and expectations of indigenous and local communities, and that the testing of alternative models, using a combination of IP and non-IP measures, is desirable" (WIPO 1999).

In 2000, WIPO decided to establish an Intergovernmental Committee on Intellectual Property and Genetic Resources, Traditional Knowledge and Folklore (IGC), aiming at creating a forum where WIPO member states could discuss intellectual property issues that arise in the context of access to genetic resources and benefit-sharing as well as the protection of traditional knowledge and traditional cultural expressions. Since then, it is noteworthy that from a terminological point of view, the terms "traditional cultural expressions" and "expressions of folklore" are now used interchangeably in WIPO discussions (WIPO 2000) https://www.wipo.int/tk/en/igc/).

Having put genetic resources and folklore under the same umbrella might be questionable as copyright law could be a better protection tool for genetic resources than for folklore, as we will discuss later.

WIPO points out that the use of IP to protect traditional knowledge and genetic resources originates from concerns expressed by indigenous communities regarding the use of new technologies, such as biotechnology, that could lead misappropriation of genetic resources and associated traditional knowledge (WIPO 2000).

IP law in this context should help to prevent and promote fair benefit sharing between holders of those assets (mostly biodiversity-rich countries) and those with the modern technologies to access and use them.

Finally, in 2009, members of WIPO agreed to develop an international legal instrument that would give traditional knowledge, genetic resources and traditional cultural expressions (folklore) effective protection. Such an instrument could range from a recommendation to WIPO members to a formal treaty that would bind countries choosing to ratify it (WIPO 2011).

In parallel to the initiatives launched by WIPO and UNESCO together, it is also to recall that in the last two decades, multiple interventions by the United Nations raised the attention to the protection of folklore and other expression of traditional knowledge from different perspectives.

In 2003, UNESCO adopted the "Convention for the Safeguarding of the Intangible Cultural Heritage", which entered into force in 2006 after the thirtieth ratification by Romania. As of September 2018, 178 states have ratified, approved or accepted the convention.

The 2003 UNESCO Convention, even if does not mention folklore, defines "Intangible cultural heritage" as "the practices, representations, expressions, knowledge and know-how, transmitted from generation to generation within communities, created and transformed continuously by them, depending on the environment and their interaction with nature and history". This notion of "intangible cultural heritage", includes 
according to the Convention (a) oral traditions and expressions, including language as a vehicle of the intangible cultural heritage; (b) performing arts; (c) social practices, rituals and festive events; (d) knowledge and practices concerning nature and the universe; as well as (e) traditional craftsmanship (art. 2), so that folklore must be considered included.

The Convention aims at working at national as well as at international level. At national level (III. Safeguarding of the intangible cultural heritage at the national level), State Parties are supposed to 'take necessary measures to ensure the safeguarding of the intangible cultural heritage present in its territory". These measures include identification of the intangible cultural heritage that exists in its territory, adoption of appropriate policies and promotion of education (art. 13).

At international level (IV. Safeguarding of the intangible cultural heritage at the international level), the 2003 Convention promotes international cooperation, which includes "the exchange of information and experience, joint initiatives, and the establishment of a mechanism of assistance" to other State Parties.

Two years later, in 2005, UNESCO adopted the Convention on the Protection and Promotion of the Diversity of Cultural Expressions. The convention entered into force on 18 March 2007 after ratification by 30 states.

The Convention addresses the many forms of cultural expression that result from the creativity not only of individuals, but also of groups and societies and that convey cultural content with symbolic meaning, as well as artistic and cultural values that originate from or express cultural identities (art. 4).

Among the Measures to promote cultural expressions, the Convention foresees at art. 7 that "Parties shall endeavour to create in their territory an environment which encourages individuals and social groups: a) to create, produce, disseminate, distribute and have access to their own cultural expressions, paying due attention to the special circumstances and needs of women as well as various social groups, including persons belonging to minorities and indigenous peoples".

Finally, in 2007, the United Nations adopted the Declaration on the Rights of Indigenous Peoples that acknowledges the right of Indigenous peoples to practice and revitalize their cultural traditions and customs. This includes the right to maintain, protect and develop the past, present and future manifestations of their cultures, such as archaeological and historical sites, but also artefacts, designs, ceremonies, technologies and visual and performing arts and literature (art. 11).

According to the UN Declaration, indigenous peoples have the right to maintain, control, protect and develop their cultural heritage, traditional knowledge and traditional cultural expressions, as well as the manifestations of their sciences, technologies and cultures, including human and genetic resources, seeds, medicines, knowledge of the properties of fauna and flora, oral traditions, literatures, designs, sports and traditional games and visual and performing arts. Even more importantly, they have the right to maintain, control, protect and develop their intellectual property over such cultural heritage, traditional knowledge, and traditional cultural expressions (art. 31).

In conclusion, we might stress that the debate on the protection of folklore at international level has been very vivacious in the last decades, although the effectiveness of the entire struggle is questionable. As it has been pointed out (Yu 2003, p. 241), the success of an international initiative in this field might depend on different issues: the forum in which the parties conduct their negotiation, the mindset itself of the negotiators, and the participation of indigenous people might play an important role in achieving effective success.

In all the cases examined in this Chapter, the communities involved in cases of cultural appropriation were rarely able to find in IP instruments an answer to their demands, which lead us to examine more in detail the concrete applicability of IP to the protection of folklore.

\subsection{The Protection of Folklore through Intellectual Property Tools}

The discourse on the applicability of intellectual property tools to the protection of folklore is full of lights and shadows. 
On the one side, the numerous efforts put in place at national level as well as at international level aimed at giving local communities adequate instruments in order to protect their expressions of folklore have not always reached the goal.

On the other side, lack of protection of folklore through an IP system may end up in denying indigenous people control over their own cultural property, and indirectly on their own cultural identity (Paterson and Karjala 2003, p. 634).

Nobody doubts that as a creation of the human mind, folklore is certainly a form of intellectual property. Nonetheless, it raises particular legal and policy questions when it comes to define a specific regime of protection. In fact, the current construction of intellectual property with its eligibility criteria and limited duration is not wholly compatible with folklore protection (Asmah 2008). Munzer and Raustiala, who dedicated a long and well documented contribution to the difficulties of protecting traditional knowledge through intellectual property rights (Munzer and Raustiala 2009), point out that the debate over the legal protection of traditional knowledge is still young and new solutions should be considered.

For the time being, anyway, an overall protection of folklore under the umbrella of IP law is difficult, even if it receives a distinct focus in many national and international regimes.

It is not to be underestimated that sometimes folklore can be protected by existing legal systems, such as copyright and related rights, geographical indications, appellations of origin and trademarks (Malaurie-Vignal 2019).

If we review the different tools that IP can offer to protect folklore, we might find interesting, although limited solutions.

Contemporary adaptations of folklore, for example, are copyrightable in theory. It is not always easy to reconcile "group ownership" that characterizes indigenous communities with "individual ownership" that is one of the main features of the Western way to think about copyright. Nevertheless, although in traditional communities works tend to be created by groups, it is possible for individuals in the community to be singled out for their exceptional talent or recognized as creators (Asmah 2008). In this case, it is possible to sort out an author, who can be identified for the purposes of protection under the copyright system.

More critics come out of the fact that IP law is based on the criterion of originality, which is difficult to meet for those traditional cultural expressions that have been passed down from one generation to another.

Trademarks can also be used to identify authentic indigenous arts. Nowadays a series of successful experiences provide noteworthy examples in this field (Torsen 2010), as in the case of the the Navajo Tribe v. Urban Outfitters, already mentioned above. Another interesting example concerns the cooperative of Coopa Roca, founded in 1981 by women located in Rocinha, one of the poorest neighborhoods in Rio de Janeiro. Women working for the cooperative are artisans who use traditional handicraft techniques, such as embroidery, crochet, knitting, patchwork and fuxico-a traditional technique that involves embroidering with pieces of fabric (Torsen 2010). The cooperative has registered its own trademark Coopa Roca and makes now expensive high-fashion clothes sold all over the world (Torsen 2010).

Notwithstanding the success of many commercial initiatives (Torsen 2010), it is noteworthy to recall that trademark protection extends only to uses in commerce, but might be inadequate to protect folklore outside the commercial use (Vézina 2019).

Geographical indications and appellations of origin may also play a role in the protection of folklore (Malaurie-Vignal 2019; Torsen 2010). A geographical indication (GI) is a name or sign used on certain products, which corresponds to a specific geographical location or origin. The use of a GI acts as a certification that the product possesses certain qualities, or enjoys a certain reputation, due to its geographical origin. A geographical indication right enables those who have the right to use the indication to prevent its use by a third party whose product does not conform to the applicable standards. 
Appellations of origin are a special kind of geographical indication. GIs and appellations of origin require a qualitative link between the product they refer to and its place of origin. Both inform consumers about a product's geographical origin and the characteristics of a product linked to its place of origin. The basic difference between the two concepts is that the link with the place of origin must be stronger in the case of an appellation of origin. The quality or characteristics of a product protected as an appellation of origin must result exclusively or essentially from its geographical origin. However, a protected geographical indication does not enable the holder to prevent someone from making a product using the same techniques as those set out in the standards for that indication (WIPO, Frequently Asked Questions: Geographical Indications, http://www.wipo.int/geo_indications/en/faq_geographicalindications.htm). Products identified by a geographical indication are often the result of traditional processes and knowledge carried forward by a community in a particular region from generation to generation (Malaurie-Vignal 2019). Similarly, some products identified by a geographical indication may embody characteristic elements of the traditional artistic heritage developed in a given region. This is particularly true for tangible products such as handicrafts, made using natural resources and having qualities derived from their geographical origin.

GIs do not directly protect the subject matter generally associated with folklore, which remains in the public domain under conventional IP systems. However, GIs may be used to indirectly contribute to their protection, for instance, by preserving them for future generations. This can be done, for example, through the description of the production standards for a GI product, which may include a description of traditional processes or knowledge (Malaurie-Vignal 2019).

One interesting example based on geographical indication concerns the Kullu Shawls in India (Torsen 2010). Kullu is located in a valley in the mountains of Himachal Pradesh, in the northern part of India, in Western Himalayas. Kullu shawls contribute significantly to the economy of the valley, where most of the inhabitants earn their living by weaving part time or full time. The Kullu shawls are part of local folklore. They are woven using handlooms that can be found in almost every home, following a traditional knowhow that local people have inherited from their ancestors.

In this context, the Kullu Shawls Weavers Association (KSWA), took the initiative and registered Kullu Shawl as a geographical indicator in 2006 (Simha 2009). According to the Geographical Indication of Goods Act of 1999, the GI, if correctly implemented, prevents sale of non Kullu shawls. It also prevents proprietors from using the name "Kullu shawls" if they are produced outside the defined geographical territory of Kullu Valley Region of Himachal State. Further, unauthorized shopkeepers or producers cannot even use signs boards/hoardings of selling Kullu shawls. In the event of anyone found selling fake shawls, a huge penalty will be imposed on them or imprisonment of 6 months to 3 years or both under the GI Act of 1999 (Simha 2009).

Despite the recognition as GI, local observers point out the difficulties in implementing the law. The Kullu Shawls Weavers Association encountered many difficulties in identifying the number of local household and commercial weavers whose shawls could be given a GI mark to protect them from imitations. The process has been slow because the weaving industry in the Kullu valley is not organized, as weavers are scattered in remote parts of the valley.

In conclusion, for local communities it is difficult and sometimes frustrating to overcome the difficulties that arise in establishing elements of traditional intellectual property protection (Paterson and Karjala 2003, p. 634; Farley 1997, p. 1). Even in the cases where the particular country has a formal law that protects folklore, it is hard to ensure compliance overseas for copyright infringement related to folklore (Asmah 2008, p. 6). That is why many voices have begun to stress the possibility of looking beyond intellectual property in protecting folklore. 


\section{Looking for New Solutions to Protect Folklore in the Fashion Field}

\subsection{The Actual Needs behind the Protection of Folklore}

In the search for new solutions, it is important to investigate the actual needs of those peoples who vindicate their rights about their own folklore.

From a first inquiry, what comes out is not just the request of a static protection of the given expressions of folklore, but more a need of collaboration in order to render folklore a way to enhance the economy of local communities, while respecting their identities and values. According to recent researches, folklore cannot only be understood as a source of identity, but also as a resource for sustainable development (Coombe and Turcotte 2012). Many initiatives have led to a global awakening of the importance of artisans and their culture to a sustainable world. For example, according to the 2011 Crafts Economics and Impact Study (CEIS) by the Crafts Council of India, 'there is recognition of the living fabric of community and social relationships that go beyond monetary value.' Increased environmental awareness has added significance to the fact that artisans prefer to use natural resources in the creation of their products (Emmett 2014).

We might say that in the protection of folklore the debate is characterized by two contrasting approaches, one that tends towards preservation of folklore in its original form and the other that connects the survival of folklore to innovation. In this perspective, the first approach tries to apply intellectual property rights to folklore in order to protect its authentic and original form. The second approach, on the contrary, tends to look to folklore in a dynamic perspective that sees in innovation the only way to sustain traditional culture on the long run (Pager 2012).

In this perspective, legal provisions on cultural property do not always seem the best solution to enhance folklore, as they allow the "assertion of fixed moral and economic ownership over fluid cultural practices and identities" (Aragon 2012). Legal rules sometimes seem to harness realities that are in constant motion and evolving. Textiles, that are now described as "traditional", are often the result of a long and constant evolution (Meneses Lozano 2014).

Analyzing some practical examples that are described by non-Western Authors (Prempree et al. 2014; Fukatsu 2014) the needs that arise do not seem to coincide with the attempt to protect folklore in its current form, as if to crystallize it for posterity.

On the contrary, the request seems much more directed to receive collaboration in order to ensure that original products, although remaining anchored to identity values of a certain culture, can evolve to meet the tastes of today's society.

This operation, which confronts artisans with the opportunities, but also with the challenges of new markets, is not without risks. If it is true that many of the craft-based products are by their very nature too traditional to appeal to a broad global market, it is also true that by changing the aesthetic of the original product to a more westernized aesthetic, the connection to the cultural history of the artefact may be lost. Additionally, it has been suggested that artisans may be persuaded to make products with which they may have little emotional connection (Bissett-Johnson and Moorhead 2018).

In a recent analysis of the silk fabric in Thailand (Prempree et al. 2014), the Authors were pointing very clearly out that "Silk fabric in Thailand is a creative artwork that must be developed and modernized to adapt to the requirements of modern markets in order to enhance the economy" (Prempree et al. 2014, p. 305). While emphasizing the identity value of silk processing, the inquiry pointed out that: "for the most part, woven silk products are made in the original form and there has been no development or adaptation to modern society" (Prempree et al. 2014, p. 305).

The idea from which the Authors start is that in order to add value and to let silk products flourish, traditional knowledge must be integrated with new tools that come out of a creative economy approach that would render traditional products more appealing in today's competitive environment. In this perspective, we find a request to protect folklore through innovation. 
The investigation on silk fabric in Thailand focuses on some critical aspects that should be innovated in order to maintain folklore alive, not only as an identity value, but also as a way to enhance community economy.

Among these critical aspects, the Authors point out that:

- the equipment used in the production process has not been modernized;

- the production is uncertain because the weavers lack knowledge of systematic management;

- the product sale prices are not standardized because the weavers do not know how to allocate prices;

- the product design does not meet the needs of the market because there is no information or research about consumer trends and preferences;

- the marketing of products is practically non-existent due to a lack of education;

- $\quad$ if there is high demand the weavers are unable to produce goods in time to meet it;

- there is no quality control process.

If we look into this variety of factors, a consideration arises spontaneously: no request arises to maintain folklore as it is, but-on the contrarya struggle appears evident in the way antique ways of producing beautiful artifacts can be rendered more adaptable to today's needs. This aim will not be achieved only through IP protection, but it could be made possible through collaboration with the holders of certain skills that generally work for Western designers.

Another example in this line is provided by an interesting project launched in Japan in order to revisit traditional textile designs in a more sustainable way (Fukatsu 2014). Here, the idea is to point out that "production of traditional textiles by local communities often tends to become too traditional and old-fashioned separating from our lives and social life" (Fukatsu 2014, p. 2).

In Japan, the current situation aims at protecting people who are holding traditional techniques in a static way, as cultural heritage and museum collection. The project suggests a different approach, reexamining traditional textiles in order to design new ideas and products for social innovation toward sustainability. One major example concerns the use of banana fibers that are generally thrown away after harvest, as material to be used for the production of environmentally friendly products. In this way, waste materials can be reused as valuable materials.

Using traditional techniques, it was possible to develop a method to extract fibers from fruit bananas, to make yarns, fabrics and papers. As in Japan there are no banana plantations and almost all fruit bananas have been imported from tropical areas, the purpose of the project is to cooperate with foreign countries where bananas are produced (Fukatsu 2014, p. 3).

These various examples lead us to the topical question: "Is it possible to create productive collaboration across cultures without exhausting or dispossessing the custodians of tradition?" (Ballenger and Hamlin 2018).

\subsection{Towards Possible New Solutions}

Looking for possible new solutions in the field of cultural appropriation in the fashion world, it is important to bring to the attention that besides legislative initiatives, an important role may be played by private governance tools and, in particular by Corporate Social Responsibility standards. Private governance can be defined as the phenomenon of private actors pursuing public goals and interests while exercising traditional state functions in the forms of rulemaking, implementation and dispute resolution.

In recent years, we have witnessed an increasing interest amongst private actors in voluntarily pursuing public values and interests such as human rights, social policy, health and environmental protection through private standard setting (Pattberg 2005; Falkner 2003; Knill and Lehmkuhl 2002).

In the fashion industry, compliance with Corporate Social Responsibility principles is developing rapidly and almost all major fashion brands have links to their corporate code of ethics or code of conduct (Cerchia and Piccolo 2019). Many contemporary designers follow social standards in their 
design practice, some through their work with traditional textile artisans including artisan techniques in their designs (Emmett 2014).

In some challenging fields, the trade associations that represent the fashion world have launched specific voluntary initiatives that aim at fixing behavioral standards for business, while enhancing awareness among consumers. In 2012, for example, Camera Nazionale della Moda Italiana together with Confindustria Moda, have launched a "Manifesto for the sustainability in Italian Fashion" that interprets the global challenges of sustainability by defining concrete and distinctive actions to be taken by Italian businesses. The Manifesto pursue various goals: it shows to Italian companies how to take advantage of the opportunities offered by the greater attention given to environmental and social aspects and, at the same time, it helps them to manage reputational and operational risks in the best way.

The same approach should be followed as far as cultural appropriation is concerned, in order to extend the principles developed in the field of environmental sustainability to social sustainability.

Fashion industries associations should become the interpreters of a new way of approaching the problem of cultural appropriation, establishing self-regulation mechanisms, like standards accompanied with a certification label (Vézina 2019).

Collaboration between Western designer and local artisans should be encouraged, in order to foster sensitivity and understanding between artist, designer, and eventually consumer. Cultural sensitivity, education, and ethical business practices will teach values and encourage conscious choices for industry and also for consumers (Ballenger and Hamlin 2018).

In the wake of the initiatives launched by UNESCO, private business should take advantage of the several results already attained.

For example, Craft Revival Trust together with UNESCO has released a study ("Designers meet Artisans", 2005), that outlines several projects that have already reached important achievements where designers and artisans have developed or co-designed new products for new markets. This publication suggests several different models for designer-artisan collaborations in both India and South America, concluding with a list of guidelines concerning the different ways to undertake collaborations.

UNESCO has also launched a Traditional Knowledge World Bank (TKWB) Web system platform designed for the dissemination and sharing of Traditional Knowledge while simultaneously paying respect to its origins (http://www.tkwb.org/w/index.php?title=TKWB). In the framework of its activities a specific "Creative Textile" project has been launched, whose main aim is to preserve, narrate and share textile traditions and their ancient techniques in order to create a cross-pollination project among textile artisans of different background and nationality (https://www.itkius.org/creative-textile-2/). The project aims at documenting and preserving ancient traditions and knowledges. The project further tries to engage communities and territories known for their traditional textile techniques into a common purpose, that is to create a stronger relation among communities around the world.

Many examples show that the idea of becoming more responsible towards local communities is spreading also in the industrial sector. Oskar Metsavaht has launched Osklen, a brand that gives priority to those productions that can help to emancipate the communities involved, creating new sources of income and giving them the tools to collaborate not only with Osklen, but also with other brands. 'As Sustainable As Possible, As Soon As Possible' philosophy, is constantly evolving ways to enhance the sustainability scope of the brand, supported by Instituto-e, a non-profit organisation dedicated to sustainable development.

Metsavaht, is also the founder of Instituto-e, a Civil Society Organization of Public Interest, that proposed the ASAP project: As Sustainable As Possible, As Soon As Possible (https://osklen.com/pages/ ethics-and-sustainability)

The institute further develops and implements environmental projects inspired by the concept of the 6 E's: Earth, Environment, Energy, Education, Empowerment, and Economics.

The projects developed until now concern training, empowerment and income generation to small communities and groups of women that live in vulnerable conditions inside Brazil and abroad. 


\section{Conclusions}

Cultural appropriation is a complex phenomenon. Lawyers who try to approach the issue should contextualize the problem from a historical perspective, trying to apply the necessary tools to cope with all the different facets that the phenomenon presents.

Indigenous people should have the possibility to access conventional intellectual property claims whenever these can allow a fair compensation for cultural appropriation.

Nevertheless, intellectual Property is not always the answer. The needs of indigenous people have to be understood and supported, taking into account their own perspective that might not coincide with Western lawyers' before imposing new laws that are oriented to defining property for profit over creative practices that are oriented to multiple social values and local livelihood goals (Aragon 2012).

That is why, next to IP tools, other solutions should be envisaged that allow folklore not only to be protected, but also to develop according to that natural and ancestral flow, which passes from generation to generation, helping to build an important identity, but at the same time guaranteeing the possibility of adapting to the survival needs of that culture.

Funding: This research received no external funding.

Conflicts of Interest: The authors declare no conflict of interest.

\section{References}

Appiah, Kwame Anthony. 2018. The Lies that Bind. Rethinking Identity. Creed, Country, Colour, Class, Culture. London: Profile Books.

Aragon, Lorraine V. 2012. Copyrighting Culture for the Nation? Intangible Property Nationalism and the Regional Arts of Indonesia. International Journal of Cultural Property 19: 269-312.

Asmah, Josephine. 2008. Historical Threads: Intellectual Property Protection of Traditional Textile Designs: The Ghanaian Experience and African Perspectives. International Journal of Cultural Property 15: 271-96. [CrossRef]

Ballenger, Suzi, and Charlotte Hamlin. 2018. Yours, Mine \& Ours: Beyond Appropriation Textile Society of America Symposium Proceedings. Available online: https://digitalcommons.unl.edu/tsaconf/1128 (accessed on 20 October 2019).

Bascom, W. R. 1959. Definitions of Folklore. In Funk and Wagnalls Standard Dictionary of Folklore Mythology and Legend. Edited by Maria Leach. New York: Funk and Wagnalls, p. 256.

Benjamin, Walter. 1936. Das Kunstwerk im Zeitalter Seiner Technischen Reproduzierbarkeit, L'opera D'arte nel Tempo Della sua Riproducibilità Tecnica (1935/1936). Milano: Bompiani.

Bissett-Johnson, Katherine, and David Moorhead. 2018. Co-creating Craft; Australian Designers meet Artisans in India Textile Society of America Symposium Proceedings. Available online: https://digitalcommons.unl.edu/ tsaconf/1073 (accessed on 28 September 2019).

Boateng, Boatema. 2014. Adinkra and Kente Cloth in History, Law, and Life. Textile Society of America Symposium Proceedings. Available online: http://digitalcommons.unl.edu/tsaconf/932 (accessed on 15 September 2019).

Braudel, Fernand. 1979. Civilisation Matérielle, Economie et Capitalisme, XV-XVIII siècle, 282.

Brown, Michael F. 2003. Who Owns Native Culture? Cambridge: Harvard University Press.

Carrier, James G. 1995. Occidentalism: Images of the West. New York: Oxford University Press.

Cerchia, R., and K Piccolo. 2019. The Ethical Consumer and Codes of Ethics in the Fashion Industry. Laws 8: 23. [CrossRef]

Chiara, Francina. 2016. Origine e fortuna del motivo cachemire nella cultura tessile occidentale. In Cachemire-Il Segno in Movimento. Edited by M Rosina and F Chiara. Como: Nodolibri.

Coleman, Elizabeth Burns, Rosemary J. Coombe, and Fiona MacArailt. 2012. A Broken Record: Subjecting Music to Cultural Rights. In The Ethics of Cultural Appropriation. Edited by James O. Young and Conrad G. Brunk. Oxford: Wiley-Blackwell, p. 173.

Coombe, Rosemary J., and Joseph F. Turcotte. 2012. Indigenous Cultural Heritage in Development and Trade: Perspectives from the Dynamics of Cultural Heritage Law and Policy. In International Trade in Indigenous Cultural Heritage. Edited by C. B. Graber, K Kuprecht and J. C. Lai. Cheltenham: Edward Elgar Publishing. 
D’Hoop, Roland. 2017. Mexique: Quand les Artisanes, Avec le Soutien de l'Etat, se Rebellent Contre le Plagiat par des Grandes Marques. Oxfam. Magasins du Monde. Available online: https:/www.oxfammagasinsdumonde.be/blog/2017/12/28/mexique-quand-les-artisan\%C2\%B7e\%C2\%B7savec-le-soutien-de-letat-se-rebellent-contre-le-plagiat-par-des-grandes-marques/\#.XV-87ugzY2w (accessed on 28 December 2017).

Demilew, Abiy. 2008. Protest Continues Against the Stolen Designs Ethiopia, Still Investigating. Available online: http://nazret.com/blog/index.php/2008/01/01/ethiopia_controversy_over_ethiopian_trad (accessed on 28 August 2019).

Emmett, Deborah. 2014. Conversations between a Foreign Designer and Traditional Textile Artisans in India: Design Collaborations from the Artisan's Perspective. Textile Society of America Symposium Proceedings. Available online: http://digitalcommons.unl.edu/tsaconf/923 (accessed on 28 August 2019).

Falkner, Robert. 2003. Private environmental governance and international relations: Exploring the links. Global Environmental Politics 3: 72-87. [CrossRef]

Farley, Christine Haight. 1997. Protecting Folklore: Is Intellectual Property the Answer? Connecticut Law Review 30: 1.

Fondazione Gianfranco Ferré. 2019. Available online: http://www.fondazionegianfrancoferre.com/home/biografia. php?lang=en (accessed on 18 June 2019).

Fowler, Sarah. 2013. The Commodification of the Native in the 21st Century. Journal Global Societies Journal 1. Available online: https://escholarship.org/uc/item/77m340wn (accessed on 20 September 2019).

Fukatsu, Yuko. 2014. Traditional Textile Design for Social Innovation. Toward Sustainability in Japan. Textile Society of America Symposium Proceedings. Available online: http://digitalcommons.unl.edu/tsaconf/915 (accessed on 23 September 2019).

Gastor, Theodor. 1959. Definitions of Folklore, Funk and Wagnalls Standard Dictionary of Folklore Mythology and Legend. Edited by Maria Leach. New York: Thomas Y. Crowell, p. 258.

Geczy, Adam. 2013. Fashion and Orientalism: Dress, Textiles and Culture from the 17th to the 21st Century. London: A\&C Black.

Geczy, Adam, and Vicky Karaminas, eds. 2018. The End of Fashion: Clothing and Dress in the Age of Globalization. London: Bloomsbury Publishing.

Greaves, Tom. 1994. Intellectual Property Rights for Indigenous Peoples, A Sourcebook. Oklahoma City: Society for Applied Anthropology.

Grosfilley, Anne. 2017. Wax \& Co.-Anthologie des tissus imprimés en Afrique. Paris: Éditions de la Martinière.

Gupta, Toolika. 2016. The Birth of the Sherwani: An Influence of the British Raj. University of Glasgow. Available online: https://www.researchgate.net/publication/308902032_The_Birth_of_the_Sherwani_An_Influence_ of_the_British_Raj/references (accessed on 10 October 2019).

Hailesalassie, Hewete. 2007. Anger over African Designs. Available online: https:/www.independent.co.uk/news/ business/news/anger-over-african-designs-763901.html (accessed on 20 August 2019).

Hall, Perry A. 1997. African-Amrican Music: Dynamics of Appropriation and Innovation. In Borrowed Power, Essays on Cultural Appropriation. Edited by Bruce H. Ziff and Pratima V. Rao. New Brunswick: Rutgers University Press, p. 31.

Heller, Susanna. 2017. Every time Victoria's Secret has been Accused of Cultural Appropriation in its Annual Fashion Show. Available online: https://www.insider.com/victorias-secret-fashion-show-accused-culturalappropriation-2017-11 (accessed on 20 August 2019).

Hobsbawm, Eric J., and Terence Ranger. 1983. The Invention of Tradition. Cambridge: Cambridge University Press.

Hsu, Tiffany, and Elizabeth Paton. 2019. Gucci and Adidas Apologize and Drop Products Called Racist. The New York Times, February 7. Available online: https://www.nytimes.com/2019/02/07/business/gucci-blackfaceadidas-apologize.html(accessed on 12 September 2019).

Khopar, Anisha. 2018. We Need to Talk About Cultural Appropriation in Fashion. Available online: https: //www.abc.net.au/life/cultural-appropriation-and-fashion/10501010 (accessed on 28 November 2018).

Knill, Christoph, and Dirk Lehmkuhl. 2002. Private actors and the state: Internationalization and changing patterns of governance. Governance 15: 41-63. [CrossRef]

Kuek, Chee Ying. 2005. Protection of Expressions of Folklore/Traditional Cultural Expressions. To what Extent is Law the Solution? Journal of Malaysian and Comparative Law 32. Available online: https:/ejournal.um.edu.my/ index.php/JMCL/article/view/16268 (accessed on 24 September 2019). 
Kuruk, Paul. 1999. Protecting Folklore Under Modern Intellectual Property Regimes: A Reappraisal of the Tensions Between Individual and Communal Rights in Africa and the United States. American University Law Review 48: 769-843.

Kutty, P. Valsala G. 2007. National Experiences with the Protection of Expressions of Folklore/Traditional Cultural Expressions. Geneva: World Intellectual Property Organization, vol. 912.

Larson, Naomi. 2015. Inspiration or Plagiarism? Mexicans Seek Reparations for French Designer's Look-alike Blouse. The Guardian, June 15. Available online: https://www.theguardian.com/global-developmentprofessionals-network/2015/jun/17/mexican-mixe-blouse-isabel-marant(accessed on 20 August 2019).

Legendre, Aimé-François. 1926. La Civilisation Chinoise Moderne. Paris: Payot.

Littrell, Mary. 2015. Fair Trade and Artisans. In Handbook of Research on Fair Trade. Edited by Laura T. Raynolds and Elizabeth A. Bennett. Cheltenham and Northampton: Edward Elgar.

Lorelle, Véronique. 2010. ¡Que viva Jean Paul Gaultier! Le Trublion de la Mode Parisienne a Égayé la Dernière Journée des Défilés de Haute Couture de sa Vision Inspirée du Mexique. Available online: https://www.lemonde.fr/vous/article/2010/01/28/que-viva-jean-paul-gaultier_1298076_3238.html (accessed on 20 August 2019).

Lunde, Kristin Scheel. 2018. Ancient, Indigenous and Iconic Textile Motifs in Contemporary Fashion Case Study: Defining Concepts through Textile Designs: Appropriation, Collaboration, Provenance and Identity (2018). Textile Society of America Symposium Proceedings. Available online: https://digitalcommons.unl.edu/ tsaconf/1093 (accessed on 20 September 2019).

Malaurie-Vignal, Marie. 2019. La protection des savoir-faire et motifs traditionnels-Pour la défense d'une mode éthique. Propriété Industrielle n.2, February. 12.

Malik, Kenan. 2017. Kenan Malik on Cultural Appropriation. Art Review, December. Available online: https://artreview.com/features/ar_december_2017_feature_cultural_appropriation_kenan_malik/(accessed on 20 September 2019).

Marchetti, Ada Gigli. 1995. Dalla Crinolina alla Minigonna. La donna, L'abito e la Società dal XVIII al XX Secolo. Milano: CLUEB.

Martin, Richard Harrison, and Harold Koda. 1994. Orientalism: Visions of the East in Western Dress. New York: Metropolitan Museum of Art, pp. 7-9.

Matip, Nicole Florence, and Konstantia Koutouki. 2008. La protection juridique du folklore dans les états membres de l'organisation africaine de la propriété intellectuelle, La. Revue Québécoise de Droit International 21: 243.

Meneses Lozano, Hector Manuel. 2014. Traditional Innovation in Oaxacan Indigenous Costumes. Textile Society of America Symposium Proceedings. Available online: http://digitalcommons.unl.edu/tsaconf/903 (accessed on 20 October 2019).

Moss, Hillary. 2011. Lisa Blue 'Lakshmi' Swimsuit Causes Outrage Among Hindus. Available online: https: //www.huffpost.com/entry/lisa-blue-lakshmi-swimsuit-hindu_n_859247 (accessed on 5 September 2011).

Mower, Sarah. 2007. Available online: https://www.vogue.com/fashion-shows/spring-2007-couture/christian-dior (accessed on 10 September 2019).

Mulvaney, Lucy. 2013. Is Cultural Appropriation in Fashion Offensive?-Part I. Available online: http://www.universitytimes.ie/2013/11/is-cultural-appropriation-in-fashion-offensive-part-i/ (accessed on 5 September 2011).

Munzer, Stephen R., and Kal Raustiala. 2009. The Uneasy Case for Intellectual Property Rights in Traditional Knowledge. Cardozo Arts \& Entertainment Law Journal 27: 37-97.

Musée Yves Saint Laurent. 2019. Available online: https://museeyslparis.com/en/biography/collection-africaine-pe (accessed on 1 June 2019).

Muzzarelli, Maria Giuseppina. 1999. Guardaroba Medioevale. Vesti e Società dal XIII al XVI Secolo. Bologna: Il Mulino.

Muzzarelli, Maria Giuseppina, and Campanini Antonella Campanini. 2003. Disciplinare il Lusso. La Legislazione Suntuaria in Italia e in Europa tra Medioevo ed età Moderna. Roma: Carocci.

Nason, James D. 1997. Native American Intellectual Property Rights: Issues in the Control of Esoteric Knowledge. In Borrowed Power, Essays on Cultural Appropriation. Edited by B. Ziff and P. V. Rao. New Brunswick: Rutgers University Press, p. 237.

Nassu, Willian. 2016. From Chintz to Chita: A Brazilian Textile and the Construction of National Identity. Textile Society of America Symposium Proceedings. Available online: http://digitalcommons.unl.edu/tsaconf/968 (accessed on 5 September 2011). 
Nicolas, George. 2017. Victoria's Secret Does it Again: Cultural Appropriation. Available online: http://theconversation.com/victorias-secret-does-it-again-cultural-appropriation-87987 (accessed on 5 September 2019).

O'Shea, Joe. 2013. Claudia Schiffer and the Satanic Breasts. The Independent, October 4. Available online: https: //www.independent.ie/style/fashion/claudia-schiffer-and-the-satanic-breasts-29630821.html(accessed on 5 September 2019).

Pager, Sean A. 2012. Folklore 2.0: Preservation Through Innovation. Utah L. Rev. 1853.

Palmer, Ewan. 2019. Is this Gucci Sweater Blackface? Company Apologizes, Pulls Item from Stores after Social Media Backlash. Newsweek, September 2. Available online: https://www.newsweek.com/gucci-sweaterblackface-company-apologizes-pulls-item-stores-after-social-1321547(accessed on 5 September 2019).

Pan, Yiling. 2018. Is it Racist?: Dolce \& Gabbana's New Ad Campaign Sparks Uproar in China. Jing Daily, November 19. Available online: https://jingdaily.com/dolce-gabbana-racism/(accessed on 5 September 2019).

Paterson, Robert K., and Dennis S. Karjala. 2003. Looking beyond intellectual property in resolving protection of the intangible cultural heritage of indigenous peoples. Cardozo J. Int'l \& Comp. L. 11: 633.

Pattberg, Philipp. 2005. The institutionalization of private governance: How business and nonprofit organizations agree on transnational rules. Governance 18: 589-610. [CrossRef]

Pham, Minh-Ha. 2013. Paul Poiret's Magical Techno-Oriental Fashions (1911): Race, Clothing, and Virtuality in the Machine Age. Configurations 21: 1-26. [CrossRef]

Poiret, Paul. 1930. En Habillant L'époque. Paris: Bernard Grasset, p. 190.

Prempree, Anuchit, Songkoon Chantachon, and Sisikka Wannajun. 2014. The integration of traditional knowledge in the design and development of mudmee, praewa and yok tong silk products for enhancing community economy. Indian Journal of Traditional Knowledge 13: 305.

Pullman, Daryl, and Laura Arbour. 2012. Genetic Research and Culture: Where Does the Offense Lie? In The Ethics of Cultural Appropriation. Edited by James. O. Young and Conrad. G. Brunk. Oxford: Wiley-Blackwell, p. 115.

Riello, Giorgio. 2012. La Moda. Una Storia dal Medioevo a oggi. Bari: Laterza.

Robinson, Georgina. 2011. Indian Fury at Hindu Goddess on skimpy swimsuits. The Sidney Morning Herald, May 10. Available online: https://www.smh.com.au/lifestyle/fashion/indian-fury-at-hindu-goddess-on-skimpyswimsuits-20110510-1egax.html(accessed on 10 October 2019).

Said, Edward W. 1978. Orientalism. London: Routledge \& Kegan Paul.

Scafidi, Susan. 2001. Intellectual Property and Cultural Products. B.U.L. Rev. 81: 793.

Scafidi, Susan. 2005. Who Owns Culture? Appropriation and Authenticity in American Law. New Brunswick: Rutgers University Press.

Segre Reinach, Simona. 2006. Manuale di Comunicazione, Sociologia e Cultura Della Moda, Orientalismi. Roma: Meltemi Editore, vol. IV.

Sgubin, Raffaella, and Roberta Orsi Landini. 2018. Occidentalismo: Modernità e arte Occidentale nei Kimono della Collezione Manavello 1900-1950. Treviso: Antiga Edizioni.

Sharoni, Sari. 2016. The Mark of a Culture: The Efficacy and Propriety of Using Trademark Law to Deter Cultural Appropriation. Fed. Cir. BJ 26: 407.

Simha, Ajay. 2009. Kullu Shawls of Himachal as a Geographical Indicator. Hillpost, News and Views from the Himalaya, April 17. Available online: https://hillpost.in/2009/04/kullu-shawls-of-himachal-as-a-geographicalindicator/12648/(accessed on 22 November 2018).

Soh, Stephanie. 2018. Does Fashion have a Cultural Appropriation Problem? Available online: https://www.bbc. com/news/newsbeat-46297329 (accessed on 22 November 2018).

Stancati, Margherita. 2011. Hindu Goddess Swimsuit Sparks Outrage. Available online: https://blogs.wsj.com/ indiarealtime/2011/05/10/hindu-goddess-swimsuit-sparks-outrage/ (accessed on 10 May 2011).

Steele, Valerie, and John S. Major. 1999. China Chic: East meets West. Yale: Yale University Press.

Summers, Julie. 2016. Fashion on the Ration. Style in the Second World War. London: Profile Books Ltd.

Tarlo, Emma. 1996. Clothing Matters: Dress and Identity in India. Chicago: Chicago University Press.

Taylor, Archer. 1959. Definitions of Folklore. In Funk and Wagnalls Standard Dictionary of Folklore Mythology and Legend. Edited by Maria Leach. New York: Funk and Wagnalls, p. 263.

Torsen, Molly. 2010. Intellectual Property Options for Protecting and Marketing Traditional Textiles, International Intellectual Property Institute. Available online: https:/iipi.org/wp-content/uploads/2010/07/Traditional_ Textiles.pdf (accessed on 10 May 2011). 
Troy, Nacy J. 2002. Paul Poiret's Minaret Style: Originality, Reproduction, and Art in Fashion. Fashion Theory 6: 117-43. [CrossRef]

UNESCO. 1989. Recommendation on the Safeguarding of Traditional Culture and Folklore. Available online: http: //portal.unesco.org/en/ev.php-URL_ID=13141\&URL_DO=DO_TOPIC\&URL_SECTION=201.html (accessed on 10 May 2011).

Valéry, Paul. 1934. La Conquête de L'ubiquité, in Pièces sur L'art. Paris: Gallimard.

Varagur, Krithika. 2017. Is This The Right Way For Fashion To Do Cultural Appropriation? Available online: https://www.huffpost.com/entry/fashion-cultural-appropriation_n_5632295ce4b00aa54a4ce639 (accessed on 18 January 2017).

Vézina, Brigitte. 2019. Curbing Cultural Appropriation in the Fashion Industry CIGI (Center fro International Governance Innovation) Papers No. 213. Available online: https://www.cigionline.org/sites/default/files/ documents/paper\%20no.213.pdf (accessed on 10 May 2011).

Vigarello, Georges. 2017. La Robe. Une Histoire Culturelle. Du Moyen Age à Aujourd'hui. Paris: Éditions du Seuil. Von Lewinski, S. 2008. Indigenous Heritage and Intellectual Property: Genetic Resources, Traditional Knowledge and Folklore. Alphen aan den Rijn: Kluwer Law International.

WIPO. 1982. Model Provisions for National Laws on the Protection of Expressions of Folklore Against Illicit Exploitation and other Prejudicial Actions with a Commentary Prepared by the Secretariats of the United Nations Educational, Scientific and Cultural Organization (UNESCO) and the World Intellectual Property Organization (WIPO). Geneva: WIPO.

WIPO. 1997. Unesco-Wipo World Forum On The Protection Of Folklore organized by the United Nations Educational, Scientific and Cultural Organization (UNESCO) and the World Intellectual Property Organization (WIPO) in Cooperation with the Department of Intellectual Property, Ministry of Commerce, Government of Thailand Phuket, Thailand, April 8 to 10, 1997 1967,1982,1984: Attempts to Provide International Protection for Folklore by Intellectual Property Rights, Document Prepared by the International Bureau of WIPO. Geneva: WIPO.

WIPO. 1999. Intellectual Property needs and Expectations of Traditional Knowledge Holders-WIPO Report on Fact-Finding Missions on Intellectual Property and Traditional Knowledge (1998-1999). Available online: https://www.wipo.int/edocs/pubdocs/en/tk/768/wipo_pub_768.pdf (accessed on 10 May 2011).

WIPO. 2000. All the Informations on IGC. Available online: https://www.wipo.int/tk/en/igc/ (accessed on 10 May 2011).

WIPO. 2011. Intellectual Property and Traditional Knowledge, Booklet No. 2, 11. Available online: http: //www.wipo.int/freepublications/en/tk/920/wipo_pub_920.pdf (accessed on 10 May 2011).

Young, James O., and Conrad G. Brunk, eds. 2012. The Ethics of Cultural Appropriation. Oxford: Wiley-Blackwell.

Young, James O., and Susan Haley. 2012. Nothing Comes from Nowhere: Reflections on Culutral Appropriation as the Representation of Other Cultures. In The Ethics of Cultural Appropriation. Edited by J. O. Young and C. G. Brunk. Oxford: Wiley-Blackwell, p. 268.

Yu, Peter K. 2003. Traditional Knowledge, Intellectual Property, and Indigenous Culture: An Introduction. Cardozo Journal of International and Comparative Law 11: 239.

Ziff, Bruce, and Pratima V. Rao. 1997. Borrowed Power, Essays on Cultural Appropriation. New Brunswick: Rutgers University Press.

Zografos, Daphne. 2010. Intellectual Property and Traditional Cultural Expressions. London: Edward Elgar Publishing, (The States that enacted specific statutes in order to protect their folklore are: Algeria in 1973; Senegal in 1973; Kenya in 1975; Mali in 1977; Burundi in 1978; the Ivory Coast in 1978; Guinea in 1980; Cameroon in 1982; Congo in 1982; Madagascar in 1982; Rwanda in 1983; Benin in 1984; Burkina Faso in 1984; the Central African Republic in 1985; Ghana in 1985; Zaire, 1986; Nigeria, 1988 and 1992; Lesotho, 1989; Malawi, 1989; Angola, 1990, Togo, 1991; Niger, 1993. In Central, South America and the Caribbeans: Bolivia, 1968 and 1992; Chile, 1970, Colombia, 1982; Barbados, 1982; Dominican Republic, 1986; Panama, 1994. In Asia Iran, 1970; Sri Lanka, 1979; Indonesia, 1987).

(C) 2020 by the author. Licensee MDPI, Basel, Switzerland. This article is an open access article distributed under the terms and conditions of the Creative Commons Attribution (CC BY) license (http://creativecommons.org/licenses/by/4.0/). 


\title{
Article \\ The Ethical Consumer and Codes of Ethics in the Fashion Industry
}

\author{
Rossella Esther Cerchia * and Katherine Piccolo * \\ Department of Private Law and Legal History, University of Milan (Università degli Studi di Milano), \\ 20122 Milan, Italy \\ * Correspondence: rossella.cerchia@unimi.it (R.E.C.); katherine.piccolo@unimi.it (K.P.)
}

Received: 30 July 2019; Accepted: 19 September 2019; Published: 24 September 2019

\begin{abstract}
Sustainability is a central challenge of the fashion industry. In an era where Internet and social networks allow information to spread quickly, more consumers are familiar with the call for "ethical fashion" as disasters such as Rana Plaza resound worldwide. However, consumers interested in buying "ethical" clothing could have a hard time orienting themselves amongst the abundance of brands claiming to be ethical on the market. Consumers might make purchasing decisions based on their knowledge of a brand. In this context, it is imaginable that corporate social responsibility (CSR) communications, including codes of ethics, could constitute one way a consumer can learn more about a company's values. These codes may serve a variety of purposes-they are undoubtedly one of the ways a brand communicates its commitment to ethical principles. Indeed, by analyzing the codes of ethics of some of the industry's well-known brands, it is evident that they primarily focus on employment and workers' rights (including equality and discrimination issues), labor safety standards, bribery and anti-corruption, counterfeiting and unfair business practices, as well as respect for (and sometimes improvement of) the environment. A company's code of ethics is also a powerful tool for improving brand image by adopting a code that responds to the issues that consumers care about. It is therefore necessary to distinguish between companies that are truly ethical and those that merely appear so. In order to protect consumer confidence in such documents, a fil rouge across legal systems may be found (although the specific characteristics may vary greatly) in the laws that protect consumers from misleading advertising.
\end{abstract}

Keywords: code of ethics; sustainable fashion; ethical consumer

\section{Introduction}

Until just a few years ago, the neologism "fashion victims" (Treccani 2012) indicated who obsessively followed fashion and new trends, a product of the eighties and the explosion of the brand cult. Today, this same term brings to mind exploited workers (Zinola 2019) from countries such as China, South Korea, Indonesia, Malaysia, India, and Bangladesh (Kristof and WuDunn 2000). ${ }^{1}$ Peoples' memories are imprinted with media images of the 24 April 2013 collapse of the Rana Plaza, the immense building where cheap apparel was produced for the Western world, resulting in the deaths of more than a thousand people (Taplin 2014). ${ }^{2}$ News of this disaster resounded all over the world, awakening the consciences of those who had not yet become interested in sustainable fashion. ${ }^{3}$

1 For more on this topic, see generally the documentary "Fashion Victims" by Alessandro Brasile and Chiara Cattaneo, recounting episodes of exploitation in the fashion supply chain (Brasile 2019).

2 Further information can be found at https://ranaplaza-arrangement.org.

3 On the main perspectives of research on sustainable retailing in the fashion industry, see Yang et al. (2017). For literature on the very broad theme, see ex multis Gordon and Hill (2015); Gwilt (2018); Gwilt and Rissanen (2011); Hethorn and Ulasewicz (2008, 2015); Minney (2011). 
It is therefore not surprising that the "Top 10 consumer trends" of 2019 (Angus and Westbrook 2019) lists the "conscious consumer" that wants "to make positive decisions about what they buy and look for a solution to the negative impact consumerism is having on the world" as one of top modern vogues. Such consumers-those who worry about how their purchasing decisions impact the world in general; those that might be defined as "ethical consumers" (Harrison et al. 2005)—could have a difficult time orienting themselves amongst the abundance of brands claiming to be committed to the same principles on the clothing market.

One of the ways an ethical consumer can learn how aligned a brand is with the issues and/or values they care most about is by visiting a company's website. Here, in addition to marketing its products, company websites tend to contain information about a company's core values and the ethical principles by which it abides. For instance, information on compliance with corporate social responsibility (CSR) principles is often published, and many fashion brands have links ${ }^{4}$ to their corporate code of ethics or code of conduct ${ }^{5}$, which are a sort of company "constitution" (Nieweler 2014).

In this context, a company's code of ethics could become an important tool that allows the consumer to discover and learn more about a brand's policies. Learning that a company has established a self-regulatory instrument to ensure adherence with principles of ethical business practice may affect the choices of ethical consumers who share the same principles and are concerned about the same issues that are reflected in the brand's code of ethics.

Thus, this article highlights some consumer sensibilities regarding a more sustainable fashion industry, aiming to offer insight on the development of the use of codes of ethics in general, and in the fashion industry in particular, especially in relation to the protection of the right to safe and healthy working conditions, as working conditions are indeed amongst the issues that ethical consumers care most about. However, given that companies may use such topics to increase sales (Binet et al. 2019), the public must take care that these are not mere words-that CSR does not translate into a façade: in the event of the latter case, an insincere CSR program might even become a barrier to finding real solutions (House of Commons 2019, p. 14). Accordingly, this article concludes by hypothesizing whether it is possible to protect consumer confidence in these codes by identifying a fil rouge across legal systems (notwithstanding any variability in the specific characteristics of national legislation) in the laws that protect consumers from misleading advertising.

\section{Consumers' Concerns}

Sustainability is a central challenge of the fashion industry. If securing a sustainable future for the planet and humankind is one of the defining challenges of our time (House of Commons 2019), then it is not surprising that non-governmental organizations (NGOs), international organizations, institutional actors, and public opinion are pushing the fashion industry in this direction. The fashion industry has been recognized as one of the most polluting (Brenot et al. 2019; Cherny-Scanlon and Agnes 2016; Conca 2015; Fletcher 2014; Jucker 2011; Kant 2012; Kuik 2004-2005; Muthu 2014; Raluca 2019; Shih and Agrafiotis 2017; Slater 2003), even if it appears that the "green fashion" movement developed simultaneously with the largest environmentalist movements of the 1960s (Gordon and Hill 2015). Furthermore, although the recent campaigns of activist groups-such as Green Peace, which has been fighting for a sustainable fashion supply chain since 2011 (Greenpeace International 2019)—indicate there remains much to be done, one of the positive effects of the many

4 An overwhelming majority of fashion brands include their code of ethics either amongst the site navigation links on the main webpage, public corporate documents, or contained in a section dedicated to sustainability and/or CSR programs. This last part is significant in so much as CSR plays an important marketing function for a company. It is equally noteworthy that only a scarce few of the brands surveyed made their codes of ethics available through separate websites (i.e., group websites, in the section dedicated to organizational structure).

5 In general, we will use the terms "code of ethics" and "code of conduct" interchangeably, except where we have intentionally distinguished between the two. On the difference between codes of ethics and codes of conduct, see generally Benatti (2014, pp. 7-13), and Nieweler (2014). 
campaigns and initiatives for sustainable fashion is the consumer response (or at least a growing number of consumers) (Gordon and Hill 2015) to the well-known slogan, "Join the Fashion Revolution. Be part of the global movement calling for a fairer, safer, cleaner, more transparent fashion industry" (Fashion Revolution 2019).

Moreover, the sweatshop problem is certainly not new to the general public. ${ }^{6}$ For example, back in the 1990s, there were reports of corporate giants (such as Nike) relocating production to lower costs and benefit from less stringent legislation: public opinion denounced these brand-names and held them accountable for the working conditions in the factories of their supply chain (ex multis, Featherstone 2002; Harrison and Scorse 2010).

Today, in an era where Internet and social networks allow information to spread far and wide almost instantaneously, more consumers are familiar with disasters such as Rana Plaza. Even if it was not the first time the fashion industry had been associated with catastrophe, ${ }^{7}$ its severity and its media exposure has compelled people to ask themselves: "who made my clothes?"8.

Indeed, the general public is aware of the "True $\operatorname{Cost}^{\text {"9 }}$ of the fashion supply chain-especially when it comes to fast fashion. ${ }^{10}$

Those who might be characterized as ethical consumers are sensitive to specific issues and share a general sentiment that they want the workers who produced their clothes to be protected (meaning, for instance, they should have an employment contract with set maximum work hours, be paid at least minimum wage, and work under safe conditions); they want the entire production chain oriented toward minimizing environmental impact and its carbon footprint; and they want to protect animals, preferring cruelty-free products. On this last point, even though one might recall the anti-fur campaigns of the 1980s and 1990s popular culture, it was only recently that brands such as Gucci, Michael Kors, and Giorgio Armani joined the Fur Free Alliance (Fur Free Alliance 2019) and banned the use of any type of fur in their collections. ${ }^{11}$ Furthermore, it was only a few months ago that Chanel stopped using furs and exotic leathers (Kolirin 2018).

The number of "ethical consumers" who view ethical fashion favorably seems to be increasing, ${ }^{12}$ but it is difficult to decipher how this attitude translates into purchasing behavior, and especially whether consumers will spend more for an ethical product. ${ }^{13}$ Yet it is still very difficult to answer the question, "To what extent do consumers favor the products of socially responsible firms or shun those produced irresponsibly?" because the results are not unique (Vogel 2005, p. 47).

Despite the forms of consumer communication and marketing strategies in this regard being very heterogeneous, many current contenders in the fashion industry portray themselves as committed to "ethical business". Indeed, some distinguish themselves by incorporating environmental aspects into their business model. In this sense, being environmentally friendly becomes a new concept of

6 For a definition of sweatshop, see Shaw et al. (2004): “Although there are a number of definitions of 'sweatshop', it can be loosely defined as factory production in which employees are exploited by means of low wages, excessive working hours, under age employees, or other exploitative practices, frequently but not exclusively in developing economies where labor laws and workers' rights can be less rigorous".

7 For instance, just two years before the Rana Plaza disaster, on 24 November 2012 a fire broke out in the Tazreen Fashions garment factory in Bangladesh leaving more than one hundred dead. See Bajaj (2012).

8 The reference is to the well-known global campaign by Orsola de Castro and Carry Somers.

9 Reference is made to the well-known 2015 documentary directed by Andrew Morgan that focuses on fast fashion.

10 For a description of fast fashion supply chains and sustainability issues, see Turker and Altuntas (2014, pp. 837-49, 838).

11 Notwithstanding this apparent progression, an Italian journalistic TV program recently conducted investigation on the purchase by well-known brands of feathers plucked from live geese in Hungary for the manufacture of down jackets. For further information, see "We're all geese" (Siamo tutti oche) by Sabrina Giannini, available online: http: //www.report.rai.it/dl/docs/14149594048311_siamo_tutti_oche_report.pdf.

12 It has been pointed out that, compared to older generations, millennials and "Generation X" are increasingly committed to taking concrete steps toward sustainable fashion (Howe 2018), despite not always being willing (or able to afford) to pay higher prices for ethical products (Coughlin 2018).

13 On consumer behavior, see Grappi et al. (2017); Kuik (2004-2005, p. 628); Laroche et al. (2001, pp. 503-20); Shen et al. (2012, pp. 234-45); Sudbury-Riley and Boltner (2011); Trudel and Cotte (2009); Vogel (2005). 
quality. Take Patagonia or The North Face, for example. Other brands might orient their competitive advantage around animal friendliness and promoting animal rights, ${ }^{14}$ and so on.

All this has resulted in a significant number of initiatives by many brands calling for improved sustainability and more ethical practices. ${ }^{15}$ However, the overwhelming number of such endeavors-in addition to the lack of real transparency-makes it difficult for consumers who are interested in buying ethical clothing to make well-informed decisions (Pookulara and Shephard 2013, p. 204). ${ }^{16}$

In the recent past, and in order to feel confident that one's clothes were not produced in sweatshops, consumers, in an approximate and generic manner, looked at the country of production.

Today, this end may be achieved in various ways, for instance, by reading the label on the inside of the clothing of those brands that participate in such movements. Indeed, other than containing details such as raw material composition and the product's country of origin, labeling could be useful to communicate information related to the environment, working conditions, and much more. ${ }^{17}$ Labels pertaining to social conditions in manufacturing have a long history (Kuik 2004-2005), but in the last few years brands have become increasingly interested in obtaining various types of certifications attesting that their products are "green", "ethical", or "animal cruelty free". Environmental certifications might guarantee that only those chemical substances not harmful to the environment were used to manufacture garments-whether during plant cultivation (such as cotton), spinning of fabric, or any subsequent processes involved in production. Social (or ethical) certifications set, for instance, minimum standards of respect for workers' rights (Koszewska 2011), and there are also certifications that specifically guarantee respect for animal welfare, certifying that the brand in question does not use materials coming from animals.

Labels containing reliable information on sustainability certainly provide fairly immediate and useful information, but clothing tags and certification labels are neither widely used nor well known and may even be difficult to navigate.

One's "knowledge" of a certain brand constitutes another important tool that an ethical consumer might avail of when making purchasing decisions. Whether one "knows" a brand depends on a variety of factors, but reading a company's statements, including its code of ethics, could be one of them. Furthermore, it is also an easy way to learn more about a company's values. What is more, although these codes are undoubtedly one of the ways a brand communicates its commitment to ethical principles, they may serve a variety of purposes. For instance, it appears that some demands for sustainable fashion are reflected in the language and structure of the codes of ethics of individual fashion brands, such as in relation to employment and workers' rights (including equality and discrimination issues), labor safety standards, bribery and anti-corruption, counterfeiting and unfair business practices, as well as respect for (and sometimes improvement of) the environment. This is not surprising given the history of the development of code of ethics, their functions, and the ethical consumers' concerns.

\section{The Emergence and Development of Codes of Ethics}

Although the underlying fundamental principles of corporate codes of ethics are not novel (Baker 1992), codes of ethics have a relatively short history (Benson 1989; Pitt and Gros-Kaufmanis 1990) - starting in the United States. Indeed, episodes of gross corporate misconduct in the 20th century induced companies to adopt methods to avoid (or at least reduce) unethical business practices (Benatti 2014; Messikomer and Cirka 2010). ${ }^{18}$

14 For example, Stella McCartney devotes a significant portion of her business activity to advocating animal welfare. See https://www.stellamccartney.com/experience/it/sustainability/themes/respect-for-animals/.

15 On this point, see generally Jacometti (2016)

16 On the consumer difficulties of engaging in eco-conscious apparel, see also Connell (2010).

17 On social, eco-labelling, and certifications in the fashion industry, see Jacometti (2016, pp. 10-17) and Koszewska (2011).

18 On the preference for self-regulation over legislative regulation, see Benatti (2014, pp. 15-17). 
The importance of self-regulation became apparent during the Great Depression, when businesses and lawmakers alike began taking steps to avoid another crisis similar to the one experienced after the 1929 stock market crash. ${ }^{19}$ However, due to the practical difficulties in regulating many heterogeneous industries, the first legislative interventions were scarcely effective. Indeed, it took nearly 30 years for companies to assimilate the regulatory push-and-pull. The first scandal that prompted companies to rethink the way they did business ${ }^{20}$ occurred in the early 1960s and concerned the electric industry, wherein numerous antitrust law violations resulted in hefty fines and the incarceration of various managers. ${ }^{21}$ In response to public backlash and the perception that the same freedom of enterprise that had contributed to the nation's economic prosperity no longer supported social values, the 1970s saw the first drafts of modern codes of ethics. As the 1970s progressed, it became evident that companies alone were inept at creating effective guidelines for corporate behavior and U.S. Congress stepped in, enacting the Foreign Corrupt Practices Control Act (FCPA) that required public companies to establish detailed internal control procedures. While some prudent companies went farther by adopting a code of ethics, as such adoption was not required, for the most part, business continued as usual (Benatti 2014).

Notwithstanding the presence of corporate internal control procedures, scandals during the $1980 \mathrm{~s}^{22}$ suggested that the era's safeguards were inefficient and, in 1988, U.S. Congress enacted the Insider Trading and Securities Fraud Enforcement Act. Although the Act essentially obliged companies operating in certain fields to adopt codes of ethics, ${ }^{23}$ what is interesting is how developments and negative public opinion about unethical practices caused more and more businesses to establish some form of self-regulation until, by the end of the 1980s, approximately $90 \%$ of companies had a code of ethics in place. Indeed, the 1980s has been named "The Age of Ethics" precisely because of this movement (Benatti 2014).

Still, the 1990s and early 2000s were not without their scandals. Measures such as the Federal Sentencing Guidelines in 1991 and the Sarbanes Oxley Act of 2002 made it increasingly difficult for Corporate America to formally maintain the status quo. ${ }^{24}$ Furthermore, as society became more critical, business reacted, not just with codes of ethics, but also with efforts such as CSR programs and ad hoc initiatives to boost revenues and improve corporate image (Benatti 2014). ${ }^{25}$

Thus, as big business sought to strike a balance between self-regulation and increasingly stringent legal requirements, it appears a trend was established. Currently, companies trading on the New York Stock Exchange must adopt a code of ethics that regulates specific issues and provides certain control procedures (Benatti 2014). Further, the recognition by more and more countries that companies can be criminally liable for organizational failures and misconduct of their agents (Heine and Grabovets 2016) has caused many small and medium enterprises (SMEs) and multi-national enterprises (MNEs) alike to implement an organizational structure analogous to a formal code of ethics. ${ }^{26}$

19 For instance, the National Industry Recovery Act of 1933 authorized the President to regulate industry via wage and price control, which eventually led to the adoption of "codes of fair practices", and the President of the SEC advocated the need for self-regulation of industry to control those areas of commerce that were too minute for government oversight (Benatti 2014).

20 i.e., by adopting compliance programs, and the establishment of the Business Ethics Advisory Council by Luther H. Hodges, then Secretary of Commerce (Benatti 2014).

21 In 1961, nearly 1500 damage suits were filed against various electric industry players — the majority of which were against General Electric and Westinghouse-and a number of their executives for antitrust violations (namely price-fixing and collusive bidding) (Nytimes.com 1964).

22 Such as insider trading on Wall Street.

23 In light of the company's duty to maximize shareholder value, and in any case not to harm corporate interests, companies were required to adopt codes of ethics because failure to do so could result in significant sanctions (Benatti 2014).

24 On the various models implemented after 2002, see Newberg (2005, p. 253).

25 On the adoption of codes of ethics to prevent, or limit, reputational damage, see Chatov (1980, pp. 20-29): “Most corporate attention is given to areas with a potential for dramatic impact on the corporation. That the corporation will be a transgressor or a victim is of most concern". See also Lee (2017, p. 14): "as negative public opinion started producing economic loss, multinational retailers and brands started taking steps to set up their internal codes to apply to their suppliers".

26 On the adoption of modern codes of ethics in a comparative perspective, see generally Benatti (2014, pp. 19-22). With particular reference to the fashion industry, see also Jacometti (2016) (discussing the sustainability issues that have prompted government and industry to regulate processes common to textile production); Sajn (2019) (describing the trends 
In this context, it appears that the corporate scandals that plagued the 1960s, '70s '80s, '90s and 2000s have contributed to the development of a global culture-both corporate and societal-that is more aware of (and sensitive to) business practices in conflict with today's socio-economic principles and standards. Furthermore, as the reach of this culture expands, the adoption of codes of ethics as a so-called institution has circulated from America throughout common law countries ${ }^{27}$ to reach Europe, and even Asia and Africa. ${ }^{28}$ Much of the relative success of the spread of codes of ethics may be attributed to the efforts of international organizations, which not only support and encourage companies to respect internationally recognized standards of conduct, but aid their spread into developing countries. ${ }^{29}$ Understanding the development of codes of ethics is a prerequisite to a better understanding of their purposes.

\section{The Purposes of Codes of Ethics}

According to one source, codes of ethics function as a sort of company "constitution" (Nieweler 2014); they are a form of self-regulation that normally contain general principles to guide behavior (e.g., that the company is committed to providing safe working conditions, that it does not use child labor, and that it undertakes to protect the environment). Unlike codes of conduct, codes of ethics traditionally do not outline specific behaviors required or prohibited as a condition of employment or provide practical details to ensure compliance with other codes or guidelines in force within a corporate structure. At the same time, events such as those mentioned in the preceding paragraphs have encouraged some companies to make their codes of ethics more detailed. Simply put, a growing number of companies do not limit themselves to merely establishing the guiding

of fast fashion-including statistics - and how the EU has responded to such trends on a legislative level, for example by passing the new Waste Directive, the Packaging Waste Directive, the Landfill Directive, as well as by laying down European standards and creating a voluntary certification program that provides incentives for fashion brands to be more eco-friendly through competitive advantage); Sajhau (2000, p. 75): "few European enterprises in the textile or footwear sectors have ... taken any structural ethical approach at the individual level leading them to adopt a code of conduct ... Mondial International has drawn up a fairly detailed code based on the United States model ... however, at the European level, initiatives in this sphere have mainly come from the trade unions ... employers' associations ... and the Commission of the European Communities. At the EU level, France presented in February 1995 (during its presidency) a proposed social charter to promote basic social rights in the multilateral trade relations. Within the Commission of the European Communities, the question of codes of ethics in the TCF sector has been the subject of a tripartite debate within the framework of the textiles/apparel sectoral 'social dialogue' ... the Union of Textile Industries (UIT) of France adopted in 1995 a code of ethics in which participating enterprises undertake to respect, within the framework of international trade, fundamental ILO standards ... In the same way, the German Textile Confederation (Gesamttexil) established in 1994 a Social Guide which establishes a number of rules to be respected in international trade concerning respect for the environment and labor standards".

27 Namely, Australia, Canada, and the UK.

28 On the globalization of codes of ethics, see Stohl et al. (2009). On the factors that contributed to the introduction of codes of ethics in developing countries, see Benatti (2014, pp. 22-26).

29 For instance, by putting pressure on producers to require compliance with such codes by their suppliers and other third party affiliates. In particular, in 1919, the International Labor Organization (ILO) established the first internationally binding convention on worldwide labor rights, and in 1998 the ILO adopted the "Declaration on the Fundamental Principles and Rights at Work" that ties all ILO member countries. The Fair Labor Association (FLA), Social Accountability International (SAI) (Social Accountability n.d.), Worldwide Responsible Accredited Production (WRAP) and Worker Rights Consortium (WRC) are third party organizations that monitor compliance with company codes of conduct in foreign countries. Canopy also works with fashion brands and their suppliers to protect against deforestation; CARE International strives to improve gender equality and achieve social justice; the Clean Clothes Campaign is dedicated to improving working conditions for textile and garment laborers; the Fairtrade Foundation works to promote fair trading conditions; the Fair Wear Foundation strives to improve working conditions for garment workers; TRAID is a charity working to stop unwanted clothes from being thrown away. For an exhaustive list of organizations involved in changing the fashion industry, visit https://www.fashionrevolution.org/key-organisations/.Additionallyy, private, independent organizations, private, independent organizations conduct factory inspections and publish findings, the ILO regulatory reports on corporate compliance with international labor principles, and social media keeps an increasingly close eye on industry practices. Indeed, the fashion industry has been marked by the launch of startup fashion companies promoting up cycling of old garments or re-using alternative materials to create new trends. See generally Pinnock (2018), Lipton (2019) and Toprak and Anis (2017). 
principles of behavior, but actually "spell out" how such principles must be respected, ${ }^{30}$ and may even "link" their codes of ethics to other internal resources and/or guidelines, such as employee handbooks (or behavioral codes of conduct).

Therefore, as far as their purpose is concerned, codes of ethics are multifunctional. From a structural point of view, codes of ethics represent (and enhance) a company's culture and values. From an organizational perspective, they may cause a company to establish a specific department dedicated to corporate social responsibility, for example, or compliance and/or monitoring. Depending on how a code of ethics is implemented, it might affect operational costs ${ }^{31}$ or support codes of conduct applicable to a company's directors. When it comes to human resources, codes of ethics may be instrumental in attracting certain talent or employees with particular traits. In the fashion industry, one of the uses that gives significant (corporate) value to codes of ethics lies in their use to portray messages about a certain brand to the public.

As such, an analysis of the codes of ethics of some of the industry's top brands is warranted to better understand how such codes could become a tool to convey some of the brand's values. ${ }^{32}$ This method was chosen because, if it is generally true that companies respond to market demands, and new generations of consumers "want brands to step up on sustainable lifestyles" (Townsend 2018), then-from the moment a significant percentage of consumers demand ethical business practices-the adoption of increasingly specific codes of ethics is a corporate response to a more ethics-conscious consumer. Thus, if the adoption of codes of ethics represents one of the ways ethical (or at least "ethics-conscious") consumers may better gather information about the fashion industry, ${ }^{33}$ then the structure, language used, and attention given to each issue within each single company code of ethics provides insight into the primary concerns of fashion producers.

\section{An Insight on Codes of Ethics in the Fashion Industry}

In response to various industry-wide issues, one of the reasons fashion brands have adopted codes of ethics is to address problems ranging from inadequate labor standards to corruption and bribery to environmental protection. Consequently, it is advisable to review the codes of some of the industry's trendsetters ${ }^{34}$ in order to identify some of the issues that might be perceived as challenges. ${ }^{35}$

30 For example, if a company's code of ethics states that all employees shall abide by the law, a more detailed code might list specific applicable law, procedures, and/or standards.

31 Whether because it is more costly to monitor compliance or because requiring compliance from the entire supply chain requires relying on more expensive suppliers, which are typically more expensive due to the increased operation costs associated with ethical business practices.

32 Overall, despite select fashion companies make express efforts to ensure environmental safety and become "greener", the main themes throughout the codes of ethics analyzed are employment and workers' rights (including equality and discrimination issues), labor safety standards, bribery and anti-corruption, and counterfeiting and unfair business practices. It appears that events that have been directly traceable to a specific fashion company drive the direction of company codes of ethics, while environmental protection is still a secondary industry concern. Specifically, a dedicated section on environment and sustainability was not present in all the codes we analyzed. Of the codes announcing a commitment to improving the environment, Gucci, Louis Vuitton, Nike (see Nike 2017a), and Adidas had the most detailed sections on commitment to the environment. Nonetheless, we cannot exclude that any company has a separate, parallel program in place to improve sustainability and reduce its environmental impact of production. For instance, Phillips-Van Heusen is noted for having an extensive CSR program, which includes efforts to preserving the environment (Phillips-Van Heusen 2018). Still, all codes concentrate heavily on labor standards and workplace safety.

33 For an in depth discussion on the creation and evolution of codes of ethics in business, see Benatti (2014). See also Bartley (2005) and Wisner et al. (2016).

34 Gucci, Armani, Prada, Fendi (n.d.), Louis Vuitton, Ralph Lauren and Polo, Levi Strauss Operating Guidelines (2019), Nike, Adidas, Phillips-Van Heusen (owner of Tommy Hilfiger and Calvin Klein, among others), and Gap (which includes Old Navy, Banana Republic, Piperlime, and Athleta).

35 The research focused on a small group of fashion brands with global presence to reveal the likely trends of a larger group. To do this, we randomly selected fashion companies from a broad group of brand names, including enterprises associated with both the "fast" and luxury fashion markets. It is interesting to show how industry issues have been incorporated into the Code of Ethics for companies, and how companies can use a different language to give different weight to each issue, depending on the perception of importance or its corporate culture/dedication to a given topic. Consequently, the numerical data are not significant for the purpose of this contribution, which-it should be reiterated-is to hypothesize whether such regulatory instruments can be perceived as marketing tools and/or documents that consumers might rely on when 
In other words, by studying the structure, language, and attention given to each issue within the ethical codes of a sample of market leaders, it has been possible to determine the key issues of the global fashion industry. 36

For example, most of the companies surveyed explicitly stated their codes of ethics are legally binding for all employees, collaborators, and suppliers (the "addressees"), no matter their position, type of employment contract, or role within the company. ${ }^{37}$ Some firms have expressly linked their codes of ethics to the primary supplier-buyer agreement, ${ }^{38}$ which remedies the code's enforceability problem connected with its clearly "accessory" (or collateral) nature. In this way, a violation constitutes a breach of the main contract (for services or procurement of goods), meaning suppliers are more likely to behave ethically due to the real threat of termination for breach. Other fashion companies might have different "versions" 39 of codes of ethics ${ }^{40}$ (one aimed at the company as a whole, and one specifically for suppliers), or a single code with multiple sections for specific addressees. ${ }^{41}$ This setup illustrates a top-down organizational structure, as the company managers (who make the decisions and give orders to the suppliers) must be ethical, while the producers receive more detailed instructions on how to behave within the organization, and must execute behaviors in line with principles that-due to various cultural contexts-may or may not be shared.

From a legal perspective, in so much as a code of ethics constitutes a sort of contract-whether because the code itself establishes it is directly binding or because it is an accessory to another agreement (between a company and its addressees) — codes of ethics tend to oblige third parties to adhere to the buyer's principles. This has two practical effects: first, it means the buyer assumes a greater risk for third party behavior and, where codes are sufficiently detailed, increases the chances the buyer will effectively terminate the business relationship in case of breach. Thus, by enforcing a code of ethics that establishes rules of conduct to support the principles upon which the code is based, companies with more detailed codes are more likely to contribute to an increasingly sustainable industry. ${ }^{42}$ Second, it effectively results in a sort of "exportation" of laws from developed countries into the developing world. Indeed, all codes state that addressees must abide by all applicable national and international law. However, since this ultimately would result in merely promoting suppliers to comply with national law (since international laws only apply in rare circumstances), all codes are additionally

making purchasing decisions. Our research, in fact, was aimed precisely at the relationship between codes of ethics and the ethics-conscious fashion consumer.

36 In addition to what has been stated above in note 32, it is important to mention that all codes concentrate heavily on labor standards and workplace safety.

37 Of the company codes surveyed, only Ralph Lauren states that its code does not constitute a contractual commitment to the company (Ralph Lauren Corporation 2016, p. 14: "[T] his Code does not constitute a contractual commitment of the Company"). On the other hand, it establishes that actions that are not unlawful may still result in termination, clarifying that unlawful actions may additionally result in civil or criminal proceedings (Ralph Lauren Corporation 2016).

38 "Armani requires all Suppliers Armani contractually engages in business with to adhere to the following standards and requirements. The Supplier Code of Conduct is referenced in Armani's Terms and Conditions so as to hold Suppliers legally accountable to this Code" (Armani 2017, p. 1). See also Ralph Lauren Corporation (2016) (referencing separate Fair Employment Practice Policy and Anti-Harassment Policy contained in employee handbook). Nearly all other brand codes of ethics contain a similar or equivalent phrase.

39 These may be called codes of conduct or employee/supplier handbooks or guidelines.

40 For instance, Ralph Lauren has a separate Code of Ethics for Principal Executive Officers (Ralph Lauren Corporation 2016, p. 9).

41 Levi Strauss distinguishes between internal principles of the firm, practices applied toward partners, and guidelines to assess supplier countries. Similarly, Phillips-Van Heusen's code of ethics is divided into general principles guiding the firm's activities and guidelines for suppliers and subcontractors. Likewise, Nike and Adidas also have a set of rules for the enterprise as a whole, and another for suppliers.

42 However, according to the 2019 Fashion Transparency Index, even companies that score relatively high on policy and commitments and governance (in the 51-60\% and 41-50\%, respectively), still fare poorly overall (Fashion Transparency Index 2019). Specifically, traceability, know, show and fix, and spotlight issues continue to be problematic. See also Thompson (2018). However, some companies might reduce their liability by expressly providing that "suppliers remain guarantors towards 'Company name' for work performed by their subcontractors and suppliers and guarantee respect by their subcontractors and suppliers of this Supplier Code of Conduct and relevant obligations (Louis Vuitton 2017, p. 1). Indeed, in the case where the supplier of a subsidiary violates the Supplier Code of Conduct, this wording could be instrumental in alleviating the group of any liability for harm; instead, the company to which the supplier directly reports remains liable. 
integrated by some wording to the effect of "and internationally recognized standards." For American and European buyers, this language means that American/European employees, collaborators, and suppliers are subject to American and European law, while non-US/EU producers must primarily respect principles. Legally, the requirement to respect different legal sources is significant.

The difference between legal principles and legal rules is a logical distinction. Both sets of standards point to particular decisions about legal obligation in particular circumstances, but they differ in the character of the direction they give. Rules are applicable in all-or-nothing fashion. If the facts a rule stipulates are given, then either the rule is valid, in which case the answer it supplies must be accepted, or it is not, in which case it contributes nothing to the decision ... If two rules conflict, one of them cannot be a valid rule... When principles intersect... one who must resolve the conflict has to take into account the relative weight of each. (Dworkin 1967, pp. 25-27)

In other words, there are explicit penalties for failing to comply with American and/or European law: depending on the applicable law, there may be civil and/or criminal consequences for the company, as well as its managers (depending on the infringement). The American and European legal systems also provide detailed requirements, procedures, and minimum standards, as well as confer specific powers to courts in various jurisdictions to ensure such laws are respected. On the other hand, principles function as values upon which to base one's behavior, but they do not prescribe conduct in any meaningful terms, nor are they easily enforceable. Indeed, the effective structure of the supply chain, combined with the laws on jurisdiction, makes the execution and enforcement of principles complicated. Further, socio-cultural differences may hinder them from fully resonating in far off, non US/European countries: "[m]ost educated people have the idea that the laws in England form some sort of system, and that ... in almost every part of the world which is thought of as a separate 'country' there are legal systems which are broadly similar in structure in spite of important differences" (Hart 1961, pp. 2-3). Therefore, by requiring non-US/EU suppliers to comply with principles_rather than writing its own set of laws, for example by way of contract, fashion companies effectively allow their suppliers to continue "work as usual" without significantly raising the bar. ${ }^{43}$

At least half of the codes analyzed provide that, in cases where there is either no local law governing a topic, or there is more than one applicable law, the law with the most stringent standards applies, ${ }^{44}$ but not all companies agree on which law or standard should be applied in business. ${ }^{45}$ Furthermore, while some codes go so far as to list specific applicable laws, conventions, or standards, those codes that remain more general use language that reflects the principles contained in relevant internationally recognized documents.

There are also companies that do not limit themselves to creating principles for addressees to follow. Rather their codes "[express values of ethical integrity] and [establish] the principles and rules of conduct deriving from them" (Prada 2007, p. 2). ${ }^{46}$ For instance, all companies surveyed promote principles such as loyalty, honesty and good faith, correctness, and integrity. Some companies go further by mandating that relations between employees, no matter their level, including between them and the third parties with whom they come into contact during the course of their work, "be marked by criteria of collaboration, loyalty, and reciprocal respect" (Prada 2007, p. 4), that criteria of merit

43 See generally (Fashion Transparency Index 2019) (discussing the importance of transparency in the fashion business and analyzing the level of transparency of some of the industry's biggest brands). See also Slot (2017).

44 Armani seeks to raise the standard in countries where it does business by "[possibly setting] standards that go beyond local legislation" (Armani 2017, p. 1). See also Prada (2007, p. 10). Phillips-Van Heusen is another example of companies that exceed industry standards.

45 This topic will not be analyzed in the present discussion, but it is necessary to remember that the issue of working conditions in developing countries is controversial and the ILO approach it is not widely accepted as being the most ethical (just consider the neoliberal approach of "Doing Business").

46 Levi Strauss even establishes specific criteria to assist those in charge of outsourcing in selecting suppliers (Levi Strauss Operating Guidelines n.d.). 
be adopted in order to valorize employees' skills and competencies, and that equal opportunities are guaranteed to all. By doing so, the code takes on a truly contractual nature-especially from a civil law perspective - as the object (or subject matter) of the "contract" is increasingly determinable. In line with the International Labor Organization (ILO) principles (adopted by every code of ethics surveyed), child and forced labor is prohibited across the board. However, the same companies that do not limit themselves to merely declaring principles by which to abide additionally require their "suppliers [to] implement a management system that verifies the age of each employee by review of legally accepted documentation"(Armani 2017, p. 1) ${ }^{47}$ and directly address the issue of abuse of apprenticeship/traineeship schemes to avoid the payment of wages or benefits. ${ }^{48}$ Moreover, some fashion brands oblige their suppliers to implement a written disciplinary procedure (Armani 2017, p. 2; Ralph Lauren Corporation 2016, p. 1). Legally, this (at least theoretically) reduces the likelihood of groundless disciplinary action and gives employees a basis for any recourse in the event of wrongful dismissal or other illegitimate corrective/punitive measures. It is additionally significant that in order to combat undeclared or illegal work, the majority of codes of ethics surveyed require (monthly) pay slips to be issued each pay period. As regards standards of pay (in line with expressed ethical principles based on ILO conventions), overtime is always contractually paid at a higher rate than normal pay. ${ }^{49}$

With regard to work hours, maximum work hours may vary but do not exceed $60 \mathrm{~h}$ per week, including overtime, and establish at least one day of rest. What is more, all companies recognize workers' rights to refuse overtime, and some expressly recognize workers' rights to "be informed about overtime in advance and permitted to reject the overtime request without punishment or retaliation" (Armani 2017, p. 2). Along these lines, companies with more detailed codes tend to require their suppliers provide workers with a written copy of their employment contract, and that such contract must be in a language the worker understands. Not only do these provisions illustrate the influence of the company's home (western) culture on its business practices-in that western fashion brands, albeit in a limited fashion, export national labor law abroad-but they provide employees with greater legal security. ${ }^{50}$ It is also interesting that-in addition to requiring suppliers provide workers with safe and healthy working/living environments—some companies list conditions that make such environments "safe and healthy" 51 or provide practical sections with "questions and examples to help apply the code" (Gucci 2016, p. 14; see also Gap 2012).

Moreover, due to the difficulty of monitoring compliance, the majority of codes appear aimed at compelling suppliers to implement a management system similar to that required by Italian Legislative Decree No. 231/2001 (with a relative grievance system), with specific personnel responsible for the management and implementation of the supplier social code, including informing all workers and

47 Nike also has a section dedicated to "proof of age" in its "Code of Leadership Standards".

48 "Employment of trainees/apprentices both under and over the age of 18 shall be conducted in compliance with local legislation and this Code. Apprenticeship/traineeship schemes shall not be used to systematically avoid the payment of wages and benefits" (Armani 2017, p. 1).

49 Notwithstanding all companies surveyed announce pay shall not be lower than the minimum standards required by applicable law, Phillips-Van Heusen and Adidas establish that "[e]very worker has a right to compensation for a regular work week that is sufficient to meet the worker's basic needs and provide some discretionary income" and that "[i]f the compensation paid does not meet the workers' basic needs and provide some discretionary income, our business partners are required to take appropriate actions that seek to progressively realize a level of compensation that does" (Phillips-Van Heusen 1995, p. 2; Adidas "Workplace Standards" 2016, p. 2). Additionally, Phillips-Van Heusen establishes that overtime must be paid at a premium, which implies a significant difference between regular and overtime pay (compared to those companies that merely establish overtime is paid at a higher rate) (Phillips-Van Heusen 1995, p. 2). This provision is significant as minimum wage required by law is not always sufficient to guarantee the basic needs of workers (i.e., so-called "living wage"). We recall countries such as Bangladesh where minimum wage is \$0.09/h (Capital 2014). It is additionally significant that Nike implements a "fair wage self assessment" (Nike 2017b, p. 30).

50 From an evidentiary standpoint, having a written agreement demonstrates an employer-employee relationship, and all the legal consequences that follow, and makes clear both parties' duties and obligations.

51 For instance, by "ensuring building and fire safety, machinery and equipment safety, access to potable water and suitable sanitary facilities, access to appropriate personal protective equipment and emergency care, and appropriate storage and handling of hazardous materials" (Armani 2017, p. 3). 
subcontractors of all applicable legislation and any changes to such. Part of this system includes ensuring the maximum dissemination of the code of ethics and educating addressees of its contents. Other codes, in addition to the above, provide anonymous reporting channels and identify a specific competent authority (such as the company's legal department) to field complaints. Therefore, given the similarities between certain codes of ethics and supplier codes of conduct, it appears many fashion brands seek to apply US/European law abroad through their contractual relationships with suppliers and subcontractors. In this respect, it appears that a company's code of ethics has the potential to become a sort of "living document" where the addressees are not only responsible for its implementation, but also have a (at least partial) voice in the mechanisms adopted to achieve the company's goals. To use some legal terminology, these types of codes of ethics resemble a sort of "framework agreement" whereby, subsequent to feedback from the bottom up, top managers may decide to amend prescribed conduct and/or procedures from time to time in order to better reflect and ensure compliance with the overarching (ethical) principles established by the code.

Simply put, notwithstanding internal documents are not available for analysis, it appears that the more detailed the code of ethics, the less likely a company's principles will be violated for profit.

A company's code of ethics is a powerful tool in that a brand may improve its image by adopting a code that responds to the issues that consumers care about. It is therefore necessary to distinguish between companies that are truly ethical and those who merely appear so.

\section{Conclusions}

The above paragraphs outline the emergence and development of codes of ethics, their purpose, and some insights into their content. It has been said that codes of ethics are a form of self-regulation that contain general principles to guide behavior and that those codes are multifunctional, as they not only serve to represent (and enhance) a company's culture and values, but also may cause a company to adopt a specific organizational and/or governance structure. Some fundamental themes relate to workers' rights (including equality and discrimination issues), labor safety standards, bribery and anti-corruption, and counterfeiting and unfair business practices, with limited direct attention given to environmental protection. ${ }^{52}$

Attention to working conditions is not surprising. As previously stated, large retailers have outsourced production to countries with low wages, poor to no union representation, and lenient (or non-existent) environmental protection, where textile workers are accustomed to poverty and child-forced and prison labor is reported (ex multis, House of Commons 2019, p. $12 \mathrm{ff}$ ). Today, these and similar issues are well known and stigmatized by public opinion around the world. In an era where Internet and social networks allow information to spread quickly, a greater number of consumers have taken interest in the challenges of ethical and the sustainable fashion cause. ${ }^{53}$ Consequently, when shopping for apparel, consumers have different concerns; the general labor conditions under which their clothing is made is one of them. Yet, when one is interested in purchasing an ethical garment, it is difficult to navigate among the many choices on the market (Vogel 2010).

Irrespective of whether CSR programs succeed in tackling problems such as poor working conditions and low wages in the clothing sector, ${ }^{54}$ they may nonetheless create a general sense of reliance and may even influence consumer choice. Codes of ethics may affect how a certain brand image is portrayed to the public: as these codes are easily accessible on the brand's website; consumers might perceive them as a tool to gain better knowledge of company's values and consequently rely upon them.

52 It is important to reiterate that, as stated above, we found that some brands had published a separate report on its commitment to environmental sustainability and/or improvement (see note 32). However, as this is not the object of the current contribution, this matter was not investigated further.

53 On the events, see the introductory paragraph and note 7 ; on the issues, see note 32.

54 For a critique on the effectiveness of CSR programs, see House of Commons (2019, p. $12 \mathrm{ff})$. 
Indeed, such codes can be used as marketing tools to attract more ethical fashion consumers precisely because they speak to issues the public finds important, such as workers' rights. They could be used as a commercial statement even if they do not take the form of "classic advertising" ${ }^{55}$ It is therefore necessary to distinguish between those companies that genuinely want to be "ethical" and those that merely aim to appear as such—without effectively being such—in the eyes of consumers. For instance, it is not news that some companies are stigmatized for practicing "greenwashing" 56 (i.e., the act of misleading consumers with regards to practices that impact the environment). ${ }^{57}$ Analogous practices could be used in other fields, such as child labor and, more generally, working conditions. ${ }^{58}$

These reflections lead us to question what might happen if, for example, a consumer discovered (perhaps from a journalistic investigation) that the apparel purchased (from a brand claiming, expressly in its code of ethics, to be ethical and sustainable) was not produced in the specific way declared ? $^{59}$ For instance, we could imagine what might happen if a brand violated its pledge not to use child or forced labor in the production of its clothes - a commitment made by every code of ethics surveyed.

If it is conceivable that consumers might reach out to some NGO and carry out or contribute to a protest campaign, as the strategy of "naming and shaming" has often been effective. Such action might even result in a boycott of famous brands: damage to image and reputation might be significant. Indeed, in the case of a lesser-known company, such a violation could be more difficult to discover, or might attract less public attention. However, for an ethical consumer, buying ethically produced apparel means buying a product that possesses certain "qualities", which form the precise basis for purchasing that (ethical) brand over another (un-, or less-ethical) brand. What legal remedy might a customer have upon discovery that a company's code of ethics, which were instrumental in the purchase decision, was nothing more than lip service to the issues that consumers value?

55 There is clearly no question as to their commercial purpose when CSR statements are not public or otherwise accessible to consumers, or in the event they are in no way connected to the promotion of products. See Beckers (2017).

56 On greenwashing in general, see Bowen (2014).

57 In the United States, the Federal Trade Commission's Green Guides are designed to help marketers avoid making environmental claims that mislead consumers. The guidance they provide includes: (1) general principles that apply to all environmental marketing claims; (2) how consumers are likely to interpret particular claims and how marketers can substantiate these claims; and (3) how marketers can qualify their claims to avoid deceiving consumers. More information is available at https:/www.ftc.gov/news-events/media-resources/truth-advertising/green-guides. In Europe the Directive on Unfair Commercial Practices-Directive 2005/29/EC (UCPD) provides two main principles related to environmental claims: (1) traders must present their green claims in a clear, specific, accurate, and unambiguous manner, to ensure that consumers are not mislead (Art. 6 and 7); and (2) traders must have the evidence to support their claims and be ready to provide it to competent enforcement authorities in an understandable way if the claim is challenged (Art. 12). These principles are also reflected in several national guidance documents on environmental claims, notably the Danish Guidance on the use of environmental and other claims in marketing, the UK Green Claims Guidance, and the French Practical Guide to Environmental Claims for traders and consumers. For more information on the E.U. position see (European Commission 2019 , p. $95 \mathrm{ff})$.

58 The Guidance on the application of the Unfair Commercial Practices Directives contains a useful definition of "ethical claims" by the Danish Consumer Ombudsman's Guidance on the use of environmental and ethical marketing claims: "'Ethical claims' means in particular the use of statements, etc., which convey the impression that the manufacturing of a product or planning of an activity of a trader is made according to generally recognized and accepted standards, for example concerning child labor and general working conditions, nature protection, health, animal welfare, corporate social responsibility (CSR) initiatives, and charity donations. Such claims are typically based on the trader's wish to accommodate general or specific developments and trends that can be inferred from consumers' behavior". The Guidance recognized that CSR has become a marketing tool used to meet the growing concern of consumers that traders comply with ethical standards and therefore, such initiatives are in most cases, "directly connected with the promotion, sale, or supply of a product" and can be qualified as a commercial practice within the meaning of the UCPD.

59 See Chemerinsky and Fisk (2004), posing challenging questions such as: "May a company selling tuna fish tell consumers-in advertisements, letters to environmental groups, and elsewhere-that its tuna is caught in a dolphin-safe manner, when company officials know that the company's nets regularly capture and kill dolphins? May a cosmetics company tell consumers - through advertisements, letters to department stores, and otherwise-that it does not test its products on animals, even though it knows that it regularly uses animal testing in a way that many of its customers would find repugnant? May an agricultural company tell consumers that its products are organic when it knows that it uses pesticides and herbicides that would not fit anyone's definition of organic? May a manufacturer represent that its products were "made in the United States" or produced with union labor, when it knows those statements are untrue?" 
Consumers have different concerns when they purchase clothing, and concerns about the conditions under which they are made should have the same protection than concerns about price or other characteristics (Chemerinsky and Fisk 2004).

If we wish to look specifically for a fil rouge across legal systems, and not focus on the various national de jure conditio and de jure condendo approaches, ${ }^{60}$ we might find common threads (despite particular details that might vary greatly between them ${ }^{61}$ ) in the laws that protect consumers from misleading advertising: all developed countries have laws aimed at helping consumers make better informed decisions based on accurate information in order to guarantee efficient market transactions (Nehf 2010, p. 107).

Generally speaking, if a brand fails to comply with a specific, clear, and verifiable undertaking (and therefore not including too general, idealistic, or aspirational statements) set out in its code of ethics, and those same representations caused a consumer to make a commercial decision that-without such affirmations-s/he would not have otherwise made, then it might not be audacious to place this case within the framework of the laws against misleading advertising and/or unfair commercial practices (Benatti 2014, p. 203; Bussoli 2010, p. 167; Chiari 2017).

This view is not dissimilar to that put forth in 2003 in the United States in a case ${ }^{62}$ against Nike. Although this case was not strictly related to a code of ethics, it nonetheless offers points for reflection. Specifically, in 1996, Nike responded to allegations of mistreatment and exploitation of workers at overseas facilities ${ }^{63}$ by (amongst others) publishing press releases and writing letters to the editors of various newspapers around the country. However, in April 1998, Marc Kasky sued Nike in California for unfair and deceptive practices, claiming Nike had violated California's Unfair Competition Law and False Advertising Law ${ }^{64}$ by making "false statements and/or material omissions of fact" about the working environments where its products are manufactured "in order to maintain and/or increase its sales." Although the lower courts ruled in favor of Nike (holding it had exercised "noncommercial speech" protected by the First Amendment), it is interesting to note that the California Supreme Court reversed the decision of the lower court (holding that "[b]ecause the messages in question were directed by a commercial speaker to a commercial audience, and because they made representations of fact about the speaker's own business operations for the purpose of promoting sales of its products, ... [the] messages are commercial speech"), but remanded for further proceedings on the grounds that the suit "is still at a preliminary stage." Following this decision, Nike appealed (petitioned for certiorari) to the US Supreme Court (USSC), which initially agreed to hear the appeal ${ }^{65}$ but ultimately, in 2003, let stand the California Supreme Court's ruling by dismissing the writ of certiorari as improvidently granted. Despite Nike and Kasky eventually settling (costing Nike \$1.5 million) (Bigge 2004) the case before any solid precedent could be established, it is nonetheless significant to note that-in light of the uproar surrounding supply chain issues-the state of California has recently enacted the CA Transparency in Supply Chains Act that requires all retainer sellers and manufacturers doing business in California with global gross receipts of at least $\$ 100,000,000$ to disclose the extent of their efforts in the areas of verification, audits, certification, internal accountability, and training. ${ }^{66}$ Thus, as far as North America

60 On varying attitudes towards codes of conduct in a European context, see Howells et al. (2006).

61 Every legal system has its own laws against misleading advertising. Generally speaking, there are different types of enforcement regimes, such for instance self-regulatory enforcement of advertising guidelines, civil enforcement through private actions for breach of advertising norms, and enforcement action brought by government agencies to police marketplace for the good of general public. See Nehf (2010).

62 Nike (2003), Inc., et al. v. Kasky, 539 U.S. 654. For an analysis of the case, see Benatti (2014, p. 203) (highlighting that this line of thought has not yet taken hold).

63 For a review of the 1990s events that involved Nike and the labor conditions of contractors in its factories, see Vogel (2005, p. 77 ff).

64 In the United States, laws against false or misleading advertising are regulated on two levels: at the state-level and on the Federal level. The Federal Trade Commission (FTC) Act (enforceable by the FTC on behalf of consumers) and the Lanham Act are two fundamental federal laws.

65 Nike (2003), Inc., et al. v. Kasky, 539 U.S. 654

66 For more information, see https://oag.ca.gov/SB657. 
is concerned, it appears legislation is shifting in the direction of holding big business accountable to the public by requiring increased transparency when it comes to production and sourcing of products.

Similarly, on the other side of the ocean, the European Unfair Commercial Practices Directive $^{67}$ - enacted in 2005 "to contribute to the proper functioning of the internal market and achieve a high level of consumer protection by approximating the laws, regulations and administrative provisions of the Member States on unfair commercial practices harming consumers' economic interests" (Art. 1, Directive 2005/29)—suggests that lawmakers might also be moving in this direction. ${ }^{68}$ In addition to its broad Art. 6(1), Art. 6(2)(b) expressly prescribes that "a commercial practice shall also be regarded as misleading if ... it causes or is likely to cause the average consumer to take a transactional decision that he would not have taken otherwise, and it involves: ... (b) non-compliance by the trader with commitments contained in codes of conduct by which the trader has undertaken to be bound, where: (i) the commitment is not aspirational but is firm and is capable of being verified, and (ii) the trader indicates in a commercial practice that he is bound by the code." 69

Likewise, Australian Consumer Law $^{70}$ also aims to protect consumers and ensure fair trading by prohibiting, in its Section $18(1),{ }^{71}$ a person from engaging in conduct in trade or commerce that is misleading and deceptive or likely to mislead or deceive. This broad prohibition could be construed to create a general standard of conduct that would encompass aspects of CSR programs, such as codes of ethics (Southalan 2008; Spencer 2003).

Codes of ethics are often seen as a "win-win" solution (Howells et al. 2006, p. 196) and may perform a variety of functions, including being used as a marketing tool to meet the growing concern of consumers that clothing complies with ethical standards. In this regard, the laws against misleading advertising should provide protection in cases where codes of ethics have been used deceptively to affect or distort a consumer's choice, or significantly impair one's ability to make an informed decision. Albeit such path is narrow-indeed, to date, there does not appear to be any relevant evidence of courts (neither US, nor Australian) having found for a plaintiff relying on Kasky's line of reasoning, and the European UCPL requirements are quite strict ${ }^{72}$-it is still one worth pursuing.

Author Contributions: R.E.C., Professor of Comparative Private Law at the University of Milan (Università degli Studi di Milano) is the author of Sections 1, 2 and 6; K.P., Ph.D. candidate in Comparative Private Law at the University of Milan (Università degli Studi di Milano) is the author of Sections 3-5.

Funding: This research received no external funding.

Conflicts of Interest: The authors declare no conflict of interest.

\section{References}

"Fashion victim" in Vocabolario Treccani on line. 2012. Available online: http://www.treccani.it/vocabolario/ fashion-victim_res-6bf5785e-89c2-11e8-a7cb-00271042e8d9_(Neologismi)/(accessed on 3 May 2019).

Adidas “Workplace Standards". 2016. (Code of Conduct for Suppliers). Available online: https://www.adidasgroup.com/en/sustainability/reporting/policies-and-standards/ (accessed on 20 May 2019).

67 Directive 2005/29 of the European Parliament and of the Council of 11 May 2005 concerning unfair business- to-consumer commercial practices in the internal market, amending Council Directive 84/450/EEC, Directives 97/7/EC, 98/27/EC, and 2002/65/EC of the European Parliament and of the Council and Regulation (EC) No. 2006/2004 of the European Parliament and of the Council, OJ L 149/22 of 11 June 2005.

68 On the liability of companies under EU law for breach of CSR obligation, see Beckers (2017, pp. 475-516).

69 It seems possible to assume that, given the Directive's purpose and availing of a teleological interpretation, this article covers both multiparty codes and self-regulatory codes. See also Chiari (2017, p. 172).

70 The ACL became effective on 1 January 2011 and replaced the Trade Practices Act 1974, as well as previous Commonwealth, state, and territory consumer protection legislation. It is contained in Schedule 2 to the Competition and Consumer Act 2010 (Cth) (CCA) and has been adopted into national legislation.

71 Section 18 of the ACL replaces the repealed section 52 of the TP Act.

72 On required safety conditions under the UCPD, see Howells et al. (2006, pp. 208-10). 
Angus, Alison, and Gina Westbrook. 2019. Top 10 Global Consumer Trends. Available online: https://www. euromonitor.com (accessed on 1 June 2019).

Armani. 2017. Supplier Social Code of Conduct. Available online: https://webcache.googleusercontent.com/ search?q=cache:Z13CH3b7Nq0J:https://www.armani.com/cloud/armanif31wp/uploads/2017/12/ArmaniSocial-Code-of-Conduct1-WEB.pdf $+\& \mathrm{~cd}=1 \& \mathrm{hl}=\mathrm{it} \& \mathrm{ct}=\mathrm{clnk} \& \mathrm{gl}=\mathrm{it} \& \mathrm{client}=$ firefox-b-d (accessed on 20 May 2019).

Bajaj, Vikas. 2012. Bangladesh Fire Kills More Than 100 and Injures Many. Nytimes.com. Available online: https://www.nytimes.com/2012/11/26/world/asia/bangladesh-fire-kills-more-than-100-and-injuresmany.html (accessed on 3 May 2019). Nytimes.com..

Baker, Mark B. 1992. Private Codes of Corporate Conduct: Should the Fox Guard the Henhouse? The University of Miami Inter-American Law Review 24: 399-433.

Bartley, Tim. 2005. Corporate Accountability and the privatization of labor standards: Struggles over codes of conduct in the apparel industry. Research in Political Sociology 14: 211-44.

Beckers, Anna. 2017. The Regulation of Market Communication and Market Behaviour: Corporate Social Responsibility and the Directives on Unfair Commercial Practices and Unfair Contract Terms. Common Market Law Review 52: 475-516.

Benatti, Francesca. 2014. Etica, Impresa, Contratto e Mercato. L'esperienza dei Codici Etici. Bologna: il Mulino, pp. $15-26$.

Benson, George C. S. 1989. Code of Ethics. Journal of Business Ethics 8: 305. [CrossRef]

Bigge, David M. 2004. Bring on the bluewash: social constructivist argument against using nike v. kasky to attach the un global compact. International Legal Perspectives 14: 6-21.

Binet, Faustine, Ivan Coste-Manière, Clément Decombes, Yan Grasselli, Dortmolk Ouedermi, and Mukta Ramchandani. 2019. Fast Fashion and Sustainable Consumption. In Fast Fashion, Fashion Brands and Sustainable Consumption. Edited by Subramanian Senthilkannan Muthu. Singapore: Springer, pp. 19-36.

Bowen, Frances. 2014. After Greenwashing: Symbolic Corporate Environmentalism and Society. Cambridge: Cambridge University Press.

Brenot, Alice, Cécile Chuffart, Ivan Coste-Manière, Manon Deroche, Eva Godat, Laura Lemoine, Mukta Ramchand, Eleonora Sette, and Caroline Tornaire. 2019. Water footprint in fashion and luxury industry. In Water in Textiles and Fashion: Consumption, Footprint, and Life Cycle Assessment. Cambridge, UK: Elsevier: Woodhead Publishing.

Bussoli, Laura. 2010. Responsabilità sociale, codici di condotta e pratiche commerciali sleali. In La Responsabilità Sociale D'impresa: Teorie e Prassi. Edited by Adalberto Perulli. Bologna: il Mulino.

Capital, Human. 2014. Highest and Lowest Minimum Wages around the World-How Does Australia Stack Up? Available online: https:/www.hcamag.com/au/news/general/highest-and-lowest-minimum-wages-aroundthe-world-how-does-australia-stack-up/140228 (accessed on 6 September 2019).

Chatov, Robert. 1980. What Corporate Ethics Statements Say. California Management Review 22: 20-29. [CrossRef]

Chemerinsky, Erwin, and Catherine Fisk. 2004. What Is Commercial Speech-The Issue Not Decided in Nike v. Kasky. Case Western Reserve Law Review 54: 1143.

Cherny-Scanlon, Xenya, and Kristin Agnes. 2016. Time for a Responsible Fashion Council? In Green Fashion. Singapore: Springer, Volume 2, p. 125.

Chiari, Dario. 2017. Is Corporate Social Responsibility So Soft? The Relationship between Corporate Social Responsibility and Unfair Commercial Practice Law. The King's Student Law Review 8: 162-76. Available online: https://blogs.kcl.ac.uk/kslr/wp-content/blogs.dir/86/files/2017/02/8.1.10-Dario-Chiari.pdf (accessed on 13 May 2019).

Conca, James. 2015. Making Climate Change Fashionable-The Garment Industry Takes on Global Warming. Available online: https:/www.forbes.com/sites/jamesconca/2015/12/03/making-climate-change-fashionablethe-garment-industry-takes-on-global-warming/\#18725edb79e4 (accessed on 12 June 2019).

Connell, Kim Y. Hiller. 2010. Internal and external barriers to eco-conscious apparel acquisition. International Journal of Consumer Studies 34: 279-86. [CrossRef]

Coughlin, Joseph. 2018. Greener Than You: Boomers, Gen X \& Millennials Score Themselves on the Environment. Available online: https://www.forbes.com/sites/josephcoughlin/2018/05/05/greener-than-you-boomers-genx-millennials-score-themselves-on-the-environment/ (accessed on 15 May 2019).

Dworkin, Ronald M. 1967. The Model of Rules. The University of Chicago Law Review 35: 14-46. [CrossRef] 
European Commission. 2019. Guidance on the Implementation/Application of Directive 2005/29/EC on Unfair Commercial Practices. Brussels: eur-lex europa, Available online: https://eur-lex.europa.eu/legal-content/EN/TXT/?uri= CELEX\%3A52016SC0163 (accessed on 3 September 2019).

Fashion Revolution. 2019. Home-Fashion Revolution. Available online: https://www.fashionrevolution.org/ (accessed on 15 May 2019).

Fashion Transparency Index. 2019. Fashion Revolution. Available online: https://issuu.com/fashionrevolution/ docs/fashion_transparency_index_2019 (accessed on 15 May 2019).

Fashion Victims. 2019. [DVD] Directed by A. Basile. Italy/India: Alessandro Basile.

Featherstone, Liza. 2002. Students against Sweatshops. Brooklyn: Verso.

Fendi. n.d. Codice Etico: Fendi. Available online: https://www.fendi.com/it/info/legal-area/code-conduct (accessed on 20 May 2019).

Fletcher, Kate. 2014. Sustainable Fashion and Textiles. Abingdon-on-Thames: Routledge, p. 51 ff.

Fur Free Alliance. 2019. Fur Free Alliance-Working together towards a fur free world. Available online: https://www.furfreealliance.com (accessed on 15 May 2019).

Gap Code of Ethics. 2012. Available online: http://ethics.iit.edu/ecodes/node/5752 (accessed on 20 May 2019).

Gordon, Jennifer Farley, and Colleen Hill. 2015. Sustainable Fashion: Past, Present, and Future. London: Bloomsbury.

Grappi, Silvia, Simona Romani, and Camilla Barbarossa. 2017. Fashion without pollution: How consumers evaluate brands after an NGO campaign aimed at reducing toxic chemicals in the fashion industry. Journal of Cleaner Production 149: 1164-73. [CrossRef]

Greenpeace International. 2019. Detox My Fashion - Greenpeace International. Available online: https://www. greenpeace.org/international/act/detox/ (accessed on 3 June 2019).

Gucci Code of Ethics. 2016. Available online: https://www.gucci.com/documents/code_of_ethics_en.pdf (accessed on 20 May 2019).

Gwilt, Alison. 2018. A Practical Guide to Sustainable Fashion, Basics Fashion Design. London: Bloomsbury Visual Arts, (reprint edition).

Gwilt, Alison, and Timo Rissanen. 2011. Shaping Sustainable Fashion: Changing the Way We Make and Use Clothes. Londton: Routledge.

Harrison, Ann, and Jason Scorse. 2010. Multinationals and Anti-Sweatship Activism. American Economic Review 100: 247-73. [CrossRef]

Harrison, Rob, Terry Newholm, and Deirdre Shaw. 2005. Introduction. In The Ethical Consumer. Thousand Oaks: SAGE Publications Ltd., pp. 1-8.

Hart, Herbert Lionel Adolphus. 1961. The Concept of Law. Oxford: Oxford University Press.

Heine, Klaus, and Kateryna Grabovets. 2016. Organizational Liability. In Encyclopedia of Law and Economics. New York: Springer.

Hethorn, Janet, and Connie Ulasewicz. 2008. Sustainable Fashion - Why Now?: A Conversation about Issues, Practices, and Possibilities. New York: Fairchild.

Hethorn, Janet, and Connie Ulaseqicz. 2015. Sustainable Fashion: What's Next?: A Conversation about Issues, Practices, and Possibilities, 2nd ed. London and New York: Bloomsbury.

House of Commons. 2019. "Fixing Fashion: Clothing, Consumption and Sustainability". House of Commons, Environmental Audit Committee. Available online: https://publications.parliament.uk/pa/cm201719/cmselect/ cmenvaud/1952/full-report.html (accessed on 17 May 2019).

Howe, Neil. 2018. Are Millennials Killing Name Brands? Available online: https:/www.forbes.com/sites/neilhowe/ 2018/11/20/are-millennials-killing-name-brands/\#2c96d95f50eb (accessed on 15 May 2019).

Howells, Geraint G., Hans-W Micklitz, and Thomas Wilhelmsson. 2006. European Fair Trading Law: The Unfair Commercial Practices Directive. Farnham: Ashgate Publishing Company, vol. 197.

Jacometti, Valentina. 2016. Diritto e Moda Sostenibile tra Iniziative Legislative e Iniziative Volontarie. In Fashion Law - Le problematiche giuridiche della filiera della moda. Milano: Giuffré.

Jucker, Ludovico. 2011. Nel labirinto dei marchi e dei certificate. In Il Bello e Il Buono. Le Ragioni della Moda Sostenibile. Venice: Marsilio Editori, p. $145 \mathrm{ff}$.

Kant, Rita. 2012. Textile dyeing industry an environmental hazard. Natural Science 4: 22-26. [CrossRef]

Kolirin, Lianne. 2018. Chanel bans Fur and Exotic Animal Skins. CNN. December 4. Available online: https: //edition.cnn.com/style/article/chanel-fur-ban-scli-intl/index.html (accessed on 21 May 2019). 
Koszewska, Małgorzata. 2011. Social and Eco-Labelling of Textile and Clothing Goods as a Means of Communication and Product Differentiation. Fibres \& Textiles in Eastern Europe 87: 20-26.

Kristof, Nicholas D., and Sheryl WuDunn. 2000. Two Cheers for Sweatshops. New York Times Magazine 24: 6-7.

Kuik, Onno. 2004-2005. Fair trade and ethical labeling in the clothing, textile and footwear sector: The case of blue jeans. ILSA Journal of International and Comparative Law 11: $619 \mathrm{ff}$.

Laroche, M., J. Bergeron, and G. Barbaro-Forleo. 2001. Targeting consumers who are willing to pay more for environmentally friendly products. Journal of Consumer Marketing 18: 503-20. [CrossRef]

Lee, Eunmi. 2017. Large U.S. Apparel Companies' Factory Monitoring Methods. Ann Arbor: ProQuest.

Levi Strauss \& Co. 2019. Worldwide Code of Business Conduct. Available online: https://investors.levistrauss. com/governance/governance-documents/default.aspx (accessed on 20 May 2019).

Levi Strauss \& Co. Global Sourcing and Operating Guidelines. n.d. Available online: https: //webcache.googleusercontent.com/search?q=cache:U1pe-mDMX2EJ:https://www.levistrauss.com/ wp-content/uploads/2019/03/Global-Sourcing-and-Operating-Guidelines.pdf $+\& c d=1 \& h l=i t \& c t=c l n k \&$ $\mathrm{gl}=\mathrm{it \& client=firefox-b-d} \mathrm{(accessed} \mathrm{on} 20$ May 2019).

Lipton, Gabrielle. 2019. Sustainable fashion moving from trend to permanent style - Landscape News. Landscape News. Available online: https://news.globallandscapesforum.org/32805/sustainable-fashion-moving-fromtrend-to-permanent-style/ (accessed on 9 May 2019).

Louis Vuitton. 2017. Supplier Code of Conduct. Available online: https://webcache.googleusercontent.com/search? q=cache:e5besNFuLmUJ:https://r.lvmh-static.com/uploads/2008/12/lvmh-supplier-code-of-conduct_

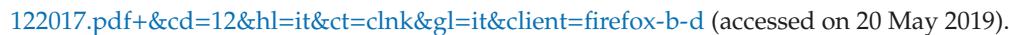

Messikomer, Carla Masciocchi, and Carol Cabrey Cirka. 2010. Constructing a Code of Ethics: An Experiential Case of a National Professional Organization. Journal of Business Ethics 95: 55-71. [CrossRef]

Minney, Safia. 2011. Naked Fashion: The New Sustainable Fashion Revolution. Oxford: New Internationalist.

Muthu, Subramanian Senthilkannan. 2014. Assessing the Environmental Impact of Textiles and the Clothing Supply Chain. Cambridge: Woodhead Publishing.

Nehf, James P. 2010. Misleading and unfair advertising. In Handbook of Research on International Consumer Law. Cheltenham: Edward Elgar Publishing.

Newberg, Joshua A. 2005. Corporate Codes of Ethics, Mandatory Disclosure, and the Market for Ethical Conduct. Vermont Law Review 29: 253.

Nieweler, Amanda. 2014. WhistleBlower Security. Available online: https://www.whistleblowersecurity.com/ code-of-ethics-and-code-of-conduct-whats-the-difference/ (accessed on 3 May 2019).

Nike, Inc., and et al. 2003. v. Kasky. 539 U.S. 654. Available online: https://www.law.cornell.edu/supct/html/02575.ZC.html (accessed on 20 May 2019).

Nike. 2017a. Code of Conduct. Available online: https://purpose.nike.com/code-of-conduct (accessed on 20 May 2019).

Nike. 2017b. Code of Leadership Standards. Available online: https://purpose.nike.com/code-of-conduct (accessed on 20 May 2019).

Nytimes.com. 1964. Suits Still Pending in 1961 Electrical Trust Case. Available online: https://www.nytimes.com/ 1964/04/08/archives/suits-still-pending-in-1961-electrical-trust-case.html (accessed on 4 May 2019).

Phillips-Van Heusen. 1995. A Shared Commitment. Available online: https://responsibility.pvh.com/resources (accessed on 20 May 2019).

Phillips-Van Heusen. 2018. Corporate Responsibility Report. Available online: https://www.pvh.com/investorrelations/reports (accessed on 20 May 2019).

Pinnock, Olivia. 2018. Sustainable Fashion Searches Surged. Forbes. Available online: https://www.forbes.com/ sites/oliviapinnock/2018/11/20/sustainable-fashion-searches-surged-in-2018/\#237a33c15fe7 (accessed on 15 May 2019).

Pitt, Harvey L., and Karl A. Gros-Kaufmanis. 1990. Minimizing Corporate Civil and Criminal Liability: A Second Look at Corporate Codes of Conduct. Georgia L. Journal 78: 1159.

Pookulara, Sanjukta, and Ariesa Shephard. 2013. Slow Fashion Movement: Understanding consumer perceptions-An exploratory study. Journal of Retailing and Consumer Services 20: 200-6. [CrossRef]

Prada Code of Ethics. 2007. Available online: csr.pradagroup.com/content/uploads/.../code_of_ethics_en.pdf (accessed on 20 May 2019). 
Ralph Lauren Corporation. 2016. Ralph Lauren Corporation Code of Business Conduct \& Ethics (Amended and Restated as of August 11). The Code of Business. Available online: webcache.googleusercontent.com/search?q=cache:XQemzdtJBEsJ:phx.corporate-ir.net/External.File? item=UGFyZW50SUQ9MzExOTk1fENoaWxkSUQ9LTF8VHlwZT0z\&t=1\&cb=635823256901320769\&cd= $4 \& \mathrm{hl}=\mathrm{it} \& \mathrm{ct}=\mathrm{clnk} \& \mathrm{gl}=\mathrm{it} \& \mathrm{client}=$ firefox-b-d (accessed on 20 May 2019).

Raluca, Creangâ. 2019. Fashion Sustainability in the Digital Realm. In Fashion Communication in the Digital Age: FACTUM 19 Fashion Communication Conference. Edited by Nadzeya Kalbaska. Ancona: Springer Nature, pp. 198-200.

Sajhau, Jean-Paul. 2000. Business Ethics in the Textile, Clothing and Footwear (TCF) Industries. Available online: https://digitalcommons.ilr.cornell.edu/codes/8/ (accessed on 4 May 2019).

Sajn, Nikolina. 2019. Environmental Impact of the Textile and Clothing Industry: What Consumers Need to know-Think Tank. Available online: http://www.europarl.europa.eu/thinktank/en/document.html? reference=EPRS_BRI(2019)633143 (accessed on 4 May 2019).

Shaw, D., E. Shui, G. Hogg, E. Wilson, and L. Hassan. 2004. Fashion Victim?: The Impact of Sweatshop Concerns on Clothing Choice. Paper presented at the 33rd EMAC 2004, Murcia, Spain, May 18-21.

Shen, Bin, Yulan Wang, Chris K. Y. Lo, and Momoko Shum. 2012. The impact of ethical fashion on consumer purchase behavior. Journal of Fashion Marketing and Management 16: 234-45. [CrossRef]

Shih, Wenying, and Konstantinos Agrafiotis. 2017. Detoxifying the Supply Chains: Production Networks of Slow Garment Factories in South-Eastern Europe. In Detox Fashion: Case Studies, Textile Science and Clothing Technology. Singapore: Springer Nature, pp. 1-28.

Slater, Keith. 2003. Environmental Impact of Textiles: Production, Processes and Protection. Cambridge: Woodhead Publishing.

Slot, Philippa. 2017. To What Extent are Fashion Companies Violating Fundamental Labour Rights in Turkish and Vietnamese Garment Factories, and How Can Such Violations Be Prevented. Master thesis, Tilburg University, Tilburg, The Netherlands.

Social Accountability 8000 Standard. n.d. Available online: http://www.sa-intl.org/index.cfm?fuseaction=Page. ViewPage\&pageId=1929 (accessed on 10 May 2019).

Southalan, John. 2008. CSR, the environment, and false advertising laws. Paper presented at the International Bar Association Annual Conference, Buenos Aires, Argentina, October 12-17. Available online: https: //www.int-bar.org/conferences/BA2008/index.cfm (accessed on 4 September 2019).

Spencer, Tamieka. 2003. Talking about Social Responsibility: Liability for Misleading \& Deceptive Statements in Corporate Codes of Conduct. Monash University Law Review 29: 297.

Stohl, Cynthia, Michael Stohl, and Lucy Popova. 2009. A New Generation of Corporate Codes of Ethics. Journal of Business Ethics 90: 607-9. [CrossRef]

Sudbury-Riley, Lynn, and Sebastian Boltner. 2011. Fashion Marketing and the Ethical Movement Versus Individualist Consumption: Analysing the Attitude Behaviour Gap. In E-European Advances in Consumer Research. Edited by Alan Bradshaw, Chris Hackley and Pauline Maclaran. Duluth: Association for Consumer Research, Volume 9, pp. 161-68.

Taplin, Ian M. 2014. Who is to blame? Critical Perspectives on International 10: 72-83. [CrossRef]

Thompson, Jennifer. 2018. Prada, Starbucks and Kraft Censured over Human Rights Transparency. Financial Times. Available online: https://www.ft.com/content/89ecc00a-050b-3e29-b3eb-5edd920d886b (accessed on 23 May 2019).

Toprak, Tuba, and Pervin Anis. 2017. Textile Industry's Environmental Effects and Approaching Cleaner Production and Sustainability, an Overview. MedCrave Online. Available online: https://medcraveonline.com/JTEFT/ JTEFT-02-00066 (accessed on 4 May 2019).

Townsend, Solitaire. 2018. 88\% of Consumers Want You to Help Them Make a Difference, Forbes. Available online: https:/www.forbes.com/sites/solitairetownsend/2018/11/21/consumers-want-you-to-help-themmake-a-difference/ (accessed on 9 May 2019).

Trudel, Remi, and June Cotte. 2009. Does it pay to be good? MIT Sloan Management Review 50: 61-68. Available online: http://econ.au.dk/fileadmin/Economics_Business/Currently/Events/PhDFinance/Kauttu_REF_Does_ it_pay_to_be_good.pdf (accessed on 4 May 2019).

Turker, Duygu, and Caren Altuntas. 2014. Sustainable supply chain management in the fast fashion industry: An analysis of corporate reports. European Management Journal 32: 837-38. [CrossRef] 
Vogel, David. 2005. The Market for Virtue, The Potential and Limits of Corporate Social Responsibility. Washington, DC: Brookings Institution Press.

Vogel, David. 2010. The Private Regulation of Global Corporate Conduct, Achievements and Limitations. Business \& Society 49: 68-87.

Wisner, Joel D., Kea-Choon Tan, and G. Keong Leong. 2016. Principles of Supply Chain Management: A Balanced Approach. Boston: Cengage Learning.

Yang, Shuai, Yiping Song, and Siliang Tong. 2017. Sustainable Retailing in the Fashion Industry: A Systematic Literature Review. Sustainability 9: 1266. [CrossRef]

Zinola, Anna. 2019. Chi Sono Le Vere Fashion Victims? La nuvola del lavoro. Corriere della Sera. May 3. Available online: http://nuvola.corriere.it/2019/05/03/chi-sono-le-vere-fashion-victims/ (accessed on 4 May 2019).

(C) 2019 by the authors. Licensee MDPI, Basel, Switzerland. This article is an open access article distributed under the terms and conditions of the Creative Commons Attribution (CC BY) license (http://creativecommons.org/licenses/by/4.0/). 

Article

\title{
Slow Fashion in a Fast Fashion World: Promoting Sustainability and Responsibility
}

\begin{abstract}
Mark K. Brewer
Sheffield Business School, Sheffield Hallam University, Howard St, Sheffield S1 1WB, UK; mkb22@cornell.edu

Received: 23 July 2019; Accepted: 24 September 2019; Published: 9 October 2019

Abstract: Through its rapid production methods that supply the latest catwalk styles almost instantaneously to the high street, the fast fashion model has revolutionized the fashion industry, while generating a significant carbon footprint and a host of social concerns. Yet, the law is either slow or ineffective in promoting sustainability in a world obsessed with image and social connectivity, while outdated notions of companies continue to dominate the legal academy. This chapter initially examines the fashion industry's environmental footprint. Then, it examines the rise of the fast fashion model and law's inadequacy to prevent the model from undermining intellectual property rights or effectively address the model's detrimental impact on environmental and social sustainability. The chapter then challenges traditional notions of corporate personality, calling for more responsible corporate behavior and greater legal scrutiny. Finally, the chapter considers various issues to enhance ethical behavior in companies, arguing that the slow fashion movement provides an alternative paradigm to the fast fashion model, since the slow fashion movement connects suppliers and producers more closely with consumers, thereby enhancing sustainability and corporate responsibility.
\end{abstract}

Keywords: fashion law; fast fashion; sustainability; corporate social responsibility

\section{Introduction}

Perhaps more than almost any other field of art and industry, fashion is inextricably woven with time, finding its essence in current, fast-moving trends and its inspiration in emerging styles. With its rapid production times and ability to capture the latest, hottest trends, the fast fashion model of production, distribution, and marketing has thrived over the past decade. From production advances in textile factories to 3D printing (or additive manufacturing), technological changes have revolutionized production methods, allowing manufacturers to create garments increasingly fast. Aside from production advances in textile factories, 3D technology has the potential to render time an increasingly negligible element of the production cycle. Further, the democratization of fashion, spurred by cheaper garments, allowing companies to market to the masses, contributes to a throw-away culture and insatiable consumer demand for the latest knock-offs of the season's "it" pieces. Additionally, the prevalence of social media fuels the virtually instantaneous movement of trends within communities and networks across the world. From the carbon footprint inherent in a supply chain spanning the globe to the reliance on enormous quantities of natural resources, the impact on society and the environment of these trends has become increasingly clear. Yet, in a world obsessed with image and social connectivity-and driven by ever-changing consumer whims, there are no quick fixes to make the fashion industry more sustainable.

This chapter examines the environmental and social impact of fast fashion and the limits of the law to respond to these challenges. Against these constraints, the chapter makes the case for supporting the emerging slow fashion movement as well as other initiatives that connect suppliers and producers more closely with consumers. First, the chapter examines the staggering environmental impact of the fashion industry and critically analyzes the so-called "fashion paradox" or the relationship between 
the fashion industry's reliance on ever-changing styles and issues of sustainability. The chapter then presents the fast fashion industry, critically evaluating its business model and the legal limitations to enhancing sustainability in the fast fashion industry. Further, the chapter considers the effectiveness of corporate social responsibility as well as other soft law initiatives. Then, the chapter analyzes corporate personality and the impact that the law plays in skewing companies away from sustainable behavior, particularly in the fast fashion industry. Finally, the chapter argues that sourcing, production, and marketing practices that connect raw materials, designers, labor, and retailers more closely with consumers-key ingredients of the slow fashion movement-greatly enhance sustainability, protect human rights, and empower communities.

\section{Discussion}

\subsection{Fashion's Environmental Footprint}

Fashion is among the world's most polluting industries: it requires enormous quantities of raw materials, creates considerable levels of pollution, leaves a significant carbon footprint, and generates alarming levels of waste. According to the World Wildlife Fund (2019), 20,000 liters of water are required to produce one kilogram of cotton. Further, the textile industry produces enormous amounts of industrial waste, with some estimates suggesting that the industry contributes $17-20 \%$ of global industrial water pollution (Kant 2012). Additionally, industrial waste water from the textile industry often contains high levels of dangerous dyes and other chemicals, which may be toxic to aquatic wildlife and harmful to human health, particularly as a number of dyes are known to contain carcinogens that have been shown to cause several cancers (Ghaly et al. 2014).

Beyond its harmful impact on water supplies, the global fashion industry accounts for $10 \%$ of the world's carbon emissions, with significant emissions through both production and its supply chain (Conca 2015). In the production of fibers and textiles, the industry produced an estimated 1.2 billion tons of greenhouse emissions in 2015, exceeding the combined carbon footprint of international flights and maritime shipping (Ellen Macarthur Foundation 2017). Further, reliance on complicated supply chains spanning the globe and "just-in-time" production cycles means that fashion companies drive a high-carbon transport network in which raw materials travel from one country to another as they evolve into the garments that ultimately end up in shops around the world.

In addition to the detrimental impact of manufacturing and transporting products, our disused and unwanted clothing is creating ever larger rubbish heaps, as society is consuming, hoarding, and discarding new garments at unprecedented levels. In the United States, the Environmental Protection Agency's most recently available estimates indicate that 11.9 million tons of clothing and footwear were discarded in 2015, of which 8.2 million tons ended up in landfills (Environmental Protection Agency 2019). Moreover, several large fashion companies such as Burberry have been accused of disposing of large quantities of new merchandise (House of Commons Environmental Audit Committee 2019), not only contributing to high levels of waste but also raising serious concerns about the ethical, social, and environmental aspects of such practices. As customers and other stakeholders more fully understand the adverse environmental impact of our throw-away clothing culture, they are increasingly demanding that companies modify their behavior to minimize their damage to the environment, with research suggesting that greater knowledge of unsustainable practices by companies influences customer behavior and judgments (Grappi et al. 2017).

Unlike natural fibers such as cotton or wool, synthetic fibers such as polyester, rayon, or nylon may take up to 200 years (or more as explained below) to decompose. The scale of devastation caused by microfibers or tiny synthetic fiber used in clothing, upholstery, and other materials is staggering, with scientists estimating that microfibers make up $85 \%$ of human-made debris on ocean shorelines (Browne 2011). Moreover, polyethylene terephthalate (PET), commonly called polyester in the textile industry and the largest segment of the synthetic fiber sector, has a particularly slow rate of decomposition, with some scholars suggesting a single PET bottle may take approximately 
800-1000 years to decompose in natural conditions (Zengin et al. 2016). As the textile industry consumes the majority of PET globally (more than plastic bottles and other PET products combined) (Shen et al. 2012), this source of microfibers is particularly harmful to the environment. Indeed, an increasing body of literature suggests that microfibers have now entered the human food chain not only through the consumption of fish and other aquatic life but more disturbingly through drinking water as well (Henry and Klepp 2019). The fashion industry's consumption of enormous quantities of raw materials, production of dangerous levels of pollution, creation of a significant carbon footprint, and generation of alarming levels of waste all pose particular problems to environmental sustainability.

Moreover, the so-called fashion paradox, or the relationship between the fashion industry's imperative to continually evolve to satisfy consumers' insatiable desire to acquire the most exclusive, latest trends, and the consequent loss of exclusivity as consumers acquire the most popular garments, suggests that the fashion industry's very raison d'être is inherently diametrically opposed to sustainability. While social critics may decry the inevitable inequality implicit in the very existence of fashion, the rise of fast fashion as discussed below has fundamentally democratized style through unleashing collection after collection of knock-off designs at minimum financial costs but significant environmental costs. Previously, the most exclusive and expensive garments were beyond the means of but the wealthiest; however, the advent of quick design processes, rapid production methods, and highly efficient supply chains to churn out garments has brought the latest styles to the masses virtually instantaneously (particularly when one considers the capability of 3D printing). Implicit in the fashion paradox is the contradiction between fashion's imperative to be "in style" with constant changes and new seasons versus sustainability and responsibility. The desire of consumers to remain "in fashion" requires a constant supply of new styles since once a new fashion goes mainstream, it becomes obsolete, losing its allure and encouraging trendsetters to search for the next new fad. Whether through globalization propelling ever-faster production cycles, the proliferation of online social media featuring the latest styles, internet influencers generating interest in new products, the burgeoning number of fashion shows internationally, or simply global economic growth, the public's addiction to ever-changing fashion fuels demand for higher carbon-producing modes of transport such as air freight, which often replace less polluting forms of transport such as shipping. Ultimately, the modern fashion cycle consumes massive quantities of raw materials and contributes an enormous carbon footprint through energy-intensive production methods and global supply chains.

\subsection{Fast Fashion}

The concurrent declining costs and increasing speed of production have provided the ideal environment for the "fast fashion" model which delivers to consumers copies of the latest trends, often before the originals themselves hit the stores (Beebe 2010). With such rapid production and quick, efficient supply chains, companies such as Zara, H\&M, Forever21, and Topshop have revolutionized the traditional fashion marketplace (Cline 2012). While these developments have had the positive effect of democratizing fashion, allowing a broad range of consumers to share in close copies of the most exclusive and expensive designers, the fast fashion model has undermined the value of intellectual property belonging to designers, dramatically expanded the industry's carbon footprint, and promoted a culture of waste. In contrast to the fashion industry's traditional focus on creating new designs, the fast fashion model is driven by trends and consumer behavior (Tokatli 2007) and focuses on providing lower cost garments that are either inspired or simply copied from the latest trends. Hence, many fast fashion companies have been accused of undermining the intellectual property of designers and weakening the incentive of consumers to spend money on more expensive original designs. As a result, the fast fashion model may actually discourage creativity and individuality as well as hamper new and emerging designers in favor of established brands which tend to set the trend for fast fashion copies as discussed below. 


\subsection{Limitations of the Law and Other Measures}

The law often only offers limited protection to intellectual property in the fashion industry, which may encourage fast fashion firms to disregard intellectual property law. Large, well-known fashion brands, such as Gucci, Adidas, and Puma, have the influence and resources to challenge intellectual property infringements, and indeed, such brands have challenged alleged infringements from the fast fashion companies such as Foreover21. However, the opportunity cost of such expensive litigation may ultimately result in higher prices on the racks and lower salaries in the industry. Further, new and emerging designers initially may struggle to achieve visibility among the cheaply made, mass-marketed fast fashion collections, and if their designs are indeed misappropriated by fast fashion firms, new and emerging designers often lack the resources to challenge intellectual property theft. In short, the tendency of fast fashion companies to mimic traditional designers poses real threats to the integrity, value, and viability of other designers. This legal lacuna not only allows for unjustified copying of designs but also tacitly promotes the fast fashion business model's wasteful approach to natural resources as well as its reliance on carbon-intensive supply chains and production methods. Further, social media's ability to spread new fads globally almost instantaneously, combined with rising levels of disposal income (particularly in rapidly growing developing countries) drives the insatiable consumer demand for cheap knock-off styles. This, in turn, further fuels the fast fashion industry's substantial carbon footprint.

An extensive network of national laws, international standards, and best industry practices regulate labor conditions. At the international level, the International Labor Organization provides a forum to promote appropriate standards, policies, and programs to protect the rights of workers. Additionally, the G7 has formulated due diligence standards for the textile industry to help improve working conditions and enhance workers' rights in the global textile supply chain. Nonetheless, many harsh conditions persist. The April 24, 2013 collapse of the eight-story Rana Plaza building in Savar Upazila in Greater Dhaka, Bangladesh, epitomizes the devastating impact of poor working conditions in the garment industry. Ignoring warnings on the day prior to the collapse, factory managers ordered garment workers to report for work or their pay would be docked, although a bank and shops on the lower floors of the building were closed in response to the concerns over the building's integrity. The collapse caused the death of 1134 people and injured approximately 2500 others (Ansary and Barua 2015).

In response to concern over working conditions and labor standards in supply chains, there is an increasing emphasis on transparency in supply chains and traceability of raw materials used in producing clothing. While various legal provisions, such as Section 1502 of the Dodd-Frank Wall Street Reform and Consumer Protection Act in the United States, the California Transparency in Supply Chains Act of 2010, and the Modern Slavery Act 2015 in the U.K., all require disclosure of supply chain details, other forms of so-called "soft law" such as voluntary codes also guide or encourage companies to adhere to higher standards in their supply chains. Indeed, de Brito et al. (2008) demonstrate that companies may not only be compelled by legal requirements, but they may also engage in more ethical behavior through seeking a competitive advantage or through pursuing policies of corporate social responsibility; however, the authors also acknowledge that companies face much ambiguity in determining the demands of various stakeholders. Moreover, many "soft law" guidelines are limited, as they often rely on voluntary adherence or lack effective enforcement mechanisms. Nonetheless, through such initiatives that promote sustainability and corporate social responsibility, many companies increasingly choose to adopt policies and practices that are intended to respect social, environmental, ecological, and economic issues locally and globally. However, why do some companies prioritize sustainability while others do not? 


\subsection{Creating a Better Company}

Given the variety of individuals and businesses involved in the fashion industry, it is difficult to generalize on the personality of such entities; yet, collectively, they exert an enormous influence on society and the environment. Companies such as Benetton have been innovators in promoting social issues, while Vivienne Westwood and Stella McCartney have become almost synonymous with sustainable fashion and social responsibility. Despite these well-known champions of sustainability, the industry at large exerts a substantial detrimental impact on the environment and society. The question arises why do so many fashion companies have such a detrimental impact on the environment, while certain other fashion companies champion sustainability? The answer most likely lies in the dichotomy of cheap prices demanded by consumers and ethical concerns of the public, together with differing models of corporate personality.

Further, prevailing concepts of corporate personality may straightjacket fashion companies into maximizing short-term corporate profits over other considerations. To explain, economists and legal scholars have long focused on rights and duties of shareholders in an attempt to explain the purpose of corporations, with two distinct views of corporate personality emerging. The dominant view in Anglo-American law, which focuses on shareholder value and shareholder primacy over other considerations, has driven short-term profits at the expense of other stakeholders, thereby accelerating global warming and rising sea levels over the past few decades. In contrast, more enlightened views of the purpose of corporations stress the importance of a wide variety of stakeholders, allowing companies to weigh longer-term considerations in making decisions. Each of these models is presented below.

Tracing its origins to the pioneering research of Berle and Means (1932) as well as Michael Jensen and William Meckling's seminal work "Theory of the Firm: Managerial Behavior, Agency Costs and Ownership Structure" (Jensen and Meckling 1976), shareholder value theory is epitomized by Friedman (1962) in his frequently quoted statement: "There is one and only one social responsibility of business-to use its resources and engage in activities designed to increase its profits so long as it stays within the rules of the game, which is to say, engage in open and free competition, without deception or fraud." Under such a construction, the interests of shareholders are paramount to all other stakeholders, which includes employees, customers, and the communities in which the company is active. Indeed, scholars espousing such a rigid view of companies point to seminal U.S. Supreme Court cases such as Dodge v. Ford ${ }^{1}$, Schlensky v. Wrigley ${ }^{2}$, and Revlon, Inc. v. Forbes Holdings ${ }^{3}$ as authority for the argument that companies must concentrate on the maximization of shareholder value, which often means ignoring other stakeholders that affect the company's long-term impact as companies pursue short-term profits at the expense of long-term stability, including the impact on local communities, labor, the environment, and other stakeholders. In contrast to such a rather myopic view of corporations, a number of other scholars (Stout 2012; Rotman 2010) have convincingly displayed the shareholder maximization model's "shaky foundation" and have argued that the case law cited in favor of the shareholder value theory is not as clearly supported as often assumed in the prevailing academic literature (Lee 2009) nor do any corporate statutes or legal decisions require companies to strictly follow the shareholder maximization model (Sneirson 2011). Moreover, it is absurd to argue that companies best serve society by simply ignoring all but corporate profits (Greenfield 2005).

Further, as legal persons, companies enjoy a number of rights and privileges-it is only fitting and right that they should also have at least moral and ethical obligations to consider the impact of their actions upon their various stakeholders beyond their shareholders. While society demands a range of ethical behavior from natural persons, the basic legal structure of corporations removes personal responsibility from decision-makers and characteristically limits liability for the business to the capital

\footnotetext{
Dodge v. Ford Motor Co. 170 N.W. 668, 684 (Mich. 1919).

Schlensky v. Wrigley, 95 Ill. App. 2d 173, 237 N.E.2d 776 (App. Ct. 1968).

Revlon, Inc. v. MacAndrews \& Forbes Holdings, Inc., 506 A.2d 173 (Del. 1986).
} 
it holds. Unlike natural persons who may be liable for tortious conduct, the corporate form insulates the individuals who may reach decisions leading to tortious conduct by the corporation, with liability for wrong-doing largely limited to the corporate level, rather than the actual decision-makers who devised, implemented, or took the actions that caused the harmful result. The diffused constellation of decision-making, control, and liability may encourage managers-who may be protected by indemnities in corporate charters-to engage in "excessive levels of risk-taking," which they would avoid in their capacity as individual persons (Ho 2013). Herein lies the so-called agency-principal problem (Jensen and Meckling 1976), which denotes the manner in which the board of managers makes decisions for the corporation and exercises control with limited oversight by its shareholders who are dispersed and meet only periodically. Moreover, the law often protects corporate boards from liability for their decisions through the business judgment rule, a concept that U.S. courts developed but now exists in various forms in other jurisdictions, including the U.K., Canada, and much of the common law world. Accordingly, courts will routinely disregard shareholder challenges if the board can identify a business purpose for such decision where the board acted in the company's best interest and in good faith with the due care of a reasonably prudent person. Absent from this analysis is the impact of decisions on the environment, the local community, consumers, the public, employers, workers in supply chains, and a host of other stakeholders. Therefore, a number of scholars have argued that the business judgment rule may often weigh in the favor of the directors at the expense of other stakeholders (Gevurtz 2011; Dibadj 2005). Yet, a more enlightened view of the shareholder value theory recognizes a broader range of stakeholders and doing so may actually enhance shareholder value. Further, a mechanical application of the business judgment rule dismisses the larger social impact that business decisions have and the detrimental impact they may exert when executed without due consideration of the larger consequences of the decision. Similarly, directors in the U.K. have a duty to manage the company in the interest of shareholders, as held in Percival v. Wright ${ }^{4}$ (1902) and codified in the Companies Act 2006. In contrast to U.S. law, however, Parliament specifically introduced the concept of "enlightened shareholder value" in the Companies Act 2006, which requires directors to consider the collective best interest of shareholders in the context of other stakeholders, including employees as well as the environment. Despite criticisms that these U.K. reforms have not lived up to expectations, the emphasis on enlightened shareholder value does introduce the imperative that companies consider other stakeholders when setting policy and making decisions.

In contrast to an extreme interpretation of the shareholder value theory which seeks to maximize shareholder wealth without regard to other stakeholders, the concept of corporate social responsibility (CSR) encourages companies to develop sustainable policies and reach decisions with due regard to the environment and society, taking into consideration a much broader range of stakeholders than simply the company's shareholders. While CSR standards are often voluntary, they may help modify behavior by raising awareness and generating consumer pressure on other companies to follow the higher ethical standards of leading competitors. Essentially, CSR not only makes sense ethically, but it is often good business. In particular, the world's top 20 companies according to revenue have all adopted some type of CSR report, and as previously mentioned, well-known designers such as Vivienne Westwood and Stella McCartney have helped to pioneer responsible policies in the fashion industry. Nevertheless, it must be acknowledged that CSR lacks the force of mandatory law and may even in some circumstances inhibit mandatory law containing higher standards where companies adopt voluntary CSR initiatives.

\subsection{Slow Fashion: Enhancing Sustainability, Protecting Human Rights, and Empowering Communities}

On the opposite end of the spectrum from the fast fashion model of production, Kate Fletcher (2007) founded the slow fashion movement by drawing inspiration from the "slow food" movement, which

4 Percival v. Wright, [1902] 2 Ch. 421. 
emphasizes responsibility in food production and consumption. Companies that emphasize more sustainable practices make up the slow fashion movement, prizing craftsmanship, good stewardship, and quality products. Therefore, they naturally promote sustainability through more ethical sourcing and production techniques as well as by using organic, recycled, or more durable materials. Further, the labor involved in the production of such garments receives higher wages and greater protection than its counterparts in the supply chain of the fast fashion industry. While finished garments may cost more, they last longer and incorporate more timeless styles that do not go "out of fashion." Through a greater emphasis on connecting raw materials, designers, artisans, retailers, and consumers, firms in the slow fashion movement promote sustainability in sourcing, production, and consumption. However, the slow fashion movement faces an uphill battle with cheap, knock-off designs massed-marketed in a world of increasing consumer appetite. Therefore, government policies, reorientation of supply chains, and greater consumer knowledge and engagement are all necessary to level the playing field between fast and slow fashion.

In response to the types of concerns discussed above, a number of organizations attempt to raise public awareness, report on the adverse impact of supply and production methods, and provide registers of raw materials sourced and produced in an ethical and sustainable manner. In particular, the Fairtrade Foundation promotes social, economic, and environmental standards across a number of agricultural products and raw materials, including bananas, coffee, tea, chocolate, cut flowers, gold, wine, and cotton. It also promotes other activities to enhance worker rights, promote fair wages, and develop communities in regions supplying such products. With respect to items of fashion, labelling schemes for fair-trade cotton like that of the Fairtrade Foundation may provide consumers with greater assurance that the sourcing and production methods allow for better and more stable incomes (Fairtrade Foundation 2019). In addition to fair-trade sourcing and production, labelling of organic cotton provides consumers with assurance that the cotton has been produced in a manner that has a lower impact on the environment by limiting the use of pesticides and fertilizers and utilizing non-modified plants. The Global Organic Textile Standard (GOTS) provides a global means to identify and promote organic textiles, including the raw materials, manufacturing processes, and labelling of products. By focusing on the complete supply chain of textiles, the GOTS provides end users assurance through independent certification that the textiles have been sourced and manufactured in adherence with relevant social and ethical criteria (Global Organic Textile Standard 2018).

Founded in 1998, the U.K.-based Ethical Trading Initiative works with its member organizations, including companies, trade unions, and NGOs, to promote international labor rights by promoting employees' freedoms and safe working environments, eradicating child labor, ensuring the payment of living wages, curtailing excessive working hours and harsh treatment, eliminating discrimination, and encouraging regular and legal employment relationships (Ethical Trading Initiative 2019). With respect to the fashion industry in particular, the ETI has promoted initiatives to improve working conditions in garment production.

Aside from these initiatives, the discussion above on corporate personality illustrates the importance of companies embedding sustainability in their sourcing, production, and interaction with consumers. Nonetheless, consumer interest in sustainable fashion has not necessarily resulted in changes in consumer behavior. For example, Sudbury and Böltner (2011) have shown that consumers may choose lower prices instead of higher standards of sustainability, even when such consumers have a greater awareness of ethical fashion. Therefore, slow fashion companies must more effectively convey to consumers the cost of cheap fashion vis-à-vis fast fashion. Additionally, they must continue to emphasize slow fashion's responsible practices and contributions to sustainability, thereby helping to guide consumer knowledge toward a reorientation away from fast fashion to more sustainable types of design, sourcing, production, and marketing. Moreover, government policies, industry bodies, and other stakeholders must work with the industry to highlight the advantages of slow fashion, while discouraging the excesses of fast fashion. 


\section{Conclusions}

The global fashion industry faces a number of challenges in terms of sustainability and social responsibility. In particular, the fast fashion model generates a significant carbon footprint and raises a number of social and environmental concerns. Given that the law currently provides only limited protection of rights in the fashion industry and is often ineffective in improving corporate behavior, corporate social responsibility and sustainability initiatives may help to combat inequality in the fashion industry as well as improve standards and conduct. Therefore, legal reforms and increased support for companies that pursue more sustainable practices are necessary to reorient the fashion industry and consumers away from the fast fashion model toward more sustainable sourcing, production, distribution, marketing, and consumption practices. Companies that adopt such slow fashion practices should provide a template for the future of the global fashion industry.

Funding: This research received no external funding.

Conflicts of Interest: The author declares no conflict of interest.

\section{References}

Ansary, Mehedi Ahmed, and Uttama Barua. 2015. Workplace safety compliance of RMG industry in Bangladesh: Structural assessment of RMG factory buildings. International Journal of Disaster Risk Reduction 14: 424-37. [CrossRef]

Beebe, Barton. 2010. Intellectual Property Law and the Sumptuary Code. Harvard Law Review 123: 834-35.

Berle, Adolph A., Jr., and Gardiner C. Means. 1932. The Modern Corporation and Private Property. New York: The MacMillan Company.

Browne, Mark Anthony. 2011. Accumulation of Microplastic on Shorelines Worldwide: Sources and Sinks. Environmental Science \& Technology 45: 9175-79. [CrossRef]

Cline, Elizabeth L. 2012. Over-Dressed: The Shockingly High Cost of Cheap Fashion. New York: Penguin, p. 96.

Conca, James. 2015. Making Climate Change Fashionable-The Garment Industry Takes on Global Warming. Available online: https:/www.forbes.com/sites/jamesconca/2015/12/03/making-climate-change-fashionablethe-garment-industry-takes-on-global-warming/\#18725edb79e4 (accessed on 8 October 2019).

de Brito, M., Valentin Carbone, and Corinne Meunier Blanquart. 2008. Towards a sustainable fashion retail supply chain in Europe: Organisation and performance. International Journal of Production Economics 114: 534-53. [CrossRef]

Dibadj, Reza. 2005. Delayering Corporate Law. Hofstra Law Review 34: 477.

Ellen Macarthur Foundation. 2017. A New Textiles Economy: Redesigning Fashion's Future. Cowes: Ellen Macarthur Foundation, p. 2. Available online: https://www.ellenmacarthurfoundation.org/assets/downloads/publications/ A-New-Textiles-Economy_Full-Report_Updated_1-12-17.pdf (accessed on 8 October 2019).

Environmental Protection Agency. 2019. Facts and Figures about Materials, Waste and Recycling. Available online: https://www.epa.gov/facts-and-figures-about-materials-waste-and-recycling/nondurable-goodsproduct-specific-data (accessed on 8 October 2019).

Ethical Trading Initiative. 2019. Available online: https://www.ethicaltrade.org/about-eti (accessed on 8 October 2019).

Fairtrade Foundation. 2019. Available online: http://www.fairtrade.org.uk (accessed on 8 October 2019).

Fletcher, Kate. 2007. Slow fashion. The Ecologist 37: 61.

Friedman, Milton. 1962. Capitalism and Freedom. Chicago: University of Chicago Press, pp. 124-33.

Gevurtz, Franklin A. 2011. The Globalization of Corporate Law: The End of History or a Never-Ending Story. Washington Law Review 86: 518.

Ghaly, Andrew, Rishi Ananthashankar, Mohammed Kadhim Alhattab, and Varsha Ramakrishnan. 2014. Production, Characterization and Treatment of Textile Effluents: A Critical Review. Journal of Chemical Engineering Process Technology 5: 11.

Global Organic Textile Standard. 2018. Ecology \& Social Responsibility. General Description. Available online: https://www.global-standard.org/the-standard/general-description.html (accessed on 8 October 2019). 
Grappi, Silvia, Simona Romani, and Camilla Barbarossa. 2017. Fashion without pollution: How consumers evaluate brands after an NGO campaign aimed at reducing toxic chemicals in the fashion industry. Journal of Cleaner Production 149: 1164-73. [CrossRef]

Greenfield, Kent. 2005. New Principles for Corporate Law. Hastings Business Law Journal 1: 91.

Henry, Beverley, and Ingun Grimstad Klepp. 2019. Microfibres from apparel and home textiles: Prospects for including microplastics in environmental sustainability assessment. Science of The Total Environment 652: 483-94. [CrossRef] [PubMed]

Ho, Virginia Harper. 2013. Of Enterprise Principles and Corporate Groups: Does Corporate Law Reach Human Rights? Columbia Journal of Transnational Law 52: 113-72.

House of Commons Environmental Audit Committee. 2019. Fixing Fashion: Clothing Consumption and Sustainability, Sixteenth Report of Session 2017-19, HC 1952, 19 February 2019. pp. 44-45. Available online: https://publications. parliament.uk/pa/cm201719/cmselect/cmenvaud/1952/1952.pdf (accessed on 25 March 2019).

Jensen, Michael C., and William H. Meckling. 1976. Theory of the Firm: Managerial Behavior, Agency Costs and Ownership Structure. Journal of Financial Economics 3: 305-60. [CrossRef]

Kant, Rita. 2012. Textile dyeing industry an environmental hazard. Natural Science 4: 22-26. [CrossRef]

Lee, Ian B. 2009. Citizenship and the Corporation. Law \& Social Inquiry 34: 129-68.

Rotman, Leonard I. 2010. Debunking the 'End of History' Thesis for Corporate Law. Boston College International \& Comparative Law Review 33: 219-72.

Shen, Li, Ernst Worrell, and Martin K. Patel. 2012. Comparing life cycle energy and GHG emissions of bio-based PET, recycled PET, PLA, and man-made cellulosics. Biofuels Bioproducts and Biorefining 6: 625-39. [CrossRef]

Sneirson, Judd F. 2011. The Sustainable Corporation and Shareholder Profits. Wake Forest Law Review $46: 541$.

Stout, Lynn. 2012. The Shareholder Value Myth: How Putting Shareholders First Harms Investors, Corporations, and The Public. San Francisco: Berrett-Koehler Publishers.

Sudbury, Lynn, and Sebastian Böltner. 2011. Fashion Marketing and the Ethical Movement Versus Individualist Consumption: Analysing the Attitude Behaviour Gap. E - European Advances in Consumer Research. Edited by Alan Bradshaw, Chris Hackley and Pauline Maclaran. Duluth: Association for Consumer Research, vol. 9, pp. 163-68.

Tokatli, Nebahat. 2007. Global Sourcing: Insights from the Global Clothing Industry-The Case of Zara, a Fast Fashion Retailer. Journal of Economic Geography 8: 21-38. [CrossRef]

World Wildlife Fund. 2019. Sustainable Agriculture. Cotton. Available online: https://www.worldwildlife.org/ industries/cotton (accessed on 8 October 2019).

Zengin, Huseyin, Amine Cicek, and Gulay Zengin. 2016. Recovery of Polyethylene Terephthalate (PET) based waste polymers, polyester fiber production phases, and chemical and chain extenders. Paper presented at International Engineering, Science and Education Conference, Diyarbakir, Turkey, December 1-3.

(C) 2019 by the author. Licensee MDPI, Basel, Switzerland. This article is an open access article distributed under the terms and conditions of the Creative Commons Attribution (CC BY) license (http://creativecommons.org/licenses/by/4.0/). 



\title{
Circular Economy and Waste in the Fashion Industry
}

\author{
Valentina Jacometti \\ Department of Law, Economics and Culture, Università degli Studi dell'Insubria, Via S. Abbondio 12, \\ 22100 Como, Italy; valentina.jacometti@uninsubria.it
}

Received: 1 October 2019; Accepted: 28 October 2019; Published: 31 October 2019

\begin{abstract}
The fashion industry has to play an important role in the path towards sustainability and the circular economy. Indeed, the fashion industry is a sector with a high environmental impact; it involves a very long and complicated supply chain, which is associated with large consumption of water and energy, use of chemical substances, water and air pollution, waste production and finally microplastic generation. In particular, textiles and clothing waste has become a huge global concern. Against this background, this paper aims at analysing the existing EU measures that have an impact on the development of sustainable practices and the transition to a circular economy in the fashion industry, with a particular focus on the EU revised legislative framework on waste adopted within the Circular Economy Action Plan of 2015.
\end{abstract}

Keywords: circular fashion; textile and clothing waste; EU Waste Framework Directive

\section{Introduction}

As affirmed on 1 February, 2019 by the president of the UN Economic and Social Council at the Sustainable Fashion Summit "sustainable fashion is key to the achievement of the 2030 Agenda"1.

In fact, the fashion industry is certainly a sector with a high environmental and social impact: it involves an extremely long and complicated supply chain, is recognized as one of the most polluting sectors and with the greatest consumption of water, and is often associated with workplace abuses (Fletcher 2014) ${ }^{2}$. In recent decades, this impact has been increased mainly by two related factors: the shift of production towards emerging or developing countries with low labour costs and the development of the so-called "fast fashion" phenomenon, that is the demand for "disposable" clothing at low prices $^{3}$.

In just two decades, clothing production has almost doubled, driven by an increase in the number of garments purchased each year by an average consumer, which is in turn mainly driven by the fast fashion phenomenon, with its low prices and increased number of clothing collections offered per year to consumers ${ }^{4}$. The continuous changes in fashion often mean that a piece of clothing, after being used for one season, is simply thrown away. This has led consumers to buy clothes as if they were candies, to buy more clothes than they need and to treat more and more low-priced garments almost

1 The term sustainability is very broad and covers economic, social and environmental aspects. Here we will refer in particular to environmental sustainability, that concerns all the actions that a company can undertake to reduce environmental impacts, such as use of organic fibres, recycled synthetic fibres or from renewable resources; reduction, re-use and recycling of resources (raw materials, energy, water) necessary at all stages of the product life cycle, from production to consumption; reducing the use of chemicals in the production process and their disposal; reduction of emissions of air pollutants and especially of greenhouse gases (carbon footprint); reduction of waste generation.

2 On the environmental impact of the fashion industry see also (Toprak and Anis 2017; Muthu 2014; Luz 2007; Kuik 2004-2005; Slater 2003).

3 More specifically on the impact of fast fashion see (Singh 2017; Anguelov 2016; Zerbo 2016; Li 2014; Turker and Altuntas 2014).

4 The average number of collections released by European apparel companies has more than doubled from 2000 to 2011 , with some companies offering up to 16 collections, like H\&M, or even 24, like Zara (Remy et al. 2016). 
as "disposable" goods that can be thrown away after just seven or eight wears (Remy et al. 2016). This sort of "democratic" vision of fashion has allowed to pay lower and lower prices thanks to increasingly lower costs, so as to render the guarantee of a good quality and an equitable production process unaffordable.

Even if awareness of the environmental impact of fashion is low among the general public, the question of sustainability is increasingly at the centre of public attention and consumers are increasingly demanding products with a low environmental and social impact. In fact, the pressure from consumers and especially of non-governmental organizations (NGOs) and the media has acted and continues to act as a stimulus for the adoption of sustainable behaviour in the fashion sector Gordon and Hill (2015).

Nowadays, there is a strong push within the fashion industry to make every phase of the production more sustainable, with a view to transition to a circular fashion model.

In fact, given the economic, social and environmental impact of the sector, to achieve the UN 2030 Agenda for Sustainable Development and the Sustianable Development Goals (SDGs), it is essential to ensure that economic growth and development are accompanied along the whole garment value chains by social justice, job protection and reduction of environmental impacts through an efficient use of resources and sustainable production and consumption models in the perspective of a circular economy.

In this perspective, the European Union is committed to supporting a new sustainable development agenda through its development cooperation, where it is promoting sustainable garment value chains at bilateral, regional and global levels (European Commission 2017).

In particular, in 2017 the European Parliament adopted a resolution on the EU flagship initiative on the garment sector (European Parliament 2017), where it asks the European Commission to strengthen its commitment and in particular to develop a EU legal framework including measures on due diligence obligations for supply chains in the garment sector and measures to strengthen supply chain transparency and traceability.

Furthermore, an initiative called European Clothing Action Plan was launched at the EU level to improve the sustainability of textiles across their life cycle from design to end of use, with a view to implement a circular economy model with particular attention to waste reduction given that textiles waste has become a huge global concern (Moorhouse and Moorhouse 2017).

Waste prevention throughout the product life cycle and minimizing waste that ends up in incinerators or landfills are two key elements for the fashion industry's transition to circular economy.

\section{Garment Value Chain and Its Environmental Impact}

The fashion industry creates global value chains ${ }^{5}$ where the various stages of production take place in different countries; complex chains that are strongly connected to each other and include design, manufacture of materials and fashion products (such as textiles, clothing, footwear, leather and fur products) as well as their distribution and retail sale to final consumers ${ }^{6}$.

This is one of the most complex production models with significant upstream and downstream linkages, where global production processes have become increasingly fragmented into complex supply chains, with a multiplicity of actors, a high use of subcontracting and forms of illegal work.

Transparency and traceability throughout the supply chain therefore appear essential in the process of evolution towards more sustainable production and the transition to a circular economy in the fashion sector.

Undeniably, the fashion industry has a global impact on the economy and the environment.

5 Value chains include "the full range of activities that firms and workers do to bring a product/good or service from its conception to its end use and beyond. This includes activities such as design, production, marketing, distribution and support to the final consumer" (www.globalvaluechains.org/concept-tools).

6 In this article fashion, textile and clothing industry will be considered together. However, for sake of clarity it is worth recalling that the textile industry is involved in the production of yarn, textiles and fabrics, thus including also household textiles and industrial textiles; the clothing/apparel/fashion industry more narrowly concerns the production and life cycle of garments; and the fashion industry can also include shoes, bags, jewelleries and other accessories see (Sajn 2019). 
Indeed, garment value chains are major contributors to the economy in many countries all over the word, especially given that in the last decades a large part of the production has been transferred from Europe and North America to emerging and developing countries such as Bangladesh, Cambodia, China, India, Turkey and Vietnam.

On the other hand, this phenomenon-largely determined by the search for cheap labour and the approaching the areas of raw materials supply_has exacerbated the global environmental impact of the fashion industry, which some believe is the second most polluting sector immediately after the oil industry ${ }^{7}$.

However, it is not easy to estimate the environmental impacts of the sector given their variety and the fact that they occur all around the word ${ }^{8}$.

In fact, environmental impacts vary depending on the products, but in general according to a life cycle analysis it is possible to identify some critical issues.

With regards to raw materials, the main problems that have emerged are relatedto energy, water, soil consumption and to the use of biocides, with regards to natural fibres, and to the consumption of non-renewable resources, to emissions into the atmosphere, to discharges into the waters and generally to $\mathrm{CO}_{2}$ emissions, with regards to for synthetic fibres.

For the transformation processes, the problems are related to energy and water consumption, to use of chemicals, to the discharge of pollutants into the environment and to the production of waste and hazardous waste.

Significant impacts also occur in the transport and distribution phase, where most textile raw materials and final products are transported from production countries to end markets, with high fuel consumption and significant emissions of greenhouse gases.

However, the consumer use phase is considered to have the largest environmental impact in the life cycle of garments, due to the use of water, energy and chemicals for their maintenance (i.e., washing, tumble drying and ironing) and to the release of microplastics into water.

Finally, as mentioned above, much attention needs to paid to the end of life of the products that are still mainly sent, with some exceptions, to landfills or incineration.

Indeed, currently, once discarded, only $20 \%$ of clothing waste is collected for re-use and recycling at a global level (Koszewska 2018), while more than half of the clothes are not re-used or recycled and end up in undifferentiated waste, to then end up in landfills or burned in incinerators. Re-use and recycling also face some issues ${ }^{9}$. For example, in Europe, a large part of second hand clothes are exported to other countries, partly to East Asian or African countries, and this can represent a threat for local textile industries, as well as increase clothing waste in those countries that are unable to deal with it (Sajn 2019). On the other hand, less than $1 \%$ of the materials used in clothing are recycled back into clothing, mainly because there is still a lack of adequate technologies for this kind of recycling (Ellen Macarthur Foundation 2017). Finally, one also has to consider the waste derived from overproduction, given that a good part of the clothing produced remains unsold, as well as the waste generated through packaging, tags, hangers and bags.

\section{The EU Legal Framework}

The legislative and regulatory context is of fundamental importance for the sustainable growth of the fashion industry.

7 See the statement by the French Minister of the Environment, Brune Poirson, at the Copenhagen Fashion Summit on 13th of May 2019: "Le secteur est le deuxième secteur industriel le plus polluant au monde. Il faut lui donner une direction".

8 For some estimates see (European Commission Joint Research Center 2016; Global Fashion Agenda 2017a, 2017b; WRAP 2017).

9 Recycling of pre-consumption textile materials (originating from waste and overproduction) or post-consumption textile materials (i.e., at the end of life cycle of the product) means any recovery operation by which these materials are inserted in a new production process, subject to adequate preparatory treatments; re-use means instead the operation by which fabrics and garments are used again for the same purpose for which they were conceived, with a consequent extension of the life cycle of the product. See also the definitions of recycling and re-use in Article 3 of Directive 2008/98/EC on waste. 
The EU institution has adopted several measures applicable to the textile and clothing sector which contribute to the sustainable management of value chains in this sector, even with an impact in third countries involved in such chains.

With regard to labelling, it is worth recalling that in 2011, the EU adopted a regulation establishing harmonised provisions on the labelling and marking of textile products in order to eliminate barriers to the internal market in the textile sector and to guarantee consumers adequate information ${ }^{10}$. The EU also introduced the EU Ecolabel ${ }^{11}$, which is a voluntary label applicable to products with a low environmental impact throughout their life cycle, from the extraction of raw material through to production, use and disposal. In order to use the Ecolabel logo, the respect of the Ecolabel requirements must be independently assessed and verified; they concern the use of biocides, water consumption and water discharge, air emissions and the use of hazardous substances. It also covers product safety requirements for the consumer. Currently, twenty-three groups of products/services can apply for the European Ecolabel, among which are footwear and textiles ${ }^{12}$.

In addition, in 2013 the EU Commission adopted a package ${ }^{13}$ introducing common methods to measure and communicate the life cycle environmental performance of products and organisations. It is worth noting that the Product Environmental Footprint (PEF) pilot specifically addressed leather, footwear and t-shirts and the Organisation Environmental Footprint (OEF) pilot also addressed the retail sector.

A particularly significant regulation for the sector is the REACH Regulation ${ }^{14}$, which regulates the manufacture, import, marketing and end use of chemicals. The regulation applies to chemicals companies as well as textile manufacturers, tanners and shoemakers, using colorants, auxiliaries, adhesives and other substances needed to transform a raw material into a marketable finished product. Beside this one has to mention the Regulation on biocidal products ${ }^{15}$, which concerns the marketing and use of biocides and respect for its provisions by the fashion sector is necessary if products such as leather or textiles have been added with biocides.

Another legislation to recall is the 2010 Directive on industrial emissions (integrated pollution prevention and control, IPPC), which brings together seven previous legislative acts on industrial emissions and establishes rules to prevent and control pollution in the atmosphere, water and soil and to avoid the production of waste coming from industrial plants ${ }^{16}$. The plants that fall within the scope of application of the Directive can operate only if they are in possession of an authorization, and the EU Commission's conclusions on the best technologies available for each sector are the reference for establishing the conditions of authorization. For the textile sector, the Integrated Pollution Prevention and Control (IPPC) Reference Document on Best Available Techniques for the Textiles Industry was adopted in 2003 and is currently under review ${ }^{17}$.

Finally, as regards waste more specifically, the main reference in the Europe is the Waste Framework Directive (Directive 2008/98/EC), which sets up a legislative framework for the handling of waste in the

10 Regulation (EU) No. 1007/2011 on textile fiber names and related labelling and marking of the fiber composition of textile products.

11 Regulation (EC) No. 66/2010 on the EU Ecolabel.

12 New ecological criteria for the award of the EU Ecolabel for textile products were established in 2014 and for footwear in 2016 (See Commission Decision (EU) 2014/350 establishing the ecological criteria for the award of the EU Ecolabel for textile products; Commission Decision (EU) 2016/1349 establishing the ecological criteria for the award of the EU Ecolabel for footwear).

13 The package comprised the Communication COM (2013) 196 final "Building the Single Market for Green Products" and the Recommendation 2013/179/EU on the use of common methods to measure and communicate the life cycle environmental performance of products and organizations.

14 Regulation (EC) No. 1907/2006 concerning the Registration, Evaluation, Authorisation and Restriction of Chemicals $(\mathrm{REACH})$, establishing a European Chemicals Agency.

15 Regulation (EU) No. 528/2012 concerning the making available on the market and use of biocidal products Text with EEA relevance.

16 Directive 2010/75/EU on industrial emissions (integrated pollution prevention and control).

17 https://eippcb.jrc.ec.europa.eu/reference/txt.html. 
European Union ${ }^{18}$, establishing some fundamental principles such as the obligation to handle waste in a way to protect the environment and human health, the principle of the waste hierarchy ${ }^{19}$ and, in application of the polluter-pays principle, the requirement that the costs of disposal of waste are borne by the holder of waste, by previous holders or by the producers of the product from which the waste came ${ }^{20}$.

\section{Circular Fashion and Waste}

It is increasingly evident that the current linear economy model (take-make-dispose) has substantial limits and does not appear to be able to attain the sustainable development goals that now dominate the agenda of policy-makers at a global level. Increasing attention is therefore placed on the development of policies that allow a transition to a circular economy model.

As there is a huge number of definitions of circular economy ${ }^{21}$, I would consider as a starting point the definition given by the European Commission's Action Plan for a Circular Economy, where it is explained as an economy "where the value of products, materials and resources is maintained in the economy for as long as possible, and the generation of waste minimised" (European Commission 2015). In a nutshell, the circular economy model proposes the prolonged use of what is taken from nature, in order to reduce future access to primary resources and reduce waste production (Murray et al. 2017; Winans et al. 2017). It is therefore a multi-dimensional concept, which presents different fields of action: first, the order of priority in waste management, which sees landfill disposal as an extreme ratio; secondly, the enhancement of by-products and the connection of waste with the production and use of new raw materials (end-of-waste); thirdly, the attention to the production phase and the transition to a sustainable bioeconomy model in which the raw materials obtained from renewable sources replace raw materials obtained from non-renewable resources, such as fossil fuels, in order to abandon the model of linear economy "production-use-abandonment"22. In a simple way it can be said that the circular economy model is "shaped by the 3R (reduce, re-use, recycle) principles that should be applied throughout the whole cycle of production, consumption and return of resources" (Koszewska 2018) ${ }^{23}$.

The limits of the linear economy model appear clearly in the garment sector, where the need to move to a circular economy model is also highlighted by industry experts and practitioners. In fact, it has been highlighted how the circular economy is one of the strategic areas of innovation for the future development of the textile and clothing sector in Europe and beyond ${ }^{24}$.

In the fashion sector, a circular vision involves promoting the extension of the end of life of textile and clothing products, their recycling and re-use for other production cycles, on the one hand, and the use of ecological and sustainable raw materials, on the other. In other words, circular fashion aims to minimize waste and keep materials within the production and consumption loop as long as possible.

18 Directive 2008/98/EC on waste.

19 The waste hierarchy that apply as a priority order in waste prevention and management legislation and policy is the following: (a) prevention; (b) preparing for re-use; (c) recycling; (d) other recovery, e.g., energy recovery; and (e) disposal.

20 On EU waste law see among others (Van Calster 2015; Fischer 2011; Scotford 2009; Koch and Reese 2005).

21114 definitions of circular economy were identified and codified already in 2017 (Kirchherr et al. 2017).

22 See whereas 40 of Directive (EU) 2018/851 amending Directive 2008/98/EC: "Fostering a sustainable bio-economy can contribute to decreasing the Union's dependence on imported raw materials. Bio-based recyclable products and compostable bio-degradable products could represent therefore an opportunity to stimulate further research and innovation and to substitute fossil fuel-based feedstock with renewable resources". With regards to bioeconomy it is worth mentioning that the Europe's Bioeconomy Strategy was launched in 2012 and updated in 2018 (European Commission 2018a). However, even though the Bioeconomy Strategy and the Action Plan for a Circular Economy have overlapping objectives and areas of intervention, where sustainability represents the core of both approaches, unfortunately they do not have connected policy agenda.

23 Actually it should be noted that various $\mathrm{R}$ frameworks have been used by scholars and practitioners, among which the $3 \mathrm{R}$ framework is the most prominent, while the $4 \mathrm{R}$ framework (reduce, re-use, recycle, recover) is at the core of the EU Waste Framework Directive (Kirchherr et al. 2017).

24 See (ETP Fibres Textiles Clothing 2016). 
The use of certain raw materials and the re-use and recycling in a circular economy system have the objective of reducing, if not eliminating, waste as the basis for a sustainable fashion system.

If the transition to circular economy responds to a logic that is both environmental and economic, achieving the goal of a society of recovery and recycling necessarily requires a framework of legal rules that are certain and uniform, if not globally, at least at European level, in order to ensure adequate consideration of both environmental and economic interests (Backes 2017).

In this perspective, the European Union has developed the above-mentioned Action Plan for a Circular Economy which provides for horizontal and vertical measures to be taken forward in line with the better regulation principles, including where appropriate an impact assessment (de Römph 2018; Hughes 2017).

In particular, regarding waste, the application of the circular economy principles implies a paradigm shift where waste is increasingly treated as a resource (Masieri 2018). In this perspective, in 2018 the EU institution adopted some legislative measures aimed at adapting the existing legislation to the objectives of the transition to circular economy, which must be implemented in the EU Member States within two years.

Since this essay is not dedicated to an in-depth examination of all the innovations introduced at European level, we will limit ourselves to taking into consideration the provisions that directly or indirectly concern the fashion sector.

First of all, as regards the objectives for the transition to circular economy, it can be observed that following the amendments introduced in $2018^{25}$, the Waste Framework Directive requires for the first time that the Member States set up separate waste collection for textiles, including a deadline for implementation, i.e., 1 January, $2025^{26}$. This provision falls within the broader perspective of the diffusion of separate collection "In order to avoid waste treatment which locks in resources at the lower levels of the waste hierarchy, increase preparing for re-use and recycling rates, enable high-quality recycling and boost the uptake of quality secondary raw materials" 27 . In particular, with regard to textiles, this appears to be fundamental to ensure that textiles are collected and handled in a correct manner so that their value is maintained through re-use or recycling. In this perspective, it is in fact required that by the end of 2024 the Commission shall consider the setting of preparing for re-use and recycling targets also for textile waste ${ }^{28}$.

In addition, more generally, the Directive introduce targets for the recycling of municipal waste, with a consequent impact on textiles, given that textiles fall under the new definition of "municipal waste", obviously if they do not derive from productive activities. In particular, 55\% of municipal waste will have to be recycled by $2025,60 \%$ by 2030 and $65 \%$ by $2035^{29}$.

At the same time, other provisions of the circular economy package may also have an impact on reducing the environmental impact of textiles and clothing. In particular, the Landfill Directive provides that by 2035 municipal waste disposed of in landfills must be reduced to a maximum of $10 \%$ of the total municipal waste, including textile waste ${ }^{30}$. Finally, given the impact of packaging also in the fashion sector, the introduction in the Packaging and Packaging Waste Directive of an overall recycling target of $65 \%$ of materials by 2025 and $70 \%$ by 2030 is certainly relevant ${ }^{31}$.

Then, in the context of the fashion industry, the definitions of waste, by-product and end-of-waste play a central role.

25 Directive (EU) 2018/851 amending Directive 2008/98/EC on waste.

26 New Article 11(1), Directive 2008/98/EC.

Whereas 41 of Directive (EU) 2018/851 amending Directive 2008/98/EC.

New Article 11(6), Directive 2008/98/EC.

New Article 11(2), Directive 2008/98/EC.

New Article 5(5), Directive 1999/31/EC on the landfill of waste, modified by Directive (EU) 2018/850.

New Article 6(1), Directive 94/62/EC on packaging and packaging waste, modified by Directive (EU) $2018 / 852$. 
According to Directive 2008/98/EC "waste" means any substance or object which the holder discards or intends or is required to discard ${ }^{32}$.

The issue of the definition of the concept of waste and of the criteria for identifying the concept of by-product or secondary raw material has been and is the subject of wide debate in all the Member States $^{33}$ and is of particular importance for the fashion and textile sector.

It seems appropriate to recall that in the interpretation provided by the European Court of Justice prior to the entry into force of Directive 2008/98/EC ${ }^{34}$, the subjective element, namely the intention of the producer or holder to dispose of the waste, appeared central, but the concept of waste "is not to be understood as excluding substances and objects which are capable of economic reutilization" by third parties and therefore "does not presume that the holder disposing of a substance or an object intends to exclude all economic reutilization of the substance or object by others" ${ }^{\prime \prime 3}$. As a consequence, there is no reason to hold that the provisions on waste "apply to goods, materials or raw materials which have an economic value as products regardless of any form of processing and which, as such, are subject to the legislation applicable to those products"36. However, according to the Court, the concept of waste had to be interpreted "widely in order to limit its inherent risks and pollution" and therefore "the reasoning applicable to by-products should be confined to situations in which the re-use of the goods, materials or raw materials is not a mere possibility but a certainty, without any further processing prior to re-use and as an integral part of the production process ${ }^{\prime 37}$.

This led to Directive 2008/98/EC, where Articles 5 and 6 introduced specific provisions on by-products and end-of-waste status that show a change of perspective with respect to the concept of waste which is then continued with the circular economy package $e^{38}$, where it is stated that it is necessary to ensure that "waste is valued as a resource" and to facilitate "the transition to more sustainable material management", rather than speaking of simple waste management ${ }^{39}$.

With particular regard to by-products, EU legislation currently indicates that "In order to promote sustainable use of resources and industrial symbiosis, Member States [shall] take appropriate measures to facilitate the recognition as a by-product of a substance or an object resulting from a production process the primary aim of which is not the production of that substance or object if the harmonised conditions established at Union level are respected" ${ }^{\prime \prime 0}$. The Commission should be empowered to adopt implementing acts in order to establish detailed criteria on the uniform application of the conditions of the by-product status. However, where criteria have not been set at Union level, they can be established by Member States. As regards the aforementioned conditions, it should be noted that they have not been subject to modification and they provide that a substance or object is considered not to be waste, but to be a by-product, if (a) further use of the substance or object is certain; (b) the substance or object can be used directly without any further processing other than normal industrial practice; (c) the substance or object is produced as an integral part of a production process;

32 Article 3 n.1, Directive 2008/98/EC.

33 Most recently in relation to circular economy see (Turunen 2018).

34 See Article 1(1)(a) of Directive 75/442/EEC on waste: "'waste' means any substance or object which the holder disposes of or is required to dispose of pursuant to the provisions of national law in force"; and Article 1(1)(a) of Directive 2006/12/EC on waste: "'waste' shall mean any substance or object in the categories set out in Annex I which the holder discards or intends or is required to discard". On the definition of waste before the Directive 2008/98/EC entered into force see among others (de Sadeleer 2005a, 2005b; Krämer 2003; Cheyne 2002; Pike 2002; Purdue and van Rossem 1998).

35 See joined cases C-206/88 and C-20788, Vessoso and Zanetti, [1990] ECR I-1461, paragraphs 7 and 13

36 See case C-9/00, Palin Granit Oy and Vehmassalon kansanterveystyön kuntayhtymän hallitus, [2002] ECR I-03533, paragraph 35 .

37 See case C-/9/00 cit., paragraph 36.

38 As underlined by Communication COM (2014) 0398 "Towards a circular economy: A zero waste programme for Europe", at paragraph 2.1: "Some EU policies and instruments already provide tools and incentives in line with the circular economy model. The waste hierarchy that underlies our waste legislation is leading progressively to adoption of the preferred options of waste prevention, preparation for re-use and recycling, and discourages landfilling".

39 See whereas 2 of Directive (EU) 2018/851 amending Directive 2008/98/EC.

40 Whereas 16 of Directive (EU) 2018/851 amending Directive 2008/98/EC. With regards to legal and theoretical approaches to industrial symbiosis as part of a circular economy see (Steenmans et al. 2017). 
and (d) further use is lawful, i.e., the substance or object fulfils all relevant product, environmental and health protection requirements for the specific use and will not lead to overall adverse environmental or human health impacts ${ }^{41}$.

With regard to end-of-waste, Article 6 of Directive 2008/98/EC has been almost completely rewritten with the aim of providing "operators in markets for secondary raw materials with more certainty as to the waste or non-waste status of substances or objects and to promote a level playing field" ${ }^{\prime 2}$. To this purpose it is important that Member States take appropriate measures to ensure that waste that has undergone a recovery operation is considered to have ceased to be waste if it complies with all the conditions laid down in the new Article 6(1) of Directive 2008/98/EC.

In particular the new Article 6 does not provide anymore that "Certain specified waste" shall cease to be waste when it has undergone a recovery, but considers "waste" which has undergone a recycling or other recovery ${ }^{43}$ operation and complies with the conditions specified therein. According to Article 6 waste can be considered to have ceased to be waste if: "(a) the substance or object is to be used for specific purposes; (b) a market or demand exists for such a substance or object; (c) the substance or object fulfils the technical requirements for the specific purposes and meets the existing legislation and standards applicable to products; and (d) the use of the substance or object will not lead to overall adverse environmental or human health impacts".

Where appropriate, the Commission shall establish detailed criteria on the uniform application of the end-of-waste status ${ }^{44}$ and according to the Directive (EU) 2018/851 amending Directive 2008/98/EC, specific end-of-waste criteria should be considered at least, inter alia, for textiles ${ }^{45}$. Where criteria have not been set at Union level, Member States may establish detailed criteria to certain types of waste and where criteria have not been set at either Union or national level, a Member State may decide on a case-by-case basis ${ }^{46}$.

In addition, the Commission, besides having the power to develop guidelines for the interpretation of the requirements set out in this Directive, including on the definition of waste, prevention, re-use, preparing for re-use, recovery, recycling and disposal, is requested to develop guidelines on the definitions of municipal waste and backfilling ${ }^{47}$.

In any case, the application of rules on by-products and end-of-waste should be without prejudice to other provisions of Union law, particularly provisions on shipments of waste, legislation on chemicals and legislation concerning the placing on the market of certain products ${ }^{48}$.

41 Article 5, Directive 2008/98/EC.

42 Whereas 17 of Directive (EU) 2018/851 amending Directive 2008/98/EC.

43 In this perspective the new definition of "material recovery" plays a central role, as it aims at clearly distinguishing energy recovery from all other forms of recovery, including any recovery operation, other than energy recovery and the reprocessing into materials that are to be used as fuels or other means to generate energy. The definition furthermore specifies that it includes, inter alia, preparing for re-use, recycling and backfilling (new Article 3 n. 15a of Directive 2008/98/EC)

44 New Article 6(2) of Directive 2008/98/EC. This criteria shall include: "(a) permissible waste input material for the recovery operation; (b) allowed treatment processes and techniques; (c) quality criteria for end-of-waste materials resulting from the recovery operation in line with the applicable product standards, including limit values for pollutants where necessary; (d) requirements for management systems to demonstrate compliance with the end-of-waste criteria, including for quality control and self-monitoring, and accreditation, where appropriate; and (e) a requirement for a statement of conformity".

45 Whereas 18 of Directive (EU) 2018/851 amending Directive 2008/98/EC. It is worth recalling that since 2008, the Joint Research Center (JRC) has collaborated closely with Directorate General (DG) Environment in the implementation of the mechanism of end-of-waste criteria. In this context, the JRC carried out a scientific analysis of different waste streams that are candidates to being considered end-of-waste, including textiles, and developed a methodology for determining end-of-waste criteria, based on a number of case studies. See https://susproc.jrc.ec.europa.eu/activities/waste/index.html\#.

46 New Article 6(3) and (4) of Directive 2008/98/EC. The original Article 6(4) provided that in case of lack of criteria at EU level, Member States may decide case by case whether certain waste has ceased to be waste taking into account the applicable case law, while now the reference to case law has been deleted. See also (Retail Forum for sustainability 2013). In general on end-of-waste regulation see among others (Turunen 2017; Brown 2014).

47 New Article 38(2) of Directive 2008/98/EC.

48 To this regard see (European Commission 2018b). In addition it is also worth recalling the judgement of the Court of Justice of the European Union (EUCJ) in the case Lapin elinkeino-, liikenne- ja ympäristökeskuksen liikenne ja infrastruktuuri -vastuualue v Lapin luonnonsuojelupiiri ry (Case C-358/11), where the Court considered the interaction of Waste Framework Directive and 
Moreover, the new Article 9, which is devoted to the prevention of waste, provides that Member States shall take measures to prevent waste generation which may have an impact on the fashion industry as, inter alia, they shall at least (i) promote and support sustainable production and consumption models; (ii) encourage the design, manufacturing and use of products that are resource-efficient, durable, reparable and re-usable; (iii) encourage, as appropriate and without prejudice to intellectual property rights, the availability of spare parts, instruction manuals, technical information, or other instruments, equipment or software enabling the repair and re-use of products without compromising their quality and safety; (iv) reduce waste generation in processes related to industrial production and manufacturing, taking into account best available techniques; (v) promote the reduction of the content of hazardous substances in materials and products; (vi) reduce the generation of waste, in particular waste that is not suitable for preparing for re-use or recycling; (vii) identify products that are the main sources of littering, notably in natural and marine environments, and take appropriate measures to prevent and reduce litter from such products. More specifically, according to Article 9 (1)(d) Member States shall also encourage the re-use of products and the setting up of systems promoting repair and re-use activities, including in particular for textile, as well as packaging.

More generally, the Directive establishes, among other things, that Member States should make use of economic instruments and other measures to provide incentives for the application of the waste hierarchy such as those specified in Annex IV of the Directive, which includes several measures that can apply to the textiles and clothing sector, such as charges and restrictions for the landfilling and incineration of waste, 'Pay-as-you-throw' schemes for waste producers, sustainable public procurement to encourage better waste management and the use of recycled products and materials, fiscal measures to enhance recycle and re-use, incentives for local authorities to promote waste prevention and intensify separate collection schemes and extended producer responsibility schemes.

\section{The Extended Producer Responsibility}

According to the Organisation for Economic Co-operation and Development (OECD) the Extended Producer Responsibility (EPR) is "an environmental policy approach in which a producer's responsibility for a product is extended to the post-consumer stage of a product's life cycle ${ }^{\prime \prime 4}$.

The European institutions have turned their attention to this policy tool by introducing it first in Directive 75/442/EEC on waste where Article 15 provided that "In accordance with the 'polluter pays' principle, the cost of disposing of waste must be borne by:- the holder who has waste handled by a waste collector or by an undertaking ...., and/or-the previous holders or the producer of the product from which the waste came" ${ }^{\prime 50}$. The EPR was therefore introduced into the legislation of some European countries in order to involve producers in the management of packaging waste, as for example in Germany, also to meet the provisions of Directive 94/62/EC on packaging and packaging waste, although the Directive itself does not impose this policy. Then, the European Union extended the use of this tool to specific waste streams ${ }^{51}$, and finally introduced it in the Waste Framework

REACH Regulation for end-of-waste, affirming that hazardous waste may be returned as secondary raw materials, and that REACH may play an important role in this respect. See also (Alaranta and Turunen 2017).

49 In the 1990s, the Organization for Economic Co-operation and Development (OECD) launched a reflection aimed at defining the principle of Extended Producer Responsibility and the conditions for its implementation which led to the publication in 2001 of a Guidance Manual for Governments on Extended Producer Responsibility (OECD, Guidance Manual for Governments on Extended Producer Responsibility, 2001), that was updated in September 2016 (OECD, Extended Producer Responsibility Updated Guidance for Efficient Waste Management, 2016). It seems appropriate to recall that the concept was defined for the first time in the early 1990s by Thomas Lindhqvist: see Thomas Lindhqvist and Karl Lidgren, "Modeller för förlängt producentansvar" ("Models for Extended Producer Responsibility," in Swedish), 26 October, 1990, published by the Ministry of the Environment in "Från vaggan till graven-sex studier av varors miljöpåverken" ("From the Cradle to the Grave-six studies of the environmental impact of products," in Swedish), DC 1991:0; in English (. Lindhqvist 1992).

50 Directive 75/442/EEC on waste, as modified by Directive 91/156/EEC.

51 Directive 2000/53/CE on end-of life vehicles, Directive 2006/66/EC on batteries and accumulators and waste batteries and accumulators and Directive 2012/19/EU on waste electrical and electronic equipment. 
Directive 2008/98, that established some principles regarding the implementation of EPR schemes by the Member States.

The 2018 amendment introduces a new definition of "extended producer responsibility scheme" and modifies the material rules by amending Article 8 and inserting a new Article $8 \mathrm{a}^{52}$. According to the new definition "extended producer responsibility scheme" means a set of measures taken by Member States to ensure that producers of products bear financial responsibility or financial and organisational responsibility for the management of the waste stage of a product's life cycle ${ }^{53}$.

The adoption of this type of measures is therefore left to the discretion of the Member States, that now must comply with the provisions of the Directive and in particular with the general minimum requirements set by the new Article 8a, introduced precisely in order to try to harmonize the various existing and future national regulations ${ }^{54}$. Indeed, the new "general minimum requirements should reduce costs and boost performance, as well as ensure a level playing field, including for small and medium-sized enterprises and e-commerce enterprises, and avoid obstacles to the smooth functioning of the internal market. They should also contribute to the incorporation of end-of-life costs into product prices and provide incentives for producers, when designing their products, to take better into account recyclability, reusability, reparability and the presence of hazardous substances" 55 . Particularly for textiles it is interesting that the financial contributions paid by the producer of the product to comply with its extended producer responsibility obligations should also take into account the durability, reparability, re-usability and recyclability of the product ${ }^{56}$.

The EPR therefore accompanies the traditional responsibility of those who, using the product, generate waste or those who hold the waste. In practice, the producers take over the responsibility for the management of the waste stage of a product's life cycle, including separate collection, sorting and treatment operations, and which can extend to waste prevention and to the reusability and recyclability of products. It is not a liability; it may be a merely financial responsibility or a "financial and organisational responsibility". Even if the EPR is based on the individual responsibility of the producer, an EPR system can be either an individual scheme when a producer organises its own system, or a collective system when several producers decide to collaborate and thus transfer their responsibility to a specific producer responsibility organisation (PRO), but collective schemes are much more common. PROs potentially exert three main functions, which can be implemented in different ways: financing the collection and treatment of the targeted waste, organising and supervising these activities and managing the corresponding data.

The provision of a system focused on extended producer liability appears to be the logical transposition of the polluter pays principle and the principles underlying the waste hierarchy and, today, is a key tool in the promotion of the circular economy.

More specifically, EPR forms an essential part of efficient waste management and in particular can represent a key tool to implement the requirement of separate collection of textiles that should be achieved by 2025. However, until now France is the only Member State that introduced an EPR system for the textile sector since 2008, while in the rest of EU the experience with separate collection of textiles is rather limited and mostly carried out on individual basis by charities or brand owners. Against this background, it is probable however that the novelties in waste management introduced by the circular economy package, where the EPR plays an essential role, will lead to the introduction

52 Article 8 of Directive 2008/98/EC provided for the opportunity of introducing the extended producer responsibility, but in a very general manner, thus leaving much discretion to Member States.

53 Article 3(21) of Directive 2008/98/EC.

54 It is provided that where extended producer responsibility schemes are established Member States shall: define in a clear way the roles and responsibilities of all relevant actors involved; in line with the waste hierarchy, set waste management targets, aiming to attain at least the quantitative targets relevant for the extended producer responsibility scheme; ensure that a reporting system is in place; ensure equal treatment of producers of products regardless of their origin or size, without placing a disproportionate regulatory burden on producers.

55 See whereas 22 of Directive (EU) 2018/851.

56 See new Article 8a of Directive 2008/98/EC. 
of EPR systems for textiles also in other Member States, that will have to comply with the minimum requirements set by Article 8a of Directive 2008/98/EC.

The French EPR system for textiles in operation since 1 January, 2007 is based on the EPR principle codified in Article L. 541-10 of the Code de 1'Environnement ${ }^{57}$. On the basis of this principle, in 2006 the French legislator introduced a new Article L. 541-10-3 that established that all natural or legal persons who place on the national market in a professional capacity new clothing textile products, footwear or household linen intended for households are required to contribute to or provide for the recycling and treatment of waste from these products ${ }^{58}$. These subjects are therefore requested to either financially contribute to a collective system or to set up an individual system for the recycling and treatment of these kind of waste. In the system currently in place, the various producers pay a financial contribution to the subject authorized by the Public Administration, Eco TLC, for the management of a collective collection system ${ }^{59}$.

\section{Final Remarks}

As already highlighted as starting point, the fashion industry has to play an important role in the path towards sustainability and circular economy, and circular economy especially is one of the strategic areas of innovation for the future development of the textile and clothing sector in Europe and beyond.

In this perspective, given the fact that textiles and clothing waste has become a huge global concern, we have emphasized how the EU circular economy package is opening new scenarios for pre-consumer waste (waste materials or processing waste) and post-consumer waste (textiles or other items) in the garment value chain.

Indeed, besides establishing targets for textile waste for the first time, the EU package includes the use of economic instruments and other measures to provide incentives for the application of the waste hierarchy, such as the extended producer responsibility, and appears to introduce a change in the concept of waste that is increasingly treated as a resource, with a significant impact on the fashion industry.

Funding: This research received no external funding.

Conflicts of Interest: The author declares no conflict of interest.

\section{References}

Alaranta, Joonas, and Topi Turunen. 2017. Drawing a Line between European Waste Regulation and European Chemicals Regulation. RECIEL 26: 163-73. [CrossRef]

Anguelov, Nikolay. 2016. The Dirty Side of the Garment Industry: Fast Fashion and its Negative Impact on Environment and Society. Boca Raton: Taylor \& Francis Group.

Backes, Chris. 2017. Law for a Circular Economy. The Hague: Eleven International Publishing.

Billet, Philippe. 2008. La nouvelle trame du recyclage des déchets textiles. La Semaine Juridique Administrations et Collectivités Territoriales, July 14, $\mathrm{n}^{\circ} 29$, act. 632.

Brown, Vincent. 2014. The "End of Waste" under EU Law. Natural Resources E Environment 28: 41-45.

Bukhari, Mohammad Abdullatif, Ruth Carrasco-Gallego, and Eva Ponce-Cueto. 2018. Developing a national programme for textiles and clothing recovery. Waste Management $\mathcal{E}$ Research 36: 321-31.

57 Article L. 541-10 code de l'environnement: “II. En application du principe de responsabilité élargie du producteur, il peut être fait obligation aux producteurs, importateurs et distributeurs de ces produits ou des éléments et matériaux entrant dans leur fabrication de pourvoir ou de contribuer à la prévention et à la gestion des déchets qui en proviennent".

58 Article L. 541-10-3 code de l'environnement: "A compter du 1er janvier 2007, toutes les personnes physiques ou morales qui mettent sur le marché national à titre professionnel des produits textiles d'habillement, des chaussures ou du linge de maison neufs destinés aux ménages sont tenues de contribuer ou de pourvoir au recyclage et au traitement des déchets issus de ces produits".

59 For an analysis of the French EPR system for textiles see (Billet 2008; Bukhari et al. 2018). 
Cheyne, Ilona. 2002. Definition of Waste in EC Law. Journal of Environmental Law 14: 61-73. [CrossRef] de Römph, Thomas J. 2018. The Legal Transition Towards a Circular Economy-EU Environmental Law Examined. Hasselt: Universiteit Hasselt.

de Sadeleer, Nicolas. 2005b. EC Waste Law or How to Juggle with Legal Concepts: Drawing the Line between Waste, Residues, Secondary Materials, By-products, Disposal and Recovery Operations. JEEPL 6: 458-77. [CrossRef]

de Sadeleer, Nicolas. 2005a. New Perspective on the Definition of Waste in EC Law. JEEPL 1: 46-58. [CrossRef]

ETP Fibres Textiles Clothing. 2016. Towards a 4th Industrial Revolution of Textiles and Clothing -Strategic Innovation and Research Agenda for the European Textile and Clothing Industry. Available online: http: //www.textile-platform.eu (accessed on 30 October 2019).

European Commission Joint Research Center. 2016. Environmental Improvement Potential of Textiles. Luxembourg: Publications Office of the European Union.

Ellen Macarthur Foundation. 2017. A New Textiles Economy: Redesigning Fashion's Future. Available online: http://www.ellenmacarthurfoundation.org/publications (accessed on 30 October 2019).

European Commission. 2015. Communication "Closing the Loop-An EU Action Plan for the Circular Economy". COM (2015) 614. Brussels: European Commission.

European Commission. 2017. Staff Working Document, Sustainable Garment Value Chains through EU Development Action. SWD (2017) 147. Brussels: European Commission.

European Commission. 2018a. A Sustainable Bioeconomy for Europe: Strengthening the Connection between Economy, Society and the Environment. Updated Bioeconomy Strategy. Brussels: European Commission.

European Commission. 2018b. Communication on the Implementation of the Circular Economy Package: Options to Address the Interface between Chemical, Product and Waste Legislation. COM (2018) 32. Brussels: European Commission.

European Parliament. 2017. Resolution of 27 April 2017 on the EU Flagship Initiative on the Garment Sector. 2016/2140(INI). Brussels: European Parliament.

Fischer, Christian. 2011. The development and achievements of EU waste policy. Journal of Material Cycles and Waste Management 13: 2-9. [CrossRef]

Fletcher, Kate. 2014. Sustainable Fashion and Textiles. London and New York: Routledge, p. 51.

Global Fashion Agenda. 2017a. A Call to Action for a Circular Fashion System. Copenhagen: Global Fashion Agenda.

Global Fashion Agenda. 2017b. Pulse of the Fashion Industry. Boston: The Boston Consulting Group, Copenhagen: Global Fashion Agenda.

Gordon, Jennifer Farley, and Colleen Hill. 2015. Sustainable Fashion: Past, Present, and Future. London: Bloomsbury.

Hughes, Richard. 2017. The EU Circular Economy package-Life cycle thinking to life cycle law? Proceedings of the 24th CIRP Conference on Life Cycle Engineering. Procedia CIRP 61: 10-16. [CrossRef]

Kirchherr, Julian, Denise Reike, and Marko Hekkert. 2017. Conceptualizing the circular economy: An analysis of 114 definitions. Resources, Conservation \& Recycling 127: 221-32.

Koch, Hans-Joachim, and Moritz Reese. 2005. Revising the Waste Framework Directive: Basic Deficiencies in European Waste Law and Proposals for Reform. JEEPL 2: 441-57.

Koszewska, Malgorzata. 2018. Circular economy-Challenges for the textile and clothing industry. AUTEX Research Journal 4: 337-47. [CrossRef]

Krämer, Ludwig. 2003. Distinction between Product and Waste in Community Law. Environmental Liability 1: 3-13.

Kuik, Onno. 2004-2005. Fair trade and ethical labeling in the clothing, textile and footwear sector: The case of blue jeans. ILSA Journal of International and Comparative Law 11: 619-35.

Li, Yongjian. 2014. Governance of Sustain Supply Chains in the Fast Fashion Industry. European Management Journal 32: 823-36. [CrossRef]

Lindhqvist, Thomas. 1992. Extended Producer Responsibility. In Extended Producer Responsibility as a Strategy to Promote Cleaner Products. Lund: Department of Industrial Environmental Economics, Lund University, pp. $1-5$.

Luz, Claudio. 2007. Waste Couture: Environmental Impact of the Clothing Industry. Environmental Health Perspectives 115: A448-54.

Masieri, Carlo. 2018. L'economia circolare nelle fonti europee e il possibile cambiamento di paradigma nell'ambito dei rifiuti. In Città Sostenibili. Edited by Valerio Bini, Alice Dal Borgo and Cristiana Fiamingo. Campospinoso: Altravista, pp. 173-86. 
Moorhouse, Debbie, and Danielle Moorhouse. 2017. Sustainable Design: Circular Economy in Fashion and Textiles. The Design Journal 20: 1948-59. [CrossRef]

Murray, Alan, Keith Skene, and Kathryn Haynes. 2017. The Circular Economy: An Interdisciplinary Exploration of the Concept and Application in a Global Context. Journal of Business Ethics 140: 369-80. [CrossRef]

Muthu, Subramanian Senthilkannan. 2014. Assessing the Environmental Impact of Textiles and the Clothing Supply Chain. Cambridge: Elsevier.

Pike, Jeremy. 2002. Waste Not Want Not: Wider Definition of 'Waste'. Journal of Environmental Law 14: 197-208.

Purdue, Michael, and Arthur van Rossem. 1998. The Distinction between Using Secondary Raw Materials and the Recovery of Waste: The Directive Definition of Waste. Journal of Environmental Law 10: 116-45.

Remy, Nathalie, Eveline Speelman, and Steven Swartz. 2016. Style That's Sustainable: A New Fast-Fashion Formula. New York: McKinsey.

Retail Forum for sustainability. 2013. Sustainability of Textiles. Available online: http://ec.europa.eu/environment/ industry/retail/pdf/issue_paper_textiles.pdf (accessed on 30 October 2019).

Sajn, Nikolina. 2019. Environmental Impact of the Textile and Clothing Industry: What Consumers Need to Know. Brussels: European Parliamentary Research Service.

Scotford, Eloise. 2009. The New Waste Directive-Trying to Do it All ... An Early Assessment. Environmental Law Review 11: 75-96. [CrossRef]

Singh, Ganit. 2017. Fast Fashion has Changed the Industry and Economy. Foundation for Economic Education. Available online: https:/fee.org/articles/fast-fashion-has-changed-the-industry-and-the-economy/ (accessed on 30 October 2019).

Slater, Keith. 2003. Environmental Impact of Textiles: Production, Processes and Protection. Cambridge: Woodhead Publishing.

Steenmans, Katrien, Jane Marriott, and Rosalind Malcolm. 2017. Commodification of Waste: Legal and Theoretical Approaches to Industrial Symbiosis as Part of a Circular Economy. University of Oslo Faculty of Law Legal Studies Research Paper Series No. 2017-26; Oslo: University of Oslo.

Toprak, Tuba, and Pervin Anis. 2017. Textile industry's environmental effects and approaching cleaner production and sustainability, an overview. Journal of Textile Engineering \& Fashion Technology 2: 429-42.

Turker, Duygu, and Ceren Altuntas. 2014. Sustainable supply chain management in the fast fashion industry: An analysis of corporate reports. European Management Journal 32: 837-49. [CrossRef]

Turunen, Topi. 2017. Deconstructing the Bottlenecks Caused by Waste Legislation: The End-of-Waste Regulation. JEEPL 14: 186-207. [CrossRef]

Turunen, Topi. 2018. The Concepts of Waste and Non-Waste in the Circular Economy. Joensuu: University of Eastern Finland.

Van Calster, Geert. 2015. EU Waste Law. Oxford: Oxford University Press.

Winans, Kiara, Alissa Kendall, and Huiqiong Deng. 2017. The history and current applications of the circular economy concept. Renewable and Sustainable Energy Reviews 68: 825-33. [CrossRef]

WRAP. 2017. Mapping Clothing Impacts in Europe: The Environmental Cost. Banbury: WRAP.

Zerbo, Julie. 2016. Fast Fashion. The Fashion Law. Available online: http://www.thefashionlaw.com/learn/fastfashions-green-initiatives-dont-believe-the-hype (accessed on 30 October 2019).

(C) 2019 by the author. Licensee MDPI, Basel, Switzerland. This article is an open access article distributed under the terms and conditions of the Creative Commons Attribution (CC BY) license (http://creativecommons.org/licenses/by/4.0/). 



\title{
Digital Market, Bloggers, and Trendsetters: The New World of Advertising Law
}

\author{
Mariacristina Reale \\ Department of Law, Economics and Culture, University of Insubria, 22100 Como, Italy; \\ cristina.reale@uninsubria.it
}

Received: 23 July 2019; Accepted: 25 August 2019; Published: 3 September 2019

\begin{abstract}
The importance of digital marketing is continuously growing, at least in the present economic phase. Within this sector, fashion bloggers play a crucial role, which reflects the relevance of fashion on an economic and a social level, as already highlighted in Georg Simmel's pioneering study. New communication opportunities made available by the development of digital technologies shed more light on this phenomenon. One of the main concerns is the need to guarantee the transparency and the correctness of commercial communications shared through social media in order to ensure the consumers' full freedom of choice. However, can traditional rules on advertising be considered sufficient, or is there a need for ad hoc rules? Can consumers' protection be reconciled with other values such as the creative freedom of advertisers and, more generally, the freedom of expression? Thus far, interventions by self-regulatory bodies and independent authorities, both at national and international levels, have proven to be effective, even if more "classic" regulatory interventions may occur in the future. After a short reference to the literature concerning fashion as a social phenomenon, the contribution focuses on the main solutions adopted in Italy and in Europe.
\end{abstract}

Keywords: fashion; influencer marketing; online advertising; self-regulation

\section{Introduction}

The development of digital technologies has not only opened new opportunities on an economic level but has also determined the appearance of new rights and the consequent need to protect them.

As regards marketing techniques, the advent of the Internet has introduced a veritable revolution, prompting companies to rethink their methods of interaction with suppliers and customers and build more solid and lasting relationships with them ${ }^{1}$. One of the main features of the so-called digital marketing consists precisely of exploiting Internet infrastructures and technologies in order to create an interactive relationship with consumers, understand their needs and desires, and succeed in promoting products or services to satisfy them.

This worldwide phenomenon has also imposed a "new dimension" in the process of implementation of the single market within the European Union. In 2015, the European Commission launched a strategy for the Digital Single Market, identifying a series of political priorities to allow people, consumers, and businesses to benefit fully from the opportunities offered by the Internet and digital technologies and to bring down regulatory and administrative barriers that could prevent the achievement of these purposes ${ }^{2}$.

In this new context where innovation and changes follow each other rapidly, traditional regulatory tools often prove to be ineffective or even insufficient to guarantee adequate protection of the different

1 See the definition of digital marketing in www.glossariomarketing.it.

2 Communication from the Commission to the European Parliament, the Council, the European Economic and Social Committee and the Committee of the Regions, A Digital Single Market Strategy for Europe, COM (2015) 192 final. 
interests at stake. An example is represented by the influencer marketing, a phenomenon that has spread from the fashion market to other economic sectors, acquiring a latu sensu social relief, and has represented a testing ground for the effectiveness of the rules governing commercial communication and advertising in general. It is therefore interesting to describe its main features and analyze the solutions adopted in some countries and at a supranational level-mainly in terms of self-regulation-with the purpose to balance consumers' protection and the legitimate interests of advertisers as well as creative and expressive freedoms of the various actors involved in this particular communication technique.

\section{The Social Relevance of the Fashion World Meeting New Technologies: A Brief Overview}

The fashion industry in particular has proven able to exploit the emerging opportunities introduced by digital marketing, increasing online sales services, and transforming its communication strategies (Foglio 2017; Dara 2017). Its versatility may be seen as one of the reasons behind its importance as a social phenomenon. After all, fashion has often represented a privileged field of interdisciplinary analysis and has been investigated under philosophical, aesthetic, cultural, and economic perspectives by studies that have also explored its different languages as well as its multiple meanings on the social level (Barthes; Baldini 2008). Within the wide literature devoted to it, an almost obligatory reference point is the essay written by Georg Simmel at the beginning of the twentieth century ${ }^{3}$.

According to the German sociologist and philosopher, fashion reflects two typical impulses of human nature: the tendency to imitate a given model and the need for differentiation. On the one hand, imposing a fashion makes it possible to affirm an individual's personality or charm, to distinguish her/him from the mass, and even to bring about societal change once that fashion proves to be successful. On the other hand, following or being seduced by a fashion can be considered as the expression of human beings' natural tendency to feel as part of a group (be this the group of belonging or of reference). In both cases, fashion would satisfy the need for social support; being "fashionable" means, in most cases, receiving approval from people placed at the same social level or doing the same things, as well as attracting the envy from those who would like to be part of that group so as to improve or advance their social status.

Simmel also conceived of fashion an expression of "class distinction", spreading and reproducing itself through the society as a top-down flow. Upper classes impose new fashions and styles and abandon or change them when these begin to be widely followed or "absorbed" by the less privileged classes. The author described this process as a sort of social pursuit game that governs the continuous fashion changes, which in turn are influenced, and even encouraged, by the advance of monetary economy. As soon as an object becomes trendy, the demand for cheaper products of the same type expands. However, when it becomes cheap and more accessible, it immediately loses its distinctive force. Consequently, upper classes look for a new trend to impose, and producers create new "objects of desire" to the purpose of increasing consumption, and the process starts again.

There is no doubt that the main value of Simmel's analysis-and the reason for its permanent interest — consists in having highlighted the ambivalent nature of fashion, which is simultaneously a "thing of imitation" and an instrument of differentiation at the social level (Godart and Aspers 2013; Maldini and Manz 2017). Alongside with the transformations of the social structure, fashion has gradually evolved from a class phenomenon to a mass phenomenon that interacts with the most diverse sectors of modern societies. It interprets and often anticipates their changes and interconnects with other "mass-media systems" that have promoted its spreading, not only in such "classic" tools as magazines, photography, or cinema, but also in marketing and advertising (Cafelato 2007). Equally acknowledged is the impact of fashion on modern national (and international) economies, another theme anticipated

3 References come from the translation edited by Anna Maria Curcio for the Italian publishing house Mimesis in 2015 (referred as Simmel 2015). 
by Simmel and constantly confirmed by a plethora of studies devoted to the expansion of this sector as well as to the growth of its turnover, not only with reference to the clothing sector 4 .

\subsection{Fashion and Social Media: The Influencer Marketing Phenomenon}

Simmel's essay also emphasized two fundamental prerequisites for the very existence of fashion-it must be followed and, for this to happen, it must be communicated. Undeniably, the appearance of the World Wide Web together with the expansion of digital technologies and the flowering of social media had a decisive impact on these aspects. As already noted, companies, and fashion firms in particular, have redefined their way of interacting with suppliers and found new strategies and tools to obtain customers' loyalty, actually clearing any distance with them. For this purpose, the so-called "dynamic" or "interactive" web together with social media proved to be very effective. They have increased the possibility of communicating and sharing opinions, not only through the "classic" personal computers, but also through a variety of devices (tablets and smartphones, first of all) that can be used in each moment of daily life and even in the absence of a material Internet connection. Moreover, individuals are no longer simply "passive" users; now, they can directly create stories and contents, channel them into the Web, and share them through videos, blogs, and posts. Of course, these new kinds of interaction need to be part-and-parcel of a group or a community. They gradually lead to the come-up of new communication's players, identified with some current use terms such as "bloggers", "vloggers", etc., referring to individuals who are very active on social channels and enjoy a broad (and in some cases, extremely wide) consensus.

These can be sportsmen, show business celebrities, or even ordinary people who prove to have a particular aptitude to capture, on certain topics such as travels, food, or fashion, the attention of groups of people for whom they become points of reference or even real sources of information.

The chance for anyone-boosted by digital technologies and tools-to be in direct and potentially permanent interaction with a favorite artist or celebrity has amplified the success of these communication media. It has also given rise to a new kind of profession — that of influencers or trendsetters, i.e., people who show a specific skill to establish a trustful relationship with their followers and present their opinions in a sound or even weighty way. By virtue of their position or their skills, they succeed in imposing themselves as "authorities" in a certain field or in being perceived as credible enough to affect consumers' decisions and purchasing behaviors ${ }^{5}$.

Given the high profitability of digital advertising ${ }^{6}$, it is easy to understand how such actors quickly attracted the attention of companies and brand owners, either already famous or emerging, which have gradually begun to engage them for their commercial strategies. Their messages, posts, or other kinds of content circulate on social media profiles, third-party sites, platforms, or even on independent sites.

These two elements feed on each other. Once it has appraised a celebrity's connection with the business area involved, a company engages her/him and asks them to review a product through its own social channels. Considering how quickly messages and opinions spread out and circulate through the new media, that company is able to increase the visibility of its products exponentially and to rely on the popularity enjoyed by the personality, reaching the target audience in a faster and more effective way. At the same time, the influencer takes advantage of the companies or the brand's reputation and reliability, which in turn allows her/him to enhance her/his contacts and level of fame.

4 For a recent review concerning the vitality of the fashion sector, its importance for the economy, and the changes deriving from the emergence of the so-called "fast fashion", see, for example, the report by Ellen MacArthur Foundation, A new textiles economy: Redesigning fashion's future, (2017, http://www.ellenmacarthurfoundation.org/publications).

5 http://www.businessdictionary.com/definition/influencers.html.

6 According to the market research agency EMarketer, during 2019, investments for digital advertising will grow worldwide by over $17 \%$, which means that, for the first time, the digital market will account for almost half of the advertising market (https://www.emarketer.com/content/global-digital-ad-spending-2019). 
In any case, as is well known, influencer marketing has become a "powerful tool for advertising"7, with a greater impact force if compared to other forms of promotional communication. It does not come as a surprise that it seems to be an ever-expanding sector, whose importance is also confirmed by a growing number of studies, observations, and reports concerning the state of this phenomenon ${ }^{8}$. To give an example, according to a survey conducted by Talkwalker (one of the main platforms for analysis and evaluation of the social media world), from a sample of over 800 professionals operating in this sector at a global level, the great majority (69\%) stated that influencer marketing is one of their main strategic priorities for $2019^{9}$.

\subsection{Influencer Marketing, Product Placement, and Advertising: Need for New Rules?}

The clear economic relevance of influencer marketing has posed the question of regulating this kind of activity in order to avoid possible distortive effects deriving from the mixture between promotional messages and editorial contents without the user being able to distinguish between one and the other.

This issue, which falls within the broader category of hidden and misleading advertising, has already been raised with reference to "editorial" advertising, in which messages for promotional purposes take the same graphic form and appearance as journalistic information. This practice then spread to radio, television, and audio-visual works, taking the form of "product placement", an advertising technique used by companies that pay for their products to be featured within non-typical promoting spaces (such as movies or television programs) without this exposure being revealed patently as a commercial communication. The Internet has amplified this phenomenon to the utmost. Its benefits in terms of ease of access and speed of information's flow have allowed companies to experiment with a new technique (the so-called "native advertising") which, by exploiting the channels of social networks, makes it possible to creep in the interest of consumers, circumventing their possible distrust towards advertising (Ciani and Tavella 2017, pp. 487-88). Promotional messages take on the same aspect of the site that hosts them, which often makes it difficult or even impossible for the user/consumer to avoid them.

In this new context, influencers' communication shows further features due to it taking place in online "environments"-mainly blogs—which do not belong specifically to the world of advertising. Blogs can be defined as a sort of online record of personal thoughts and opinions expressed by the authors and often contain different kinds of contents (video, photographs, or links to other websites) provided by the writers for other people to read and comment. Through this channel, bloggers build a real trust relationship with their followers, which can also take place on a daily basis with a very high degree of emotional involvement. The interplay of these two aspects can produce a lowering of users' attention, preventing them from distinguishing between advertising content and free comments that, in fact, coexist within the same message and the same narrative structure.

The techniques are well known; the blogger is portrayed in a moment of her/his everyday life while, in a way that appears casual, a product appears in the image or the shot with the brand in plain view. Or, in the context of a "normal" conversation via social media, the blogger declares her/his approval for a product, a brand, or a service, generating an advertising effect that is not explicitly declared. In other words, she/he seems to act spontaneously or to express an objective and disinterested opinion, while in

7 As defined also by the Italian Antitrust Authority in a press release of December 2017 concerning transparent advertising on social media (https://www.agcm.it/media/comunicati-stampa/2017/12). The point will be examined later in more detail

8 To give an Italian example, in April 2019, the National Observatory on influencer marketing (ONIM) was established, a non-profit association aimed at informing and improving the use of influencer marketing by involving all the stakeholders interested: influencers, agencies, brands, software houses, etc. (https://www.onim.it).

9 Talkwalker, The Global State of influencer marketing in 2019, https://www.talkwalker.com/it. The report also shows that the main objectives pursued through the influencer marketing are the brand visibility $(65.8 \%)$ and the creation of lists of possible customers-the so-called leads $(16.9 \%)$. 
fact, she/he is paid (in cash or other kind of benefits) for her/his comments. Moreover, the impact of the message is particularly effective-often viral_-given the already mentioned web features.

However, all this posits an evident problem of transparency. The user should be able to understand whether or not the communication he is assisting or participating in has a commercial purpose in order to consciously decide whether or not to follow the "suggestion" coming from the blogger without being passively exposed to the advertising conditioning. In the mentioned examples, the behavior of the blogger or the influencer is likely to fall into the category of hidden advertising.

"Audio-visual commercial communications shall be readily recognizable as such" 10 ; this is the cardinal principle underlying the rules that govern advertising at both supranational and national levels ${ }^{11}$. However, even if nobody seems to question that online advertising must be subject to the same standards regulating traditional commercial communications ${ }^{12}$, the "new frontiers" opened by technological developments have raised interesting legal questions.

Firstly, it has been necessary to dispel the doubts raised about whether the existing rules governing advertising could fit the characteristics of digital advertising or whether it was necessary to develop specific rules in the field. In any case, rapid changes and developments make the digital world a phenomenon that is often hard for law to regulate or manage timely and effectively. The question seems to be linked to the doubts and the objections put forward by advertising operators against the idea of adding "new" rules. Many of them have expressed the fear that introducing new kinds of constraint could limit creativity and lower its innovative potential, subsequently jeopardizing the impact of the messages (Cramer 2016). Specifically regarding the influencer marketing, some also stated that followers would have no interest at all in knowing whether or not the celebrity is paid for comments. These doubts seem instrumentally connected to the false myth considering the Internet as a law-less area ${ }^{13}$.

Secondly, as already mentioned above, separating promotional contents and personal opinions within digital commercial communications can be quite a difficult exercise (Ruffolo 1996). Any limits placed on this type of communication should therefore be reconciled with the safeguards that guarantee the freedom of expression (in Italy, Article 21 of the Constitution).

Thirdly, it should be borne in mind that the interests at stake are different and have many nuances to consider. On the one hand, there is the "classic" goal of consumers' protection. Even though they could be portrayed as completely naïve, they have the right to be informed about the advertising purpose of the message shared by the celebrities followed. This is not only in order to guarantee their freedom of choice but also to protect their privacy, taking into consideration the possibilities that the "likes" expressed are subject to profiling. The issue assumes an even greater relevance if

10 See Article 9, 1 (a), of Directive 2010/13/EU, 10 March 2010, of the European Parliament and of the Council on the coordination of certain provisions laid down by law, regulation, or administrative action in Member States concerning the provision of audio-visual media services (Audio-visual Media Services Directive); ELI: http://data.europa.eu/eli/dir/2010/13/oj. The article also specifies that "[s]urreptitious audio-visual commercial communication shall be prohibited".

11 As regards the Italian legal system, the principle of advertising transparency is laid down in Article 5 of the Legislative Decree 2 August 2007, n. 147, implementing Article 14 of the European Directive 2005/29/EC concerning unfair business-to-consumer commercial practices in the internal market (ELI: http://data.europa.eu/eli/dir/2005/29/oj), as well as in Article 22, 2, of the Consumer Code (Ciani and Tavella 2017, p. 497; D'Antonio and Tarantino 2011, p. 1).

12 Within the EU legal order, this principle can be traced back to the abovementioned EU directive 2005/29/EC, which extended the concept of commercial advertising to the more general concept of commercial communication. During the annual meeting organized by the Italian Institute of Advertising Self-Regulation (IAP), focusing on rules, guidelines, and balances on the Web (Milan, 15 May 2017), Antonio Martusciello, Commissioner at the Italian Authorità per le Garanzie nelle comunicazioni (AGCOM), underlined that "even online (... ) advertising must be clearly recognizable as such, in compliance with regulatory provisions" (https://medium.com/@AGCOMunica/lintervento-del-commissario-agcom-martusciello-suregole-orientamenti-ed-equilibri-in-internet-acec132448e1).

13 In Italy, the change of attitude on this subject can be traced back to the judgement made by the Tribunale di Milano (24 February-2 April 2010 n. 1972, IV Sez. Penale), which found guilty of privacy violation three Google managers with reference to a video uploaded on the famous search engine that portrayed a disabled child insulted and beaten by his schoolmates. See also the speech by AGCOM Commissioner Francesco Posteraro during a meeting on the responsible use of the network and the protection of rights, held in Rome, 19 October 2018 (https://www.agcom.it/19-ottobre-2018-usoresponsabile-della-rete-e-tutela-dei-diritti). 
referring to young people and minors, who now spend most of their time on social media. Moreover, it appears that there are few users who claim to succeed in distinguishing a commercial message from the so-called "organic content", i.e., the part of online communication that is not supported by paid ads ${ }^{14}$. On the other hand, the need to protect the brand or the company from the potential risks resulting from a possible association with a controversial testimonial or even with inappropriate content expressed by the celebrity engaged should also be a matter of concern ${ }^{15}$.

\section{A Viable Solution: Soft Law and Self-Regulation Tools}

In light of the abovementioned factors, which are apparently hindering regulatory actions perceived as too rigid, a solution may come from soft law tools, an expression that refers to a variety of instruments such as guidelines, codes of conduct, private standards, etc. These are informal regulation means explored and used in an increasing number of sectors to harmonize regulatory approaches both at national and supranational levels (Senden 2004) in order to ultimately manage problems and challenges posed by emerging technologies (Marchant and Allenby 2017). Soft law procedures look less time-and-resource-consuming as well as more effective in guaranteeing legitimacy and transparency vis-à-vis traditional regulatory processes. Besides, because of their more proactive than reactive nature (Muela-Molina and Perelló-Oliver 2014), they appear to be particularly suited to the communicative dimension of advertising.

For this reason, it is very interesting to examine some of the actions taken by independent administrative authorities or by self-regulatory agencies and bodies, both in Europe and overseas, to counter hidden advertising on social media.

\subsection{Some Examples in the UK and USA}

Between April and August 2016, the UK Competition and Markets Authority (CMA) carried out a series of investigations aimed at discovering and sanctioning unrevealed advertising in articles and online blogs. As an outcome of one of these initiatives, CMA sent warning letters to 43 celebrities-and to 15 businesses whose names were not revealed-involved in a commercial campaign organized by the marketing company Social Chain promoting films, games, and apps without revealing to users that they had been paid for the content published by them. The Authority reminded the addressees that forms of advertising not declared as such were contrary to consumer protection laws and asked that they include a clearly visible label for consumers, for example, "\#ad" or "\#sponsored", in social media communications. Social Chain then agreed not to use its social media accounts to organize new unlabeled advertising campaigns in the future ${ }^{16}$.

The US Federal Trade Commission (FTC) moved along the same lines. In March 2016, Lord \& Taylor, a US chain of luxury department stores, after having been investigated by the FTC, acknowledged that it had paid 50 influencers to post photo shoots on Instagram while wearing garments from its Design Lab clothing line ${ }^{17}$. In July of the same year, the FTC reached an agreement with Warner Bros. Home Entertainment after ascertaining that it had engaged some famous YouTubers to get positive reviews on a video game ${ }^{18}$.

14 As it emerges from the research "Italians and social media" (ed. 2018) carried out by the Italian platform Blogmeter, one third of Facebook and Instagram users stated that they are not able to understand when they are looking at an advertising message (https://www.blogmeter.it/it/reports/italiani-e-social-media-seconda-edizione).

15 For some examples of "transparent" advertising campaigns in which the choice of the hired testimonial turned out to be a double-edged sword, reference can be made to www.socialacademy.com/academies/upa-academy/posts/a-ciascuno-il-suoil-testimonial-in-pubblicità.

16 https://www.decisionmarketing.co.uk/news/cma-fingers-social-media-agency-over-hidden-ads.

17 FTC Press release, 15 March 2016, https://www.ftc.gov/news-events/press-releases/2016/03/lord-taylor-settles-ftc-charges-itdeceived-consumers-through.

18 FTC Press release, 11 July 2016, https://www.ftc.gov/news-events/press-releases/2016/07/warner-bros-settles-ftc-charges-itfailed-adequately-disclose-it. 
In both the cases mentioned, the FTC acted on the ground of "Guides Concerning the Use of Endorsements and Testimonials in Advertising" (hereafter the "Endorsement Guidelines"), adopted since the 1970s. This is a typical soft law tool that is not legally binding but is compelling enough to prompt its addressees to adopt "virtuous" behaviors and comply with advertising laws. Their effectiveness relies on the enforcement power conferred to the FTC (Ciani and Tavella 2017, pp. 503-6). Under the Endorsement Guidelines, the existence of a "material connection" between endorser and advertiser must be disclosed unless it emerges unequivocally from the context of the advertising communication. The advertiser is free to decide how to proceed with such disclosure, which be in any case clearly visible and understandable by users. Following some complaints brought about by consumers and their associations, the FTC monitored the activities of several celebrities on social media. In April 2017, it sent moral suasion letters to over 90 influencers and advertisers with the purpose of reminding them of their duty to reveal the existence of a commercial link with the brands endorsed ${ }^{19}$ and inviting them to adapt their disclosures tools to the characteristics of the media used so as to allow consumers to get their meaning unequivocally.

In September 2017, the FTC updated its Endorsement Guides, adding some practical suggestions about the use of endorsement in social media, emphasizing some points that companies should respect. In particular, they should:

(a) Clearly reveal whether they have a financial or family relationship with a brand; in particular, they cannot assume that followers know all about their business connections;

(b) Not assume that using disclosure tools provided by social media platforms is adequate enough that they could not be missed or misunderstood by users;

(c) Avoid using ambiguous labels such as "\#thanks", "\#collab", "\#sp", "\#spon", or "\#ambassador";

(d) Not rely on disclosure placed in easy-to-miss locations or where people would see it only after a "click more" link.

\subsection{Advertising Self-Regulation at European Level: The Coordination Carried out by EASA}

In Europe, a point of reference is the "Best Practice Recommendation on influencer marketing"20, adopted in December 2008 by the European Advertising Standard Alliance (EASA), the association that brings together the self-regulatory organizations (SRO) of various European countries. Even though, in 2008, EASA had already adopted some guidelines concerning digital marketing in general ${ }^{21}$, different reasons prompted it to give a special consideration to this advertising practice and to add further guidance. In particular, whilst recognizing the growing importance of this marketing technique, EASA also acknowledged the peculiar role played by the influencers themselves, seen as independent third parties that cannot be considered as "part of the self-regulatory system in its present form" (page 9). It also stressed that the content this creates is viewed, followed, and shared by an ever-increasing number of young people and minors, for whom the time spent on social media is often a wide part of their everyday life (page 10).

This document seeks to check and coordinate the practices adopted by the different self-regulatory bodies as well as to evaluate the most effective methods to face the challenges posed by this spreading phenomenon. The coordination strategy consists of pointing to some key elements considered as crucial in order to improve the correctness of advertising and to develop uniform and coherent behavior guidelines related to influencer marketing.

EASA leaves to national SROs the possibility to interpret its recommendations in a flexible way, following a more elastic or more stringent approach according to the differences and the peculiarities

19 FTC Press release, 19 April 2017, https:/www.ftc.gov/news-events/press-releases/2017/04/ftc-staff-reminds-influencersbrands-clearly-disclose.

20 https://www.easa-alliance.org.

21 https://www.easa-alliance.org/issues/digital-marketing. 
of their own national systems (page 6). In order to determine if the activities performed by influencers can be considered as commercial communications, it stressed that two main elements must be taken into consideration:

(a) Firstly, the level of "editorial control" by the advertiser on the message posted by the influencer (page 10) - this concept should be broadly understood to include a wide range of conducts, from bland forms of interference such as simple suggestions concerning the message structure or the tones used by the influencer to more straightforward interventions relating, for example, to scripts or dialogues.

(b) Secondly, the compensation granted to the influencer-this may take different forms, ranging from a cash remuneration based on contractual agreements to other kinds of advantages such as gifts, discounts or samples of the products, or benefits committed to the celebrity.

The principles inspiring EASA Best Practices on the influencer marketing correspond to the "classic" standards governing the commercial communication in general and are consistent with the guidelines defined by the International Chamber of Commerce Code ${ }^{22}$.

Recognizability is the fundamental rule considered the cornerstone for honest and responsible advertising. There is full congruity here with the already mentioned general standards applied to traditional media, according to which commercial communications must be recognizable as such, whatever the means used. Therefore, an influencer's communication combining a promotional message with informative or editorial content should be planned and presented in such a way that the widespread audience can immediately identify it as sponsored content.

Disclosure can take place in different ways, provided it is easily visible and understandable. National SROs are invited to provide practical examples of acceptable formats and, to that purpose, EASA recommends taking into account some features, for example: the label should be placed in an easy-to-read position within the post or the screen; it should last long enough to draw the attention of the users; special consideration should be devoted to the wording used, avoiding expressions that are likely to confuse the consumers or that in any case may not allow them to correctly identify the nature of the relationship between influencers and advertisers ${ }^{23}$.

Once again, SROs are free to choose whether or not to set out a list of general criteria with the purpose of adapting to the rapid changes distinguishing the digital world as well as new tools and techniques made available by the web platforms.

EASA also stresses that the rules concerning correct advertising should be deemed as applicable to all kinds of commercial communication and consequently to all those who participate in "the "digital marketing eco-system". Therefore, advertising businesses and operators as well as influencers are attracted to the orbit of stakeholders required "to adhere to responsible marketing practices" and to comply with the self-regulation codes (page 13).

Interestingly, EASA Best Practices are consistent with the wishes expressed by the institutions of the European Union-a point already mentioned and which is discussed more extensively in the last paragraph—which, within their policy aimed at implementing the Digital Single Market, encourage the Member States to acknowledge the role that can be played by effective self-regulation mechanisms "as a complement to the legislative, judicial and administrative mechanisms in place"24.

Given the consequences resulting from the impact of new digital technologies on national economies as well as on citizens' and consumers' rights, self-regulation mechanisms show a number

22 Advertising and Marketing Communication Practice-Consolidated ICC Code (2011), https://iccwbo.org.

23 These directives are analogous to those defined by the FTC Endorsement Guides (Ciani and Tavella 2017, pp. 504-6).

24 See, for example, the remarks expressed in the 14th recital of the new European Directive on audio-visual media services, which are also examined later on; Directive (EU) 2018/1808 of the European Parliament and of the Council, of 14 November 2018, amending Directive 2010/13/EU on the coordination of certain provisions laid down by law, regulation, or administrative action in Member States concerning the provision of audio-visual media services (Audio-visual Media Services Directive) in view of changing market realities (ELI: http://data.europa.eu/eli/dir/2018/1808/oj). 
of advantages if compared to traditional legal instruments. What matters is the higher degree of involvement of the interested parties, the greater tendency to adhere to shared rules immediately, as well as their flexibility and speed of adaptation to changes. According to some scholars, this is the reason why, while facing the need to regulate online behavioral advertising, the European Commission did not focus on self-regulation promoted by the Information and Technology industry but preferred to encourage the mediation work realized by the EASA and then implemented by national self-regulatory bodies and industry actors (Senden 2004). It should be emphasized that self-regulation and co-regulation practices are currently mainstreamed in the European Commission strategy for the implementation of the Digital Single Market ${ }^{25}$.

\subsection{The Italian Experience between Self-Regulation and National Regulatory Authorities}

Many countries have already adopted specific guidelines regarding influencer marketing ${ }^{26}$ Among them, the initiatives taken by the Italian Istituto dell'Autodisciplina Pubblicitaria (IAP) deserve special interest. IAP is a private association that involves companies, publishers, media, and industry associations in monitoring the most diverse forms of advertising and commits them to comply with both the rules of a "Codice di Autodisciplina della Comunicazione Commerciale" (Code of Marketing Communication Self-Regulation; hereafter the "Code") and with the decisions of the Institute's decision-making bodies, i.e., the Jury and the Review Board ${ }^{27}$. The Code, adopted in 1966, has been updated several times over the years, which has enabled its adaptation to the continuous changes in the advertising world, especially those resulting from the developments of digital technologies.

In 2016, IAP adopted a "Digital Chart", a tool aimed at providing a first answer to the needs of transparency in online advertising. This document identifies the most common forms of digital commercial communications, from endorsement to native advertising, from social networks to content sharing sites, and advertisements included in apps or interactive electronic games. For each type, the main characteristics are summarized, and practical examples are provided concerning the criteria that operators should follow to make them consistent with Article 7 of the Code ("Identification"), according to which "[m]arketing communication must be clearly distinguishable as such".

In particular regard to the forms of endorsement of a product or a brand expressed by influencers within the messages shared through their social media profiles, the Digital Chart states that the underlying marketing relationship with the advertiser and the commercial purpose of the contents must be made evident to the users with appropriate means. Alternative solutions are provided depending on the medium (post or video) used.

Concerning messages posted online, some identification marks or labels are suggested, such as "Pubblicità/Advertising", "Promosso da ... /Promoted by", "Sponsorizzato da ... /Sponsored by ...", or "in collaborazione con ... /In partnership with ...", together with the indication of the brand. These labels should appear in the initial part of the post or within the first three hashtags (\#). In the case of vlogs, appropriate written or verbal disclosures, such as "brand presents ... " or "in partnership with ... brand", should be inserted in the opening or the closing scenes or shots containing the promotional content. Where there is no marketing agreement between influencer and advertiser but only an occasional relationship consisting of the simple sending by the latter of products for free or for a modest value, the abovementioned disclosures may be replaced by a clearly visible or clearly expressed statement (such as "product sent by ... ").

25 https://ec.europa.eu/digital-single-market/en/policies.

26 As indicated in Annex I to the EASA BPs, Belgium, France, Germany, Ireland, Sweden, the Netherlands, and the United Kingdom have already adopted specific guidelines, while in Austria, Romania, and Spain, the process is currently underway.

27 The IAP Code is binding for agencies, consultants, media, sales houses, and all of those who accept it by entering into an agreement or by signing a contract for advertising. The adherents include an acceptance clause in their contracts or those of their associates asking users to follow the Code and self-regulatory policies (https://www.iap.it/about/mission/?lang=en). 
Although formally presented as a list of suggested practices, in the early stages of its life, the Digital Chart has drawn its prescriptive force indirectly from Article 7 of the Code, which is immediately binding for all parties adhering to the advertising self-regulatory system ${ }^{28}$. From the beginning, therefore, it could be qualified as something more than a "simple" ethic code; indeed, it is a true instrument of soft law.

During the first two years after its adoption, the Digital Chart was applied with reference to 97 advertising messages examined by the Jury or the Review Board. Only 30 were considered consistent with the Code's rules, while the others were blocked because they were found to be in conflict with the principle of recognizability or were modified upon request by the Review Board. Almost all of the cases $(92 \%)$ fell into the influencer marketing category, while the product sector most "involved" was that of clothing and accessories $(24.7 \%)^{29}$.

The IAP's Jury clarified some important aspects regarding online commercial communications and the responsibility of advertisers in the first case in which it applied the Digital Chart ${ }^{30}$.

In May 2018, the Review Board ordered Peugeot Automobili Italia SpA to stop the distribution of commercial messages relating to the brand "Peugeot" shared by a celebrity on his Instagram account through the "Instagram Stories" tool. These "stories" consisted of some shoots and short videos portraying the artist while visiting the car manufacturer's stand during the international tennis tournament held in Rome (and officially sponsored by Peugeot).

While appearing as the simple report of a private moment of the celebrity's life, the messages actually had a patent commercial purpose, considering their actual contents as well as some of their formal features; for example, the brand was always clearly visible and framed, and the product's qualities were described and emphasized by the artist himself. However, according to the Review Board, the advertising intent was not immediately recognizable by the users, because none of the appropriate measures suggested by the Digital Chart had been adopted.

Peugeot declared that the production and the publication of the "Stories" were due to an occasional and autonomous initiative assumed by the artist in breach of the sponsorship agreement concluded with him under which, inter alia, he should abide by the self-regulatory rules when publishing commercial contents.

The Jury stated that the disputed messages fell precisely into the scope of the Self-Regulation Code. It stated that, in such cases, the advertising nature of a communication can be ascertained not only by referring to a sponsorship agreement between the artist and the company concerned (which, in fact, was undisputed in the case in question) but also by evaluating the content of the communication, irrespective of the subjective position and the intentions of its author.

The Jury then added that the existence of an upstream sponsor relationship did not allow the artist's behavior to be considered as simply "occasional" and, at the same time, it was enough to realize the material connection necessary to ascribe to the advertiser the communications realized by the artist $^{31}$. It also underlined that Peugeot had not provided for sanctions or other deterrent mechanisms in its contract to prevent the breach of self-regulatory rules, a behavior defined "unwise" by the Jury, particularly when adopted by advertisers who, in order to promote their brand, have recourse to personal accounts of celebrities, bloggers, vloggers, and influencers acting on social media. With this respect, it pointed out that communication diffused through these new media is more "opaque" because it is horizontal peer-to-peer, which may cause a higher risk of confusion between advertising,

28 Proceeding n. 45/2018, 26 June 2018, Comitato di Controllo v. Peugeot Automobili Italia S.p.a. and Newtopia S.r.l.; https: //archivio.iap.it/. The Jury added that the Article 7 is also directly applicable to those "who have agreed to observe the Code in relation to single commercial communications".

29 See the IAP Annual Report 2018 IAP, https://www.iap.it/incontro_annuale_iap19/. Data provided by courtesy of IAP Secretariat.

30 Proceeding n. 45/2018, see note n. 28 above.

31 The Jury also referred to the definitions contained in the ICC Code on advertising and marketing communication and in the EASA Best Practice Recommendation on digital marketing communications, as well as to its consolidated case law. 
information, and non-commercial content compared to traditional vertical media or mass media. Regarding the case examined, the very structure of the "Stories" made it highly probable that the average consumer could really believe that he was looking "only" at a private tale of a celebrity.

It must be remarked that a rapidly evolving commercial sector such as influencer marketing has proven to fully understand the relevance of the self-regulatory system and to seize the opportunities offered by it in order to ensure the transparency of communication and to better protect the brands' and the companies' reputations. Indeed, between the end of 2018 and the beginning of 2019, some of the main agencies and influencers joined the IAP ${ }^{32}$ (among the first was famous fashion blogger Chiara Ferragni through her company, TBS Crew). This provides further evidence of how it is important for all operators and users involved to dispose of precise and structured rules and to find an interlocutor that helps to abide by the rules governing, in particular, the influencer marketing's world.

Recently, the Digital Chart underwent an important legal development, which was supported by the companies. As of 29 April 2019, it includes a specific Regulation on the Recognizability of Marketing Communication Distributed over the Internet ${ }^{33}$, which explicitly refers to Article 7 of the IAP Code, suitably rephrased ${ }^{34}$. As IAP itself underlined in presenting the initiative, this step fully realizes the proactive role that self-regulation systems should be able to play, as was hoped for in the numerous interventions of the European institutions dealing with this issue. In this way, the Digital Chart has become an integral part of the Code and has acquired a direct, binding force for the members of the self-regulatory system and from a formal point of view.

In Italy, the Digital Chart played a "forerunner" role to further initiatives aimed at managing the influencer marketing phenomenon. In July 2017, the Italian Authority for Competition and the Market $(\mathrm{AGCM})^{35}$, at the end of an investigation concerning a series of posts and content shared via Instagram, sent moral suasion letters to seven influencers and 11 well-known brands' owners, warning them for having realized non-transparent promotional messages. After recalling the general principle according to which advertising must be clearly recognizable and perceivable as such by consumers, the Authority invited the addressees to comply with the requirements of the Italian Consumer Code, adopted since 2005 and containing the rules relating to consumer protection. It emphasized that the prohibition of hidden advertising has a general scope, and it is therefore applicable to communications shared by influencers via social channels. It therefore asked the recipients to make the promotional purpose of their messages and contents clearly recognizable, by inserting specific warnings or labels such as "\#advertising ...", "\#sponsored by ...", "\#paid advertisement ...", or "\#product provided by ..." together with the indication of the brand.

In other words, AGCM actually referred to the same behavior's guidelines already expressed by the Digital Chart, indirectly validating IAP's initiative. The Italian Antitrust Authority has subsequently continued to monitor influencers' activities and, in August 2018, it took a second moral suasion initiative, this time extended also to the so-called "micro-influencers" who have a more limited number of followers (between 1000 and 100,000) but nonetheless have significant promotional importance. Significantly, in this new intervention, AGCM highlighted that the simple positioning of a tag or a label referring to the site of the brand's owner or to the celebrity's social profile may not be sufficient to make evident the promotional aim of the communication to all consumers when further elements are missing to make this character clearly recognizable.

Both these initiatives were judged "largely satisfactory" by AGCMitself, which required influencers and companies to not only commit publicly but also to effectively adopt more transparent behaviors

32 https://www.iap.it/conoscere-iap/associati.

33 https://www.iap.it/codice-e-altre-fonti/regolamenti-autodisciplinari/digital-chart.

34 Article 7 of the IAP Code was integrated with a new paragraph, which states: "As regards certain forms of commercial communication disseminated through the Internet, the main suitable measures are indicated in the Digital Chart Regulations".

35 As is known, the AGCM is an independent administrative authority established by law of 10 October 1990, n. 287. It is aimed, inter alia, at protecting consumers against all unfair commercial practices put in place by companies, including misleading advertising spread out by any means (https://www.agcm.it/competenze). 
towards consumers by revealing the brand with which they have established contractual or even occasional relationships. The Authority also emphasized that social network platforms have to provide specific tools in order to increase the disclosures of sponsored content. For example, in June 2017, Instagram, which is considered the platform preferred by influencers for their marketing operations ${ }^{36}$, announced that it had included in its posts and stories the label "Paid Partnership with" to highlight the commercial relationships existing between celebrities and companies and acknowledge that "a healthy community should be open and consistent about paid partnerships"37.

The positive reaction by the influencer marketing world to the guidelines edited by self-regulatory bodies has been confirmed by several investigations and surveys.

For example, Buzzoole, an Italian technological services provider, recently published a white paper on Transparency in Influencer marketing ${ }^{38}$. This research, focused on the Italian market, analyzed the number of transparency hashtags used during 2018. Data show that posts containing labels such as those suggested in the Digital Chart have increased by $235 \%$ compared to the previous year. Moreover, the market sector that made the most use of transparent posts was the fashion sector (clothing and footwear), which recorded the greatest number of interactions in terms of comments, likes, and shares.

On 18 June 2018, IAP and AGCM signed a cooperation agreement aimed at ensuring better consumer protection through more effective control on commercial communication ${ }^{39}$. This agreement falls clearly among the policies aimed at encouraging the forms of self-regulation, consistent with the EU recommendations, and provides for coordination between the two Authorities within their respective competences on regulatory, technical, and economic levels. IAP and AGCM will therefore carry out research and guidance activities aimed at identifying the different forms of commercial communications as well as the related obligations in order to guarantee the fairness and the transparency of advertising.

This cooperation agreement seems to be a first step towards the creation of a real "system" of integrated initiatives aimed at managing and regulating a slippery phenomenon such as that of hidden advertising, falling in line with the hopes expressed by the current IAP President, Mario Barbuto ${ }^{40}$. This could also allow for a deeper coordination between preventive protection measures (such as the interruption of harmful advertising practices or the removal of offending message) and the imposition of fines on the subjects found guilty.

\section{Conclusions: Can Self-Regulation Alone Be Enough? The Impact of the New European Directive on Audiovisual Services}

Despite its positive effects, as shown by the Italian experience, one cannot think that self-regulation alone may suffice to regulate a phenomenon as elusive as online advertising. The main problem coincides with the doubts raised about the actual capacity of the self-regulatory tools to boost virtuous attitudes among companies over time and convince them to conform to the commitments undertaken on a "voluntary" basis.

This is perhaps one of the main reasons why, despite the limits already highlighted, "stronger" statutory interventions are invoked to avoid leaving the implementation of these commitments solely to the good will of the interested parties. Preventive measures are recommendable, for example, by requiring companies to communicate to national authorities the commitments existing with the celebrities engaged or to include specific clauses in their contracts with the testimonials binding them to respect the rules of transparency. Downstream, the most mentioned approach concerns the accountability of online platform managers and their involvement in the adoption of effective tools to guarantee the transparency of commercial communications (Ciani and Tavella 2017, p. 517).

\footnotetext{
36 As confirmed, for example, by www.brand-news.it.

37 https://instagram-press.com/blog/2017/06/14/bringing-more-transparency-to-commercial-relationships-on-instagram.

38 https://buzzoole.com/resources/transparency-influencer-marketing.

39 https://www.iap.it/2018/06/accordo_quadroagcom_iap.

40 https://www.engage.it/media/web-marketing-digital-chart-iap.
} 
With this respect, a possible first answer seems to be provided by new Audiovisual Media Services Directive (AVMSD), which was adopted in late $2018^{41}$.

As is known, a few decades ago, the European Union developed a prescriptive regime for the audio-visual media services. After the first directive concerning the exercise of television activities (the so-called "Television without Frontiers Directive", 89/552/EEC of 3 October 1989), the regulatory framework had to be adapted to the developments deriving from technological innovations and the consequent changes in consumers' and users' habits. The Television without Frontiers Directive was then repealed in $2010^{42}$. With the 2018 revision, the AVMSD Directive pays special attention to commercial communication, trying to preserve the competitiveness of European industries and to guarantee consumer protection while simultaneously improving guarantees for vulnerable subjects such as minors. Its purpose consists also of increasing transparency, legal certainty, and the possibility to settle disputes more easily.

One of the fundamental principles introduced is that all authors of audio-visual content must be treated according to the same rules. The Directive thus provides uniform rules for all the subjects involved in audio-visual communications at any level and develops principles applicable to relationships between online platforms and companies. Those principles should therefore be considered applicable to other players of commercial communication, such as influencers or bloggers, when they promote brands or products on the basis of sponsorship agreements.

This seems to be further confirmed by the fact that the new AVMSD Directive explicitly acknowledges and supports the role of self-regulation systems. As provided for under Article 4 bis, "Member States shall encourage the use of co-regulation and the fostering of self-regulation through codes of conduct adopted at national level in the fields coordinated" by the Directive itself. Moreover, some of the fundamental guidelines identified through co- and self-regulation experiences and directly involving the media service providers are, in fact, codified. For example, pursuant to Article 9 of the new AVMSD Directive, Member States shall ensure that audio-visual contents provided by those subjects under their jurisdiction comply with requirements such as the immediate recognizability of commercial communications as such, the prohibition of surreptitious advertising and of subliminal techniques, the respect for human dignity, and the ban of discriminatory messages as well as contents encouraging behaviors prejudicial to health or safety.

Finally, under Article 28 ter of the AVMSD Directive, Member States should ensure that media service providers subjected to their jurisdiction adopt and apply proportionate and appropriate measures in order to guarantee the consumers' protection in several respects. These measures should be envisaged by considering the nature of shared contents, of the harm that may be caused, as well as "the characteristics of the category of persons to be protected" and "the rights and legitimate interests at stake". Under paragraph 3, (c) of the same article, media service providers should adopt "a functionality for users who upload user-generated videos to declare whether such videos contain audio-visual commercial communications as far as they know or can be reasonably expected to know".

As is known, Member States have a certain degree of leeway regarding the legal tools and the procedures to implement European directives within the time limit laid down by the Institutions. Therefore, it will take time to verify whether or not they will be able to coordinate their actions effectively, avoiding the risk of elaborating fragmented disciplines and the recourse to a sort of forum shopping by companies.

41 Directive (EU) 2018/1808 of the European Parliament and of the Council of 14 November 2018 amending Directive 2010/13/EU on the coordination of certain provisions laid down by law, regulation, or administrative action in Member States concerning the provision of audio-visual media services (Audio-visual Media Services Directive) in view of changing market realities (PE/33/2018/REV/1); OJ L 303, 28.11.2018, pp. 69-92. ELI: http://data.europa.eu/eli/dir/2018/1808/oj.

42 Renamed Audiovisual Media Services Directive: Directive 2010/13/EU of the European Parliament and of the Council of 10 March 2010 on the coordination of certain provisions laid down by law, regulation, or administrative action in Member States concerning the provision of audiovisual media services (OJ L 95, 15.4.2010, pp. 1-24; ELI: http: //data.europa.eu/eli/dir/2010/13/oj. 
Funding: This research received no external funding.

Conflicts of Interest: The author declares no conflict of interest.

\section{References}

Baldini, Costanza, ed. 2008. La moda, i filosofi ed i sociologi. In Sociologia Della Moda. Rome: Armando Editore, pp. 7-55.

Barthes, Roland. Il Senso Della Moda. Forme e Significati Dell'abbigliamento. Turin: Einaudi.

Cafelato, Patrizia. 2007. Mass Moda: Linguaggio e Immaginario del Corpo Rivestito. Rome: Molteni Editore, pp. 13-25. First published 1996.

Ciani, Jacopo, and Massimo Tavella. 2017. La riconoscibilità della natura pubblicitaria della comunicazione alla prova del digital: Native advertising tra obbligo di disclosure e difficoltà di controllo. Informatica e Diritto 1-2: 485-17.

Cramer, Theresa. 2016. The Deal with Disclosure and the Ethics of Native Advertising. Available online: https://digitalcontentnext.org/blog/2016/09/06 (accessed on 23 May 2019).

D’Antonio, Virgilio, and Domenica Tarantino. 2011. Il Product Placement Nell'ordinamento Italiano: Breve Fenomenologia di uno Strumento Pubblicitario. Available online: http://www.comparazionedirittocivile.it/ prova/files/dantonio_product.pdf (accessed on 20 May 2019).

Dara, Virginia. 2017. Fashion e Luxury 2.0: Se la Rivoluzione è Digitale. Available online: www.insidemarketing. it/white-paper (accessed on 20 May 2019).

Foglio, Antonio. 2017. Il Marketing Della Moda. Politiche e Strategie di Fashion Marketing, 5th ed. Milan: Franco Angeli, pp. 25-26.

Godart, Frédéric, and Patrik Aspers. 2013. Sociology of Fashion: Order and Change. Annual Review of Sociology 39: 171-92.

Maldini, Irene, and Luciana Ragna Manz. 2017. From "Things of Imitation" to "Devices of Differentiation": Uncovering a Paradoxical History of Clothing (1950-2015). Fashion Theory 22: 69-84. [CrossRef]

Marchant, Gary E., and Brad Allenby. 2017. Soft law: New tools for governing emerging technologies. Bulletin of the Atomic Scientists 73: 108-14. [CrossRef]

Muela-Molina, Clara, and Salvador Perelló-Oliver. 2014. Advertising self-regulation. A comparative analysis between the United Kingdom and Spain La autorregulación publicitaria. Un análisis comparativo entre Reino Unido y España. Communication \& Society 27: 1-18.

Ruffolo, Ugo. 1996. Pubblicità redazionale, manifestazione del pensiero e limiti (anche costituzionali). al rimedio inibitorio/censorio. Responsabilità, Comunicazione, Impresa 2: 167-86.

Senden, Linda. 2004. Soft Law in European Community Law. Oxford: Hart Publishing.

Simmel, Georg. 2015. La Moda. Milano: Mimesis. First published 1920.

(C) 2019 by the author. Licensee MDPI, Basel, Switzerland. This article is an open access article distributed under the terms and conditions of the Creative Commons Attribution (CC BY) license (http://creativecommons.org/licenses/by/4.0/). 
Article

\title{
The Protection of Fashion Shows: An Uncharted Stage
}

\author{
Elena Varese * and Valentina Mazza * \\ Intellectual Property and Technology Department, DLA Piper, 20123 Milan, Italy \\ * Correspondence: elena.varese@dlapiper.com (E.V.); valentina.mazza@dlapiper.com (V.M.)
}

Received: 27 August 2019; Accepted: 12 November 2019; Published: 17 November 2019

\begin{abstract}
The history of fashion shows goes back more than a century, and over the years, catwalks have gone from being private sales channels for a few wealthy customers to pure entertainment shows promoted globally. In this article, we analyze both national and international laws dealing with the protection of fashion shows in order to establish how fashion shows could be protected under intellectual property laws in Italy, with specific regard to copyright. The possibility for fashion shows to access copyright protection opens up a list of interesting questions: Who is the author of the work? Are models to be considered as performers? This scenario gets even more complicated if we consider how fashion shows have been changing in the last few years, turning to new technologies such as holograms, augmented reality, and drones. Further, copyright protection could be accompanied by further tools, such as registered or unregistered designs for the single elements of a scene and choreography or unfair competition if the general look and feel of a former fashion show has been slavishly imitated. A final section of this article is dedicated to the use of cultural heritage and historical museums, which are increasingly chosen by fashion houses for the settings of their shows.
\end{abstract}

Keywords: fashion shows; fashion law; copyright; performers' rights; collective works

\section{Introduction}

Fashion shows today are far more than just a couple of models on a catwalk. They include real stories and performances and entail very significant investments and the participation of a great deal of contributors. Examples vary from Fendi's iconic defile on the water of the Trevi Fountain in Rome or Louis Vuitton's carousel in black feathers and laces or, lately, Gucci's disruptive set of a hospital operating room, including models walking with sculptures of their own severed heads.

In this article, we move from a comparative perspective in order to analyze how France and the United Kingdom (UK) have dealt with the legal protection of fashion shows and how such creations could be protected in Italy, where it is still an unexplored matter. France, where the legal framework is similar to that of Italy, was the first country to take a position in relation to the legal protection of fashion shows in the leading Ashby case in 2008. Besides France, the UK is the only other country in the European Union (EU) where scholars have engaged in academic research on the issue. Therefore, for the purposes of this article, in order to come up with a possible regime of protection for Italy, we limited our research to the UK and France, which are not so far from Italy when it comes to the fashion industry.

The possibility for fashion shows to access copyright protection opens up a list of interesting questions: Who is the author of the work? Are models to be considered as performers?

In this article, we aim to answer these questions and to suggest how fashion houses should protect their rights in order to ensure that they can fully exploit what is often a multi-million-dollar investment. In doing so, we will also consider how new technologies and artificial intelligence are reshaping the fashion industry.

In particular, we will argue that, given the uncertainty of Italian law in applying the composite or collective work regimes to fashion shows and consequently identifying their author, if a fashion house 
wants to acquire intellectual property rights in a show, it should ensure the transfer of all the economic rights in the show, not only by the director, but also by all the relevant contributors.

As to the second question, because international treaties, such as the Rome Convention and the 1996 WIPO Performances and Phonograms Treaty (WPPT), define protected performances as those that are interpretations of a copyrighted work, we conclude that performers' rights should be extended to runway models as a matter of compliance with international law. Models have traditionally been ignored by policymakers, and despite being the protagonists of the catwalk, they have remained in the shadows when it comes to legal protection. However, the Copyright Directive (EU) 2019/790 on copyright and related rights in the digital single market has recognized the need to set up a more solid and protective set of rules for the benefit of performers.

Therefore, countries should no longer ignore their obligations and should take appropriate steps to ensure that models enjoy adequate protection. Fashion is currently going in a more sustainable and ethical direction. Many campaigns have focused on models' health issues, but fashion companies also have a legal and moral obligation to provide them with fair remuneration.

\section{EU Countries Dealing with Fashion Show Protection}

\subsection{France and the Leading Case: Ashby}

France, where the legal framework is similar to that of Italy, was the first country to take a position in relation to the legal protection of fashion shows. In particular, Article L. 112-1 of the French Intellectual Property Code provides that all works of the mind are protected regardless of their gender, form of expression, merit, or purpose, provided that they are original. Further, Article L. 112-2 enumerates a non-exhaustive list of copyrightable works. As to the specific issue of fashion shows, based on the provisions above in the case Ashby $v$ Gaulme, Kenzo et Lacroix, the French Supreme Court opened up a new path in the fashion law system, holding that fashion shows can be protected by copyright $^{1}$. The suit for copyright infringement, not only with respect to the clothes, but also with respect to the fashion shows themselves, was brought by the French Federation of Couture and five haute couture companies (including Chanel, Christian Dior, and Hermes) against three photographers, who uploaded photographs as well as videos of the fashion shows in question on a website ${ }^{2}$.

In fact, the French Federation of Couture developed a strict system in order to monitor the use of photographs taken during fashion shows, whereby only photographers indicated by press organizations, which had agreed to standard contract terms, were allowed to use the photographs and only for information purposes, with express exclusion of any commercial purposes.

Ashby Donald and the other two photographers claimed that they were allowed to upload the photographs on the internet for the purposes of reporting current events under Article L. 122-5, No. 9 of the French Intellectual Property Code as well as under Article 10 ("Freedom of Expression") of the European Convention on Human Rights. Under these provisions, the author of a copyrighted work cannot prevent the reproduction or communication to the public, in whole or in part, of a graphic, architectural, or artistic work in written, audiovisual, or online forms for the exclusive purpose of immediately informing the public, as long as the author's name is clearly indicated.

Based on this exception, the photographers were found not liable at the first instance, but the Paris Court of Appeal reversed the decision and held that the photographers had engaged in copyright infringement, not only of the claimants' clothes, but also of the fashion shows themselves. The photographers appealed the decision to the French Court de Cassation, but the action was dismissed. Therefore, they decided to bring their case to the European Court of Human Rights (ECHR) in Strasbourg for the alleged violation of their freedom of expression.

Ashby v Gaulme, Kenzo et Lacroix, French Court of Cassation, 5 February 2008.

Ashby $v$ Gaulme, Kenzo et Lacroix, Court of Appeal of Paris, 13e chambre, 17 January 2007. 
According to the ECHR, the exercise of the freedoms envisaged by Article 10 of the European Convention on Human Rights is subject to duties and responsibilities and may also be subject to formalities, conditions, restrictions, or penalties only to the extent that they are prescribed by law and are necessary in a democratic society ${ }^{3}$.

As some photographs were available for online download only upon payment and the photographers' commercial purpose was thus evident, the French Court of Appeal and the ECHR denied the application of the exception of freedom of expression and found the defendants liable for copyright infringement, pursuant to Articles L 335-2 and 3 of the Code de la Propriété Intellectuelle.

\subsection{The UK and the Broad Interpretation of the Copyright, Designs, and Patents Act (CDPA)}

Following the Ashby decisions, discussions on the eligibility of fashion shows for copyright protection have also taken place in the $\mathrm{UK}^{4}$.

Unlike the legal framework of Italy and France, the UK Copyright, Designs, and Patents Act 1988 requires fixation for a work to access copyright protection. However, this is not an obstacle, because fashion shows can be captured through audio-video recording or photographs.

Another difference in the civil law systems is that the CDPA does not provide for an open-ended list of copyrightable works. Therefore, under UK law, the main issue is to establish whether fashion shows may fit within the categories of protectable works set by section 3(1) of the CDPA.

Indeed, section 3(1) of the CDPA can be interpreted to include fashion shows within the two categories of "dramatic works" or "choreographic works". With respect to dramatic works, it can be argued that the very essence of fashion shows is to be performed by models walking down the runway and that, together, they hold sufficient dramatic unity to satisfy the relatively low threshold set by the UK case law, which merely requires that the substance of the work is not left to chance or mere randomness ${ }^{5}$.

As an alternative interpretation, the clothing, directing, and staging of models may be considered as a form of choreography, because models have to walk in a certain order, presumably wearing a series of similar clothes in a first round, followed by another series in a second round, and so on.

A similar reasoning has already been followed by UK courts in relation to "aesthetic" or "choreographed" sports, such as cheerleading, synchronized swimming, figure skating, acrobatic gymnastics, ice dancing, and wrestling. In particular, the courts distinguished such choreographed sports from more traditional "adversarial" sports, such as football, baseball, basketball, cricket, and hockey, on the grounds that the former present a repetition of basic individual movements, i.e., a sort of plot. Therefore, given their low margin of improvisation and unpredictability and the fact that they are not affected by the movements of the adversarial players, UK courts have recognized the repetitive and choreographic nature of "aesthetic" sports and decided for their copyrightability ${ }^{6}$.

Therefore, even if there is some criticism against the inclusion of fashion shows within the definitions of copyrightable subject matter under the CDPA, we believe that there is room to argue that they may also be protected by copyright under UK law, falling within the category of dramatic or choreographic works.

\footnotetext{
Ashby Donald v France, App No. 36769/08, ECHR, 10 January 2013.

(Derclaye 2008); see also (Pavis 2018c).

Norowzian v Arks Ltd (No 2) [2000] EMLR 67; The Ukulele Orchestra of Great Britain v Erwin Clausen and another (t/a the United Kingdom Ukulele Orchestra) [2015] EWHC 1772 (IPEC); Banner Universal Motion Pictures Ltd v Endemol Shine Group Ltd [2017] EWHC 2600 (Ch); Green v Broadcasting Corp of New Zealand [1989] RPC 469, applied in Robin George Le Strange Meakin v British Broadcasting Corporation and others [2010] EWHC 2065 (Ch) paras 29-31 (Arnold J).

6 See https://www.entsportslawjournal.com/articles/10.16997/eslj.1/\#targetText=In\%20Norowzian\%20v\%20Arks\%20Ltd, being $\% 20$ performed $\% 20$ before $\% 20$ an $\% 20$ audience.
} 


\subsection{Possibility of Protecting Fashion Shows in Italy through Copyright}

Fashion shows at Milan Fashion Week are becoming a true experience, with scenic effects often taking place in historic locations. The sets are more and more complex and involve the work of architects and artists, who are asked to create extraordinary and multi-sensorial shows, where everything, such as lights, sounds, and colors, has to be studied in detail.

Fashion shows today are no longer the mere presentation of the designer's latest creation; rather, they have become a cultural phenomenon-a means of expression of artistic, social, historical, and sometimes political values. Let us think, for instance, about Missoni, dressing models in pink caps as a symbol against female discrimination, the echo of Queen Elizabeth's first time sitting in the front row of a fashion show next to the legendary Vogue Editor-in-Chief Ann Wintour or Valentino Garavani's three-day spectacular farewell to the catwalks in Rome to celebrate his 45-year-long relationship with the Eternal City, etc. ${ }^{7}$.

Yet, in Italy, no reported case has ever dealt with how fashion shows could be legally protected. The issue is not irrelevant, given - on the one hand-the high investment made for the setting up of the show, which justifies protection against imitation as soon as the work is created, and-on the other hand-the possibility of reproducing fashion shows through audiovisual means and photographs, at a later stage. Therefore, after a comparative analysis of the French and UK legal systems as described above, we will now consider the main factors in favor and against the copyright protection of fashion shows in Italy.

Some policy considerations against the copyright protection of fashion shows could be that they are ancillary to the sale of a product (i.e., the last collection of garments created by the fashion maison) and therefore do not present a sufficient degree of originality. Yet, the ultimate aim to trigger an economic advantage to the creator or its assignees should not be taken into account to prove copyright protection, as shown, for instance, by the fact that advertising creations are protectable in Italy as autonomous works of art. Thus, under Italian law, copyright should exist insofar as the concerned work is original, without taking into account its ultimate purpose. Further, originality merely requests that the work carries out an expression of the author's personality, without entering into the merits of the creation.

It is, therefore, reasonable to argue that the majority of modern fashion shows might present a sufficient degree of originality to access copyright protection in the Italian system, insofar as they bring together a combination of scenic and technical solutions, music, costumes, and settings.

From a purely legal perspective, a second objection might be that fashion shows are a sort of "volatile" creation that is displayed once and for all and would be incapable of being repeated over time, as they have no sufficient unity and definition, which are requirements that are often difficult to prove, for example, in the case of formats. In this regard, the Italian case law traditionally granted protection as formats to works that presented a given number of fixed elements, including scenes, characters, and narrative solutions. For instance, the Italian Supreme Court, in its decision No. 18633 of 27 July $2017^{8}$, granted copyright protection to formats, provided that they presented "a basic scheme identifying the main characteristic features of a TV show or, more often, of a whole series of truly coordinated episodes". Such features have been identified in the "main structural elements of the story, the setting in an identified time and space, the common thread of the narration and the characters in their peculiarities". For this reason, the protection of fashion shows as formats might present issues, as there might not be a sufficient repetition and definition of fixed elements, given the limited length of the show and the fact that it is not divided into episodes.

7 For an overview of the 100 most spectacular fashion shows from the ' 60 s to date see https://www.iodonna.it/moda/news/ 2019/02/19/sfilate-momenti-memorabili/.

8 Available in the database http://cassazione.net/. 
Considering, however, that modern fashion shows have more often an actual directorship and plot and could be theoretically repeated, they can be said to have a sufficient unity of definition. In one of the most recent and illustrative cases, the Dolce \& Gabbana AI 2020 show in the Valley of the Temples, Sicily, was directed by the Oscar-winning filmmaker Giuseppe Tornatore, who created what the press defined as a "couture mythology" atmosphere, with models walking around the ruins similar to the Greek muses of the ancient myths 9 .

Further, copyright protection is granted also to creations that might vary over time within the lines of a given plot (this is the case, for instance, for performance arts). Unlike other legal systems, such as that of the United States, fixation is not a requirement to access copyright under Italian law, which protects oral works or works that cannot be repeated. In this regard, performance arts, rather than choreographic works, seem to be the most akin creation to fashion shows. On the one hand, and as an exception to the general rule, choreographic works request a certain degree of fixation of the main lines of the work, as provided by Article 2, paragraph 3 of the Law of 22 April 1941, No. 633 Italian Copyright Law (ICL). Such fixation is requested in writing or through audiovisual means and might be, in some cases, a potential obstacle for the assimilation of fashion shows to choreographic works.

On the other hand, performance arts do not require the fixation of the plot and theoretically allow a wider degree of discretion and variation, depending also on social and environmental factors.

Overall, it is not necessary to justify the protection of fashion shows through copyright by making such creations fall within the listed categories of protected works. In fact, the conclusive argument to allow the protection of fashion shows in the Italian system is that Article 2, paragraph 3 of the ICL grants protection to different kinds of creative works and-different from other legal systems such as the UK-provides for an open-ended list of copyrightable works, insofar as they are sufficiently original.

This has already paved the way in other jurisdictions to discuss the extension of copyright protection to other subject matters relevant to the fashion system, such as the debated case of perfumes ${ }^{10}$.

Thus, under Italian law, fashion shows might well account for an autonomous copyrightable work (albeit not expressly named by the ICL), as long as they meet the originality threshold provided by the ICL, which is, traditionally, not particularly high.

\section{Who Is the Author?}

Once ascertained that fashion shows can be protected by copyright, the next question is who is the copyright owner of the work?

Fashion shows are the result of the work of a number of contributors, including architects, set designers, sound and light technicians, hairdressers, makeup artists, seamstresses, etc.

The question of authorship of fashion shows is controversial, as they might fall under at least two different regimes provided by the ICL for works made by more than one contributor.

In a first scenario, fashion shows might fall within the category of "composite works", as their various parts cannot be separable, as opposed to works whose components are formed by distinct and reciprocally autonomous contributions. In this case, Article 10(1) of the ICL will apply, and copyright will be vested in each coauthor of the components falling within the communion regime. Thus, unless differently provided in writing, each coauthor is free to use autonomously the component that he has devised.

According to a second interpretation, fashion shows might fall within the category of "collective works", defined as the union of works or parts of works by different authors that are autonomous creations, brought together as a result of choice and coordination for a given literary, scientific, educational, religious, political, or artistic purpose. Collective works exist regardless of the separability

9 See https://www.vogue.it/moda/article/dolce-and-gabbana-agrigento-sfilata-alta-moda-tempio-della-concordia.

10 Kecofa/Lancôme, Dutch High Court, HR, June 16; 2006, LJN AU8940; Thierry Mugler Parfums c/GLB Molinard, Tribunal de commerce de Paris (1999); Société Bellure/SA L'Oréal et al., Cour d'appel de Paris, 25 January 2006. 
of their respective components. Classic examples of collective works are encyclopedias, anthologies, magazines, and movies. Under Article 7 of the ICL, the author of the collective work is considered to be whoever organizes and directs the creation of the work itself. In our case, and given their increasing complexity and spectacularism, the coordination of the different components of the fashion show is often managed by an external director specifically appointed by the fashion house to devise the show and supervise its development. Such director would likely be considered to be the author of the fashion show, if we consider the latter to be a collective work.

Therefore, given the uncertainty in applying the composite or collective work regimes, if the fashion house wants to acquire the intellectual property rights to a fashion show, it should ensure the transfer of all the economic rights of the show, not only by the director, but also by all the relevant contributors (including the creators of the original music and scenography).

However, it should be noted that under Italian law, only economic rights in a copyrighted work can be transferred, whereas moral rights will remain vested in the different contributors, who will keep the right to be indicated as the authors of their respective works.

\section{Can Models Be Considered Performers?}

Since both national and international law define protected performances as those that are the interpretations of a copyrighted work, this would include the performance of a fashion show by runway models.

In this regard, Article 80(1) of the ICL considers acting and performing artists to be "actors, singers, musicians, dancers, and other persons who perform, sing, act, recite, or in any way execute intellectual works, should this be protected or of public domain". Similarly, Article 3(b) of the Rome Convention and Article 2(b) of the 1996 WIPO Performances and Phonograms Treaty provide protection to "actors, singers, musicians, dancers, and other persons who act, sing, deliver, declaim, play in, or otherwise perform literary or artistic works", mirroring the classification of copyrightable subject matter provided by the Berne Convention for the Protection of Literary and Artistic Works. In addition, the Beijing Treaty on Audiovisual Performances of 2012, dealing with the intellectual property rights of performers in audiovisual performances, grants performers economic and moral rights with specific reference to unfixed (live) performances ${ }^{11}$.

If we read international treaties as conferring performers' rights to anyone who interprets a "work" within the meaning of copyright law, such protection should be extended to runway models as a matter of compliance with international law ${ }^{12}$.

Further, another level of interpretation considers the Rome Convention and the WPPT to establish a de minimis standard of protection, where protected performances would be, at a minimum, those that are interpretations of protected or protectable works under copyright law.

This interpretation is supported by Article 9 of the Rome Convention, which specifies that "[a]ny Contracting State may, by its domestic laws and regulations, extend the protection provided for in this Convention to artists who do not perform literary or artistic works", so implying that the existence of a copyrighted work underlying the performance is central to the definition of protected performers under Article 3(a).

11 The Beijing Treaty on Audiovisual Performances was adopted by the Diplomatic Conference on the Protection of Audiovisual Performances, which took place in Beijing from 20 to 26 June 2012. As to unfixed (live) performances, the treaty grants performers three kinds of economic rights: (i) the right of broadcasting (except in the case of rebroadcasting); (ii) the right of communication to the public (except where the performance is a broadcast performance); and (iii) the right of fixation. With respect to moral rights, they include the right to claim to be identified as the performer (except where such an omission would be dictated by the manner of the use of the performance) and the right to object to any distortion, mutilation, or other modification that would be prejudicial to the performer's reputation, taking into account the nature of the audiovisual fixations.

12 See (Pavis 2018a, 2018b). See also (Pavis 2019). 
Consequently, national laws may depart from the Rome Convention only to the extent that they provide a more generous standard of protection than that granted under the international agreement, but they cannot deny performance rights with respect to copyrighted works. Failure to do so would place signatory countries in breach of their international obligations. Therefore, as far as fashion shows are to be considered as protectable subject matter in Italy, performers' rights could be granted to models who "execute" the fashion show through a given number of movements in an assigned timing.

It is, however, to be seen if, in order to access protection as a neighboring right, models walking down the catwalk will be deemed to play a role of "remarkable artistic importance", as requested by Article 82(1) of the ICL to acting and performing artists of literary, dramatic, and music works. One argument could exclude this threshold, as fashion shows might fall within the category of artistic works and not within those expressly listed by Article 82(1) of the ICL. On the other hand, it would be unfair to impose a lower requirement to access neighboring right protection to models as opposed to other categories of performers. Thus, it would be reasonable to protect the performance of models within fashion shows insofar as they cover a role of "remarkable artistic importance", which is not such an higher threshold, especially in light of the length and level of elaboration of modern fashion shows.

The recognition of performers' rights to fashion models represents a significant step ahead towards the protection of their category, which has traditionally been neglected by policymakers.

First, these intellectual property rights guarantee models adequate remuneration by conferring the right to control and monetize the fixation and distribution of their performance on the runway. In fact, runway models are increasingly becoming protagonists of the fashion system and can now be found within other forms of productions with clear distribution lines and extended commercial longevity, as the many related dedicated TV shows demonstrate ${ }^{13}$. Second, performers' rights confer protection in the form of moral rights, i.e., the rights to protect the integrity of their performance and to ensure that they are given credit for it. Thirdly, because performers' rights may be enforced collectively through representative organizations, they would eventually give models' unions significant leverage in negotiations with other players in the industry.

The need to set up a more solid and protective set of rules for the benefit of performers has also been recently recognized by the Copyright Directive (EU) 2019/790 on copyright and related rights in the digital single market, which warns that "performers tend to be in the weaker contractual position when they grant a license or transfer their rights, including through their own companies, for the purposes of exploitation in return for remuneration" (Whereas 72). In fact, Article 18 of the New Copyright Directive provides that " $[\mathrm{m}]$ ember States shall ensure that where authors and performers license or transfer their exclusive rights for the exploitation of their works or other subject matter, they are entitled to receive appropriate and proportionate remuneration". In addition, Article 19 lists a series of transparency obligations for the performers' counterparties in order to ensure that they are made aware of the modes of exploitation of all revenues generated and of the remuneration due for their works.

Although this is not enforceable law and it is up to the member states to implement the obligations set forth in the New Copyright Directive, we believe that if the New Copyright Directive dedicates two provisions to the protection of performers' rights, this is proof that performers' rights should be awarded to anyone who interprets a "work" within the meaning of copyright law.

\section{The Impact of New Technologies}

The above background gets even more complicated if we consider how fashion shows have been changing in the last few years, turning to new technologies such as holograms, augmented reality, and drones.

13 See for example the TV shows "Project Runway", "The Face", and "Make Me a Supermodel" based on fashion designing and runway modeling performances. 
In New York, Intel partnered with numerous designers, including Erin Fetherston, Prabal Gurung, and Band of Outsiders, to live broadcast their shows in virtual reality. Similarly, the London-based fast fashion retailer Topshop provided shoppers with headsets, enabling them to see its catwalk show in real-time through a three-dimensional (3D) virtual world.

Designer Rebecca Minkoff, meanwhile, turned to augmented reality via a partnership with shopping app Zeekit, which allowed viewers to upload a picture of themselves to see what they would look like in their favorite items following the show.

One of the most interesting innovations, however, came in the mixed reality space. This time, it was not so much about capturing and replicating an experience to transport users but, rather, creating an experience layered over the real world through holograms. This was used on a runway for the first time by the legendary Alexander Mc Queen back in 2006, when a hologram version of Kate Moss modeled a dramatic organza gown. Holograms have recently appeared in the fashion shows of Diesel, Guess, and Ralph Lauren, creating optical illusions and taking the relationship between fashion and technology to the next level.

Lastly, during a recent fashion show in Milan last February, luxury designers Dolce \& Gabbana did not trot out handbags on the arms of slender humans. Instead, drones did the heavy lifting, emerging from backstage to the cheers of the audience, capturing it all on smartphones.

The impact of new technologies on fashion shows opens up a set of unanswered questions. Are models to be replaced by holograms and drones? Could holograms and drones be considered performers? Who is the author of the collective work created by artificial intelligence?

The starting point of the discussion on the copyright protection of creations of artificial intelligence (AI) - which could also involve fashion shows taking place in augmented reality and created by AI-is that, under Italian law, creative works must be original to get copyright protection, and traditionally, the requirement of originality has been linked to the physical person of the author. In fact, under Article 6 of the ICL, "the original entitlement of the acquisition of copyright consists of the creation of the work, as a particular expression of intellectual work of the author". Therefore, machines and AI seem to be excluded from the notion of authorship. However, this does not mean that algorithmic artworks cannot afford copyright protection, as long as human choices are involved ${ }^{14}$.

Because the revolution of artificial intelligence is affecting almost every field and it is currently at the center of some legislative studies, we believe it will not be too long for this issue to come before national courts.

\section{Location Matters: Use of Artistic Monuments}

Given the bigger role played by artistic monuments and museums in recent fashion weeks, a special section of this article is dedicated to the historic monuments and artistic and architectural works used as sets of fashion shows ${ }^{15}$.

In fact, from the Louvre Museum for Louis Vuitton, the Tour Eiffel for Yves Saint Lauren, the Valley of Temples for Dolce \& Gabbana, and the Capitoline Museums in Rome for Gucci, fashion houses continue to choose iconic monuments of relevant cities for their catwalks.

Under Italian law, pictures of historic monuments, artistic and architectural works, buildings and, generally speaking, all works that have a cultural value are subject to a specific legal regime.

In fact, even when such works are no longer covered by copyright protection, the Italian Code on Cultural Heritage and Landscape (Legislative Decree No. 42/2004—Codice dei beni culturali e del paesaggio) also applies.

14 For a discussion on the relationship between artificial intelligence and copyright, see, among others, http://www.caaai.eu/ wp-content/uploads/2012/08/MdeCockBuning-Copyright-and-robotisc-robotics-law-journal_03_november_2015.pdf.

15 https://blogs.dlapiper.com/iptitaly/2018/10/fashion-runways-and-right-of-panorama-a-trendy-combo/. 
More specifically, Articles 107 and 108 of such law require those who want to use pictures reproducing goods that belong to Italian cultural heritage to seek authorization from the authority that possesses it, which can either be the state or a local public entity. In any event, once the authorization is granted, a fee must be paid to the relevant authority. There is not a fixed fee to be paid but, rather, is determined by each authority depending on the kind of use to be made.

Exceptions to this rule are limited and could be included in the so-called "right of panorama", that is "the freedom to photographically reproduce monuments, artistic and architectural works, buildings and any public space in general without infringing third parties copyrights on such goods".

Although, under Italian law, the right of panorama exception is more limited than in other EU countries, the Article 108 mentioned above provides that no authorization and no fee are due for the reproduction of such works (a) by individuals in the case of personal use or for study purposes; (b) by private or public subjects for the purpose of enhancement, provided that they are implemented without profit; or (c) in the case of non-profit activities, study, research, manifestation of thought, or creative expression and promotion of cultural heritage.

Therefore, with respect to the right of panorama, a distinction shall be made between the fashion house hosting the show and the guests and journalists posting pictures of the runway.

In fact, the exception applies only to the personal use of the latter groups, who are free to publish images of the models and of the historic monuments and artistic and architectural works used as the sets of such shows.

Use of such works by the maison hosting the catwalk is, instead, made for commercial purposes and thus requires it to seek authorization from the competent authority and pay the relevant fees. The same is also true for press campaigns, tv spots, and any other commercial use made by the fashion brands with respect to historic monuments, artistic and architectural works, buildings and, generally speaking, all works that have a cultural value.

\section{Conclusions}

This work builds on the extension of copyright protection to fashion shows to answer three questions that are crucial in the fashion industry: Are fashion shows copyrightable subject matter? Who is the copyright owner of the work? Are models considered performers?

As to the first question, fashion shows can be protected under copyright in Italy, as there is not a fixation requirement for copyright works nor is there a closed catalogue of copyright subject matter. In this respect, the most akin creations to fashion shows are performance arts, which allow the repetition of a given plot but are also subject to a certain degree of variation, influenced by environmental and social conditions.

Regarding the second question, fashion shows fall within the category of "collective works" and, although they are the result of the work of a number of contributors (architects, set designers, sound and light technicians, hairdressers, makeup artists, seamstresses, etc.), the author has to be considered the director, who is in charge of devising and organizing such work. Typically, fashion maisons appoint well-known art directors to create and coordinate fashion shows.

With respect to the role of models, international laws set a minimum standard whereby as long as a performance is the interpretation of a copyrighted work, performers' rights shall apply. It is reasonable to argue that the performance of the model in the context of the fashion show involves a role of "remarkable artistic importance", thus warranting protection by neighboring rights. Therefore, if this is the case, and once it is established that fashion shows enjoy copyright protection, countries denying performer rights to models walking down the catwalk might theoretically be in breach of their international obligations.

To be on the safest side, fashion companies should include in their agreements a clause whereby all the relevant individuals, including fashion directors and models, transfer their economic rights as authors, coauthors, and performers of the fashion show. 
Finally, copyright protection could be accompanied by further tools, such as registered or unregistered designs for the single elements of a scene or choreography or unfair competition, if the general look and feel of a former fashion shows has been slavishly imitated.

Author Contributions: Writing—original draft, E.V. and V.M.

Funding: This research received no external funding.

Conflicts of Interest: The authors declare no conflict of interest.

\section{References}

Derclaye, Estelle. 2008. French Supreme Court rules fashion shows protected by copyright-what about the UK? Journal of Intellectual Property Law \& Practice 3: 286-7.

Pavis, Mathilde. 2018a. If Runway Models Are Performers ... Is France in Breach of Its International Obligations? Available online: http://ipkitten.blogspot.com/2018/07/if-runway-models-are-performersis.html (accessed on 10 August 2019).

Pavis, Mathilde. 2018b. Runway Models Are Not Performers. Are You Sure? Available online: http://ipkitten. blogspot.com/2018/07/runway-models-are-not-performers-are.html (accessed on 10 August 2019).

Pavis, Mathilde. 2018c. Runway models, runway performers? Unravelling the Ashby jurisprudence under UK law. Journal of Intellectual Property Law \& Practice 13: 867-77.

Pavis, Mathilde. 2019. "In Fashion, One Day You Are in, the Next You Are out": Comparative Perspectives on the Exclusion of Fashion Models from Performers' Rights. Cairo: EIPR, vol. 41.

(C) 2019 by the authors. Licensee MDPI, Basel, Switzerland. This article is an open access article distributed under the terms and conditions of the Creative Commons Attribution (CC BY) license (http://creativecommons.org/licenses/by/4.0/). 
Article

\title{
Photoshop \& The (Virtual) Body of Models
}

\author{
Susy Bello Knoll \\ Internal Evaluator of Research Projects, Austral University, Cerrito St. 1250, C1010AAZ Buenos Aires, Argentina; \\ susybelloknoll@gmail.com
}

Received: 14 July 2019; Accepted: 31 December 2019; Published: 19 January 2020

\begin{abstract}
In this paper, Photoshop is analyzed with a special focus on the bodies of models and a detailed analysis on the legal issues posed by this specific area. For the sake of a thorough development of the topic of this paper, it is necessary to define relevant concepts such as photography and personal image. Regarding the first notion, problems related to intellectual property and, more specifically, copyright are discussed in this paper. Additionally, personal image is one of the most complex and comprehensive areas of law since the protection accorded to it is not equal in different jurisdictions of the world, so its study involves an analysis that goes beyond the scope of this paper. However, various safeguard mechanisms undertaken by some legislations chosen for this purpose will be presented, while also mentioning some specific cases both in the European continental system (Spain and Argentina) and in common law (United States of America and United Kingdom). Finally, the focus is placed on the use of Photoshop for the modification of body shape, particularly that professional models, as these are the ones that work primarily with their image. There will also be a description of some new regulations and mechanisms attempting to restrict image manipulation practices and those that warn the consumers against modified images to eventually conclude on the insufficiency of the same ones and the need for new proposed actions.
\end{abstract}

Keywords: image; right of privacy; right of publicity; Photoshop; models

\section{Introduction}

We live in a world dominated by images. In certain sectors such as advertising or fashion these are used to send attractive messages and thus encourage for the purchase of goods or services. There is a great number of models who, besides inducing you to buy, present an example of what is considered an appropriate way of being or living, thus inspire eagerness to imitate them within the target audience.

Photography then becomes the basic tool not only to capture an image, but to modify it through technical mechanisms. There are, on the one hand, the rights of the subject who is involved in getting the image and, on the other, the rights of the person photographed. Firstly, questions related to photography and the photographer will be developed throughout these pages.

Then, in the second part of this paper, as personal image has developed such a significance that cannot be ignored by Law, there will follow an analysis about the concept of the image.

Protection of the image in different legislation from around the world differs, and for that reason, examples of the diversity of treatments will be illustrated from both a legal and a more specific perspective. The development of the legal protection of images has been deep, wide and controversial around the world, so in this paper we cannot go further than simply enumerating the relevant differences in legislation and the treatment of the courts of the jurisdictions chosen by way of example. To show the complexity of the issue, it is worth mentioning that American law has developed the concept of right of publicity out of the right of privacy, which is conceptually different from the protection granted in countries of continental tradition and even in other common law countries. Consequently, a special analysis will be made in this paper. Additionally, within the United States 
of America, regulations are governed by each state, thus overlapping with common law and certain national legislations, as indicated, all of which renders the analysis increasingly difficult.

Finally, after dealing with photo retouching, a legal concept of modeling will be chosen to show the importance of image in that business and to demonstrate that manipulating images of models may lead, in some circumstances, to infringements of their rights.

Conclusions open a path for future reflections and propose certain actions for Photoshop to be used reasonably with respect to the body of the models.

\section{Photography}

Photography is defined in the Dictionary of the Royal Spanish Academy as "the procedure or technique that allows to obtain still images of reality through the action of light on a sensitive surface or on a sensor" (https://dle.rae.es/fotograf\%C3\%ADa).

In 1838, Louis Daguerre, through the invention of daguerreotype, recorded the first photograph of people in Paris. At the same time, Bayard was working on the invention of a device similar to that of Daguerre but was not quite as successful. However, he was seemingly the author of the first photographic forgery in the 1830s through his Portrait of the photographer looking as if he had drawn it. It is a photograph of Bayard himself, dead, feigning suicide. For this reason, Tabachnik (2012) asserts that photo retouching was also born with photography.

According to the World Intellectual Property Organization (WIPO) a "still image produced on a surface sensitive to light or other radiation, irrespective of the technical nature of the procedure (chemical, electronic, etc.) used to perform the image" (Lipszyc 1993, p. 84; López 2009, p. 381).

We can affirm that there are two types of photographs in Law: some of them are regarded as photographic works and others are referred to as mere photographs. Both forms are protected, but differently. Thus, the Directive of the European Union 2006/116/ EC ${ }^{1}$, article 10 establishes that “... a photographic work under the Berne Convention must be considered original if it constitutes an intellectual creation of the author that reflects his personality, without taking into consideration of any other criteria such as merit or purpose. Protection of the other photographs must be left to national legislation".

It is worth establishing at this stage of the analysis that the type of photography referred to by the cited rules to the one produced by a human being (Villalba and Lipszyc 2012) and not that produced by machines or animals. This is firstly because we consider that artifacts are designed, produced and, more recently, programmed by people. Secondly, because the American Courts have already established that copyright regulations are not applicable to an ape who, after seizing a photographer's camera, obtained several photographs that included one of himself (https://petapixel.com/2018/04/24/ photographer-wins-monkey-selfie-copyright-case-court-slams-peta/).

The person holding proprietary rights - the owner-of the photograph is the photographer. That is, the one who captured the image is the author of the photograph and is hence protected by the Copyright regulations. Strong (1995) indicates that "copyright is born from the moment of creation of the work just like the soul begins to exist with birth". However, the owner of the right to the image itself is the person photographed (Quaini v. Imexca 2009) ${ }^{2}$.

It is said that there are four possible protection systems of photographic work (López 2009, p. 380) ${ }^{3}$, to wit:

(a) Protection granted by copyright rules, with no demand of specific requirements.

(b) Protection granted by copyright rules, with a demand of specific requirements.

1 Directive (EU). 2006. https://eur-lex.europa.eu/legal-content/ES/TXT/PDF/?uri=CELEX:32006L0116\&from=ES; Directive (EU). 2015. https://eur-lex.europa.eu/legal-content/EN/TXT/PDF/?uri=CELEX:32015L2436\&rid=5.

Quaini v. Imexca, G National Court of Civil Appeals, Argentine (2009).

3 Referring to Colombet. 
(c) Protection granted by copyright rules for works regarded as artistic and protection as a related right for simple photographs (Lipszyc 1993, p. 85) ${ }^{4}$,

(d) Protection granted by specific safeguard rules ${ }^{5}$.

Copyright regulations protect both the moral and economic rights of the photographer, who is the author of the photograph.

With regard to the former, moral rights, photographer has the right to decide whether or not to disclose his work (right of disclosure), to be recognized for the proprietary right in it (right of attribution) and not to be altered (right of integrity).

Economic rights imply the "power to control the exploitation of the work" (Lipszyc 2019, p. 80) so that the photographer enjoys a wide range of rights such as the right of reproduction, public communication and transformation (Lipszyc 1993, p. 11). The photographer enjoys, in principle, as many economic rights "as forms of use" (Lipszyc 2019, p. 76) by third parties or associated with them, where possible.

Economic rights are subject to a specific term of protection based on a certain circumstance established by the regulations so that countries have been adopting different terms. The Berne Convention (Act of 1971), in its article 7.4., establishes that the term of protection of photographic works cannot be less than 25 years. However, WIPO Copyright Treaty states that "the Contracting Parties shall not apply the provisions of article 7.4. of the Berne Convention" so that, within the framework of that Treaty, the general term that imposes the protection of works for the entire life of the author and seventy years after his death from January 1 of the following year is applied produced the same (Lipszyc 2004), or to her statement in favor of her heirs or right holders.

Moral rights of the photographer have no restriction (Lipszyc 1993, p. 219); however, their economic rights are limited in their exercise to the extent that they are dealing with the photograph of a person who in turn possesses the right to his/her own image, being able to prohibit the reproduction of it. The recognition of this right is a limitation on the right to dispose of the photographic work grounded on copyright rules.

\section{Personal Image}

Image is the representation of our identity (Bello Knoll 2019, p. 117).

According to the Spanish Dictionary of Legal Terms, it is the set of physical traits or details that identify a person. Image will then allow us to differentiate from others. It is the diversity principle among human beings. Personal image is what makes us unique and different.

As image is so essential for each individual, the Law, as the mechanism ordering social conducts, cannot ignore its importance (Bello Knoll 2019, p. 117).

However, in the international sphere, there is no rule, declaration or pact referring directly to the right of the image itself. In 1948, the United Nations Assembly approved the Universal Declaration of Human Rights ${ }^{6}$, and this instrument, although there is no specific reference to image itself, states in article 12 that no one may be subject to arbitrary interference in his private life, nor can he/she suffer attacks to his honor or reputation. Then, this indirect protection is stated again in the International Covenant on Civil and Political Rights of $1966^{7}$ in keeping with article 19, which refers to freedom of expression with due respect for the rights and reputation of others. We can then observe the focus is placed on two questions referring to the right to one's own image relating it to other rights. The first refers to dignity and honor. The second to freedom of expression. Thus, the right to image itself is an autonomous right regardless of other rights but which is socially balanced with them (Zingaretti 2018).

\footnotetext{
It is indicsated that Austria and Italy have this protective regime.

It is indicated that Norwegian countries have this protective regime.

Universal Declaration of Human Rights (1948). Retrieved from https://www.un.org/en/universal-declaration-human-rights/.

https://www.ohchr.org/Documents/ProfessionalInterest/ccpr.pdf.
} 
At a regional level, for example, in 1989 the European Parliament approved the Declaration of Fundamental Rights and Freedoms (1989) which makes reference to the protection of identity in its article 6 (Sáez Tapia 2017) but without recognizing the independence of the right to the image itself, while the same has occurred in Latin America.

Different legislation around the world has dictated, to a greater or lesser extent, the rules to protect human image at a domestic level in each country. Regulatory diversity is huge. In some countries of the continental tradition, protection has constitutional status, as in the case of Spain. In other countries of an equivalent legal tradition, there is specific legislation referring to the right of the image itself, such as in Spain or in Mexico. There are only provisions in the Civil Code in countries such as Argentina, Bolivia, Brazil, Costa Rica, France, Italy, Peru and Portugal. References to the law of image itself are also found in laws referring to other issues, such as copyright in Germany, Argentina, Austria, Belgium, Brazil, Colombia, Costa Rica, Ecuador, El Salvador, Guatemala, Honduras, Italy, Mexico, Paraguay, Peru, Portugal, the Dominican Republic and Uruguay (Antequera Parilli 2012). In the countries of common law, there is also a diversity of treatment and, for example, state standards converge in the United States of America, which are in turn articulated through judicial resolutions and national rules.

The complexity and the wide-ranging scope of image protection is a topic that transcends this paper, so for that reason the decision taken has been to show the example of regulations and case law of two countries of the continental tradition: Spain and Argentina; and of two countries in the field of common law: United States and the United Kingdom. This has been made only for the purposes of providing a broad view of the protection of the image, which will help determine the importance and peculiarities of the right involved in the Photoshop manipulation conducted in the body of the models.

\subsection{Examples of Regulation in Continental Law Countries: Spain and Argentina}

Spain is at the forefront of innovation in this right as autonomous in its Constitution, thus ensuring the right to one's own image (Rougés 2009; Vidal Beros 2015). In "Fundamental rights and duties", in the chapter dealing with rights and liberties, Section 18.1., "The right to honor, personal and family privacy and image itself is guaranteed". The right to image itself is then a fundamental right framed within so-called personal rights, personality rights or existential rights (Navarro Floria 2016, p. 12), lacking heritage content (Martin Muñoz 2001, p. 1715). That is, these are those rights inherent to the natural person and which are recognized by the mere fact of their existence (Villalba Díaz 2011). The right to personal image recognized in this Fundamental Charter becomes a part of the set of values considered relevant by society, and is thereby capable of being protected by way of legal action for the safeguarding of a constitutional privilege (amparo).

Then, a Spanish organic law, LO 1/1982, has dealt with the civil regulation of the right to self-image and establishes in its first article that: "The fundamental right to honor, personal and family privacy and the image itself, guaranteed in article eighteen of the Constitution, will have civil protection against all kinds of illegitimate interference, in accordance with the provisions of this Organic Law". This rule establishes that the right to image itself is an inalienable right and not subject to any statute of limitations as asserted before by legal experts (Fernández-Lasteguy Quintana et al. 2018, p. 117).

As stated by law, the requirement is that there must be an express consent of the owner of the image for its use by third parties; however, in section eight there are exceptions stipulating the following: "In particular, the right to one's own image will not prevent: (a) its capture, reproduction or publication by any means when it comes to people exercising a public office or a publicly notorious profession or with a public projection and in case the image is captured during a public event or in places open to the public; (b) The use of the cartoon of said persons, according to social usages; (c) The graphic information about a public event or event when the image of a specific person appears as merely accessory. The exceptions referred to in paragraphs (a) and (b) shall not apply with respect to the authorities or persons who perform functions which by their very nature calls for the anonymous status of the person exercising them". 
One of the biggest problems around consent is rule 2.3, which establishes that "the consent referred to in the preceding paragraph shall be revocable at any time, but in any case, damages sustained are to be compensated, including reasonable expectations". Considerable uncertainty is generated in assignment contracts, as revocation of consent may cause severe damage even if paying for a compensation is contemplated, which actually turns out to be difficult to assess (Castilla Barea 2011).

Publishing the image and its mere capture or reproduction qualifies as a tort. If this illegality is proved, it results in the compensation for injured feelings and reputation (moral damages) (De Verda y Beamonte 2011, p. 53).

In the case of Joaquin Cortés v. Letona $S A_{,}^{8}$ the plaintiff filed a claim for violation of his image against a dairy company in a commercial. In that advertisement, a person appeared dancing flamenco with a naked torso, long hair and black pants, all of which were his characteristics. The Court of Barcelona, Spain, considered that those identifying elements constituted the image of the dancer. However, in the case Emilio Aragón v. Proborín SL ${ }^{9}$, the Spanish Constitutional Court rejected the claim by plaintiff, as it was held that the use of his own expressions, black pants and white boots were not "the reproduction of the person's face or physical features but an imaginary representation of the external characteristics of a television character". Undoubtedly, this inconsistent case law, which is based on the distinction of the constitutional aspects of civilians, generates uncertainty in the legal domain (De Verda y Beamonte 2011), and the same uncertainty applies to the fact of ascertaining the legal notions that demarcate image as definition seems to be absent. When LO 1/1982 refers to misappropriation, it extends the protection of image to human apart from image per se, which has meant a broader interpretation of the identification of a person in case law.

Spanish legal scholars, when analyzing the cases resolved both in the constitutional and civil spheres, assert that for the purposes of effective protection representation of physical appearance of a human being must be at stake; there must be an act of reproduction of physical appearance of a human being, and the person must be recognizable (Castilla Barea 2011).

Courts in Spain have stated that the right to one's own image can only be relinquished in case a right of equal ranking is to be prioritized, such as the right to freedom of information (Barnett 2000, p. 1244).

In the Argentine Republic, as stated above, protection of image is governed in the Civil and Commercial Code of the Nation, as it regulates the country's international obligations to preserve image as a basic right of persons. Consequently, in Sections 52 and 53 of the chapter dealing with personal rights and acts, cases when a person's dignity is affected are contemplated, especially when the image is damaged, so a prohibition is imposed on the reproduction of images without the consent of the person, save for in some exceptional cases (Villalba Díaz 2011), as stipulated by Spanish legislation.

Under these norms, the image is protected as an "essential human right", while also protecting their economic content, which necessarily results in a redress and monetary compensation (Vidal Beros 2015, p. 95). In this jurisdiction, for the purposes of using the image of a third party, the following requirements must be met: (1) asking for prior consent, and (2) checking that there are no exceptions to the request for prior consent. In the case Maradona, Diego Armando v. Telecom Personal $S A^{10}$ and others the Court expresses that the "mere evidence of an unauthorized publication determines the arbitrariness of that publication as there is a legal rule expressly preventing and sanctioning such conduct". The court further stated that "consent is not presumed and is of restrictive interpretation."

There are two sides of the same coin in the Argentine legal system, as in the Spanish civil law: (a) the right of each person to register, reproduce and publish their image, and, (b) the right to prohibit their capture and publication without authorization (Sáez Tapia 2017; Fernández-Lasteguy Quintana et al. 2018, p. 117). Image represents an asset for its owner, and therefore each individual has the

Cortés v. Letona SA, Secc. 2002. 17 Audience of Barcelona, Spain.

Aragón v. Proborín SL. 2001. 104 BOE 50 Spanish Constitutional Court. Madrid: Aragón v. Proborín SL.

10 Maradona v. Telecom Personal SA. 2014. D National Court of Civil Appeals, Argentine. 
possibility to exploit it at a personal level, in society or to assign the right to third parties either in exchange for a valuable or non-monetary compensation (Schötz 2015, p. 157). It is Civil Law, in the different laws around the world, that deals with regulating these contractual relationships exceeding constitutional protection on the economic component of image.

Since 1933, Intellectual Property Law $(11,723)$, still in force, has protected the commercial publication of the photographic portrait. Thus, prior to the entry into force of the Civil and Commercial Code, the Courts grounded their resolutions on Section 31 of that law in order to allow for compensation for publicity of the unauthorized image of a person either with commercial purposes or otherwise. In the case S.B. v. Arte Televisivo Canal $13^{11}$ the image of the lady was obtained in a street interview in order to know her opinion on a particular subject, but during the interview her denture got off while she was speaking and tried to fit it while she was being recorded. Subsequently, the channel used the image in a mocking tone and as a blooper. The Court interpreted that harmonization with the right to information of the right to self-image required the preservation of the very personal right of women framed within the provisions of said intellectual property law.

Additionally, Argentine judicial precedents, very much like other cases, have established that the image of minor child is not the same as the image of an adult. The United Nations Convention on the Rights of the Child (CRC) $)^{12}$, subscribed to by almost all countries in the world, states that children enjoy the same protection as adults, but it also manifests that they deserve special protection because of their condition as human beings who are not fully developed physically and mentally. This is what the Court held in Ochoa, J. v. Medios y Contenidos Producciones SA Cris Morena Group UTE ${ }^{13}$, where the defendant was held liable for the harmful consequences caused to a young child based on Article 16.1 of said Convention, among other national and international standards.

Furthermore, the concept of protection of image has also been laid down in Argentine judicial decisions, such as the case Braunstein, Tamara Ileana v. Palermo Films SA et al.li. ${ }^{14}$ The advertising model claimed payment for the use of their image after the termination of the contract. She did not accept the new monetary offer by the company, so the company used the video where the model was part of a dance group representing the movement of the bristles of a toothbrush and replaced her face. The Court found against Palermo Films and Procter \& Gamble Interaméricas LLC sucursal Argentina for having sectioned, by mutual agreement, the body of the model. Since the defense contended that the body was wrapped in a white jumpsuit, the Court held that it does not really matter whether the body of the person is covered or not; rather, the fact that is the body of a given person is what really counts.

In the case Ochoa, which has already been cited in this paper, the reason the photograph was taken is highlighted, so the Court makes a pronouncement against the use of photography for another purpose It has always been stressed that the purposes of use must be specified in the consent granted. (Burbidge 2019, p. 81).

In the case Braunstein - already cited-as well as in P., A.A v. Indo $S A^{15}$, the expiration of the term of the advertising contracts gave rise to rulings in favor of the claimants. For that reason, the adequate course of action in assignment of image rights is the following: (a) specify the purpose for which the image will be used; (b) establish the term during which the image will be used.

The goal sought is always the same: to make sure that the personal image is evaluated on a case by case basis and, based on that, to determine whether the publication affects the right to one's own image. In the case Massola, Facundo Albino v. Ford Motor Company ${ }^{16}$ the compensation sought by the horse rower was rejected because of the fact that the image was used for non-commercial purposes by

11 S.B. v. Arte Radiotelevisivo Argentino SA-Canal 13, B National Court of Civil Appeals, Argentine. 2014.

12 The United Nations Convention on the rights of the Child (CRC) (1989). Retrieved from https://ec.europa.eu/anti-trafficking/ sites/antitrafficking/files/un_convention_on_the_rights_of_the_child_1.pdf.

13 Ochoa v. Medios y Contenidos Producciones SA Cris Morena Group UTE, H National Court of Civil Appeals, Argentine. 2015.

14 Braunstein v. Palermo Films SA, and others. 2017. 368 National Court of Labor Appeals. Argentine: Bulletin.

15 P. v. Indo SA. 2013. III Mar del Plata Court of Civil and Commercial Appeals, Argentine.

16 Massola v. Ford Motor Company. 2013. F National Court of Civil Appeals, Argentine. 
Ford in its magazine as part of the information that the company was sponsoring, and, additionally, the focus was not on the image of the person but on the event.

\subsection{Examples of Regulations in Common Law Countries: United States of America and Great Britain}

In the United States of America, the right to the personal image is established, firstly, within the framework of the right to privacy, defined as the right to be left alone (Sáez Tapia 2017). However, a posteriori, the foundations of the right of publicity were developed, which is recognized in state laws. but not in federal law.

This right of publicity seeks to protect celebrities. This is suggested in an 1890 article by Samuel Warren and Louis Brandeis, in which they propose a special right to protect celebrities' identities against the interference of journalists (Slater 2017). Nonetheless, the right to the commercial value of a personal image is widely regarded as having universal importance (Higueras 2001, p. 89).

The Restatement (Third) of Unfair Competition of $1995^{17}$, in Section 46, defines the right of publicity as: "One who appropriates the commercial value of a person's identity by using without consent the person's name, likeness, or other indicia of identity for purposes of trade is subject to liability for the relief appropriate under the rules stated in $\S \S 48$ and $49^{\prime \prime}$. That is, it protects the commercial value of the identity of a human person and limits such protection to the commercial use of the image consented by the owner of it. "It does not protect the personality itself, but its financial value" (Higueras 2001, p. 53).

It is still, as of today, a state regulation (http://rightofpublicity.com/statutes), meaning that there is a big difference in both the regulation and in the jurisprudence of the various states, and it is thus considered a "convoluted mix of inconsistent and unorganized interpretations" by the doctrine (Barnett 2000, p. 1227). Arkansas and Alabama are states that have recently approved special regulations. At the state level, this right is considered an economic right (Burbidge 2019) that allows the person to control the commercial use of their identity, as has been explained before (Seeger et al. 2019; Rovira Sueiro 1997). Commercial use in the right of publicity is expressed in the narrow sense of advertising activity or the promotion of goods or services (Barnett 2000, p. 1230). The doctrine construes three rights in one: the approval of the use of the image, authorization of the commercial use, and that of digital printing of the image (Johnson 2017).

The rule in New York, the jurisdiction where almost 25\% of US cases are resolved (Igartua Arregui 1991, p. 96), allows for the protection of the personal image when there are commercial purposes in play for either a celebrity or a normal person, but it does not allow post mortem rights. One of the landmark cases is Haelan Laboratories v. Topps Chewing Gum, which in 1953 found the company guilty of unauthorized use of the athlete's image in chewing gum packages (Tushnet 2015).

California has a double-layered protection, perhaps because it was Hollywood, at the time of Marilyn Monroe, that was already demanding better protection for celebrities. On the one hand, common law acknowledges the appropriation of the image without consent leading to damages and, on the other hand, codification adds the element of intent of the improper use in direct connection with the economic purpose (Slater 2017). In this State, the duration of the right is for the entire life of the owner of the image plus 50 years after their death. The validity varies from State to State, reaching up to 100 years after death in Indiana, and, in Tennessee, it is considered a perpetual right (Barnett 2000, p. 1231).

Some States continue to resolve disputes based on common law and also resort to federal protection of copyright rules established in 1787, which causes conflicts with state copyright rules, as well as with the right of publicity itself. In 1880, a United States Court established that photographs are protected by the Copyright Act which, as previously mentioned, implies federal protection. The new intellectual property regulations of 1976 establish that the owner of the photographed image is the

17 https://is.muni.cz/th/169953/pravf_m/Extract_III.pdf. 
one who operates the camera and not the person portrayed (Slater 2017). In Maloney $v$ T3Media, Inc. ${ }^{18}$, the California Court held that the intellectual property rule prevails in the athlete's claim.

For some authors, the right of publicity is an area for the protection of controversial images (Tushnet 2015; Seeger et al. 2019). However, from our point of view, it must be studied in depth, since there are no similar developments in other jurisdictions such as those in Europe or Latin America.

As it is a common law legal system, case law is the main tool for the study of this concept. As seen in the cases of Spanish resolutions, the lack of case law precision of the extension of the concept of personal image to certain representations has led to contradictory rulings in the United States such as Keller v. Electronic Arts Inc ${ }^{19}$,, where an athlete's claim was rejected for being incorporated into a video game and Winter $v$. DC Comics ${ }^{20}$, where the right of musicians to be compensated was granted for being included in comics. In Lindsay Lohan v. Take-two Interactive Software Inc., ${ }^{21}$ Lindsay Lohan sued Take-Two for using her image in a video game when the image had been computer created. The New York Court of Appeals ruled in March 2018 that under Civil Rights Law $\S 50$ and 51, the representation in a video game constitutes an image, but in this case the claimant was not recognizable in the video and thus it was interpreted that the main point was the possibility of precise identification of the owner of the image (Higueras 2001, p. 55). In White v. Samsung Electronics America Inc. ${ }^{22}$, the host of the program "The Wheel of Fortune", Vanna White, sued the company for using, in a magazine advertisement, the figure of a female-shaped robot dressed as the host did and spinning the wheel of fortune, arguing her identity was being used. The California Court ruled in favor of White with an important dissenting vote of Judge Alex Kozinski for what the doctrine considers to be important: the identification or not of the person (Barnett 2000, p. 1235), as previously discussed in the Spanish case.

Particularly, the right of publicity is generally limited by the First Amendment of the United States Constitution, which advocates for freedom of speech and has the public interest in mind, although it is sometimes difficult to define the latter in this particular case (Slater 2017). In Grant v. Esquire Inc., Esquire magazine reused a $1971^{23}$ photo of Cary Grant in an article on fashion trends. The photograph had appeared in a previous issue of the aforementioned magazine in 1946, and the Court ruled that the photo of 1971 did not speak at all about the taste in clothes of the actor and that his face was only used to attract attention (Higueras 2001, p. 60).

The United Kingdom does not have a law that protects personality rights per se. Nor is the right of publicity or the tort of appropriation of personality (Smith 2001, p. 65). Therefore, all claims rely on the right to privacy as a basis (Burbidge 2019, p. 73). Although not as usual, it is also possible to defend the right to personal image by citing intellectual property rights within the UK (Burbidge 2019, p. 76).

For the purpose of restricting the abuse, exploitation or unauthorized use of one's own image, remedies such as passing off, defamation and malicious falsehood within the common law must be taken into account, although the latter is rarely used except in cases of fiction (Smith 2001, p. 68).

The Human Rights Act of 1998 widely accepts that the European Convention on Human Rights of 1950 establishes in article 8.1 that "everyone has the right to respect for his private and family life, his home and his correspondence", and in Article 8.2, that any interference must be "in accordance with the law". In Campbell v. MGN ${ }^{24}$, the House of Lords ruled that, in certain circumstances, even if photographs are taken on public roads without the person's consent, they may violate the individual's privacy. Supermodel Naomi Campbell had denied having a drug addiction, but photographers for

18 Maloney v.T3Media Inc. 2017. 9 th. Cir. California, USA. https://law.justia.com/cases/federal/appellate-courts/ca9/15-55630/ 15-55630-2017-04-05.html.

19 Keller v. Electronic Arts Inc. 2014. 135 S. Ct. 42, 189 L. Ed. 2d 894, USA.

20 Winter v. DC Comics. 2003. 69 P.3d 473, 480 USA (Cal. 2003).

21 Lohan v. Two-Take Interactive Software Inc. 2018. NY Court of Appeals, USA. http://www.nycourts.gov/reporter/3dseries/ 2018/2018_02208.htm.

22 White v. Samsung Electronics America Inc, 971 F.2d 1395 (9 $9^{\text {th }}$ Cir. 1992)

23 Grant v. Esquire Inc. 1973. 367 F Supp 876, 878 (SD NY 1973).

24 (n.d.) Campbell v. MGN, 2 A.C. 457. 
the Daily Mirror obtained photos of the celebrity exiting a Narcotics Anonymous meeting that were later published. The House of Lords based its ruling on Article 8.1 of the Human Rights Acts of 1998, because privacy is independent of whether or not the person is famous and refrained from commenting on the advertisement or price of the image as they are pertinent to civil law or the rules and laws governing false advertising (Cornish et al. 2013).

The consent given for the use of the image is relevant for the Court, as evidenced by Fenty and Ors v. Arcadia Group Brands Ltd. (t/a/ Topshop) and Anor of 2013. In it, Topshop and Arcadia had to pay compensation to singer Rihanna for stamping her image on shirts and profiting from it without prior authorization (Schötz 2015, p. 161; Burbidge 2019, p. 77).

Moreover, as was previously mentioned for another jurisdiction in this paper, the Courts emphasize the protection of minors. In the case of Murray v. Associated Newspapers, ${ }^{25}$ writer JK Rowling and her husband complained about a violation of privacy carried out by Sunday Express by publishing a photograph of them and their two-year old son in a stroller in public. Although the ruling in the first instance was not favorable, the ruling was reversed in the parents' favor after an appeal was made (Cornish et al. 2013).

As it was with the aforementioned cases in different jurisdictions, a balance between the right of personal image and freedom of expression is always the main concern. In Douglas, Zeta-Jones, Northern $\mathcal{E}$ Shell Plc v. Hello! Limited ${ }^{26}$, based on the Human Rights Act of 1998, it was ruled in favor of the claimants, despite the fact that Lord Justice Keene's decision expresses the difficulty of resolving a case where freedom of press is involved. The celebrity couple had signed a contract that gave explicit rights of the wedding photos to OK! Magazine, but its competitor Hello! published unauthorized photos of the wedding that were obtained in violation of the couple's privacy (Smith 2001), so that the right to privacy also subsists when their owners exploit their image commercially.

It is worth mentioning that the Human Rights Act of 1998 exceeds the requirements of the aforementioned European Convention since it establishes circumstances in which a Court may provide measures to stop a publication that may cause harm (Cornish et al. 2013). The doctrine established that in contrast to the United States Constitution, the European Convention does not give presumed priority to freedom of speech (Smith 2001, p. 86).

\section{Virtual Image of Models}

To define modeling activity, the Argentine tax regulation refers to advertising models as those that work by displaying their own image to promote an object, product idea or service in a promotional campaign or fashion models that sell their image by appearing on stages or catwalks for the presentation of clothing, jewelry, hairstyles, cosmetics and other similar products or services. The provision also includes the commercial promotion and work in films or television where the task is executed according to a choreographic routine and a scenography established by a third party, static or in movement, to record the image on any type of magnetic or electronic support in order to transmit or reproduce it by any means.

Professional models are people who live from their image (Lencina 2017), as indicated by the aforementioned norm. This means that the reproduction of that image implies for them a greater degree of care and attention regarding the use given by third parties. Misuse of their image could affect the economic interest of the person as seen in C.R.T.E. v. HSBC B.A. SA ${ }^{27}$ and others, where the photographs of a casting for an advertising model were used without their authorization and without compensation.

\footnotetext{
Murray v. Associated Newspapers. 2008. E.C.D.R. 12.

Douglas, Zeta-Jones, Northern \& Shell Plc v. Hello! Limited, 2 W.L.R. 992. 2001

C.R.T.E. v. HSBC SA. 2016. F National Court of Civil Appeals, Argentine.
} 
As part of the professional exercise of models, temporary contracts are signed that establish, in addition to economic compensation for the model, the activity to be carried out by the model. However, it is not customary to determine in these agreements the specific extremes for the use of the image related to the purpose of the contract, the extent of the usage, the means by which the image will be exhibited, the admitted adjustments, the term, or the resolution of conflicts related to the personal image. The tasks performed under the contract by the models usually exceed the particularities established in the standard chosen to describe the profession. Oftentimes, although less frequently, an employment relationship is established where the aforementioned characteristics are not detailed, and the personal image is neglected.

The improper or unauthorized use of the image of models, even within the framework of a contract (Martín Muñoz 2001, p. 1714) may also affect the personal rights of the personal image so that a law such as Article 3.a. of the Spanish advertisement law 34/1998, of November 11, deems as illegal any advertisement that violates the dignity of the person or the values and rights recognized in the Constitution, emphasizing the protection of women's image, bearing in mind that Spain has constitutionally comprised the right of personal image in Article 18 (Higueras 2001, p. 283).

Italy is the forerunner in installing ethical principles related to the work of the models. Already in 2006, the Nazionale della Moda Italiana imposed a Code of Ethics that has been respected since. France, in turn, in 2017 imposed a mandatory muscle mass threshold certificate for models to preserve their health (Burbidge 2019, p. 171-72).

\section{Photo Manipulation}

Before photographs, records of personal images were done by means of paintings, drawings or sculptures. For a long time, both people and landscapes have been colored in photographs.

In laboratories, it was possible to superimpose negatives, open closed eyes and modify photographic records, and yet popular culture associates photography with the representation of reality.

Science and technology have created something unprecedented, a permanent record of images available through cellular phones. These devices also allow you to eliminate excessive brightness or add light to the shot among many other tweaks. Social networks such as Instagram also offer the possibility of photo manipulation.

The use of photo manipulation is common in areas such as news media, advertising or fashion where image is of utmost importance. In these cases, computer programs are used ranging from very simple to highly complex ones. Perhaps the best-known software license is Adobe ${ }^{\circledR}$ Photoshop ${ }^{\circledR}$ (Tallarico 2010). This program allows for the creation and editing of digital images, but it is not the only one that exists. Adobe Inc. frequently sends emails to authors of web pages that use the term "Photoshopped" informing them that only Adobe Inc. or people that have bought the license can use the terms "modified by Photoshop software". Recently, this company, together with the University of Berkley, developed an artificial intelligence tool that detects facial retouching made with the software and returns them to their original state.

In principle, the usual goal is to make sure that the images look better, i.e., more beautiful. This creates a cultural dilemma, since the idea of beauty is usually built within a certain group of individuals who share experiences, stories, life events and even a similar physical environment. For example, Barbie is considered an icon of American culture (Bartow 2019).

Globalization has caused waves to impose a certain concept of universal beauty for purposes other than the search for beauty. Advertising today, as an instrument to foster consumption of products, works on images that show a specific beauty canon that can be studied in depth with the analysis of what is exhibited in the market, particularly in relation to female charm (Martinez Oña 2015). To achieve this aesthetic, digital manipulation of images that can go unnoticed or be rude is used.

Photo manipulation has created a virtual reality that is nothing short of fantasy (Sartori 1998, p. 33). Persons who see the advertising do not have the aesthetics of the retouched image and are thus 
motivated to imitate the model (Ramos Lahiguera 2017). This creates negative consequences such as discrimination (Martinez Oña 2015) or loss of self-esteem, particularly among adolescents (Pozzo 2016, p. 366), women (Scafidi 2019, p. 434) and children. During the Milan Fashion Week in 2007, the anorexic image of model Isabelle Caro for the advertising brand Nolita showed the consequences to human health that the search for a distorted image ideal may cause (Ramos Lahiguera 2017).

Technical manipulation of images is not inherently bad, but the intention or effect that is pursued can be, and that can promote deceit or cause psychic and physical harmful behavior for the recipients of the manipulated images.

In 2012, supermodel Coco Rocha was photographed by Elle Brazil magazine in a dress with cutouts and a skin-colored cape. Rocha has a policy of not appearing totally or partially naked, so she was wearing another dress underneath, but Elle Brazil altered the image to remove it to show more skin. The model expressed frustration at the disrespectful manipulation of her image (Williams-Vickery 2018).

In that same year, Israel passed a law that was baptized by the press as "The Photoshop Law" that prohibits advertisers from using excessively thin models and forces them to put a specific statement on photos that have been manipulated by image editing software. Also in 2012, in the Autonomous City of Buenos Aires, Argentina, law 3960 was passed, which establishes in its first article that "All billboards exhibited on public roads, in which a human figure is used as a support or as part of the context or landscape of the advertisement that has been digitally manipulated and/or modified through computer programs, must display the following disclaimer properly and in a sufficiently prominent place: "the image of the human figure has been retouched and/or digitally modified". Frances has passed a law of similar characteristics in 2017.

Within the context of claims for the digital manipulation of the figure of models, American Courts are placing an increasing amount of emphasis on the nuances of the consent given in the contracts. The New York Supreme Court, in particular, emphasizes the study of manipulation so as to see if there exists a new image that cannot be consented. The doctrine indicates, however, that the right of privacy and right of publicity are not sufficient in these cases and a new right must be created to resolve these violations (Williams-Vickery 2018).

Authorities that regulate advertising standards in different countries such as the British Advertising Standards Authority (ASA) are increasingly imposing stricter rules for the respect of the human image in advertising (Pozzo 2016, p. 379). On June 21, 2019, it established a new rule that states that advertisers should not include gender stereotypes that could cause harm or a serious or widespread offense. France and Italy are two other countries where there exists this invaluable help to restore social dignity.

Also, there are blogs, websites and social activists such as www.theillusionists.org that denounce tweaks give way to new movements that promote what is called "real beauty" (Ramos Lahiguera 2017). All this helps raise awareness on the consumers side and the enforcement of existing regulations in their defense, but it does not seem to be enough; more public action and mandatory laws for image protection are required, particularly in advertising.

\section{Conclusions}

There is no doubt about the importance of the image throughout the history of humanity, but it has been accentuated in recent times; technology has democratized the possibility of portraying and being portrayed. Here we have shown that the Law is concerned with protecting it, although it does not always provide correct solutions given the diversity in existing norms and their different judicial interpretations.

The right of privacy and the right of publicity are not enough to face the challenges of the digital resolution of images and the interpretation of the doctrines and case law are not enough to resolve the conflicts that arise. It is necessary to develop a new generation of rights that protect the personal 
image of the creation of avatars that try to reproduce it, the replacement of essential characteristics that define it, and the rude retouchings to which it is subjected.

For models that make professional use of their image and that sign contracts for this purpose, it is advisable that they establish clauses that:

(a) Grant an express consent for the use of the image;

(b) Establish the specific object for which this image will be used;

(c) Set a deadline for permitted use;

(d) Authorize only a reasonable retouching of the image;

(e) Create a way to resolve conflicts related to the image, such as arbitration; and,

(f) Lay down an indemnity value or an effective calculation of compensation in accordance with the possible violations of the moral and economic rights of the image.

As there are not many jurisdictions that have rules that force advertisements to inform the consumers that images have undergone digital manipulation, it is vital that countries adopt this legislation.

Lil Miquela works as a model for Prada, giving interviews from California and has more than 1.5 million followers on Instagram. She is only a bundle of pixels since it was designed by the technology company Brud, who initially concealed its origin when it was launched in 2016 (Hsu 2019). That is how the first completely virtual model appeared, not conditioned by any legal parameter. Faced with situations like this and the descriptions of real models that use their image as an instrument of professional work and suffer the manipulation of it, us jurists must study the social effects of the hyper-reality that the market creates to generate proposals that contribute to the balance of the real with the virtual, respecting rights and personal and cultural essences.

Funding: This research received no external funding.

Acknowledgments: The author of this paper would like to thank Luis Denuble and Natalia Tenaglia-Argentine lawyers residing in New York-for their help in searching material on the right of publicity. She would also like to thank Cecilia Irrazábal for her professional assistance in the English version of this paper.

Conflicts of Interest: The author declare no conflict of interest.

\section{References}

Antequera Parilli, Ricardo. 2012. Derechos Intelectuales y Derecho a la Imagen en la Jurisprudencia Comparada. Madrid: Reus.

Barnett, Stephen. 2000. El derecho a la propia imagen: El right of publicity norteamericano y su correspondencia en el derecho español. Revista de Derecho Mercantil Núm 237: 1225-49.

Bartow, Ann. 2019. Barbie in bondage: What Orly Lobel's Book “You don't own me: How Mattel v. MGA Entertainment exposed Barbie s dark side" tells us about commoditization of the female body. Fordham Intellectual Property, Media \& Entertainment Law Journal XXIX: 435-76.

Bello Knoll, Susy. 2019. La imagen profesional y el Derecho. Cuadernos del Centro de Estudios en Diseño y Comunicaaión (Ensayos) Palermo University Núm 97: 117-23.

Burbidge, Rosie. 2019. European Fashion Law. A Practical Guide from Star-Up to Global Success. London: Elgar Practical Guides.

Castilla Barea, Margarita. 2011. Las Intromisiones Legitimas en el Derecho a la Propia Imagen. Cizur Menor: Aranzadi-Thomson Reuters.

Cornish, William, Llewelyn David, and Aplin Tanya. 2013. Intellectual Property, 8th ed. London: Sweet \& Maxwell.

De Verda y Beamonte, José. 2011. El derecho a la propia imagen en la Ley Organica 1/1982, de 5 de mayo. In De Vera y Beamonte (Coord.). El Derecho a la Imagen Desde Todos los Puntos de Vista. Cizur Menor: Aranzadi-Thomson Reuters, pp. 41-64.

Declaration of Fundamental Rights and Freedoms. 1989. Available online: http://www.europarl.europa.eu/charter/ docs/pdf/a2_0003_89_en_en.pdf (accessed on 2 January 2020). 
Fernández-Lasteguy Quintana, Javier, García de la Rasilla Arambarri, Carolina, López López, Alba María, and Espín Martí Cristina. 2018. Fashion Law (Derecho de la Moda). Edited by Ortega Burgos and Enrique. Cizur Menor: Aranzadi-Tomson Reuters, pp. 117-30.

Higueras, Inmaculada. 2001. Valor Commercial de la Imagen. Aportaciones del Right of Publicity Estadounidense al Derecho de la Propia Imagen. Pamplona: Ediciones Universidad de Navarra.

Hsu, Tiffany. 2019. These Influencers Aren't Flesh and Blood, Yet Millions Follow Then, New York Times. Available online: https://www.nytimes.com/2019/06/17/business/media/miquela-virtual-influencer.html (accessed on 2 January 2020).

Igartua Arregui, Fernando. 1991. La Apropiación Commercial de la Imagen y del Nombre Ajenos. Madrid: Tecnos.

Johnson, Eric. 2017. Disentangling the right of publicity. Northwestern University Law Review 111: 891.

Lencina, Marcelo. A. 2017. El derecho a la imagen en el Código Civil y Comercial de la Nación. Temas de Derecho Civil Persona y Patrimonio 379.

Lipszyc, Delia. 1993. Derecho de Autor y Derechos Conexos. Buenos Aires: Zavalia.

Lipszyc, Delia. 2004. Nuevos Temas de Derecho de Autor y Derechos Conexos. Buenos Aires: Zavalia.

Lipszyc, Delia. 2019. Régimen Legal de la Propiedad Intelectual. Buenos Aires: Hammurabi.

López, Beatriz. 2009. Reflejo de las especiales características de la obra plástica en la sucesión mortis causa del derecho de autor. Anuario de la Facultad de Derecho La Haban Cuba XXVII: 380.

Martín Muñoz, Alberto. 2001. El contenido patrimonial del derecho a la propia imagen. Revista de Derecho Mercantil, Octubre-Diciembre 242: 1711-76.

Navarro Floria, Juan. 2016. Los Derechos Personalísimos. Buenos Aires: El Derecho.

Pozzo, Barbara. 2016. La pubblicitá del prodotto de moda e la tutela della dignitá della donna: Le nuove iniziative in un'analisi di diritto comparato. In Fashion Law. Le Problematiche Giuridiche Della Filiera dell Moda. Edited by Pozzo Barbara and Jacometti Valentina. Milano: Giuffré Editore.

Ramos Lahiguera, Carlos Manuel. 2017. Photoshop y el Cuerpo Publicitario: Naturalidad y Artificio en la Belleza Femenina. Doctoral's Dissertation, Universidad Miguel Hernández, Elche, España. Available online: http://dspace.umh.es/bitstream/11000/4532/1/TD\%20\%20Ramos\%20Lahiguera\%2C\% 20Carlos\%20Manuel.pdf (accessed on 2 January 2020).

Rougés, Carlos. 2009. La Necesidad del Consentimiento para la Utilización Comercial de la Imagen de las Personas: Una Sentencia del Tribunal Supremo de Madrid a Contramano de ese Derecho. Available online: http://www.elDial.com (accessed on 2 January 2020).

Rovira Sueiro, Maria. 1997. La responsabilidad civil derivada de los daños al honor, a la intimidad personal y familiar y a la propia imagen. Doctoral's Dissertation, Universidad A Coruña, A Coruña, Spain.

Sáez Tapia, Carolina. 2017. Derecho a la Imagen Propia y su Manifestación en Internet. Master's Dissertation, Universidad de Chile, República de Chile. Available online: http://repositorio.uchile.cl/handle/2250/151565 (accessed on 2 January 2020).

Sartori, Giovanni. 1998. Homo videns. La sociedad teledirigida. Buenos Aires: Taurus.

Scafidi, Susan. 2019. Towards a jurisprudence of fashion. Fordham Intellectual Property, Media \& Entertainment Law Journal XXIX: 429-34.

Schötz, Gustavo. 2015. Merchhndising en la industria de la Moda. In Derecho y Moda. Edited by Susy Bello Knoll and Pamela Echeverria. Buenos Aires: Marcial Pons, pp. 153-64.

Seeger, Laureen, Ellie Boragine, and David Bernstein. 2019. Advertising. Successful Partnering Between Inside and Outside Counsel. In R. Haig Overview of Advertising Law-Third-Party Rights-Right of Publicity (ACC). (56:27). Toronto: Thomson Reuters.

Slater, Caitlyn. 2017. The sad Michigan fan what accidentally becoming an internet celebrity means in terms of right of publicity and copyright. Michigan State Law Review 2017: 865.

Smith, Simon. 2001. Image, Persona and the Law. London: Sweet \& Maxwell.

Strong, William. 1995. El libro de los Derechos de Autor. Guía Práctica, 4th ed. Buenos Aires: Heliasta.

Tabachnik, Silvia. 2012. Sobre la alteración lúdica de las imágenes en la era del fotoshop. AdVersus 9: 122-34.

Tallarico, Diego. 2010. Patente, Registro o Software Libre. Cuestiones Esenciales en Miras a una Solución Racional al Problema. Available online: http://www.elDial.com (accessed on 2 January 2020).

Tushnet, Rebecca. 2015. A mask that eats into the face: Images and the right of publicity. Columbia Journal of Law $\mathcal{E}$ the Arts 38: 157. 
Vidal Beros, Christian. 2015. Derecho e imagen en la industria de la moda. In Derecho y Moda. Edited by Susy Bello Knoll and Pamela Echeverria. Buenos Aires: Marcial Pons, pp. 89-106.

Villalba, Carlos, and Delia Lipszyc. 2012. Diferencia entre el daño moral y el daño al derecho moral del autor. La Le. Volume 1991-E 606.

Villalba Díaz, Federico. 2011. Nuevas fronteras del derecho a la imagen. Revista Critica de Derecho Privado 4: 35-48. Williams-Vickery, Jessica. 2018. A (thigh) gap in the law: Addressing egregious digital manipulation of celebrity images. Georgia State University Law Review 34: 795.

Zingaretti, Gisela. 2018. Pactos Nacionales e Internacionales: Nuevas Tendencias. El Reto de ser Libres Frente al Desarrollo Tecnológico: ¿Un Nuevo Pacto Comunitario? Available online: http://www.elDial.com (accessed on 2 January 2020).

(C) 2020 by the author. Licensee MDPI, Basel, Switzerland. This article is an open access article distributed under the terms and conditions of the Creative Commons Attribution (CC BY) license (http://creativecommons.org/licenses/by/4.0/). 
Article

\title{
Fashion as Art: Rights and Remedies in the Age of Social Media
}

\section{Lucrezia Palandri}

Department of Legal Sciences, University of Florence, Florence, 50121 Firenze FI, Italy; lucrezia.palandri@unifi.it Received: 22 January 2020; Accepted: 27 February 2020; Published: 11 March 2020

\begin{abstract}
Today's increasingly widespread recognition of fashion's artistic value has revamped the debate on the appropriateness of rights and remedies provided by IP law to fashion designs. From an Italian-US comparative perspective, this article inquires whether copyright protection, traditionally accorded to artists, is eligible and applied for fashion, detecting that rights and remedies are better accessible to major fashion companies and for iconic items, while they are not easily attainable by smaller designers. Analyzing a number of case studies, this article describes a growing phenomenon in the age of the digital revolution, that is, controversies regarding the fashion world tend to be disputed on social media rather than in courtrooms. Beyond the debate on which existing formal legal tools are suitable for fashion, the purpose is to bring the phenomenon of informal self-regulation out of court into conversation, examining advantages and disadvantages. Social media platforms are more suitable to fashion's nature and dynamics, and ultimately, their verdicts seem to obtain better results than litigation, balancing the unequal positions of established and emerging brands.
\end{abstract}

Keywords: fashion; art; copyright law; intellectual property law; artistic value; social media; comparative law

\section{Introduction: Fashion and Art Intertwined}

A lobster dress, a shoe hat, red painted fingernails gloves are only a few of the iconic pieces that the fashion designer Elsa Schiaparelli and the surrealist artist Salvador Dali created together from 1935 to 1954 , closing year of the Schiaparelli maison in Paris. Such out-of-ordinary collaboration has been referred to as the one that opened the ongoing, prolific dialogue between the fashion and art worlds (Cutler and Tomasello 2015; Geczy and Karaminas 2012) ${ }^{1}$.

Especially in the haute couture, but also in the prêt-à-porter, stylists and artists have constantly been a mutual source of inspiration, influencing and stimulating each other's innovation and creativity.

From the historical Mondrian day dress by Yves Saint Laurent and Souper dress by Andy Warhol in the $1960 \mathrm{~s}^{2}$, through the incursions of artists Jackson Pollock, Dan Flavin, Sol Lewitt, and Robert Morris into the fashion magazines, the relationship between fashion and art flourished in the early 90s with designers such as Rei Kawakubo of Comme des Garçons, Hussein Chalayan, Martin Margiela, and Alexander McQueen. It is, then, only in the last fifteen years that thriving collaborations between

1 Previous collaborations involved Paul Poiret with Raoul Dufy and Jeanne Paquin with Lèon Bakst of the Ballets Russes in pre-war France. In Italy, the Futurist movement was very engaged in the theory and the design of fashion. Several manifestos on clothing were issued over the years. Fortunato Depero designed the colorful futurist vests in 1923-1924, Giacomo Balla designed the Futurist men and women's clothing, and Ernesto Thayaht invented the unisex jumpsuit.

2 The painter Piet Mondrian did not create the Mondrian day dress alongside Yves Saint Laurent for his 1965 Autumn collection, but the Dutch artist's work served as inspiration for the designer to realize a dress that has become one of the most long-lasting symbols of the cross-fertilization between fashion and art. In 1966-67 the artist Andy Warhol, blurring the boundaries between art and fashion, designed a series of paper dresses titled the Souper dress for the Campbell Soup company, which gave each customer a dress in exchange for two soup cans' labels plus one dollar. 
fashion brands and artists have exponentially increased. To name a few, Louis Vuitton, in particular when Marc Jacobs was the creative director, started famous partnerships with such artists as Richard Prince, Yayoi Kusama, Takashi Murakami, and more recently Jeff Koons.

The boundaries between the two spheres are crossed so repeatedly to become more and more blurred.

In the early $80 \mathrm{~s}$, fashion started its transition into museum spaces, with fashion exhibitions on view in the most prestigious cultural institutions around the world ${ }^{3}$. At the same time, established museums opened their doors to fashion by inaugurating permanent collections dedicated to couture garments ${ }^{4}$.

Over the past decade, there has been a remarkable increase in the number and popularity of fashion exhibits, as well as in the size of the audience they can attract ${ }^{5}$. Furthermore, fashion houses have been creating their own museums (including virtual ones, such as the Valentino Garavani Virtual Museum) dedicated to designs and models from their historical collections, iconic objects, photographs and press clippings, evidence of careers that have spanned groundbreaking decades over the last two centuries. The Salvatore Ferragamo Museum and the Gucci Garden in Florence are among the most successful instances of such a proliferating phenomenon of clothing on display outside retail storefronts.

Tightly connected to the entering of fashion objects into gallery spaces is the rise of archives, both public and private, with the purpose of preserving and valuing fashion as cultural heritage. Several public institutions have become repositories of historical garments, textiles and related artifacts ${ }^{6}$, and private companies have been investing significant resources in building, maintaining and promoting their own archives in order to enhance their brands' history and identity (Calanca and Capalbo 2018).

\section{Background and Premises: The Widespread Recognition of Fashion's Artistic and Cultural Value}

The interaction between fashion and art has been a highly discussed topic in popular culture and the mass media, among professionals of both the fashion and art communities, as well as scholars from various disciplines, including fashion theory, art history, cultural studies, aesthetics, sociology, anthropology.

Leaving aside the classical debate on whether fashion is art (Norell et al. 1967), this article is based on the premise that increasingly over the past two decades, the creative endeavor of fashion has been celebrated by the experts and the general public (Buccafusco and Fromer 2017). Fashion "is now

3 The Metropolitan Museum of Art in New York organized a major exhibition of Yves Saint-Laurent's works in 1983: it was the first time that such a recognition was granted to a living tailor. In 2017 Rei Kawakubo, founder of Comme des Garçons, will have been the next one to be recognized in this way. Schneier, Matthew. 2017. A Sneak Peek at the Met's Rei Kawakubo/Comme des Garçons show. The New York Times, 6 March. Available at: https://www.nytimes.com/2017/03/06/ fashion/rei-kawakubo-comme-des-garcons-met-museum-exhibit-paris-fashion-week.html. Since then, the MET hosted a number of fashion exhibitions, from the celebrated Alexander McQueen's "Savage Beauty" in 2011, to the last, less conventional "Camp: Notes on Fashion". Ferrier, Morwenna. 2019. How will Met Gala 2019 guests translate camp into costumes? The Guardian, 3 May. Available at: https://www.theguardian.com/fashion/2019/may/03/how-will-met-gala-2019guests-translate-camp-into-costumes. In 2000, the Italian designer Giorgio Armani's retrospective was presented at the Guggenheim Museum in New York and then moved to Bilbao, Berlin and London. Breward, Chris. 2003. Shock of the frock. The Guardian, 18 October. Available at: https://www.theguardian.com/artanddesign/2003/oct/18/art.museums (all websites last accessed on 1 January 2020).

4 Above all, the pioneeristic Anna Wintour Costume Center of the Metropolitan Museum of Art, with Diana Vreeland as a special consultant from 1972 to 1989, the Fashion Room (No. 40) of the Victoria \& Albert Museum in London, but also the Museum of Costume and Fashion of the Uffizi Gallery in Florence and the Musée des Arts Décoratifs of the Louvre Museum in Paris.

5 In 2015, Alexander McQueen's "Savage Beauty" show at the Victoria \& Albert Museum in London broke all the records, being the most visited exhibition in V\&A history and even prompting the museum to stay open 24 hours a day during the last weekends of the exhibition. See The Guardian, 3 August 2015, available at: https://www.theguardian.com/fashion/ 2015/aug/03/alexander-mcqueen-show-savage-beauty-most-popular-victoria-and-albert-history (last accessed on 1 January 2020).

6 The Prato Textile Museum in Italy is one of the most important cultural institutions for studying and preserving the textile industry, ancient and contemporary fashion. See the museum website: https://www.museodeltessuto.it/?lang=en (last accessed on 1 January 2020). 
recognized as a form of creative expression" (Scafidi 2006). More precisely, fashion objects' artistic, aesthetic, expressive value has been widely and commonly accepted, in addition to their functional, utilitarian, non-expressive nature as industrial products ${ }^{7}$. What has been generally acknowledged is that clothing serves the practical purpose of covering the body, but also represents a mean of expressing individual creativity for fashion designers and consumers 8 alike (Palavera 2016; Simmel 1957).

"[T] he fact that [fashion] is, usually, designed to be worn [ ... ] does not prevent it from being meaningful, and the art world's continued fascination with fashion [, as well as its increased presence in museums internationally,] underlies its cultural significance." (Arnold 2009). As one of the most influential phenomena of the modern world, fashion reflects and, at the same time, has a profound role in, shaping human culture. "[O]n a parallel footing to art", fashion contributes to the "larger system of visual culture and communication" we are embedded in (Sischy and Celant 1982).

The widespread recognition of this multifaceted nature of fashion creations as functional, artistic, and cultural objects makes their legal treatment very difficult and raises the debate on the appropriateness, effectiveness and fullness of the different kinds of protection offered to fashion items by intellectual property (IP) law.

In the Italian legal system, fashion creations have been traditionally protected as functional products by industrial property law ${ }^{9}$, a bundle of rights which includes designs ${ }^{10}$, patents ${ }^{11}$, and trademarks ${ }^{12}$, and by provisions against unfair competition ${ }^{13}$.

How is fashion protected for its artistic and cultural value? Does fashion receive the same types of protection as art?

The field of art in Italy is regulated by cultural property law, enshrined in the Code of Cultural and Landscape Property ${ }^{14}$, and by copyright law ${ }^{15}$.

As far as the first branch is concerned, nowadays, cultural property law regime does not generally apply to fashion, although single objects or collections may be included under the notion of 'cultural heritage $^{\prime 16}$.

7 "European fashion industries are at the crossroads where manufacturing meets creativity." Commission Staff Working Document. Policy Options for the Competitiveness of the European Fashion Industries 'Where Manifacturing Meets Creativity', Brussels, 26.9.2012, SWD (2012) 284 final.

8 The function of communication derived from wearing a piece of clothing, even if not a deliberate act of will and self-expression, is in any case unavoidable. "It's impossible to wear clothes without transmitting signals" Morris, Desmond. 1977. Manwatching: A field guide to human behavior. New York: Abrams. "The right to wear is a corollary of the freedom of speech" (Palavera 2016). See Cohen v. California, 403 U.S. 15 (1971), the famous US Supreme Court case where wearing a jacket with the lettering "Fuck the draft. Stop the war" is obviously equivalent to verbal communication. However, also note Tinker v. Des Moines Independent Community School District 393 U.S. 503 (1969), where wearing black armbands to protest the Vietnam war is protected as symbolic speech "closely akin to pure speech". "Symbolism is a primitive but effective way of communicating ideas", West Virginia Bd. of Ed. v. Barnette, 319 U.S. 624, 632 (1943).It is worth to mention the related issue of fashion as identity. Fashion is inextricably related to both individual identity (cf. the artwork by Barbara Kruger "I shop therefore I $\mathrm{am}^{\prime \prime}$ ) and collective identity (each subculture's clothes are often well defined and recognizable, used as a sort of uniform expressing the identity of the group). See Barnard, Malcolm. 1996. Fashion as Communication. London: Routledge. A critical factor in the construction of identities through fashion is related to the so-called cultural appropriation issues, raising when the dynamism of communication leads mainstream fashion to improperly appropriate meanings that specific groups attribute to certain types of garments and accessories (see infra).

9 Code of Industrial Property ('C.I.P.'), Legislative Decree no. 30 of 10 February 2005. The notion of Industrial Property was introduced as a sub-category of Intellectual Property (IP) by the Italian literature, simply to juxtapose intellectual products with an industrial character, regulated by industrial property law, to mere intellectual products, regulated by copyright law. In the United States, the notion of intellectual property has a partially different definitory and regulatory meaning. The notion covers indistinctly the different kinds of protection afforded by trademarks, design patents and copyrights.

10 Registered design, art. 31 ss. C.I.P. At the EU level, 'unregistered design' regime was introduced by art. 11 Regulation 6/02/CE of 21 December 2001

11 Art. 45 ss. and 82 ss. C.I.P.

12 Art. 7 ss. C.I.P. Trademarks law was recently subject to significant amendments by Legislative Decree no. 15 of 20 February 2019 in compliance with the EU Directive 2015/2436.

13 Art. 2598 ss. Civil Code.

14 Legislative Decree no. 42 of 22 January 2004.

15 Law no. 633 of 22 April 1941 and art. 2575 ss. Civil Code.

16 Private collections need a specific declaration of cultural interest. For instance, last April 2019, the archive owned by the well-known Italian stylist Renato Balestra, featuring over forty thousand sketches and drawings, has been declared by the 
The Cultural Property Code establishes conditions and requirements that are not usually consistent with the nature of fashion: the objects must not be made by a living author, nor produced less than fifty years ago ${ }^{17}$. Fashion items are made for daily use and, even when they are part of museums' exhibitions or private collections and archives, they are often created by living designers.

The current wider appreciation of fashion's cultural value ${ }^{18}$, according to a few scholars, may have opened a new path towards the future recognition of fashion objects under the discipline of cultural property law ${ }^{19}$. It might be interesting to inquiry whether this may be a suitable kind of protection for fashion but that goes beyond the scope of this article.

Regarding copyright regime, one can argue that fashion has been protected by copyright law for a long time. At the same time, however, the recognition of the artists' protection for fashion designers has always been heatedly discussed among scholars, legislators and judges.

Originally, the debate swung between the two extreme positions of who, on the one side, regarded fashion as a utilitarian object and who, on the other side, considered apparel as a form of artistic expression. Adopting a comparative perspective, the two poles corresponded to the opposite approaches of United States and France.

In the US, copyright protection is reserved exclusively for works of art, therefore, industrial designs may not, as a matter of principle, be assimilated to artistic works protected by copyright. At the very most, if the utilitarian product presents artistic features that can be identified separately and independently from the support to which they are associated, such features may enjoy copyright protection. Consistent to a dominant commercially driven approach, the US intellectual property regime for fashion designs has been built around the common idea of fashion as a thriving industry that is not damaged at all by plagiarism ${ }^{20}$ (Andrews 2012), and, even if it functions with limited or low levels of IP protection, it has still incentives to create and innovate (Raustiala and Sprigman 2006).

In France, the théorie de l'unité de l'art ${ }^{21}$ affirms that art may be expressed in any forms, and fixed in any material support. If artistic features are embodied in a functional article, such a creative expression deserves recognition as a work of art and cannot be distinguished and disqualified merely because it is associated to a utilitarian object ${ }^{22}$. Therefore, copyright law explicitly protects fashion creations, without assuming any distinction between fine arts and applied arts $^{23}$.

Today, the general widespread recognition of fashion's artistic value has led to interesting developments, towards a higher level of fashion's protection as a work of art. Nonetheless, the status of fashion under copyright law maintains, in fact, a certain degree of uncertainty and lack of use,

Archival and Bibliographic Superintendency of Lazio, on behalf of the MiBAC, an item of "particularly important historical interest" (art. 13 ss.), including it under the notion of "bene culturale", according to the Code of Cultural and Landscape Property (art. 10).

17 Art. 10(5). On the subject, see Caponigri, Felicia. 2017. Problematizing fashion's legal categorization as cultural property. Aedon. 2. See also Casini, Lorenzo. 2016. Ereditare il futuro. Dilemmi sul patrimonio culturale. Bologna: Il Mulino; Id. 2018. Riprodurre il patrimonio culturale? I "pieni" e i "vuoti" normativi. Aedon. 3.

18 Work summary, Study Commission for the Identification of Public Policies for the Protection, Conservation, Enhancement and Use of Italian Fashion as Cultural Heritage. Available on the Ministry of Cultural Heritage (MiBAC) website (last accessed on 1 January 2020).

19 Caponigri, Felicia. 2017. Problematizing fashion's legal categorization as cultural property, cit.

20 I am aware that the terms 'plagiarism', 'piracy', and 'counterfeiting' have different technical meanings in both the Italian and the United States legal systems. In the present article, I use 'plagiarism' or 'piracy' when referring to copyright infringements; 'counterfeiting' is used when industrial property rights violations are involved. Generally, I tend to use the term 'copying'.

21 Art. L. 112-1, French Code de la propriété intellectuelle: "Les dispositions du présent code protègent les droits des auteurs sur toutes les oeuvres de l'esprit, quels qu'en soient le genre, la forme d'expression, le mérite ou la destination".

22 See Standing Committee on the Law of Trademarks, Industrial Designs and Geographical Indications, Ninth Session, Geneva, 11-15 November 2002. Industrial Designs and their Relations with Works of Applied Art and Three-Dimensional Marks.

23 French Code de la propriété intellectuelle, Art. L 112-2: “14 ) Les créations des industries saisonnières de l'habillement et de la parure. Sont réputées industries saisonnières de l'habillement et de la parure les industries qui, en raison des exigences de la mode, renouvellent fréquemment la forme de leurs produits, et notamment la couture, la fourrure, la lingerie, la broderie, la mode, la chaussure, la ganterie, la maroquinerie, la fabrique de tissus de haute nouveauté ou spéciaux à la haute couture, les productions des paruriers et des bottiers et les fabriques de tissus d'ameublement". 
therefore the question on to what extent fashion can be offered the same protection as art remains open for investigation.

This article first analyzes fashion's copyright regimes in Italy and the United States. Despite the increasingly widespread recognition of the art-like nature of fashion and a general trend towards an enhanced protection, the copyrightability of fashion objects as works of art is still a debated issue among scholars and in case law. Second, several criticisms will be made on the appropriateness, and even the necessity, of this kind of protection, in light of the peculiar nature and dynamics of fashion. The analysis will take into consideration two key factors of the current times: the social media advent and the unequal positions of well-established fashion houses and emerging designers. Last, analyzing a number of case studies, a growing phenomenon can be described, that is, controversies regarding the fashion world tend to be disputed on social media rather than in courtrooms. The author's purpose is to bring such a phenomenon of self-regulation out of court into conversation, examining the advantages and disadvantages. Social media platforms are more suitable to fashion's nature and dynamics, and ultimately, their verdicts seem to obtain better results than litigation, balancing the unequal positions of established and emerging brands, and enforcing IP rights more effectively and rapidly. Fashion cases are global: the article focuses on the Italian legal system adopting a comparative approach, in particular referring to the United States context.

\section{The Legal Protection of Fashion as Art}

\subsection{From 'Separability' to 'Artistic Value' Requirement}

The general debate on fashion as art has been in the background along the path towards the recognition of copyright protection, typically the domain of the artists, to fashion creations.

Prior to 2001, Italian copyright law afforded protection to works of art applied to industry only if their artistic value could be expressed and appreciated independently of any functional purpose, being ideally separable from the industrial products to which they pertained ${ }^{24}$, in a very similar way to the provisions of the current Law on Copyright in the United States ${ }^{25}$.

If few cases on two-dimensional designs, including a Naj-Oleari pattern for fabrics, considered the artistic features separable, therefore protected ${ }^{26}$, the so-called requirement of separability ('scindibilità') was soon interpreted by judges as "non-existent in the three-dimensional objects of industrial design", thus rendering the provision de facto inapplicable ${ }^{27}$. Overseas, the United States courts had been elaborating numerous tests to determine both physical and conceptual separability of the artistic qualities from the object's functional character ('separability' or 'useful articles' doctrine); the multiplicity of cumbersome, unclear and competing tests led to conclusions mostly for the non-copyrightability of three-dimensional designs of useful articles ${ }^{28}$.

24 Art. 2.4, L. of 22 April 1941 n. 633, abrogated by Lgs. D. no. 95/2001: “works of sculpture, painting, drawing, engraving and similar figurative arts, including scenic art, even if applied to the industry, provided that their artistic value could be appreciated separately from the industrial nature of the products to which they pertained".

2517 U.S.C. $\$ 101$ (1976): "The design of a useful article [ . . ] shall be considered [eligible for protection as a work of art] only if, and only to the extent that, such design incorporates pictorial, graphic, or sculptural features that can be identified separately from, and are capable of existing independently of, the utilitarian aspects of the article". The 1976 Copyright Act, which revised the prior 1909 version, incorporated the Supreme Court landmark decision Mazer v. Stein, 347 U.S. 201 (1954), expressly protecting "two and three-dimensional works of fine, graphic, and applied art".

26 Fiorucci spa v. Manifattura Naj Oleari spa, Civil Court of Cassation, sec. I, judgement no. 7077 of 5 July 1990 ; see also Como IP court, order of 12 February 1996.

27 Civil Cassation Court, sec. I, judgement no. 10516 of 7 December 1994, which denied copyright protection to the famous chaise-longue by Le Corbusier.

28 In most cases, US judges seem to base their decisions on a "we know it when we see it" rationale. See Perlmutter, Shira. 1990. Conceptual Separability and Copyright in the Designs of Useful Articles. J. Copyright Soc'y U.S.A. 37: 339. See also Keyes. 2008. Alive and Well: The (Still) Ongoing Debate Surrounding Conceptual Separability in American Copyright Law. Ohio State L. J. 69:109; Report of the House Committee on the Judiciary contextual to the entry into force of the Copyright Act (H.R. Rep. No. 94-1476 1976). A few important judgements: Kieselstein-Cord v. Accessories by Pearl, Inc., 632 F.2d 989,990 (2d Cir. 1980), Carol Barnhart, Inc. v. And with. Cover Corp., 773 F.2d 411, 412 (2d Cir. 1985), Brandir International v. Cascade 
If, so far, the Italian and US approaches were alike, the Italian scenario was about to drastically change with the implementation of the European Union Directive 98/71/EC in 200129. The Law on Copyright was amended, abrogating the separability requisite, and determining the new conditions for copyright to be granted to industrial design objects in, besides having a creative character, displaying an inherent artistic value ${ }^{30}$.

Moreover, the Directive required member states to comply with the principle of cumulation between design and copyright regimes of protection ${ }^{31}$. From that moment on, fashion objects could potentially be protected not only as industrial products under the Code of Industrial Property, but also as artistic creations under the Law on Copyright.

In the ideal spectrum of fashion copyright protection, where the United States are on the one end, with fashion as part of "IP's protection gap or negative space" (Raustiala and Sprigman 2006), falling through the cracks of IP protection in a "doctrinal no man's land" (Rosenblatt 2011), and France is on the opposite end, providing the same type of protection for both fine and applied arts on the basis of the theory of unity of art, the Italian approach shifted from the former and moved closer to the latter.

The EU Directive had left each member state free to determine the extent to which, and the conditions under which, copyright protection would have been conferred (art. 17). The majority of the IP scholars agrees that the Italian legislator added, besides the creative character, the 'inherent artistic value' criterion (art. 2 no. 10 L. 633/1941) for a dual reason: first, to let the design regime be the ordinary tool of protection for fashion products, and second, to prevent industrial design objects of daily use from obtaining an indiscriminate access to the strong monopolistic protection afforded by copyright (Dalle Vedove 2001; Bonelli 2003; Galli 2004; Fabbio 2012; Morri 2013; Vanzetti and Di Cataldo 2018). Copyright, in fact, encompasses both the right of economic exploitation of the work during the author's life and for seventy years after their death, and the time-unlimited moral rights to have authorship recognized and to preserve the integrity of the work ${ }^{32}$. In addition, copyright does not require registration or any other formality as a prerequisite for protection. In this way, then, even when any other form of IP protection is expired or unavailable, copyright may still be invoked ${ }^{33}$.

In sum, despite having expanded the protection for industrial design compared to the pre-2001 regime, the intention of the legislator was to limit the scope of the provision in order to avoid the

Pacific Lumber Co., 834 F.2d 1142 (2nd Cir. 1987), Whimsicality v. Rubie's Costume Co., 891 F.2d 452 (2d Cir. 1989), Pivot Point International, Inc. v. Charlene Products, Inc. 372 F.3d 913, 930-31 (7th Cir. 2004), Jovani Fashion, Ltd. v. Fiesta Fashions, 500 Fed. App'x 42 (2d Cir. 2012), Star Athletica, LLC v. Varsity Brands, Inc., 580 U.S. _(2017) (see infra).

29 Legislative Decree no. 95 of 2 February 2001.

30 Law on Copyright (n. 633/1941), Art. 2, n. 10: "works of industrial designs which themselves have a creative and artistic value".

31 Article 17 of the Directive 98/71/EC. Art. 5.2 (prohibition of cumulative protection), D. R. no. 1411/1940, abrogated by Lgs. D. no. 95/2001.

32 Moral rights include right of attribution or paternity (art. 20 L. 633/41), right of integrity (art. 20 L. 633/41), right of withdrawal (art. 142 L. 633/41 and art. 2582 Civil Code), and right of disclosure (implied in the art. 142 L. 633/41). In the United States, moral rights do not apply to industrial design. After the late ratification of the Berne Convention in 1989 , they are attributed "only to the author of a work of visual art" (VARA, 17 U.S. C. § 106A(b)) and explicitly excluded for applied art (17 U.S.C. § 101: "A work of visual art does not include-(A)(i) [ . . ] applied art"). See the latest US Copyright Office report on "Authors, Attribution, and Integrity: Examining Moral Rights in the United States", 23 April 2019, available at: https://www.copyright.gov/policy/moralrights/full-report.pdf (last accessed on 1 January 2020).The extension of moral rights to fashion design is a recently debated issue among US academics and case law. On the implementation of a sui generis form of moral rights for fashion, see Ruff, Elise, 2017. If the Shoes Fit: The Effects of a Uniform Copyright Design Test on Local Fashion Designers. The John Marshall Review of Intellectual Property Law. 17:262; Andrews, Katelyn N. 2012. The most fascinating kind of art: fashion design protection as a moral right. N.Y.U. Journal of Intell. Prop. E Ent. Law. Vol. 2:188; and also, Akanegbu, Anuli. 2012. Fashion's Moral Dilemma: Exploring How a Lack of Moral Rights in the United States Disproportionately Harms Emerging Fashion Designers. 8 May. Available at: https://ssrn.com/abstract=2054783 or http://dx.doi.org/10.2139/ssrn.2054783 (last accessed on 1 January 2020). See also Wade, Margaret E. 2011. The Sartorial Dilemma of Knockoffs: Protecting Moral Rights without Disturbing the Fashion Dynamic. Minnesota Law Review. 96: 336; Hansmann, Henry, Santilli, Marina. 1997. Authors' and Artists' Moral Rights: A Comparative Legal and Economic Analysis. J. Legal Stud. 26: 95.

33 This is the case of the Moon Boot decision, see infra. 
opening of the floodgates to an arbitrary, over-extended protection for industrial products, and thus interfering with the proper functioning of the market (Spada et al. 2002).

\subsection{Judicial Interpretation of 'Artistic Value' and Its Latest Developments}

After the reform, the Italian courts have been playing a crucial role in defining the broad 'artistic value' standard. The judges followed the approach suggested by the legislator and, consistently with the ratio of the new provision, proved extremely cautious in extending copyright protection to industrial design. Several decisions even considered the chaise-long designed by the worldwide famous architect and artist Le Corbusier as creative product lacking artistic value, with the motivation of its serial, large scale reproducibility. Such a reasoning meant denying the eligibility for copyright protection to industrial design in toto, since reproducibility represents the very nature of industrial design objects ${ }^{34}$.

It took five years before the Specialized section for industrial and intellectual property matters of the Milan Court issued a decision granting copyright protection, not specifically to fashion, but to industrial design ${ }^{35}$. The famous Panton chair by Verner Panton, according to the judges' opinion, comprised a particular degree of creativity and an inherent artistic value because that was the "general perception that might have been consolidated in the society and especially in the cultural circles" 36 . An additional parameter for the copyrightability of the Panton chair was its display in the collections of many contemporary art museums, thus confirming its significance and value beyond a mere characterization as a model of chair, rising interest not only among design experts and consumers but also the general public.

The subsequent case law allowed copyright protection for industrial designs of well-known products, created by worldwide celebrated designers and artists, exhibited in museums and included in art textbooks as representative of a specific period or artistic movement. None of the cases concerned fashion designs yet, mostly regarding, again, design objects such as the Panton chair ${ }^{37}$, or the Arco lamp, realized in the 1960s by Achille and Pier Giacomo Castiglioni for the Flos company, "expression of that post-war style research, characterized by essentiality and formal rigour" 38 , or finally, the chaise longue by Le Corbusier, icon of the Italian rationalism, made in 1928 and exhibited all over the world, "whose aesthetic value is still intact decades after its creation, confirming the specific representative capacity of an artistic taste, which can differentiate this product from the congeries of ephemeral and ordinary design production" ${ }^{\prime 39}$.

With the purpose of maintain a high threshold to protection, 'per se artistic value' was so conceived as to reserve the special copyright defense to the most valuable, above-average design ('fascia alta' or 'alta gamma') (Franzosi and Scuffi 2014).

In order for a design to meet the requirement, the courts, throughout their decisions, have set out an objective standard, to be measured by several indicators: among others, the display in contemporary art or design museums' collections, the reproduction of the work in art or design publications, experts' opinions, technical consultants' reports, the achievement of design's awards, the author's fame, the

34 Cassina spa v. Dimensione Direct Sales srl, Bologna court, order of 3 August 2004; Cassina spa v. Galliani Host, Monza court, orders of 23 April 2002 and of 16 July 2002.

35 Vitra Patente ag $v$. High Tech srl, Milano IP court, order of 28 November 2006, confirmed in appeal by Milano IP court, order of 18 January 2007. See Naj-Oleari, Marella. 2007. Tutela d'autore per il design. Sole 24 Ore. 3 January. Available at:

36 Id. https:/www.studioscarpellini.it/wp-content/uploads/2012/07/03gennaio2007.pdf (last accessed on 1 January 2020).

37 Vitra Patente ag $v$. High Tech srl, Milan IP court, judgement no. 9917 of 13 September 2012.

38 Flos spa v. Semeraro Casa \& Famiglia spa, Milan IP court, judgement no. 74660 of 29 December 2006; Flos spa v. House World Arredamento, Florence specialized court for business matters, judgement no. 525 of 16 February 2010.

39 Cassina spa v. High Tech srl, Milan IP court, judgement no. 2311 of 17 February 2014. See also Ca. spa v. High Tech srl, Milan IP court, order of 28 April 2011. 
affiliation to a well-known artistic movement, but also commercial success, willingness of consumers to pay high prices for the work, and exclusive distribution channels ${ }^{40}$.

The nature of fashion-vocation for temporariness—does not seem to comply with such standards: it is quite rare that a piece of clothing can last more than one season, let alone being able to historicize the taste of a period. This seems to be the assumption every time a judge hears a case on apparel design copyright. So, the Rome IP court denied the presence of artistic value to a pair of earrings of the designer Delfina Delettrez, the fourth generation of the Fendi family, because they did not raise that particular collective appreciation associated with works of art ${ }^{41}$. The same occurred for Max Mara's 'The Cube', a modular winter coat, not recognized as an art piece because "the three letters of fashion museums produced by the plaintiff [were] not sufficient to prove the existence of a design object whose artistic value is universally known and appreciated"42. A few more cases. The design of Conbipel's 'Opale' scarf: however original and creative, it did not seem to have, according to judges, an artistic value whose perception had been consolidated in the collective imagination ${ }^{43}$. The costumes of the television show 'Ballando con le stelle', on the other hand, were appreciated by the large audience, but they were not so recognized by museums or specialized journals ${ }^{44}$.

A complete reversal of this judicial trend occurred when the IP specialized section of the Milan court, in 2016, decided for the copyrightability of the 'Moon Boot' (Appendix A, Figure A1), the popular après-ski designed in 1970 by Giancarlo Zanatta, against the 'Anouk' model by the Anniel group ${ }^{45}$. Design registration had expired, there was no three-dimensional trademark on the shape of the boot: copyright protection was claimed, and judges granted it on the basis of compelling evidence filed by the applicant ${ }^{46}$. Inspired by the Apollo 11 moon landing and very much in vogue at that time, then resurfaced as a fashion trend in the early 2000s, Moon Boot is considered an "icon of the Italian design and a symbol of its capacity to guide the taste of an epoch in matter of daily use objects". "Not surprisingly, the snow boots have been the subject of important publications focusing on Italian and international contemporary design, received favorable criticism from experts and gathered a vast enduring popularity". Lastly, in 2000 Moon Boot was chosen "as one of the newest symbols of 20th century design at an international level by the Louvre Museum" and exhibited in its rooms.

For the first time in the Italian legal system, a fashion product enjoyed copyright protection ${ }^{47}$. Such an outcome is not to be taken for granted because its precedents clearly show that, while the application of the 'creative character' condition has been self-evident as "any expression of the author's personality", the quid pluris required by the artistic value has been subject to a particularly rigorous assessment to be made on a case-by-case basis.

Several scholars noted the significant impact that the Moon Boot judgement might have for the future. If upheld by subsequent case law, the decision would have been the leading case that paved the way for copyright protection of fashion items (Caselli 2017; Barabino and Varese 2016).

40 Thun spa v. Egan srl, Civil Court of Cassation, sec. I, judgement no. 7477 of 23 March 2017; Metallo spa v. City design srl, Civil Court of Cassation, sec. I, judgement no. 23292 of 13 November 2015. See Fabbio, Philipp. 2016. Che cos'è arte? Una sentenza del Tribunale di Venezia sul "valore artistico" delle opere di design e sul giudizio dell'esperto. Riv. Dir. Ind. 1:62; Id. 2015. Contro una tutela autoriale "facile" del design. Considerazioni a margine di una recente pronuncia della Cassazione tedesca (Bundesgerichtshof, sent. 13 novembre 2013 - "Geburtstagszug") e brevi note sul diritto italiano vigente. Riv. Dir. Ind. 2:45.

41 De. Be. v. Delettrez srl and De. De. Fe., Rome IP court, judgement of 13 June 2011.

42 Max Mara Fashion Group srl v. Liu Jo spa, Milan IP court, judgment no. 6397 of 21 May 2015, confirmed by Milan Court of Appeal, sec. 1, judgement no. 1893 of 5 May 2017.

43 Frame srl v. Conbipel spa, Torino IP court, order of 5 November 2013.

44 Rome IP court, order of 29 January 2015.

45 Tecnica group spa v. Anniel group spa, Milan IP court, judgement no. 8628 of 12 July 2016.

46 Varese, Elena, La tutela delle forme delle creazioni di moda: problemi e prospettive, 29 March 2019, lecture in the context of 'Fashion Law. Diritto e cultura nella filiera della moda' course, University of Florence.

47 This was the first case concerning industrial fashion products. Copyright was previously granted to a high fashion dress that was handmade and not industrially manufactured. It was a unique piece realized on commission for a showgirl who published the dress on her website without attribution. The dressmaker obtained the right to attribution and a compensation of court costs (Milan IP court, order of 11 December 2014). 
At the moment, if this case has been followed by recognitions of artistic value to iconic industrial design objects as the Vespa motorbike or the Avalon armchair ${ }^{48}$, the few judgements involving fashion or fashion-related items did not accord protection ex art. 2 no. 10 of the L. 633/1941 ${ }^{49}$. For instance, the 'screw heel' model realized by the designer Dina Subkhankulova and allegedly copied by Prada: the judges have no doubt that "[i]t certainly cannot be considered sufficient documentation [to prove its artistic value,] an award received during a footwear fair in Russia or the publication of the model in some commercial magazines" ${ }^{\prime 50}$. An interesting case regarded rosaries. In considering them not protectable under copyright law, the Venice court of appeal added an important indication for the judges to interpret the 'artistic value' criterion: the widespread distribution, and thus the commercial success of the product, cannot be a proof of its artistry ${ }^{51}$.

If, so far, the Moon Boot case had no impact on fashion controversies, the tendency would be likely to change after the latest decision by the European Court of Justice, Cofemel v. G-Star ${ }^{52}$.

In Portugal, the clothing company G-Star successfully sued Cofemel for copyright infringement. The case reached the Portuguese Supreme Court, which stayed the proceedings and asked the EU Court whether the Directive 2001/29 on the harmonization of certain aspects of copyright precluded national legislation to provide an additional criterion as the qualification as "artistic creation" or "work of art" for an industrial design to be copyrightable. Last September 2019, the European judges established that copyright may be granted to "any original subject matter constituting the expression of its author's own intellectual creation"; no extra requirement must be fulfilled.

The Italian criterion of 'artistic value' is challenged, like any other extra set of criteria required for copyright protection in other EU countries. Even if the European Court clarifies that the requirement is to be identified also bearing in mind its specific indications in $\mathrm{Cofemel}^{53}$, and thus the evaluation "is to be a thorough one, [ ... ] the judgment clearly mandates a change of approach" (Rosati 2019). The decision was delivered only few months ago: it will be interesting to track the evolutions in the Italian context.

At this stage, a closer comparison with the United States is worth making because, in spite of different legal frameworks and doctrinal backgrounds, resembling trends can be highlighted.

\subsection{Enhanced Protection for Fashion? A New Separability Test}

Traditionally, in the US legal system, fashion is protected under the various regimes of intellectual property law: trademarks ${ }^{54}$, trade dress ${ }^{55}$, design patents ${ }^{56}$, and copyright ${ }^{57}$.

48 Zhejiang Zhongneng Industry Group Co Ldt v. Piaggio \& C. spa, Torino Court of appeal, sec. V, judgment no. 677 of 16 April 2019; Cassina spa v. Centrufficio Loreto spa, Milan IP court, order of 5 August 2017; Trifirò Salvatore v. Sony Music Entertainment spa, Milan IP court, order of 15 June 2017.

49 G.R. v. E.C., Bologna IP court, judgement no. 457 of 20 February 2019, regarding clothing; Rolex spa v. Swift Company srl, Torino IP court, judgment no. 1509 of 16 September 2019, regarding specific models of watch bezels by Rolex.

50 Dina Rinatovna Subkhankulova v. Prada spa, Milano IP court, judgement no. 8219 of 24 July 2017.

51 L.A.L. srl v. Ghirelli srl, Venice Court of Appeal, judgement of 2 May 2017.

52 Cofemel-Sociedade de Vestuario sa v. G-Star Raw cv, Court of Justice of the European Union, judgement C-683/17 of 12 September 2019. See Court of Justice of the European Union. Copyright protection may not be granted to designs on the sole ground that, over and above their practical purpose, they produce a specific aesthetic effect. Press Release No 109/19, Luxembourg, 12 September 2019. Available at: https://curia.europa.eu/jcms/upload/docs/application/pdf/2019-09/ cp190109en.pdf (last accessed 1 January 2020).

53 Id. According to the Court, there is no original work whether originality is "dictated by technical considerations, rules or constraints which leave no room for creative freedom".

54 The Lanham Act, against the sale of goods that bear confusingly similar marks, 15 U.S.C. § 1125(a) (2006), dilutive marks, $\S 1125(\mathrm{c})$, or counterfeit marks, § 1114 .

55 A product may be protectable as 'trade dress' when it is so distinctive as to have 'secondary meaning', i.e. consumers associate the design of the product with its source and consider the design to be source identifying. See Wal-Mart Stores, Inc. v. Samara Bros., Inc., 529 U.S. 205 (2000).

5635 U.S.C. 171.

57 17 U.S.C. § 101. 
A longstanding debate exists on what should be the most appropriate and effective protection for fashion items, whether design patent or copyright regime; mutatis mutandis, such a debate is common to the Italian scholarship. The opposing arguments originate from "fashion's hybrid nature of creative activity consisting in the design of mass-produced practical objects, the shape of which harmonizes and merges the functional and aesthetic profiles in one, thereby increasing the commercial value of industrial products so made" (Floridia 1984; Giudici 1989).

Opponents to copyright protection believe that fashion's functional nature is prevailing and that renders a patent approach, provided for manufactured articles, more suitable to protect fashion objects. On the contrary, proponents of copyright protection identify the growing acceptance of fashion designs' artistic value, even with their functional aspects, as an indication that designers are artists and deserve the protections afforded by authorship status (Ellis 2010; Tsai 2005).

Copyright advocates have made several attempts to change the law, in order to remove the 'separability' requirement and extend copyright protection to industrial design. Two bills were introduced into Congress: the 2006 Design Piracy Prohibition Act ("DPPA") ${ }^{58}$, which was revised as the Innovative Design Protection and Piracy Prevention Act ("IDPPPA") in $2010^{59}$ and reintroduced in 2012 as the Innovative Design Protection Act ("IDPA") ${ }^{60}$. This last proposal has yet to be passed by either house of Congress.

Whereas the efforts at legislative level fell short, an unexpected window opened up few years later in the judiciary. The Supreme Court, in its 2017 opinion on Star Athletica L.L.C. v. Varsity Brands $I n c .{ }^{61}$, accorded copyright protection to Varsity Brands' designs of stripes, chevrons, zigzags, and color-blocking realized to be incorporated on cheerleading uniforms, and copied by Star Athletica, the competing brand producing clothing and accessories for athletics (Appendix A, Figure A2).

The decision has been hailed as a turning point in the longstanding debate on what should be the most appropriate and effective protection for fashion, whether design patent or copyright regime, potentially shedding light on the future copyrightability of fashion designs.

The Star Athletica Court received fifteen amicus curiae briefs, analyzed nine different previous tests to determine the separability between useful and decorative elements, and eventually created one of its own. "[A] feature incorporated into the design of a useful article is eligible for copyright protection only if the feature (1) can be perceived as a two- or three-dimensional work of art separate from the useful article and (2) would qualify as a protectable pictorial, graphic, or sculptural work-either on its own or fixed in some other tangible medium of expression-if it were imagined separately from the useful article into which it is incorporated" 62 .

Applying this test to the decorations on the cheerleading uniforms, it can be concluded that, first, the arrangement of colors, shapes, stripes, and chevrons on the surface of the cheerleading uniforms could be qualified as pictorial, graphic, or sculptural works, and second, such two-dimensional works of art could exist independently from the uniforms' utilitarian features, "for example, on a painter's canvas" 63 .

58 H.R. 5055, 109th Cong. (2006).

59 S. 3728,111 th Congress (2010).

60 S. 3523, 112th Congress (2012).

61 Star Athletica L.L.C. v. Varsity Brands Inc., cit. For case notes and comments, see Fashion Law Institute et al. 2017. Brief of Fashion Law Institute et al. as Amici Curiae in Support of Respondents in Star Athletica v. Varsity Brands. Available online: https://www.scotusblog.com/wp-content/uploads/2016/09/15-866-respondent-amicus-FLI.pdf (last accessed on 1 January 2020); Denicola, Robert. 2018. Imagining Things: Copyright for Useful Articles after Star Athletica v. Varsity Brands. U. Pitt. L. Rev. 79: 635; Caponigri, Felicia. 2017. Conceptual Separability in Star Athletica L.L.C. v. Varsity Brand Inc. et al: "Designs" of Useful Articles as (Non)Copyrightable Subject Matter? Law and Media working paper series. No. 5/2017; Buccafusco, Fromer; Ruff, Elise, 2017, cit.; Schroeder, Jared, Kraeplin, Camille. 2019. Give Me A (C): Refashioning the Supreme Court's Decision in Star Athletica v. Varsity into an Art-First Approach to Copyright Protection for Fashion Designers. UCLA Entertainment Law Review. 26:1.

62 Star Athletica L.L.C. v. Varsity Brands Inc., cit.

63 Id. 
For the first time, fashion design was considered copyrightable, and the expectations on the future implications for the fashion industry were high.

Since the 1954 leading case Mazer $v$. Stein ${ }^{64}$, that upheld the copyrightability of statuettes of Balinese dancing figures used as bases for table lamps, courts have been struggling to draw the line between the expressive/protected and functional/unprotected aspects of useful objects. "The line between art and industrial design [ . . ] is often difficult to draw": it is Justice Thomas himself in the opinion of the Court that stresses the importance of this decision to "resolve widespread disagreement over the proper test for implementing § 101's separate-identification and independent-existence requirements"65. The separability test applied for industrial designs' copyright protection "has confounded courts and commentators" over the years (Denicola 2018) ${ }^{66}$ : finally, the Star Athletica Court explicitly addressed the issue, aiming to bring order to the former chaos.

In fact, though, the test established in Star Athletica leaves "too much room for ambiguity" (Mulam 2019) ${ }^{67}$. Justices Breyer and Kennedy, in their dissenting opinion, objected that the test might render potentially any industrial design copyrightable. "That is because virtually any industrial design can be thought of separately as a "work of art" [ . . . What design features could not be imaginatively reproduced on a painter's canvas?"68. The result would be quite a radical departure from the previous regime of copyright protection.

Further critics to Star Athletica's lack of clarity came already a week after its delivery, when the Puma brand filed a lawsuit against Forever 21 for allegedly copying designs from their Fenty-by-Rihanna footwear collection. The Californian district court judge, who decided against Puma, took the chance "to point out a large flaw in Star Athletica over how much of a difference has to exist for a product to count as copyright infringement" (Mulam 2019) ${ }^{69}$.

If the actual impact on fashion industry is still limited—so far, are copyrightable the designs of a banana costume $e^{70}$ and of a swimsuit ${ }^{71}$ - , what is undisputed is that the Star Athletica decision has revamped the debate on what is the most suitable protection for fashion designs, in particular, which kind of regime fits better with the nature and characteristics of today's fashion world.

Now that upholders of copyright should be closer to achieve their goals and a new path towards strong, enhanced protection for fashion has been opened, the status of fashion's protection is still uncertain. The dual question arises as to whether copyright regime is suitable to fashion's logics and dynamics, and even to whether there is any need of such kind of protection in the fashion world.

\subsection{Copyright Fashion-Related Criticisms: (a) Unsuitable, (b) Unnecessary, (c) Harmful}

According to many fashion designers and legal scholars, the Star Athletica decision signed an important evolution in the field of intellectual property law as a significant strengthening of protection

64 Mazer v. Stein, cit.

65 Star Athletica L.L.C. v. Varsity Brands Inc., cit.

66 "Of the many fine lines that run through the Copyright Act, none is more troublesome than the line between protectible pictorial, graphic and sculptural works and unprotectable utilitarian elements of industrial design", Goldstein, Paul. 1989. Copyright: Principles, Law and Practice. Boston: Little Brown. "Courts have twisted themselves into knots trying to create a test to effectively ascertain "whether the artistic aspects of a useful article can be identified separately from and exist independently of the article's utilitarian function". T Masquerade Novelty, Inc. v. Unique Indus., 912 F.2d 663,670 (3d Cir. 1990).

67 Even only the first prong of the test, deciding whether the design is a pictorial, graphic or sculptural work, is a long-debating and unsolved question. Cf. "It would be a dangerous undertaking for persons trained only to the law to constitute themselves final judges of the worth of pictorial illustrations, outside of the narrowest and most obvious limits." Justice Holmes, Bleistein v. Donaldson Lithographing Co., 188 U. S. 239, 251 (1903). The Holmes prescription has been repeatedly invoked by judges to justify their restraint in deciding about artistic matters, stating their inadequacy to engage in aesthetic determinations. See Palandri, Lucrezia. 2016. Giudicare l'arte. Le corti degli Stati Uniti e la libertà di espressione artistica. Firenze: FUP.

68 Star Athletica L.L.C. v. Varsity Brands Inc., cit.

69 Puma SE v. Forever 21, Inc. (2017), 2:17-cv-02523 U.S. District Court for the Central District of California.

70 Silvertop Associates Inc. v. Kangaroo Manufacturing Inc., No. 18-2266 (3d Cir. 2019).

71 Triangl Group Ltd. v. Jiangmen City Xinhui District Lingzhi Garment Company (S.D.N.Y. 2017). 
for the fashion industry. Despite the different legal framework, the Italian Moon Boot decision was similarly perceived as a crucial step for the fashion community.

Nonetheless, the role of IP in the every-day of fashion practice is very limited, if not insignificant.

In the United States, the core forms of IP law provide only very limited protection for fashion designs. Fashion creations might be covered under trademark law, but occasionally, and only for the more established companies with better-known logos. The subcategory of trademark law that is defined as 'trade dress' is even more restricted, being applied only for a few, truly iconic and enduring products. Design patents are extremely expensive and require an excessively long review process, at odds with the speed of fashion cycles.

Similar criticism could be made for the Italian high IP regime of protection for fashion products. Even if Italy presents a wide plethora of pervasive regimes, including the special tool of the EU unregistered design, "the behavior of fashion industry firms [does not change] much from one side of the Atlantic to the other" (Raustiala and Sprigman 2006).

In spite of the enthusiasm with which the Moon Boot and Star Athletica decisions have been welcomed in their respective legal systems, even the strong protection they would have granted has remained, in fact, unutilized. Using the words of the ECJ Advocate General Szpunar in the Cofemel decision, "despite the fact that the protection of works of applied art is as old as IP, it is not something that has been devoid of issues" ${ }^{\prime 72}$. Several observations can be formulated in the attempt to explain this phenomenon.

First, fashion is characterized by short product life cycles. Due to its long duration, copyright does not seem suitable to fashion's dynamics because it would accord an over protection to apparel designs, giving a strong monopoly to the designer, discouraging creative expression, stifling innovation, and limiting the free competition on the market.

Second, copyright protection is unnecessary for the fashion world because data and statistics show that fashion is a fast-growing, multi-billion dollar business that does not seem economically harmed by plagiarism, even if copies have exponentially increased in recent years. Rather, a so-called "piracy paradox" argument has been developed, according to which "copying produce a faster creative cycle and more consumption of fashion due to the quicker deterioration of apparel's status-conferring value" (Raustiala and Sprigman 2009). This process would explain why the fashion business is not harmed by extensive and free ride copying; not only, this would even represent a benefit and a push for designers and the industry as a whole. Conversely, upholders of copyright argue that such an accelerated fashion cycle has other, more severe harmful effects that might be mitigated by an increased protection, above all, environmental damages and exploitation of low-cost manufacturing by outsourcing part of the production process. However, the piracy paradox, if ever valid, seems applicable only regarding major fashion houses with major financial capability.

Third, the availability of copyright protection can even be harmful, bringing more drawbacks than benefits, especially to emerging designers.

"Fashion is a very hierarchical business. [ ... ] Established fashion designers and couture houses at the top of the pyramid have the resources and in-house legal teams to combat copycats with intellectual property remedies" (Wade 2011). Such instruments are mostly accessible to major fashion companies, while they are not easily attainable by smaller designers ${ }^{73}$.

In Italy, the narrow interpretation of the 'inherent artistic value', made by the judges of the famous Moon Boot après-ski, goes in the direction to limit copyright protection to a few historical fashion items, excluding creations of the seasonal collections, conceived to stay in stores only for a limited amount of time. These ones constitute the largest part of the production in the fashion industry; iconic products are not the daily business of the apparel brands. Judges do not seem to rule in favor of emerging

72 Cofemel-Sociedade de Vestuario SA v. G-Star Raw CV, Court of Justice of the European Union, cit.

73 This is confirmed by interviews I conducted with Italian emerging designers, like the Florentine brand SuperDuper Handmade Hats. 
designers, whose products could achieve protection on the basis of their artistic qualities, but not of their long-lasting presence on the market, substantial marketing efforts, or capability to be exhibited in a museum. The current approach seems to rather privilege already well-established, solid companies.

Similarly, in the US, Professor Ronald Mann analyzed the cheerleading uniforms' case from the viewpoint of the small firm Star Athletica founded by a former employee of the dominant industry leader Varsity Brands, and concluded that "it has become increasingly obvious that broad protection for industrial designs provides considerable market power for industry leaders" (Mann 2017). Yet, when piracy creates an obstacle, this mainly stands in the path of small brands.

Overlapping regimes of protection are theoretically able to grant each fashion object a case-by-case, ad hoc, specific kind of protection. In practice, though, these tools do not seem appropriate to the logics and nature of fashion, especially considering fashion's classic hierarchical vocation and the unbalanced dynamics between major fashion labels and independent designers.

The current phase of the digital revolution has exacerbated the whole situation but, ultimately, has also offered an alternative solution.

\subsection{The Digital Revolution}

Over the past decade, the evolution of the Internet and the advent of the social media networks have made, on the one side, fashion more accessible and available, and, on the other side, the work of copycats much easier and faster ${ }^{74}$.

The phenomenon of piracy in fashion is not new at all. Back to the beginning of the haute couture, at the end of the nineteenth century, fashion houses sent stylists to fashion shows in Paris to sketch designs and buy individual pieces to be copied. However, the technological change "that's happened in the last ten years [ ... ] has changed the game one hundred percent. The protection hasn't caught up to the level of technology" (Hernandez 2011).

Fashion blogs, websites, and the social media accounts of the brands themselves instantly broadcast runaway shows photos worldwide: from that moment on, copying designs, counterfeiting logos, and reproducing haute couture garments for mainstream consumers becomes a matter of days for the largest apparel retailers ${ }^{75}$.

Social media, then, are used in a smart way by emerging designers, who effectively self-promote their work, uploading their creations to the different digital platforms available today. If this gives benefits to the independent creatives, on the other side, fast fashion giants, such as Zara, H\&M, Forever 21 and Urban Outfitters, can quickly and cheaply reproduce the latest designs' trends easily found online, and ship the items out to stores almost immediately_often before the original designers can even start to produce the collection ${ }^{76}$.

The rapid technological progress has exacerbated the inadequacy of intellectual property rights against plagiarism, with the consequence of mostly harming, once again, the emerging designers. Whereas "major fashion houses have such strong brand recognition that consumers identify the original garment and still choose to buy the original over the copy" (Scafidi 2007), an emerging designer's

74 See Wade, Margaret E. 2011, cit., 337: "Fashion piracy is not a new phenomenon, but with the rise of new technology and evolving consumer behaviors, copycat fashion is more common than ever before". See also Adler, Amy, Fromer, Jeanne C. 2019. Taking Intellectual Property into Their Own Hands. California Law Review. 107: 1455; Roth, Judith S., Jacoby, David. 2009. Copyright Protection and Fashion Design. In Advanced seminar on copyright law (PLI Intellectual Prop. Handbook Ser. No. G-967, 2009): "The advent of online, real time access to the exhibition of new designs and rapid-fire manufacturing capabilities through CAD and other technological advances have facilitated design piracy"; Reasons to Stop Fashion Piracy: The Testimony of Susan Scafidi. 2006. Available at: http://www.arts-of-fashion.org/stopdesignpiracy.html (last accessed on 1 January 2020).

75 "[T] here [are w]eb sites now where you get a runway show, and they can literally zoom into the garment front and back, copy stitch for stitch, and pretty much print it and make it in a couple days flat and ship it before we ourselves can even take orders on the product", Hernandez, Lazaro. 2011, cit.

76 Cf. my interview with Veronica Cornacchini and Matteo Gioli by SuperDuper Hats, talking about Zara insiders sent to Pitti Immagine in Florence, one of the most important fashion fairs in Italy, to photograph previews of new designs, 4 April 2019. 
brand is not known yet and, if a copy enters the market before the original, the consumers will not be aware that they are not buying an original design.

At this point, regardless of the formal protection offered by IP law, it is unlikely that small brands could effectively resort to those instruments. Emerging designers usually "lack deep pockets to chase down versions they find similar" (Binkley 2010), and before of that, to preventively register their creations, which, however, would rarely meet the requirements.

With the digital revolution, though, comes the other side of the coin. Social media offer the small designers an alternative way, free and accessible, to solve their conflicts and obtain compensation.

"Despite the increased availability of legal protection, one can see little litigation involving fashion designs" (Raustiala and Sprigman 2006). Rather, a more widespread use of social networks by emerging, independent designers and artists in the attempt to seek justice against plagiarism can be identified.

NYU Professors Adler and Fromer wrote an extensive article on the subject, using a diverse array of recent examples; their work has been my sherpa through the next section.

\section{Fashion Controversies on Social Media Rather Than in Courtroom}

\subsection{Tuesday Bassen v. Zara}

In 2016 Tuesday Bassen, an independent apparel designer and illustrator based in Los Angeles, discovered by chance that her original illustrations for pins and patches had been unlawfully reproduced by the multinational company Zara ${ }^{77}$. With the evolution of technology, the ease of copying and counterfeiting has increased, but so it has the ease of detecting copies (Adler and Fromer 2019). Initially, Bassen was aware of only four of her patches taken by Zara. Then, with the help of colleagues and friends, including the artist Adam Kurtz, Tuesday found two more of her pieces, along with seventeen other young artists' works; none of them was first contacted by Zara for a license agreement. Adam Kurtz's immediate reaction was the launching of Shop Art Theft, a Tumblr blog that compared major retailers' allegedly copied products with the original designs. Kurtz added also the links to the artists' websites and invited to support them by purchasing their artworks ${ }^{78}$.

In similar cases, even if the small designer decides to embark on litigation and sue someone for copyright infringement, the timing of a legal process contrasts with the speed of fast fashion industry. The consequence is that fast fashion retailers have very little fear of producing by exploiting emerging designers' works, because the products of fast fashion clothing chains disappear from the store shelves before a lawsuit can even be filed against them.

Tuesday Bassen's case is far from an isolated one: there is an entire community of designers whose work has been copied without any consent ${ }^{79}$. For this reason, the LA based illustrator decided to take legal action against Zara, despite the heavy financial costs, and through her lawyer sent a cease-and-desist letter to the retailer. This one replied: "The lack of distinctiveness in the designs that are supposed to be his client's makes it very difficult to establish that a significant part of the population anywhere in the world would associate drawings with Tuesday Bassen".

77 See Puglise, Nicole. 2016. Fashion brand Zara accused of copying LA artist's designs. The Guardian, 21 July. Available at: https://www.theguardian.com/fashion/2016/jul/21/zara-accused-copying-artist-designs-fashion; Zara Comes Under Fire for Copying Indie Artists Designs. The Fashion Law, 20 July 2016. Available at: http://www.thefashionlaw.com/home/zaracomes-under-fire-for-copying-indie-artists-designs (both last accessed on 1 January 2020).

78 The Tumblr blog is still active at shoparttheft.tumblr.com. Such an instrument is very powerful, cf. the famous Diet Prada Instagram page and its unrelenting coverage on fashion allegedly copycatting cases, at https://www.instagram.com/diet prada/ (both last accessed on 1 January 2020).

79 In 2016 Emily Oberg, designer for her own company Sporty \& Rich, accused Forever 21 and Fresh Tops of replicating her graphic sweatshirt designs. James Soares accused Urban Outfitters of stealing his graphic printing designs that were sold on his site, Society 6 (Ruff 2017). 
After Zara's refusal to take her claims seriously, the designer decided to post the letter on her Instagram account (Appendix A, Figure A3). Her large following took her side, writing comments and sharing the post so that the case rapidly became very popular on the Internet.

Given such a great support of the public opinion to Bassen, Zara changed its tone and made a completely different statement: "Inditex [Zara is the main brand of the Inditex group] has the utmost respect for the individual creativity of all artists and designers and takes all claims concerning third party intellectual property rights very seriously. Inditex was recently contacted by the lawyers of artist Tuesday Bassen who noted the use of illustrations in some badges sourced externally and on clothes in its Group stores. The company immediately opened an investigation into the matter and suspended the relevant items from sale. Inditex's legal team is also in contact with Tuesday Bassen's lawyers to clarify and resolve the situation as swiftly as possible. We are also currently investigating other allegations of illustrations used on badges provided by external suppliers on a case by case basis."

Nowadays, it is commonplace for emerging designers to use social networks as free platforms to share and promote their work, but also as a place to assert their voice in case their work has been plundered by a fashion giant. Reactions on these platforms are instantaneous and in most cases very supportive: the backing of thousands of people from around the world pushes the established fashion houses to reformulate their first response, to offer apologies, to seek an agreement with the small designers' lawyers or directly with the designers, and to take reparative measures such as the withdrawal of the items from the sale and the launch of investigations on external suppliers.

As a matter of fact, despite existing formal regimes of protection, a large number of fashion controversies tend to be informally disputed on social media platforms rather than in courtrooms. Especially when the conflict involves emerging designers against well-established fashion brands, Facebook, Instagram, Twitter are powerful tools capable to balance the positions of the different players at stake and to bridge the divide between big retail companies and small independent creatives.

A brand cannot simply ignore countless comments often characterized by the recourse to 'shaming' techniques (Grinvald 2011) if it wants to protect its public image—or its sales.

\subsection{The Reputation Factor: The Cool and the Bully}

Certain factors, such as reputation and recognition, assume a decisive role in the fashion industry.

Intellectual property regulates the fashion world only up to a certain point. Fashion is a normative system made up of unwritten rules that often weigh more than written ones. In other words, the fashion community is governed by social norms and ethical considerations that have more influence on both producers and consumers' decisions, and generate a more significant impact, than legal norms.

Social networks are effective means of exerting pressure on major companies, being able to build a good or bad reputation, to shape the public opinion, and to affect the outcome of a conflict. In light of these considerations, deciding to file a lawsuit, or sometimes even just to ignore a social campaign, may be an improper, even self-defeating, choice for a fashion giant.

If a fashion house chooses to bring a case before a court, it is very probable, regardless of a favorable legal outcome, that in practice such a fashion company would obtain different results, that can span from bad reputation and exclusion from the fashion community, to boycott and consequent drastic drop in sales. With legal action comes the risk of being labelled as "bully" 80 or "not cool" 81 , and in

80 See Rosenblatt, Elizabeth L. 2013. Fear and Loathing: Shame, Shaming, and Intellectual Property. DePaul L. Rev. 63:1; and also Chan Grinvald, Leah. 2011. Shaming Trademark Bullies. Wis. L. Rev. 2011:625 (discussing how businesses and individuals use shaming techniques to defend themselves against trademark bullies).

81 Adler and Fromer (2019) underline the phenomenon of "cool" cease-and-desist letters as a way to subvert a "bully" label. See also Tim Nudd, Tim. 2017. Netflix Sent the Best Cease-and-Desist Letter to This Unauthorized Stranger Things Bar. AdWeek, 20 September, reporting positively on a "quite adorable" cease-and-desist letter written to the owners of an unauthorized Stranger Things bar "in the style of the Stranger Things universe". Rosenblatt (2013) discusses a creative cease-and-desist letter from Jack Daniel's that generated good publicity for the rightsholder. On the contrary, the Mattel company has many times proven to be "not cool". First, suing the MCA Records for the pop song 'Barbie Girl' by Aqua, see Mattel, Inc. v. MCA 
fashion world the importance of "the cool factor" (Adler and Fromer 2019) is not to be underestimated. Similar logics and unspoken rules govern the art world as well.

The role of the bully was played by Louis Vuitton, which in 2011 sued the Danish, Amsterdam-based artist Nadia Plesner ${ }^{82}$ for her work 'Darfurnica', where the multicolored 'Audra' bag, a Vuitton model as reinterpreted by the artist Takashi Murakami, was worn by a black malnourished child (Appendix A, Figure A4). Plesner responded explaining why one should be allowed to include references to status symbols in artworks. The Court of the Hague agreed with the artist. Vuitton did not win the case because an average observer would not have deduced from the painting the association of the fashion house with the genocide in Darfur, rather, connecting the famous LV pattern to an idea of luxury. "Owners of the most famous companies should accept a large critical use of their brands" 83 . Vuitton did not suffer damages to its name and reputation from the use of its 'Audra' bag in Plesner's work, while its public image was damaged, instead, after the artist's social media campaign, claiming her right to freedom of expression.

\subsection{Gucci and GucciGhost}

Emerging designers and independent artists who decide to resort to social media to seek their relief for IP infringement could accomplish probably even more than what they could have hoped to derive from a successful lawsuit. The path is faster and cheaper, and also more "attention-grabbing than court trials" (Adler and Fromer 2019), bringing the creative to the unexpected attention of the public. The resonance created by social media platforms grants the author their right of attribution of their works. Furthermore, as in the Bassen case, where Zara declared that it would have reached Ms. Bassen's lawyers to find the best solution, the small designer certainly obtains monetary compensation.

However, sometimes, compensation can be even more. This happens when, instead of filing a lawsuit, sending a cease-and-desist letter or shaming online, the parties start actual collaborations. Controversies are handled by "[re-appropriating] perceived misappropriations, therein generating new creative works" (Adler and Fromer 2019). In these situations, conflictual aspect is completely overcome.

Trevor "Trouble" Andrew, a Brooklyn-based artist and former professional athlete, wanted the Italian fashion brand Gucci to notice him ${ }^{84}$. When in need of a Halloween costume, he turned a Gucci linen into a ghost costume, and GucciGhost was born. From that moment on, he started to paint a graffiti-like version of the Gucci logo not only on clothing but on a variety of objects, posting every creation on his Instagram account (Appendix A, Figures A5 and A6). Finally, Gucci reacted, but in a completely unexpected way. Alessandro Michele, Gucci's creative director, decided to hire GucciGhost and commission him its 2016 Fall collection. Fashion insiders and consumers' reaction was of appraisal of such an audacious and surprising tactic. Certainly, Gucci had much more financial benefits than from a litigation against a young emerging artist. At the same time, the brand avoided the misattribution

Records, Inc., 296 F.3d 894 (9th Cir. 2002). Then, deciding to sue the artist Tom Forsythe, who photographed naked Barbie dolls in absurd sexual positions on kitchen appliances, creating the series "Food Chain Barbie", see Mattel, Inc. v. Walking Mountain Productions, 353 F.3d 792, 802 (9th Cir. 2003).

82 It is not the first episode of the controversy between Plesner and Vuitton. A different lawsuit was filed by the fashion brand against the artist in 2008. See Artist Chronicles 3-Year fight with Louis Vuitton in New Book. The Fashion Law, 9 July 2015. Available at: http://www.thefashionlaw.com/home/artistfightslouisvuitton (last accessed 1 January 2020).

83 Nadia Plesner Joensen v. Louis Vuitton Malletier sa, Court of the Hague, Civil Law Section, 389526/ KG ZA 11-294, 4 May 2011. Nadja Plesner published on her website the verdict delivered by the court of the Hague: http://www.nadiaplesner.com/upl/ website/simple-living--darfurnica1/VerdictEnglish.pdf (last accessed on 1 January 2020).

84 On the case, see Adler, Fromer. 2019, cit. Additionally, see Gucci's Alessandro Michele: Creative Genius or Glorified Copycat? The Fashion Law, 9 August 2017. Available at: http://www.thefashionlaw.com/home/guccis-alessandro-michelesaddened-by-claims-of-copying; and In Conversation with Trouble Andrew on Gucci website: https://www.gucci.com/it/it/ st/stories/inspiration-and-codes/articles/agenda_2016_issue05_guccighost_collection_troblu_andrew_qa (both last accessed on 1 January 2020). 
of Andrew's work and claimed the attribution of its logo. Not to mention the advantage of having bypassed a legal battle that might have easily been unsuccessful due to 'fair use' defenses ${ }^{85}$.

\subsection{Gucci and Dapper Dan}

During the presentation of the Gucci 2018 Cruise collection, there was a garment on the catwalk that many immediately identified as the derivative of a puff-sleeved bomber jacket created by Daniel Day, better known as Dapper Dan, a designer who, between the late 1980s and early 1990s in his atelier in Harlem, contributed to that mix of styles which he defined as a "macho type of ethnic ghetto clothing", associated with African-American hip hop culture. Dapper Dan gave shape to a unique imagery, in which co-habited both an awareness of the artistic and cultural relevance of a whole community and a sense of upliftment and social advocacy, expressed through the appropriation and ironic reuse of the logos of the great European luxury brands.

The director Alessandro Michele replied to the online plagiarism allegations with declarations of homage to the creativity of Dapper Dan, implemented by mixing fabrics and accessories with Vuitton, Fendi and, precisely, Gucci logos (Appendix A, Figure A7). All without licenses, which partly motivated the closure of his store in 1992. A shop atelier that in January 2018 reopened with the financial support and collaboration of Gucci, in some way closing the circle (Appendix A, Figure A8).

Dapper Dan's fans, including many celebrities, resorted to social media to call out Gucci for its appropriation. Such mainstream media coverage is likely what led Gucci to its apologetic reaction and to the announcement of the Gucci-Dapper Dan joint venture (Adler and Fromer 2019) ${ }^{86}$.

The case of Gucci imitating Dapper Dan's jacket carries further implications and goes beyond copycat controversies to find itself at the center of the so-called cultural appropriation debate ${ }^{87}$. (Scafidi 2005). Even if it is not the subject matter of this article, it is worth mentioning that cultural appropriation cases are, too, most effectively solved through the social control on digital platforms ${ }^{88}$.

\subsection{From Litigation through Settlement to Social Media: Advantages and Disadvantages}

The copying of original designs, as well as other kinds of fashion-related or art-related cases, are all issues that call for both legal, written, formal and extralegal, unwritten, informal considerations during their assessment.

Reputation has always been a key factor for fashion companies, but in the last few years "social media has changed the game" (Adler and Fromer 2019). First, the sentence is delivered with a click and becomes viral overnight, therefore, brands need to be responsive and act quickly if they want to have a chance to repair the damage. Second, everyone has been empowered to "wage campaigns that can bring a brand to its knees in a matter of hours" (Adler and Fromer 2019).

The result is that social networks provide accessibility to satisfactory remedies to all, especially to small designers and emerging artists who do not usually have the money and the capacity to initiate judicial action. In this regard, the fashion pyramid structure that marks huge disparities between strong and weak actors might be potentially overcome.

85 The US 'fair use' doctrine is a defense against a claim of copyright infringement on the basis of a limited and 'transformative' use, such as parody, of copyrighted works.

86 See Schneier, Matthew. 2017. Did Gucci Copy 'Dapper Dan'? Or Was It 'Homage'? The New York Times, 31 May. Available at: https://www.nytimes.com/2017/05/31/fashion/gucci-dapper-dan-jacket.html; Cooper, Barry Michael. 2017. The Fashion Outlaw Dapper Dan. The New York Times, 3 June. Available at: https://www.nytimes.com/2017/06/03/fashion/ dapper-dan-harlem-gucci.html; Cochrane, Lauren. 2017. Homage or copy? Why fashion (especially Gucci) loves Dapper Dan. The Guardian, 2 June. Available at: https://www.theguardian.com/fashion/2017/jun/02/homage-or-copy-why-fashionespecially-gucci-loves-dapper-dan (all last accessed 1 January 2020).

87 Cartner-Morley, Jess. 2017. Dapper Dan and Dries van Noten address cultural appropriation debate. The Guardian, 1 December. Available at: https://www.theguardian.com/fashion/2017/dec/01/dapper-dan-and-dries-van-noten-addresscultural-appropriation-debate (last accessed on 1 January 2020)

88 This is the subject of an upcoming article. 
What can be identified as a growing phenomenon in the fashion world is that equal access, justice, resolution, and fair compensation seem to be obtained in a different and yet effective manner out of court.

As stated in the previous paragraphs, IP laws play an insignificant role in the field of fashion: in fact, the available rights and remedies are not appropriate to fashion dynamics. In search of other venues in which fashion designs can receive adequate protection, in case of dispute, fashion actors most of the time decide not to lodge complaints before a court, but they rather step away from the juridical, passing through the extra-judicial, and ultimately landing on the social. From litigation, through cease-and-desist letters and settlement agreements, to the judgment of the public opinion in social media courtroom: the juridical sphere is definitely abandoned, yet regulation is still in place.

Resolution of controversies through social media often accomplishes the same results of the ones that could be expected from a successful litigation: monetary compensation, getting attribution of one's own work and avoiding misattribution of the copyist's work (Adler and Fromer 2019). Frequently, as it has been already mentioned, such outcomes are even greater if gained outside the juridical sphere.

Certainly, the path to relief is faster and cheaper than bringing a lawsuit before a court. The secondary effect is not contributing to the judicial system overload. Furthermore, it may be sharable the objection according to which courts lack the expertise to solve disputes on fashion issues and may not be the best option in such cases.

The advantages that can be delineated by the phenomenon of getting satisfaction through social media are numerous and varied. A few more. Regarding established fashion companies, they not only avoid negative publicity and reputational damages, but rather, they enhance the brand's image for being cool, while invoking law and undertake litigation would have done the opposite, building a bad reputation for being a bully. As far as small designers and emerging artists are concerned, instead, the rise of the Internet and social media has equipped them with a powerful weapon against big retailers and brands. The inequality between parties regarding access to justice is balanced through the opening of an alternative avenue to find solutions and get satisfaction.

Speed, efficiency and equal access ${ }^{89}$ have their own downside. The resolution of controversies through social networks has been faced with several criticisms, above all, the lack of procedural guarantees ensured in a fair trial ${ }^{90}$. Additionally, social media outcry lacks accuracy and might boost the spread and circulation of incorrect or false information, undervaluing the cost of mistakes for the unjustly, or partially unjustly, accused party ${ }^{91}$. Social protests, boycotts, campaigns, petitions, and shaming may lead to uncalibrated forms of punishment.

Another concern regards the balancing between the competing interests of the rightsholder's protection and of the public's freedom to copy. An extra-judicial way of controversies' resolution might lead to unduly limitations to the free market, undermining creativity and competition.

However, it is this article's assumption that "informal social control as an alternative to formal law" (Strahilevitz 2005) brings more benefits than disadvantages. Against a backdrop of inadequate legal regulation, the digital age enables "self-help" (Adler and Fromer 2019) as a more efficient and accessible alternative to legal action.

89 Costs of access to justice in civil proceedings are expensive and include court fees, lawyer fees, transportation costs, time spent by litigants on a procedure. Even if big fashion companies could afford such costs, they still would need to adjust for the increased costs of litigation and filing expenses, and they would likely pass these new costs on to consumers, meaning raising the cost of clothing.

90 Article 111 of the Italian Constitution sets the principles of the due process of law. Art. 111 states that all parties shall be entitled to equal conditions before an impartial, third-party judge. To guarantee that, all judicial decisions shall include their reasoning. Furthermore, any party can appeal to the Supreme Court of Cassation in case of violations of law. In the United States, Fifth and Fourteenth Amendments contain a due process clause that, due to the broad interpretation by the Supreme Court, includes the protection of fair procedures.

91 The risk is that a copyist might bring a lawsuit for defamation against excessive shaming. However, most of the contents posted on social media are the truth, plus are statements of opinions rather than facts. These conditions are absolute defenses to defamation. For such reasons, a defamation lawsuit is unlikely to succeed. 


\section{Social Media as an Alternative Method of Conflicts Resolution: Is This the End of the Story? A Caveat}

The resolution of controversies through social media is a powerful and an effective tool, suitable to fashion's nature and logics. For this reason, rethinking and reproposing categories, rights and remedies offered to fashion designs by traditional IP law should not be the effort.

The need for regulation, according to the author, should rather lie in the dynamics of the Internet. The more urgent and pressing challenge seems to be that one of bringing the law into the digital world, with the function of controlling the new battleground that are social networks.

In this latest phase of the digital revolution - the age of social media-, the recourse to social networks does not happen only ex-post, in case of conflict, but also ex-ante, when designers connect to consumers and create communities around their brands, developing personal interactions.

Social media have deeply affected the way people acquire and process information. While Facebook, Instagram, and Twitter reflect common opinions, beliefs, attitudes, at the same time they shape them, playing a prominent role in the formation of public opinion. In this regard, it becomes vital to regulate the way public opinion is formed on social media.

Against the anti-regulatory thesis claiming to support free speech, but in fact protecting and expanding property rights of media corporations, it is our concern that social media platforms should be regulated by the law (Balkin 2004).

Mass media are controlled by a relative handful of very wealthy corporations. Mark Zuckerberg, co-founder and CEO of Facebook, is so influent he even forged his own coin ${ }^{92}$. Few owners control the flow of digital content through the networks, and control the distribution, use, transformation - manipulating information, allowing fake accounts, altering campaigns, addressing information, selecting information— to the extent of controlling individuals' life choices, desires, and opinions.

Against this background, the law has still an essential part to play and my proposal for future research is to acknowledge and define such an important role. Public regulation is necessary to guarantee an open, transparent, trustable space, available to a wide variety of speakers.

And if it is true that law is ill equipped to deal with many of the most important problems in the digital era, not knowing nor understanding how social media and ever-changing technologies work, it remains crucial to create a legal framework able to regulate, even if to do so it needs the contribution of private parties (administrative agencies, software designers, tech companies).

In the European context, a regulatory solution, even involving social media providers, seems more acceptable than in the United States, where the free speech clause protected by the First Amendment prohibits in absolute terms state interference.

Law should enter the game in a different role and form: legal protection, but with the help of self-regulation, policies and guidelines, principles of soft law, technological designs and structures.

However, this is material for another article.

Funding: This research received no external funding.

Conflicts of Interest: The author declares no conflict of interest.

92 https://libra.org/en-US/. Kharif, Olga. 2019. Why (Almost) Everybody Hates Facebook's Cryptocurrency Libra. Bloomberg, 16 July. Available at: https://www.bloomberg.com/news/articles/2019-07-16/why-everybody-almost-hates-facebook-sdigital-coin-quicktake (last accessed 1 January 2020). 
Appendix A

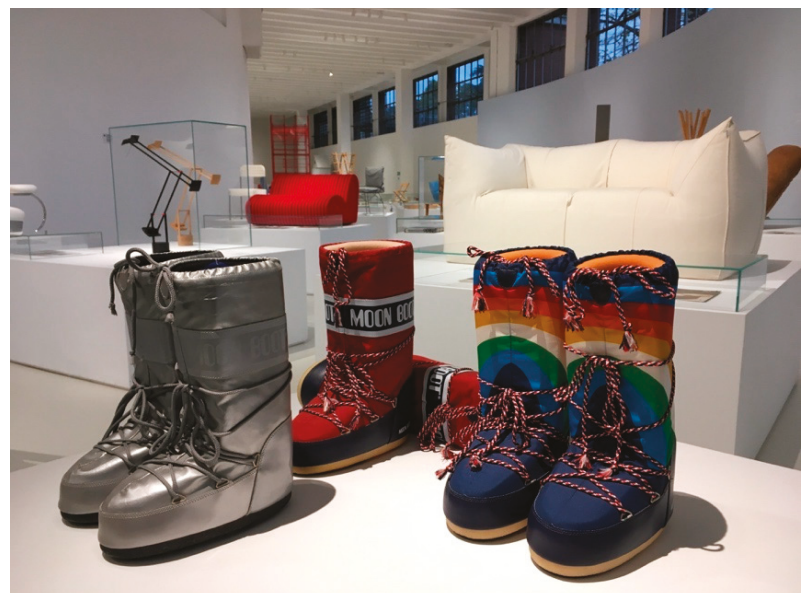

Figure A1. Moon Boot in Tecnica group spa v. Anniel group spa. Photo by the Author at Triennale Design Museum, Milan. 


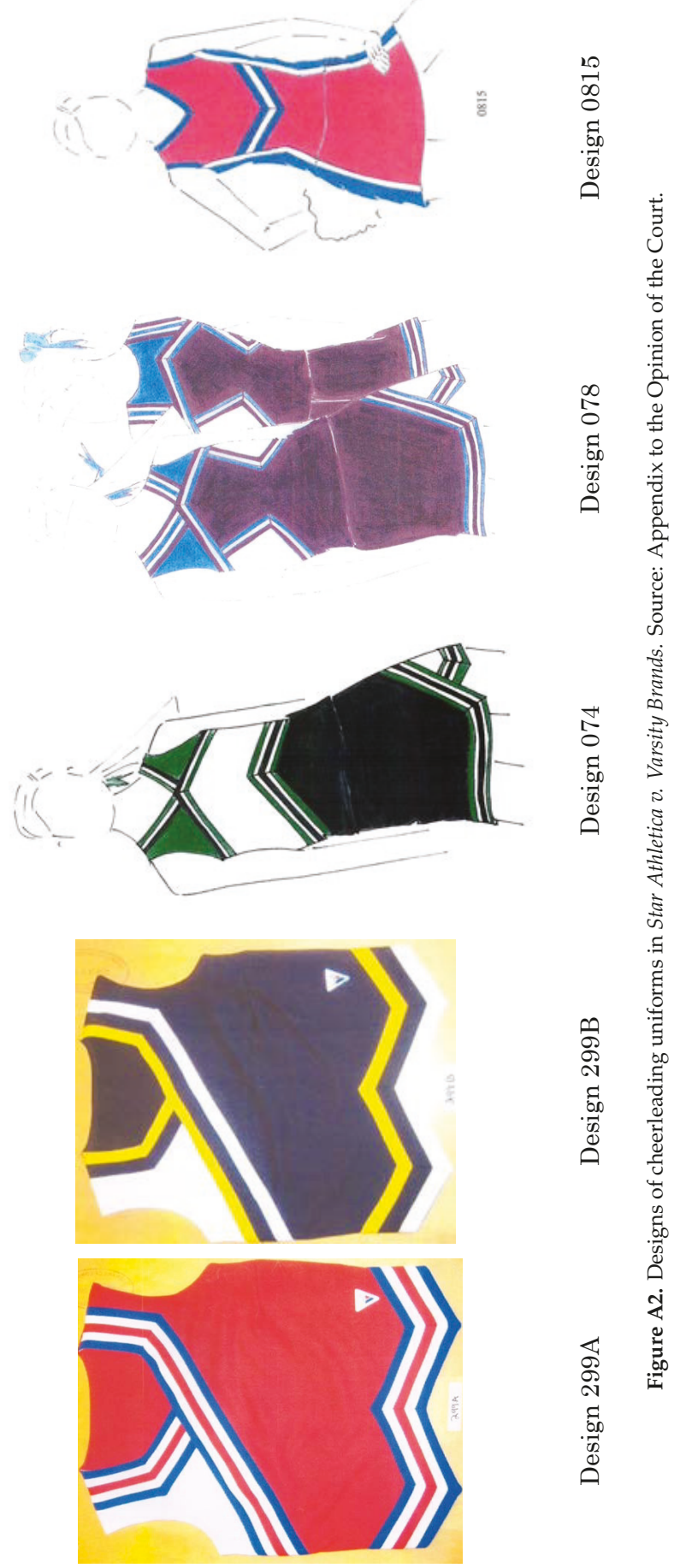



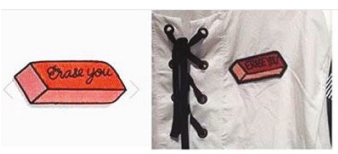

MINE

ZARA'S COPY

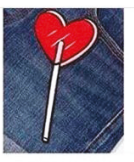

MINE

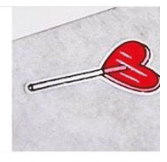

ZARA'S COPY

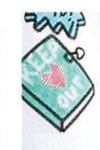

ZARA'S COPY

MINE

ZARA'S COPY

MINE

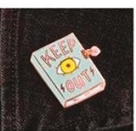

We reject your claims here for reasons similar to those already stated above: the lack of distinctiveness of your client's purported designs makes it very hard to see how a significant part of the population anywhere in the world would associate the signs with Tuesday Bassen. This is our firm view, and being fully aware of the 3rd party notifications that you have brought to our attention. In this last regard, please note that such notifications amount to a handful of complaints only; when it is borne in mind that millions of users worldwide visit the respective websites monthly (Zara: $98,000.000$ average monthly visits last year, Bershka: 15.000 .000 average monthly visits last year) the figures clearly put those few notifications into sharp perspective.

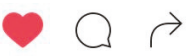

\section{- 465 likes}

tuesdaybassen I've been pretty quiet about this, until now. Over the past year, @zara has been copying my artwork (thanks to all that have tipped

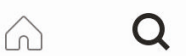

Figure A3. Tuesday Bassen copied by Zara. From Bassen Instagram profile.

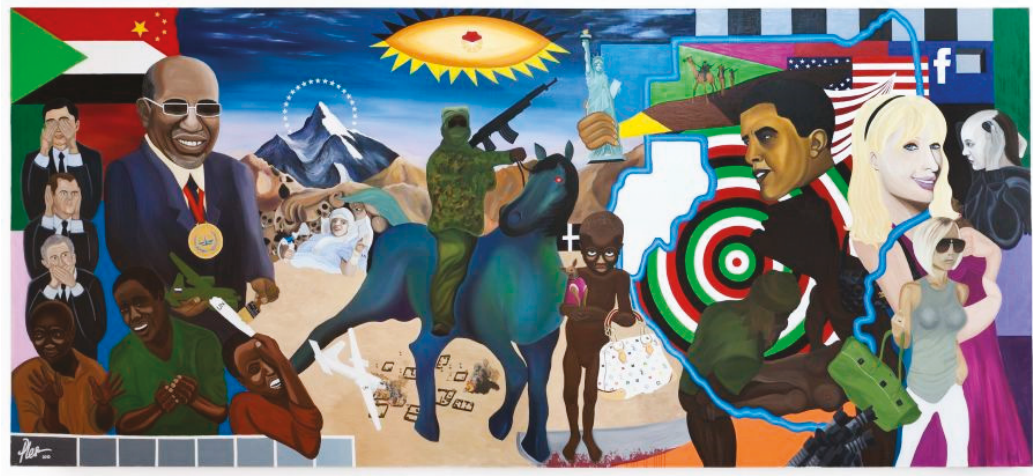

Figure A4. Darfurnica, Nadia Plesner, 2010. From the artist's website http://www.nadiaplesner.com/. 


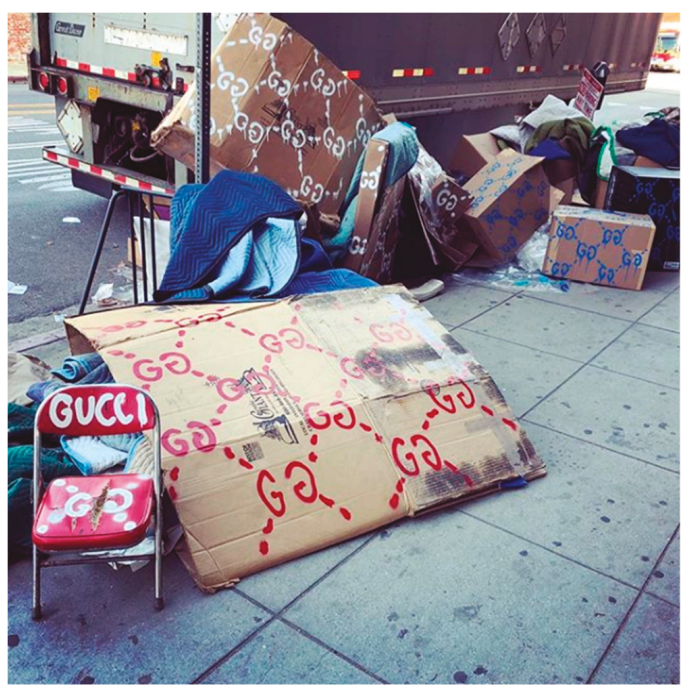

Figure A5. A work by GucciGhost. From Trouble Andrew Instagram profile, 24 Jun. 2018.

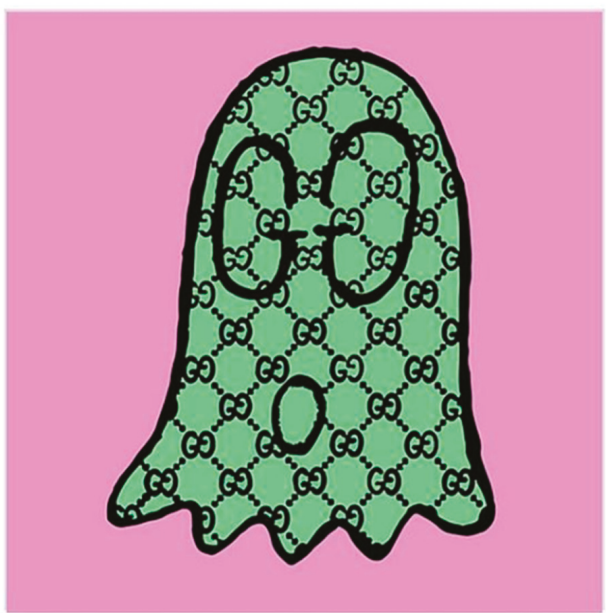

Figure A6. A work by GucciGhost. From Trouble Andrew's Instagram profile, 28 Sept. 2019. 

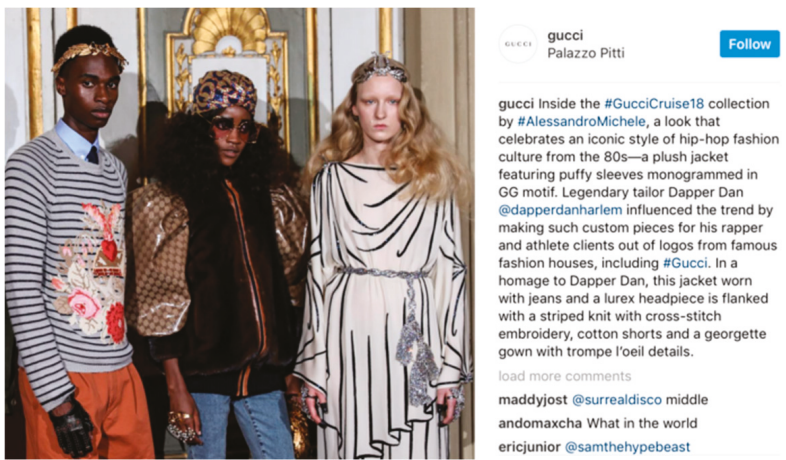

maddyjost @surrealdisco middle

andomaxcha What in the world ericjunior@samthehypebeast

Figure A7. Gucci jacket, Cruise 2018 collection, 'inspired' by Dapper Dan. From Gucci Instagram profile.

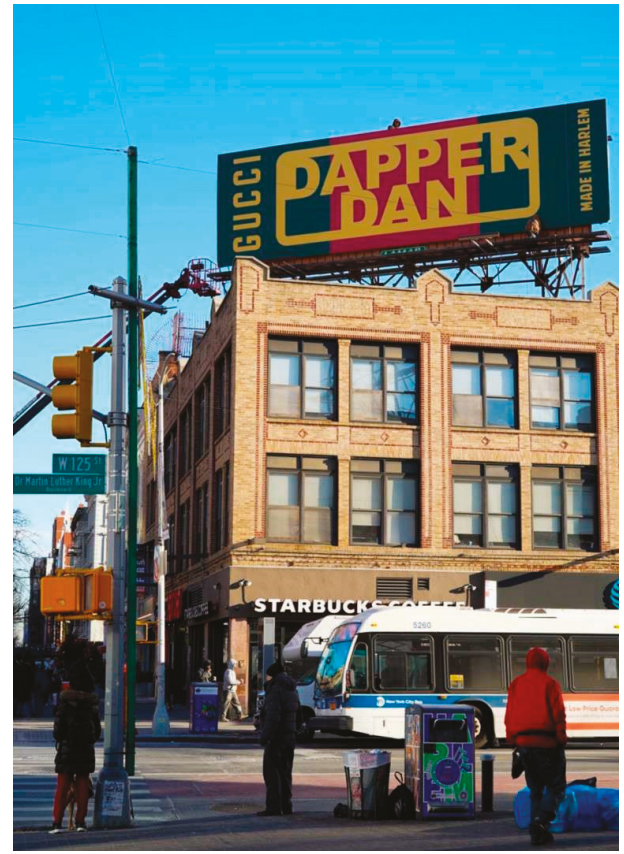

Figure A8. Dapper Dan-Gucci boutique, New York, 2018. From Gucci website.

\section{References}

Adler, Amy, and Jeanne C. Fromer. 2019. Taking Intellectual Property into Their Own Hands. California Law Review 107: 1455.

Andrews, Katelyn N. 2012. The most fascinating kind of art: Fashion design protection as a moral right. The New York University Journal of Intellectual Property \& Entertainment Law 2: 188.

Arnold, Rebecca. 2009. Fashion: A Very Short Introduction. Oxford: Oxford University Press.

Balkin, Jack M. 2004. Digital Speech and Democratic Culture: A Theory of Freedom of Expression for the Information Society. Yale Law School Faculty Scholarship Series 79: 1.

Barabino, Sofia, and Elena Varese. 2016. Fashion Law. In Le Problematiche Giuridiche Della Filiera Della Moda. Edited by Barbara Pozzo and Jacometti Valentin. Milano: Giuffrè, pp. 93-108. 
Binkley, Christina. 2010. The Problem with Being a Trendsetter: Copycat Fashions Move Faster Than Ever, Making It Harder to Protect Original Ideas; Smaller Designers Bear the Brunt. Wall Street Journal, April 29.

Bonelli, Giacomo. 2003. Industrial design e tutela del diritto d'autore. Diritto d'Autore 4: 519.

Buccafusco, Christopher, and Jeanne C. Fromer. 2017. Fashion's Function in Intellectual Property Law. Notre Dame Law Review 93: 51. [CrossRef]

Calanca, Daniela, and Cinzia Capalbo. 2018. Fashion and Cultural Heritage. ZoneModa Journal 8.

Caselli, Sara. 2017. Le ultime tendenze sulla tutela autorale del design e sul requisito del "valore artistico". Rivista di Diritto Industriale 2: 333

Cutler, E. P., and Julien Tomasello. 2015. Art and Fashion: Collaborations and Connections between Icons. San Francisco: Chronicle Books.

Dalle Vedove, Giampaolo. 2001. Dal modello ornamentale all'industrial design. Diritto d'Autore 3: 341.

Denicola, Robert. 2018. Imagining Things: Copyright for Useful Articles after Star Athletica v. Varsity Brands. University of Pittsburgh Law Review 79: 635. [CrossRef]

Ellis, Sara R. 2010. Copyrighting Couture: An Examination of Fashion Design Protection and Why the DPPA and IDPPPA Are a Step Towards the Solution to Counterfeit Chic. Tennessee Law Review 78: 163.

Fabbio, Philipp. 2012. Disegni e modelli. Padova: CEDAM.

Floridia, Giorgio. 1984. La protezione del diritto d'autore sulle opere dell'industrial design. Rivista di Diritto Industriale 1: 375.

Franzosi, Mario, and Massimo Scuffi. 2014. Diritto industriale italiano. Padova: CEDAM.

Galli, Cesare. 2004. Il design. In Il Codice Della Proprietà Industriale. Edited by Luigi Ubertazzi. Giuffrè: Milano.

Geczy, Adam, and Vicki Karaminas, eds. 2012. Fashion and Art. London and New York: BERG.

Giudici, Silvia. 1989. Dall'opera d'arte applicata all'industrial design. Rivista di diritto industriale 2: 269.

Grinvald, Leah Chan. 2011. Shaming Trademark Bullies. Wisconsin Law Review 2011: 3. [CrossRef]

Hernandez, Lazaro. 2011. Statement. In Innovative Design Protection and Piracy Prevention Act: Hearing on H.R. 2511 Before the Subcomm. on Intellectual Property, Competition, and the Internet of the H. Comm. on the Judiciary, 112th Cong. 4. Available online: https://www.govinfo.gov/content/pkg/CHRG-112hhrg67397/pdf/ CHRG-112hhrg67397.pdf (accessed on 1 January 2020).

Mann, Ronald. 2017. Opinion Analysis: Court uses cheerleader uniform case to validate broad copyright in industrial designs. SCOTUS Blog. March 22. Available online: https://www.scotusblog.com/2016/10/argumentpreview-court-to-consider-copyright-protection-for-cheerleading-uniforms/ (accessed on 1 January 2020).

Morri, Francesca. 2013. Le opere dell'industrial design tra diritto d'autore e tutela come modelli industriali: Deve cambiare tutto perché (quasi) nulla cambi? Rivista di diritto industriale 1: 177.

Mulam, Kshithija. 2019. The Intellectual Property Implications of Star Athletica v. Varsity Brands. The Intellectual Property Implications of Star Athletica v. Varsity Brands. Undergraduate Law Review. April 15. Available online: https:/www.culawreview.org/journal/the-intellectual-property-implications-of-star-athletica-vvarsity-brands (accessed on 1 January 2020).

Norell, Norman, Louise Nevelson, Irene Sharaff, Alwin Nikolais, and Andre Courreges. 1967. Is Fashion an Art? The Metropolitan Museum of Art Bulletin New Series 26: 129-40. [CrossRef]

Palavera, Rosa. 2016. Abbigliamento, diritto e marginalia. In Fashion Law. Le Problematiche Giuridiche Della Filiera Della Moda. Edited by Barbara Pozzo and Valentina Jacometti. Milano: Giuffrè, pp. 277-340.

Raustiala, Kal, and Christopher Sprigman. 2006. The piracy paradox: Innovation and intellectual property in fashion design. Virginia Law Review 92: 1762.

Raustiala, Kal, and Christopher Sprigman. 2009. The Piracy Paradox Revisited. Stanford Law Review 61: 1201.

Rosati, Eleonora. 2019. CJEU rules that copyright protection for designs only requires sufficient originality. Journal of Intellectual Property Law \& Practice 14: 12.

Rosenblatt, Elizabeth. 2011. A Theory of Intellectual Property's Negative Space. Columbia Journal of Law and The Arts 34: 317.

Scafidi, Susan. 2005. Who Owns Culture? Appropriation and Authenticity in American Law. New Brunswick: Rutgers. Scafidi, Susan. 2006. A Bill to Provide Protection for Fashion Design. Hearing on H.R. 5055 Before the Subcommittee on Courts, the Internet, and Intellectual Property of the Committee on the Judiciary House of Representatives, 109th Cong. 2. Available online: https:/www.govinfo.gov/content/pkg/CHRG-109hhrg28908/html/CHRG109hhrg28908.htm (accessed on 1 January 2020). 
Scafidi, Susan. 2007. Intellectual Property and Fashion Design. In Intellectual Property and Information Wealth: Issues and Practices in the Digital Age. Edited by Peter K. Yu. Westport: Greenwood Publishing Group, vol. 1.

Simmel, Georg. 1957. Fashion. The American Journal of Sociology LXII: 6.

Sischy, Ingrid, and Germano Celant. 1982. Editorial. ArtForum 20: 34.

Spada, Paolo, Paolo Auteri, and Gustavo Ghidini. 2002. Industrial design e opere d'arte applicata all'industria (dialogo tra Paolo Spada e Paolo Auteri commentato da Gustavo Ghidini). Rivista di Diritto Civile II: 272.

Strahilevitz, Lior Jacob. 2005. A Social Network Theory of Privacy. University Chicago Law Review 72: 919. [CrossRef]

Tsai, Julie. 2005. Fashioning Protection: A Note on the Protection of Fashion Designs in the United States. Lewis $\mathcal{E}$ Clark Law Review 9: 447.

Vanzetti, Adriano, and Vincenzo Di Cataldo. 2018. Manuale di diritto industrial, 8th ed. Milano: Giuffrè.

Wade, Margaret E. 2011. The Sartorial Dilemma of Knockoffs: Protecting Moral Rights without Disturbing the Fashion Dynamic. Minnesota Law Review 96: 336.

(C) 2020 by the author. Licensee MDPI, Basel, Switzerland. This article is an open access article distributed under the terms and conditions of the Creative Commons Attribution (CC BY) license (http://creativecommons.org/licenses/by/4.0/). 
Article

\title{
Wearable Technologies and Smart Clothes in the Fashion Business: Some Issues Concerning Cybersecurity and Data Protection
}

\author{
Giovanni Ziccardi \\ Law Department «Cesare Beccaria», University of Milan, 20122 Milan, Italy; giovanni.ziccardi@unimi.it;
} Tel.: +39-02-50312714

Received: 21 April 2020; Accepted: 13 May 2020; Published: 29 May 2020

\begin{abstract}
Wearable devices and smart clothes give rise to pivotal technological and legal issues in the fashion business. The cybersecurity attention in the digital society, and the advent of General Data Protection Regulation No. 2016/679 (GDPR) in the European, and global, legal framework, implied the need to evaluate which norms and aspects of the European Regulation could apply to wearable devices, which are becoming more and more invasive. Wearable devices are, first of all (and from a data protection point of view), intrusive tools that can put users' personal (and intimate) data at risk. In particular, we will discuss the aspects of the spread of an accountability "culture" (also) in the fashion business, the need for correct management policy of data breaches, the rights of transparency for users/customers who are using wearable devices and smart clothes, and respect for the dignity and nondiscrimination of the individual during the data collection and processing. These are, all, fundamental points: the protection of the individual's data in the digital landscape is, in fact, strictly connected to the protection of his/her fundamental rights in the modern digital society.
\end{abstract}

Keywords: wearable devices; GDPR; data breach; smart fashion; smart clothes; transparency; privacy; data protection; legal informatics; cybersecurity

\section{Introduction}

Several recent field studies and business reports prospected, in the last two years, the fact that the wearable technologies market will have a strong impact and an unstoppable growth, even in the fashion sector (CCS Insight 2019). These studies described a wearables market worth $\$ 34$ billion by 2020 and an existing solid presence of wearable technology in the digital society, with multiple applications in the retail, automobile, medical, and insurance sectors (Arnault 2018).

On the one hand, in fact, technologies are getting smaller. On the other hand, all the objects that surround us are designed to "contain" a specific technological device.

This market includes companies inventing, designing, and building miniature body-borne computational and sensory devices and creating wearable devices that can be worn under, over or in clothing, or, of course, "may also be themselves clothes" (Mann 2012).

In fashion shows, and in the most important events around the world, the first prototypes presented aroused wonder and admiration on one side, and concern on the other; also, the apparel industry is going "through a period of fast tech-driven transformations, with fashion brands working hard to capture the needs of the modern fashion consumer" (Arnault 2018).

In this case, as it is clear, digital fashion joins fashion in the strict sense, given that most digital objects have also become fashion or design garments.

The evolution consists in the fact that "wearable technology found in modern fashion garments are no longer just smart sensors but have evolved into being part of a complex ecosystem comprising sustainable and innovative apparel, aiming for a cleaner industry and a healthier lifestyle" 
(Arnault 2018): contemporary fashion tech garments "are made from biomaterials such as leather from fungi and pineapple, textiles from algae, 3D printed rubber from recycled plastics, and lab-grown leather, all recorded on the blockchain" (Arnault 2018).

For reasons of space, we will not deal with the interesting relationship between blockchain and data protection (there are many projects concerning the application of blockchain systems in the fashion sector), but there are several scholars who are tackling the problem in a very precise manner (Finck 2017).

From a technical point of view, therefore, these devices are interesting for the scholar for two reasons.

The first is that they are "real sensors": they contribute to building up the sensor society and are capable of capturing data from a person or his/her devices.

The second aspect is that these sensors communicate with the environment surrounding us, and being wearable clothes or objects, they communicate with all the other sensors they encounter during the movements of the same person who wears them.

The fashion world is trying, on one side, to radically change the wearable devices market: "This is a departure from the approach to date, where technical features have led the race, with most devices competing solely on battery life and capabilities. But technology is no stranger to fashion; from smart fabrics, models wearing Google Glass on the runway, to fashion designer Adam Selman sporting the next generation of payment enabled dresses on the catwalk-wearable tech is increasingly claiming its place in fashion" (Lambert 2019).

On the other side, legal scholars (Russey 2018) have started to try to connote with precision what is meant, from a legal point of view, as a "wearable device", "smart watches" (Chuah et al. 2016) or "smart clothes," the consequent legal implications, and what are the differences with respect to other technological objects and devices of daily use (like, for example, smartphones) (Kim 2016).

In our opinion, the difference between a smartphone and a wearable sensor is radical: the smartphone is invasive but remains disconnected from the human body and from the "physical" idea of "person." A sensor that enters the clothes, or is attached to a part of the user's body, becomes much more subtle (especially if the user, at a certain point, gets used to its presence and no longer realizes that he/she is constantly monitored).

On the one hand, therefore, the scholar notes an incessant evolution of the world of fashion that pursues, in many aspects, the evolution of technology and, above all, of technological society. On the other hand, the legal framework tries to adapt to the evolution of the digital society and, consequently, shows interest also for the fashion sector when countless devices of common use (sensors, Radio Frequency Identification systems, locators, touch screens, message or chat notification systems) enter clothes and the fashion business.

At the same time, these issues raise important cybersecurity problems, which need to be addressed in a summary way in order to better understand the consequent legal regulation as well.

This is why, in this chapter, we will have to deal simultaneously with business, technological, legal, and data protection issues. All four sensitively characterize the present and will probably characterize the future.

\section{Data Processing and Cybersecurity in the Fashion Business}

From a data processing, data protection, and cybersecurity point of view, two types of objects/devices in the fashion business can be identified, and they are very different from each other.

The first one is, in fact, an object that is worn as an accessory: a watch, a necklace, a bracelet, an earring. This "object" can have some technological characteristics, or networking and wireless connection capabilities, as well as the ability to process data and communicate them to the user or to "the outside" (for example: to the producer of the device, or to a shop).

The second type consists of real "smart clothes": wearable garments that have the ability to interact with the body and the health of the person and act autonomously in the analysis of the data of the subject who is wearing them; garments that can monitor sweating and skin pores, health status, heart 
rate, or can check if the subject is healthy and fit in a given moment. They also could adapt, for example, the color of the dress to the color of the skin (analyzing, for example, a face more or less tanned).

Often, this second type of device is also connected to "smart shops," "smart factories," or "smart companies," in order to create a union that allows not only, for example, the control of a music stream with a tap on the dress, or to warn about the presence of threat factors in the external atmosphere (for example: a dress that can "hear" the presence of radiations, or gas), but also to change the configuration of the device and the reaction of the technology depending on the surrounding urban, shopping, or domestic situation.

This second type of wearable technology is clearly more interesting also from a legal point of view, because it is potentially more invasive with reference to the rights and freedoms of the individual (Katyal 2014).

This is the reason why wearable technologies and smart clothes, in the last few years, were also under the lens of jurists (Ching and Singh 2016) and cybersecurity and data protection experts (Burbidge 2019; Allery 2019).

The idea that the diffusion of objects with certain advanced functions can be not only related to "simple" smart glasses, or bracelets for fitness, or watches/smartphones, but also to real sensors that analyze our body and tell us (or someone else) if we are, for example, hypertensive, dehydrated, or if we need to drink or eat, or that try to communicate with our brain waves, or (perhaps in the future) with microchips implanted under our skin, raises interesting legal issues.

\section{Some Preliminary Legal Issues}

First of all, we are talking about technologies that, compared to other smart objects, are extremely "personal" (Satyanarayanan 2001) and, above all, invasive of the most intimate part of the individual (Pearce 2016).

These are devices that are not designed to create a network, or to share information with other people, but that aim to adapt to a specific person, continually acquiring data on that subject and, above all, constantly operating for that purpose, not only during working hours, but also during the night and in extremely personal (or intimate) environments and contexts.

Wearable technologies and smart clothes are, in other words, "environmentally conscious": they are constantly monitoring and observing everything that happens in the surroundings, and then generate a large amount of data ("big data") that give rise to interesting GDPR issues (Wachter and Mittelstadt 2019), especially concerning data protection during big data analysis (Zarsky 2017).

There is an important, preliminary distinction (Mann 2012) between "wearable" devices and "portable" devices, like handheld and laptop computers: in fact, Mann says, "the goal of wearable computing is to position or contextualize the computer in such a way that the human and computer are inextricably intertwined" (Mann 2012).

"In this sense"-Mann writes-" wearable computing can be defined as an embodiment of, or an attempt to embody, Humanistic Intelligence. This definition also allows for the possibility of some or all of the technology to be implanted inside the body, thus broadening from 'wearable computing' to 'bearable computing' (i.e., body-borne computing)" (Mann 2012).

The idea of "Humanistic Intelligence" is very interesting if related to the interaction capability of wearable devices and smart clothes: as Mann correctly states, "One of the main features of Humanistic Intelligence is constancy of interaction, that the human and computer are inextricably intertwined. This arises from constancy of interaction between the human and computer, i.e. there is no need to turn the device on prior to engaging it (thus, serendipity). Another feature of Humanistic Intelligence is the ability to multitask. It is not necessary for a person to stop what they are doing to use a wearable computer because it is always running in the background, so as to augment or mediate the human's interactions. Wearable computers can be incorporated by the user to act like a prosthetic, thus forming a true extension of the user's mind and body" (Mann 2012).

Today, wearable devices in the fashion world exist, basically, in three types/forms. 
The first type is made by clothes that can "activate functions," for example, for cyclists (that can start specific tasks by simply touching the clothes), often connected to smartphones or other communication devices.

The second type consists in technical clothes designed for athletes, monitoring, for example, blood pressure and heart rate values.

The third type combines clothes, body, and technology, for example, showing the messages or tweets received on the surface of the dress itself, or changing the colors of the clothes depending on the context, on the skin, or on the mood of the subject.

Even the wearable technologies sector, as, in general, the Internet of Things sector (the two sectors are strictly connected), has been overwhelmed by the advent of new ways of doing business through the collection and use of big data, especially with reference to the profiling of the most intimate aspects of the consumer.

Hence, there is the need to rethink, from a legal point of view, the delicate issue of protecting this information, the connected possibilities of discrimination related to misuse or abuse of this information (Rodotà 2015), the risk to the customer's reputation and, in general, the profiling and management of data of all those customers who use similar devices.

There are several fundamental points, from a Legal Informatics point of view, that are of particular relevance for the interpreter: they are all linked to the concepts of "data protection" and "cybersecurity."

The first point concerns the new methods of commercial use of consumers' data, modern e-commerce and marketing activities, the constant customer profiling activity (that, we will see, has an important impact for the GDPR), and the consequent consumer protection linked to the use of similar devices (Burbidge 2019).

This is an area of study that, on the one hand, is linked to the traditional business and marketing activities of companies and that, on the other hand, is increasingly conditioned by the presence of the companies on social networks and the need to innovate the ways of disseminating commercial information based on the collection, in fact, of big data coming from the daily life of customers.

To this end, wearable devices and smart clothes allow the achievement of two objectives.

The first is a control, also from a "geographical" point of view (GPS), of the consumer, even in his/her shopping activities and paths. This factor becomes very important from a marketing point of view: fashion is a sector where the relationship between in-store purchases and online purchases is very problematic to analyze in modern days, and the capacity to monitor consumer paths at any time and in any place takes on an enormous value.

The second objective is the ability to generate a profiling activity that is more precise than all those previously carried out; above all, because it can finally involve sensitive characteristics of the client. This is the reason why this issue inevitably has to deal with data protection legislation which, especially in Europe, has always tried to limit as much as possible these procedures, while respecting the need for data circulation and the need for business.

These first two protection requirements have been accompanied by the necessary attention to possible data breaches, i.e., the "escape" of data collected (with consequent reputation problems and fines coming from local Control Authorities) and the use of chatbot, automated systems that must be transparent to the customer for correctness (the user must always be aware that he/she dialogues with a robot and not with a human being).

To these first problems, there are specific implications involving smart fabrics, nanotechnologies, and, generally, the Internet of Things. Wearable and connected technologies can be very useful, but they have security problems, as does the Internet of things in general: every device that is connected is vulnerable.

The implementation of the GDPR since May 2018 in all EU Member States has entered such a delicate and unstable framework and had to face new problems that are not easy to solve.

The idea of the protection of digital data is transversal to all the problems listed above. 


\section{Four Points of Discussion}

It seems to us that there are four clear points of discussion that today concern wearable devices and smart clothes from a legal and data protection point of view:

(i) the need to introduce a new "culture" of data protection (training, for example, all the people who are processing data) when dealing with such intimate devices and data, especially if what is being processed is not only customers' data, but also information related to employees/workers (Allery 2019);

(ii) the need to plan correct data breach management, as the collection of large amounts of data made by these wearable devices and smart clothes will inevitably, sooner or later, lead to the threat of a data breach;

(iii) the need to guarantee a transparent legal framework regarding the delivery of the information, the collection of consent of the customer, and the development of less intrusive forms of marketing and targeting;

(iv) finally, the need to always guarantee the exercise of the rights of those who wear these devices, up to the cancellation of all customers' data and the disconnection of the device.

In this study, the four aspects indicated above will be in summary highlighted. We will try to link, in particular, the phenomenon of wearable devices and smart clothes to the GDPR norms, and to the most common cybersecurity approaches (and best practices).

\section{Discussion}

I. Wearable technologies and data protection norms

The General Data Protection Regulation (GDPR) is having a very strong impact on the world of fashion and on its commercial practices (Allday 2018).

The theme of data protection has become central and involves, today, both personal and particular (or "sensitive") data: types of data that, in the fashion world, are very common.

Data is instrumental in marketing, as Allday correctly states: "allowing retailers to bridge the gap between online/offline and digital/physical stores (where applicable), so retailers may struggle to maintain this without as much consumer information. Currently, the online shopping experience is often a $24 / 7$ engagement, with emails landing throughout the night offering similar items to your shopping/browsing history. Without this constant presence, online fashion retailers will have to find less intrusive ways of keeping high levels of engagement with their consumers. Although companies will still be able to see what their customers are purchasing, there will be less scope for them to track closely their browsing habits and histories. The consumer's 'right to be forgotten' must be addressed within one month, and customers will also have the right to have their personal data erased. Although thousands of fashion products sold online are inspired by luxury catwalk items, trends are equally driven by consumer shopping habits and patterns. If customers request that they be erased from retailers' systems, it could limit insights into what their customers are looking for next" (Allday 2018).

As Allday says: "online fashion companies will have to change the way they interact with their customers and use their personal information. For pure play retailers like Amazon, ASOS, Boohoo and Missguided, all of whom have benefited from the ambiguity of the EU's existing data laws, the General Data Protection Regulation has the potential to drastically, perhaps catastrophically, alter how they operate" (Allday 2018).

Also the presence on social media of the most important brands in the fashion industry will change: "Lax data laws have allowed fashion retailers to leverage social media even more by offering personalised shopping links that lead to clicks and therefore sales. Online fashion brands are faced with the momentous task of overhauling not just their business strategy, but ensuring that their brand identity is not watered down by GDPR" (Allday 2018).

First of all, as Arthur correctly writes (Arthur 2016), from a data processing point of view, some of these wearable devices and smart clothes "even stretch what the term 'wearables' might mean-stepping 
beyond connected textiles into deeper fibre science, which is the area looking the most likely to shape the future of our wardrobes" (Arthur 2016).

The author cites, for example and among others: Levi's and Google Project Jacquard ("a piece of wearable technology designed for urban cyclists. Conductive yarn is weaved into the left cuff enabling touch interactivity so users can tap, swipe or hold to fulfill simple tasks like changing music tracks, blocking or answering calls or accessing navigation information delivered by voice"); The Unseen for Selfridges ("a start-up that has captured the simple idea of colors that alter based on user interaction or the environment they're placed in. The resulting line of luxury accessories for Selfridges [ ... ] included a backpack, scarf, phone case and more, which responded to things like air pressure, body temperature, touch, wind and sunlight. An Italian alligator-skin shoulder bag for instance saw environmentally-responsive ink shifting from black in the winter, to red in the spring, blue in the summer and green fading to red in the autumn"); and Emel+Aris (a smart coat with hidden intelligent heating technology inside: "Made from a lightweight polymer, rather than a load of wires, it produces FIR (far infrared) heat energy from various panels across the garment that is then absorbed by the skin to heat the muscles and increase blood flow") (Arthur 2016).

In 2017, in another example, University of Manchester's National Graphene Institute "produced a dress in collaboration with wearable tech company Cute Circuit. The dress is made with a fabric that has 'wonder material' graphene which causes the dress to change color according to the wearer's breathing patterns" (Draper 2018).

We are therefore in the presence of technologies that are not just wearable objects, but are real tools for the transmission of data and are particularly complex technologies in their functions (even invasive of the privacy of the individuals). In other words, we are in the presence of potentially dangerous technologies for human beings.

So, the first necessary point, when discussing the (cyber) security of wearable devices and smart clothes, is to understand the need for the diffusion of a "culture" of data protection that, in many cases and due to security costs, has not been implemented.

This must be done even before designing such tools, and must become an essential part of the production process itself of these products.

In a period of market crisis, investments in information security have been minimal: often these are the first balance voices to be cut. However, at the same time, there is a commercial rush to collect data. This commercial rush is arising new legal challenges (Mathys 2014).

The GDPR, first of all, demands, with a particular attention to the idea of accountability, that the security must be placed "inside" the device itself, and the accountability must be "inside" the company itself. Also, this approach must be demonstrable at any time.

This entails the need for large-scale training of all operators, from the top to the subjects who process the data, to ensure a safe and secure data environment. This can happen with ad hoc training and with the writing of policies, regulations, and best practices.

This first, general point is clearly described in the text of Article 32 of the GDPR: "Taking into account the state of the art, the costs of implementation and the nature, scope, context and purposes of processing as well as the risk of varying likelihood and severity for the rights and freedoms of natural persons, the controller and the processor shall implement appropriate technical and organizational measures to ensure a level of security appropriate to the risk, including inter alia as appropriate: (a) the pseudonymization and encryption of personal data; (b) the ability to ensure the ongoing confidentiality, integrity, availability and resilience of processing systems and services; (c) the ability to restore the availability and access to personal data in a timely manner in the event of a physical or technical incident; (d) a process for regularly testing, assessing and evaluating the effectiveness of technical and organizational measures for ensuring the security of the processing."

The big news of the GDPR is that it leaves the company free to decide how to implement security measures in its specific reality. There are no longer any lists of mandatory measures, but it is up to the 
data controller to decide which measures to implement. This is a completely new approach that will be tested in the coming years.

The description of the risks strictly connected to data processing are in the second paragraph of Article 32: "In assessing the appropriate level of security account shall be taken in particular of the risks that are presented by processing, in particular from accidental or unlawful destruction, loss, alteration, unauthorized disclosure of, or access to personal data transmitted, stored or otherwise processed."

This means that anyone who produces wearable devices and smart clothes, or whoever resells them, must, before starting to make use of these tools and give them to their customers, evaluate the possible risks and prepare safety measures that protect the processed data.

Concerning, finally, the diffusion of a "culture" of data protection, paragraph 4 of Article 32 of the GDPR is clear: "The controller and processor shall take steps to ensure that any natural person acting under the authority of the controller or the processor who has access to personal data does not process them except on instructions from the controller, unless he/she is required to do so by Union or Member State law."

This is a central aspect: all data processors must first be trained on data protection issues. This becomes particularly important when smart devices communicate, for example, with a store and not directly with the factory. All the subjects who process the data, even those with less important or temporary job positions, must be aware of the existence of the legislation on data protection and on the best ways of protecting customer data.

The second crucial point, the data breach management, involves the most important threat connected to the collection of data using wearable devices today. Understanding how to recognize a data breach, how to manage it (to avoid millionaire fines), how to report it to the supervisory authority but also to customers, and how to manage the data breaches that may not take place on site but in shops, stores, or companies connected to the main factory is linked to the ability to know how to assess risks of image, reputation, discrimination, possible identity theft, and economic losses.

The norms related to data breach are included in Articles 33 and 34 of the GDPR. Article 33 states that "In the case of a personal data breach, the controller shall without undue delay and, where feasible, not later than $72 \mathrm{~h}$ after having become aware of it, notify the personal data breach to the supervisory authority competent in accordance with Article 55, unless the personal data breach is unlikely to result in a risk to the rights and freedoms of natural persons. Where the notification to the supervisory authority is not made within $72 \mathrm{~h}$, it shall be accompanied by reasons for the delay."

Article 34 indicates that "When the personal data breach is likely to result in a high risk to the rights and freedoms of natural persons, the controller shall communicate the personal data breach to the data subject without undue delay." However, "The communication to the data subject referred to in paragraph 1 shall not be required if any of the following conditions are met: (a) the controller has implemented appropriate technical and organizational protection measures, and those measures were applied to the personal data affected by the personal data breach; in particular those that render the personal data unintelligible to any person who is not authorized to access it, such as encryption; (b) the controller has taken subsequent measures which ensure that the high risk to the rights and freedoms of data subjects referred to in paragraph 1 is no longer likely to materialize; (c) it would involve disproportionate effort. In such a case, there shall instead be a public communication or similar measure whereby the data subjects are informed in an equally effective manner."

Then, there is the fundamental aspect of transparency, along with information and collection of consent, which have always been central to the European data protection system. This directly involves targeted marketing and profiling but also spam, newsletters, apps, and websites.

Finally, there is the aspect of the exercise of rights, especially with the request to delete and update the databases.

At the center of all these four aspects, there is the general idea of accountability, i.e., the entire system must be framed around the idea of protecting the data by design and by default, and all this must be demonstrable. 
Privacy and security, in conclusion, are at the heart of wearable technologies, and they are two different aspects. The main risk is obviously the direct collection of sensitive data that these devices make, such as precise geolocalization, credit card numbers for possible payments, information on health status, and collection of habits and physical condition for a long period of time.

II. The specific accountability issues of wearable devices and smart clothes

The starting point, even in the context of wearable devices and smart clothes, is the understanding of 'accountability,' the new security approach required by the GDPR to set up corporate and productive activities and personal data handling from a correct data protection perspective.

The idea of accountability consists in doing and demonstrating (in other words, in "creating"), an environment aimed at data protection, and being able to document and prove it anytime.

The first step is usually considered that of training: training all operators so that their behavior is correct and aimed at protecting the data while not hindering its circulation. Particular attention, also in the fashion world, should be paid to three areas: (i) marketing and sales, (ii) human resources, and (iii) information technology staff. These are the three most vulnerable sectors.

Marketing and sales will have to pay particular attention to information, especially for TV spot, web, and app activities and highly targeted campaigns, including campaigns based on the physical characteristics of customers and the management of large databases. Human resources will have to pay particular attention to the protection of employee data, especially if wearable devices are given also to the staff. The IT department controls the whole data system and the processing and protection of the information.

In practice, in all these three areas, accountability is achieved through a list of fulfillments: the information and consent, the appointment of a Data Protection Officer, the keeping of a treatment register, the assessment of the risk and impact in the case of particular treatments, the contractualization of relations with external processors, and a framework of security measures also made up of training and policy plans for managing data breaches, phishing attacks, and payment systems fraud.

Companies should ensure that all of their employees' practices are aimed at promoting data security and, above all, human resources staff must establish policies, business operations, and contracts with employees that take into consideration the use of wearable technologies in the workplace. The essential problem, in this case, is the privacy of the worker, especially the violation of privacy and the risk of spreading sensitive information about the worker. They must be able to choose whether or not to wear the device, and the functioning must be transparent and well illustrated. Furthermore, the devices must not function beyond working hours.

\section{Wearable Technologies and Data Breach Issues}

The data breach, or data loss following a violation, is the most feared threat. It can happen in many ways: an external attack, but also a ransomware virus, loss or theft of a computer or tablet, access to a peripheral system that allows access to the central archive. In this case, transparency towards the supervisory authority and the users has become essential, especially if customers' rights are at risk.

The management of a data breach therefore entails an initial assessment of the risk, to frame the event in a simple accident, where an incident log will be held, or in a serious event that must be reported. The first comparison will be with the supervisory authority, and must be reported within $72 \mathrm{~h}$ in specific ways. The second comparison will have to be with users in order to inform them, and here the reputation problem of the company is the most important issue. The preparation of a policy with both internal purposes (keeping track of all incidents) and external purposes (specific methods for managing and communicating data breaches) is essential.

Given the great risks, companies that develop wearable technologies should implement appropriate cybersecurity measures. There is no standard checklist, but measures must be adapted to the situation (for example: the volume and nature of the data collected, and the cost of a potential data breach as an impact on people's rights). Certainly, the protection should already be incorporated when thinking 
about the product and developing it ("privacy by design"), and the subject should have full control of his/her device.

As Allday correctly notes, GDPR will also "expose brands whose security systems are not as sophisticated as they should be, as retailers will be required to notified regulators of any data breach within $72 \mathrm{~h}$ and in some case, they will be legally obliged to notify their customers too. Before, some retailers lacked transparency, urgency and in some case, honesty, when dealing with data breaches. Forcing retailers to be transparent when it comes to security breaches will expose certain websites' shortcomings, which challenges brand safety, reliability and credibility" (Allday 2018).

Another key point will involve exactly how retailers remove their consumers' data, particularly when information is stored on several distinct databases: "For some companies, a complete redesign of internal IT systems will be required; for others, it will be a matter of whether a customer's data is anonymized or completely deleted, and whether it will be possible to mix the two actions within one database" (Allday 2018).

The new regulations also "make clear that it is not just the IT departments of retailers who should be clued up on data breaches and their prevention, but all members of the corporation, no matter what level, as well as third party affiliate companies, such as PRs, freelancers, insurance companies and recruiters" (Allday 2018).

\section{Transparency and consumers attention}

In the GDPR system, the principle of transparency is closely connected to the idea of information and consent. The disclosure/information notice is an essential requirement that allows you to inform the user about how the data will be processed. The contacts, purposes, legal basis, data retention period, and transfer (or not) abroad are the most important points, to which are added the recipients and the possibility of exercising their rights.

Consent is now given in electronic format and poses the problem both of verifying the age and the will of the subject, and of filing it to verify possible revocations.

Most of the data concern health and fitness, the steps taken every day, sleep cycle, calories burned, and these are all data that, if exposed, would make the subject very vulnerable.

The large volume of so much data allows analysis to be carried out by those who have access to this data, which would not be possible with smaller datasets. Furthermore, data relating to habits could be used for other purposes, such as insurance purposes, or employee control. Transparency, with such types of data, means knowing who the data owner is, where data are stored, if they are encrypted, how they can be used and if they can be resold.

It is therefore essential to draft terms of services and privacy policies that highlight which data are collected, how they are stored, their use, if third parties are involved in management, and security measures. The collection and storage of data should then be limited, and the encryption of information should be the standard.

Attention to the consumer must also be connected to the profiles of responsibility connected to the product and to its functioning. The brand is exposed to possible responsibilities, both for physical damage and for the possibility of distraction by the user while driving or walking, or for damage to third parties.

The rights of data subjects are the central part of the European system: the possibility of exercising rights not as simple consumers but with reference to the data concerning one's person. The right to be forgotten, but also the rights to rectification, or the acquisition to treatment, are central.

As Allday states, online retailers "must therefore find ways of leveraging their loyalty schemes and other forms of advertising without creating a retail space in which legal consent is required from the consumer. The success of data-driven advertising has been, in part, down to the fact that so many consumers are unaware of it. When presented with a box on the screen asking if you want to give away your personal details, many people would say no. 'Consent' is often built into the cookies that the average Internet user accepts without reading the T\&Cs. The new limitations will require 
more traditional, less intrusive forms of targeted advertising, which will involve looking to more authentic advertising used in physical stores. Euromonitor figures show that online fashion retailing now accounts for $20 \%$ of all apparel and footwear sales in the UK and $15 \%$ in the whole of Western Europe, but GDPR will drastically alter the landscape of fast fashion if the key players do not address and adapt to the new, more private shopping landscape online" (Allday 2018).

In our opinion, even if the issues of transparency and consensus are not strictly related to the technological aspect of the topic we are dealing with (i.e., the hardware that collects the data), they are still central in view of a broad spectrum of protection. Even the fashion industry has long based its activity on data processing, and correct information, related to a clear manifestation of will, assumes central importance in the more general framework of data protection.

\section{Conclusions}

The fashion sector will most likely be affected by the new regulatory framework brought by the GDPR; the same will happen for wearable devices and smart clothes, which will probably play an increasingly important role in the near future.

Some data protection issues are common to all commercial sectors and all digital technologies, from network connectivity to the use of smartphones; others are more specific, and peculiar, to wearable devices. In particular, the management of big data of customers and workers (Allery 2019) collected in these ways will be a central problem in the near future, along with profiling and marketing activities aimed at collecting and processing such data. This aspect, however, is common to many commercial sectors and does not present particularly innovative features in the topic we are dealing with.

In our opinion, a peculiar feature that will concern the relationship between fashion and data protection will be the close connection between the data and the human person (and its everyday life). For the first time, the same clothes that the subject will wear will also function as sensors to collect, in real time, a large amount of data. This will cause such actions to be perceived as invasive, able to penetrate into the depths of the person and, therefore, more urgent to regulate from a legal point of view.

The vulnerability of the data must be taken into consideration, not only for the value that the commercial archives have, but because we are discussing data, in this case, which must be considered critical and sensitive, given their close connection with the person. The creation of an ad hoc policy on security and privacy, which is usually more common in other areas (i.e., banking, insurance, telecommunications, public sector), is today essential also in the fashion sector.

We refer, in particular, to a policy that is able to better prepare all the subjects who process the data to deal effectively with a data breach. The essential points of such a policy, for example, could be the following:

1. Understand what a data breach is and be able to identify it and communicate it to security personnel. Remember that a data breach, from the point of view of the GDPR, is not only an attack on data from outside, but also a defect or vulnerability of an app or electronic bracelet or a smart device that can cause uncontrolled spreading of data.

2. React with particular urgency as soon as you know the data breach and also provide some basic essential information to understand the seriousness of the event.

3. Activate a communication flow both to the Control Authority and to the customers that allows the maximum transparency of the accident.

4. Immediately try to limit the damage and its consequences.

There are two methods of protection that are most evident and that can be used to mitigate damages related to a data breach: (i) the use of anonymous data, and (ii) the encryption of information.

If we extrapolate anonymously a profile of each user of a brand, which contains interests based on the places the customers frequent, it can allow for detecting interesting data and implementing 
different strategies depending on the level of brand affinity and also on physical movements, even if the data is processed anonymously.

It becomes useful, in fact, to know how to dominate and govern data throughout the customer journey, made of many stages in the offline and online world, focusing on "location intelligence" to analyze in-store traffic, to understand the tastes of customers around the world, and to present personalized and hyperlocalized offers.

Then, there will be an almost exclusive importance of mobile technologies, since the data collected through the mobile devices of the customers will be integrated with artificial intelligence technologies (Luce 2019) able to predict consumer behavior and offer advice through virtual assistants.

This point is, from a legal perspective, very interesting. Several scholars are studying the existence of a 'right to explanation' (Edwards and Veale 2017) of all decisions made by automated or artificially intelligent algorithmic systems as a tool to enhance the accountability and transparency of automated decision-making (Wachter et al. 2017).

All the fashion houses are, these days, equipping themselves with data scientists who know how to analyze this enormous amount of data and generate new value. Less attention is devoted to the recruitment of legal and cybersecurity experts.

The hard point is that real anonymization is becoming increasingly difficult due to the constant possibility of correlating data and information.

The wearable technologies are the most suitable for perfecting this data collection, as they follow the movements of the individual and collect data closely related to the personality (and also to the health) in all moments of the individual's life, both private and in society. It is an enhancement of the advertising possibilities that has no equal, especially if combined with artificial intelligence, machine learning, and virtual and augmented reality (Kamarinou et al. 2016).

So, the first point of conclusion is that processing data as anonymously as possible becomes essential.

The second aspect, data encryption, in addition to anonymization, seems to be the most effective technical tool for protecting data after the collection and, above all, when the individual communicates, through the wearable devices, with the fashion company.

The norms and, in this case, the GDPR clearly recall these needs to protect the customer who wears the device: an anonymous processing of the data based on security and encryption.

To this end, the wearable devices that will be created, or have already been created, with privacy and security in their DNA will certainly succeed in combining efficiency and new marketing opportunities with the protection of people's rights.

Allday, in conclusion, highlights four interesting focal points that we can use to connect the wearable devices world, the cybersecurity best practices, and the GDPR:

(i). It is essential to guarantee, first of all, that all "staff members are made aware of what constitutes a data breach; how serious they are, no matter how few people may seem affected initially; how to report them; how to prevent them" (Allday 2018). The data breach, it was said, is seen as the first and the most important threat, with reference to data collected through wearable devices and smart clothes. It is the idea that the most intimate data of people, closely related to the body, can come out and be made public, or violated.

(ii). Then, it is important to invest in "Customer Relationship Management, both to allow customers a human point of contact for questions and queries regarding their personal data, and to maintain personal engagement between the retailer and consumer that could suffer as a result of GDPR" (Allday 2018). This second point concerns respect for the consumer also from a data protection point of view, which is reflected in the many actions and obligations provided by the GDPR.

(iii). More, it is fundamental to be "transparent with customers about exactly what their rights are, how they can request more information and how they can have their data removed. As the world saw in the wake of the Cambridge Analytica and Facebook scandal, transparency and honesty are both vital to keep customers loyal and to ensure that they feel safe on the Internet" 
(Allday 2018). From this point of view, it becomes important to respond immediately to any request from customers concerning their data (we find that the requests for cancellation of the information are, in this perspective, the most important).

(iv). Last, but not least, it will be important the focus on "social media marketing and advertising to ensure personalized content that keeps individual consumers engaged and interested in the brand, without their data being compromised or exploited" (Allday 2018). It will be important, in particular, to find a good compromise between the data protection needs and the need, in the digital society, to process data with great speed and precision.

Funding: This research received no external funding.

Conflicts of Interest: The authors declare no conflict of interest.

\section{References}

Allday, Florence. 2018. Is the Fashion Industry Ready for GDPR? London: Euromonitor International. Available online: https://blog.euromonitor.com/fashion-industry-ready-gdpr/ (accessed on 25 May 2018).

Allery, Charlotte. 2019. Wearable Technology in the Workplace and Data Protection Law, retrieved from ComputerWeekly.com, February. Available online: https://www.computerweekly.com/opinion/Wearabletechnology-in-the-workplace-and-data-protection-law (accessed on 26 February 2019).

Arnault, Laurenti. 2018. The Only Thing That Buyers Want from Wearable Technology Fashion, WTVOX, 30 July. Available online: https://wtvox.com/fashion/wearable-technology-fashion/ (accessed on 30 July 2018).

Arthur, Rachel. 2016. The Future of Fashion: 10 Wearable Tech Brands You Need To Know, Forbes, 30 June. Available online: https://www.forbes.com/sites/rachelarthur/2016/06/30/the-future-of-fashion-10-wearabletech-brands-you-need-to-know/\#5faad8b14220 (accessed on 30 June 2016).

Burbidge, Rosie. 2019. European Fashion Law. Cheltenham: Edward Elgar.

CCS Insight. 2019. CCS Insight Study: Wearables Market to Be Worth $\$ 25$ Billion by 2019. Available online: https://www.ccsinsight.com/press/company-news/2332-wearables-market-to-be-worth-25-billionby-2019-reveals-ccs-insight/ (accessed on 29 October 2015).

Ching, Ke Wan, and Manmeet Mahinderjit Singh. 2016. Wearable Technology Devices Security and Privacy Vulnerability Analysis. International Journal of Network Security \& Its Applications 8: 19-30. [CrossRef]

Chuah, Stephanie Hui-Wen, Philipp A. Rauschnabel, Nina Krey, Bang Nguyen, Thurasamy Ramayah, and Shwetak Lade. 2016. Wearable technologies. The role of usefulness and visibility in smartwatch adoption. Computers Human Behavior 65: 276-84.

Draper, Sam. 2018. Are Smart Fabric the Future of Fashion? 82211 Herrsching am Ammersee, Germany: WT (Wearable Technologies). Available online: https://www.wearable-technologies.com/2018/06/are-smartfabrics-the-future-of-fashion/ (accessed on 12 June 2018).

Edwards, Lilian, and Michael Veale. 2017. Slave to the Algorithm? Why a 'Right to an Explanation' Is Probably Not the Remedy You Are Looking for. Duke Law \& Technology Review 16: 18. Available online: https://papers.ssrn.com/sol3/papers.cfm?abstract_id=2972855 (accessed on 24 May 2017).

Finck, Michèle. 2017. Blockchains and Data Protection in the European Union. Max Planck Institute for Innovation \& Competition Research Paper No. 18-01. European Data Protection Law Review 4: 17-35. Available online: https://papers.ssrn.com/sol3/papers.cfm?abstract_id=3080322 (accessed on 6 December 2017).

Kamarinou, Dimitra, Millard Christopher, and Singh Jatinder. 2016. Machine Learning with Personal Data. Queen Mary School of Law Legal Studies Research Paper No. 247/2016. Amsterdam: Elsevier. Available online: https://papers.ssrn.com/sol3/papers.cfm?abstract_id=2865811 (accessed on 8 November 2016).

Katyal, Neal. 2014. Disruptive Technologies and the Law. Geo. LJ 102: 1685-89.

Kim, Young Ah. 2016. New Legal Problems Created by Wearable Devices. Illinois Business Law Journal. Available online: https://publish.illinois.edu/illinoisblj/2016/02/29/new-legal-problems-created-by-wearable-devices/ (accessed on 29 February 2019).

Lambert, Jorn. 2019. Technology and Fashion Unite as the Wearable Market Matures. New York: TechRadar. Available online: https://www.techradar.com/news/technology-and-fashion-unite-as-the-wearable-market-matures (accessed on 22 February 2019). 
Luce, Leanne. 2019. Artificial Intelligence for Fashion: How AI is Revolutionizing the Fashion Industry. San Francisco: Apress.

Mann, Steve. 2012. Wearable Computing. In The Encyclopedia of Human-Computer Interaction, 2nd ed. Edited by Mads Soegaard and Rikke Friis Dam. Hershey: Idea Group Reference. Available online: http: //www.interactiondesign.org/encyclopedia/wearable_computing.html (accessed on 31 December 2005).

Mathys, Roland. 2014. Legal Challenges of Wearable Computing, 30 April. Available online: https://www.swlegal.ch/files/media/filer_public/2c/7a/2c7a67fa-96ed-489e-981f-6c10d0266326/ 140801_roland-mathys_legal-challenges-of-wearable-computing.pdf (accessed on 30 April 2014).

Pearce, Sarah. 2016. Wearable tech and data privacy: What you need to know. UKTN. October 25. Available online: https://www.uktech.news/news/wearable-tech-privacy-issue-20161025 (accessed on 25 October 2016).

Rodotà, Stefano. 2015. Il Diritto di Avere Diritti. Roma and Bari: Laterza.

Russey, Cathy. 2018. How to Limit Legal Risks that Come with Wearable Devices. Herrsching am Ammersee: WT (Wereable Technologies). Available online: https://www.wearable-technologies.com/2018/11/how-to-limitlegal-risks-that-come-with-wearable-devices/ (accessed on 13 November 2018).

Satyanarayanan, Mahadev. 2001. Pervasive Computing: Vision and Challenges. IEEE Personal Communications. Available online: http://www.cs.cmu.edu/ \{\}./aura/docdir/pcs01.pdf (accessed on 31 August 2001).

Wachter, Sandra, and Brent Mittelstadt. 2019. A Right to Reasonable Inferences: Re-Thinking Data Protection Law in the Age of Big Data and AI. Columbia Business Law Review 2019: 494. Available online: https: //papers.ssrn.com/sol3/papers.cfm?abstract_id=3248829 (accessed on 5 October 2018).

Wachter, Sandra, Mittelstadt Brent, and Floridi Luciano. 2017. Why a Right to Explanation of Automated Decision-Making Does Not Exist in the General Data Protection Regulation. International Data Privacy Law 7: 76-99. Available online: https://papers.ssrn.com/sol3/papers.cfm?abstract_id=2903469 (accessed on 24 January 2017). [CrossRef]

Zarsky, Tal. 2017. Incompatible: The GDPR in the Age of Big Data. Seton Hall Law Review 47: 995. Available online: https://papers.ssrn.com/sol3/papers.cfm?abstract_id=3022646 (accessed on 22 August 2017).

(C) 2020 by the author. Licensee MDPI, Basel, Switzerland. This article is an open access article distributed under the terms and conditions of the Creative Commons Attribution (CC BY) license (http://creativecommons.org/licenses/by/4.0/). 

MDPI

St. Alban-Anlage 66

4052 Basel

Switzerland

Tel. +41 616837734

Fax +41 613028918

www.mdpi.com

Laws Editorial Office

E-mail: laws@mdpi.com www.mdpi.com/journal/laws

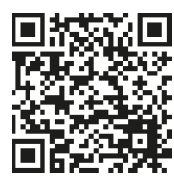



MDPI

St. Alban-Anlage 66

4052 Basel

Switzerland

Tel: +41 616837734

Fax: +41 613028918

www.mdpi.com 